

\section{ALVMNVS BOOK FVND}

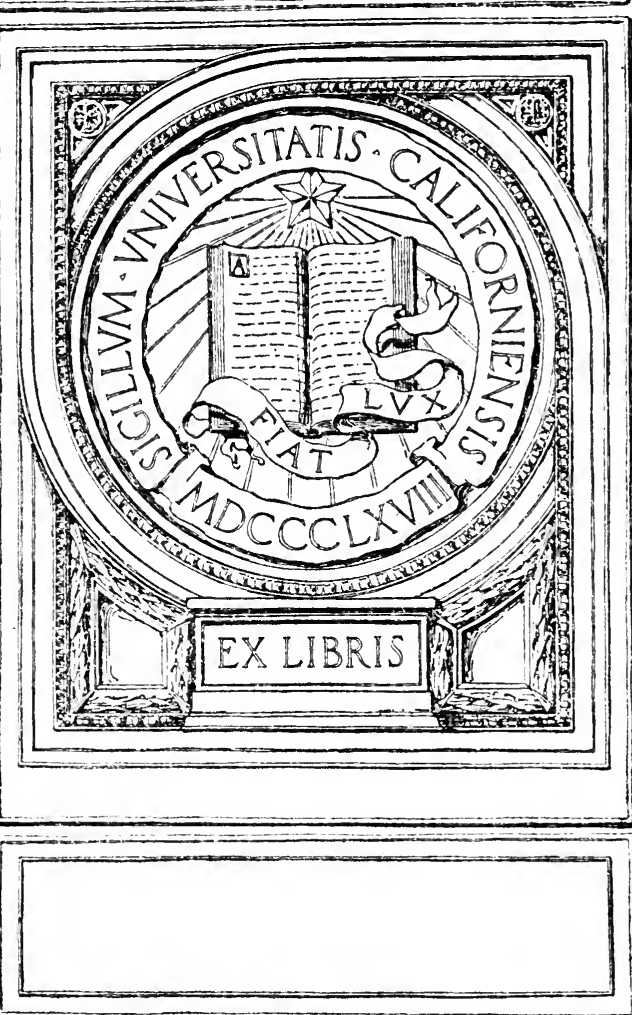


Digitized by the Internet Archive in 2007 with funding from Microsoft Corporation 
)

- 

NATURAL AND SOCIAL MORALS 
BY THE SAME AUTHOR.

\title{
THE METAPHYSICS OF NATURE
}

\section{Second Edition, Demy 8vo, Cioth,} Price 7s. 6d. net.

"We hail with delight a work so masterly and so moderate, and written with such lucidity and often with brilliance."-The Examiner.

A. AND C. BLACK, SOHO SQUARE, LONDON, W.

\author{
AGENTS
}

america - The Macmillan Company 64 \& 66 Fifth Avenue, New York

australasia The Oxford University Press 205 Flinders Lane, Melbourne

Canada - The Macmillan Company of Canada, Ltd. 27 Richmond Street West, Toronto

India - . Macmullan \& Company, Ltd. Macmillan Bullding, Bombay 309 Bow Bazan Street, Calcutta 


\title{
NATURAL AND SOCIAL MORALS
}

BY

CARVETH READ, M.A.

GROTE PROFESSOR OF PHILOSOPHY IN THE UNIVERSITY OF LONDON AUTHOR OF "THE METAPHYSICS OF NATURE"

\author{
LONDON \\ ADAM AND CHARLES BLACK \\ 1909
}




$$
\begin{gathered}
\text { BJ } 1311 \\
\text { R35 }
\end{gathered}
$$

$$
\begin{aligned}
& \because \because \quad, \because \vdots \vdots \vdots \vdots \vdots
\end{aligned}
$$

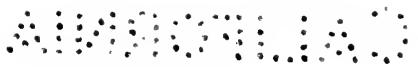




\section{CONTENTS}

\section{PREFACE AND INTRODUCTION}

SECT.

PAGE

$\mathbf{x i}$

2. The Metaphysics of Nature as prolegomena to Natural and Social Morals

3. Natural and social morals in relation to the metaphysics of ethics .

4. Human Society, essentially co-operative, cannot advance unless the breed of men is improved. Eugenics

5. The principles of heredity assumed in this book, how related to Mendelism

\section{BOOK I.-MORALITY NATURAL TO MAN}

\section{Chapter I.-Practical and Theoretical Morality}

1. Morality in some form is universal amongst men as a condition of social cohesion

2. Misconceptions of Naturalism in Morals ; Morality and Reason

3. Practical Morality, sanctioned by Common Sense, supplies the data which all moral theories must explain . $\quad$. $\quad 8$

4. Morality as observance and as character. Motive and Intention .

5. Some moral Systems have been based on Rules; but all rational Morality implies an End such as men can understand, desire and strive after

6. Every relation of Means to End implies a corresponding law of Cause and Effect. Scientific Morality deals with the tendencies of actions to promote the Chief Good . . . .

7. Advantages of considering Moral Science as a study of tendencies .

xii

$\mathrm{x} \nabla \mathrm{i}$

$\mathrm{xx}$

xii

\section{Chapter II.-Conceptions of the Chief Good}

1. All philosophical Ends imply spontaneous desires; and desire is always for some kind of experience

2. The philosophic Ends are not in conflict. Happiness, Perfection, Wisdom, Beauty of Character, Virtue, Tranquillity-are all naturally desired . 
SECT.

3. - but not by all men. Few are yet capable of philosophic morality. The conception of it depends upon human development in Society; but there are hindrances to it in social life. .

4. The socialisation of man has depended on illusions and limitations 28

5. The opposition between Egoism and Altruism is misunderstood ; but, so far as it is real, Egoism, though in some measure a rational End, is not of equal rank with Altruism . . .

6. The philosophical Ends are the true Good because they represent the co-ordination of social life according to human choice and reason, from which there is no appeal. They are, in fact, different names for the same life . . . . .

7. But if one name must be preferred, Philosophy is the best; and this was the judgment of Aristotle and Spinoza . . .

\section{Chapter III.-The Social Character of Morals}

1. Actions are right, wrong or indifferent. The possibility of the last may be denied under early conceptions of absolute Custom or Law, but follows from the limitation of responsibility by intention. Every intention, even though mainly prudential, includes social consequences . . . . .

2. Men, being imperfectly socialised, need restraint; which developes in the forms of Custom, Religion, Law, Morality . .

3. Such restraints are effective because of corresponding sentiments in the tribesman, such as Love of Approbation, Honour, Duty .

4. Primitive character of moral sentiment: not to be confused with military or juridical obligation . . . .

5. Moral sentiment and moral reason : the danger of associating the sentiment with particular or temporary observances . .

6. To recognise the universality of the moral End, there must be a development of thought and effective sympathy. Different functions of sympathy . . . . . .

7. Attitudes of philosophers to the social conception of Morality .

\section{Chapter IV.-Character}

1. Personal morality depends upon character ; and this upon selection, heredity, tribal education, and opportunities of expression.

2. For the study Morality characters may be classified (1) as initiative and sequacious; (2) as egoistic, ego-altruistic, altruistic and public ; (3) as to degree of elevation ; (4) as to their stability. Development of volition : effort .

3. Variety of types of character is socially useful. Conditions of the growth of altruism. Distinction between altruistic and public dispositions

4. The influence of Ideals personal and national $\quad . \quad r \quad \cdot \quad \cdot \quad \cdot$ 
5. Ideals spring from Institutions: (1) The divine Royal Family; (2) inspired mediators-Priest, Prophet, etc. ; (3) offices of citizenship-Judge, Noble, etc. ; (4) and of industry-the Merchant and Ploughman; (5) Self-culture; (6) Women's ideals-the Hostess, the Mother, the Virgin . . .

6. The conditions of a change of character

\section{Chapter V.-Physical and Biological Conditions OF MoRALITY}

1. Morality may be considered as a practical science of Causation, defined by the relation of actions to the Chief Good. The Moral Axioms are forms of the principle of Causation; and the definitions of the Moral Categories imply Causation . .

2. Primary Laws of Morality state the tendencies of actions in relation to the Chief Good in simple cases; Derivative Laws state the results in complex cases. Casuistry . . . .

3. The proof of Moral Laws depends on the ordinary scientific methods. Importance of the Natural History of Morals . . .

4. The connexion of Morality with physical principles and with Spencer's formula of evolution . . . . .

5. Moral character as affected by natural selection and by Eugenics. On certain objections to Eugenics. Elimination a more hopeful policy than preferential breeding

6. Life and pleasure : their connexion according to Spencer discussed. Relations between pleasure, desire and character

\section{BOOK II.-MORALITY AND INSTITUTIONS}

\section{Chapter VI.-The Influence of Custom}

1. Unconditional Morality, a deduction from concepts, has no content. Moral Science is inductive, but must not be confounded with the Natural History of Morals . . . . . .

2. Custom was the first ground of all restraint : a precondition of Law, public Religion and Morality . . . . .

3. Control by Custom is morally unsatisfactory; but Custom everywhere changes, less or more rapidly, from various causes; and so private judgment is liberated . . . . .

4. Relations of Custom to Public Opinion and to Common Sense

5. From Tribal Customs must be distinguished the Customs of a caste, profession or trade, which are liable to have an anti-sociai bias, and therefore to be morally inferior . . .

6. Custom is a hindrance to the improvement or alteration of Law, Religion and Morality . . . . . . 


\section{Chapter VII.-The FAMily}

SECT.

1. Our ape-like ancestors probably monogamic .

2. - but, taking to the ground and to hunting, at the same time became gregarious; and in the hordes thus formed various types of sexual relationship may have arisen . .

3. The monogamous Family and chastity. Corruption of the sexual instinct in man by the desuetude of seasonal marriage and other causes

4. Relations between parents and children in the monogamous Family -how affected by the interference of the State . . .

5. Effects of the pressure of population upon the Family and upon the numbers and quality of the children . . .

6. The Family is the chief source of our moral life. Divorce, etc. •

7. How the morality of the Family is related to the morality of the Tribe or World beyond it.

\section{Chapter VIII.-Influence of the State on Morals}

1. Some discussion of the Origin and End of the State, and of the grounds of its stability and authority. Patriarchal, Contractual and uther theories . . . . .

2. Moral effects of the size of the State. City States and large Country States . . . . . . .

3. Influence of the form of Government: Despotism and Oligarchy. Of Conquest. Of distinctions of rank . . . .

4. Democracy: its dependence on leaders. The ideas of liberty and equality. Country life and Town life. The Crowd . •

5. The effect of Parties and Factions; which arise from the different attitudes of individuals and classes toward the same national interests, and are apt to exhibit the vices of crowds. In some ways unfavourable to truthfulness and justice . . .

6. Relation of Law to Morality. Law ought to be the exemplar of Justice to every citizen. 'Natural Rights': importance of this idea, and its grounds . . . . .

7. Punishment and Reward. Theories of Punishment; how far it is satisfactory or justifiable. Opinions of Westermarck, T. H. Greene and others. Why Reward is less in use than Punishment as a sanction. Difficultyof using it impartially . .

8. Moral Influence of Industry and Commerce. Slavery and free labour. Relation to Honesty, Prudence, Enterprise, Independence, Property, Socialism, Co-operation . . . .

9. Moral difficulties in the external relations of a State. Diplomacy, War, Conquest . . . . . . . 


\section{Chapter IX.-Religion and Morals}

SECT.

PAGE

1. Natural origin of belief in the supernatural. Animism and Magic. Magic and Science

2. Peculiar quality of religious belief. Lower and higher religions: persistence of the lower. Social and personal religion .

3. The utility of ethnic religions : in peace and war; in art, politics and morals

4. Growth of priesthoods establishes a conservatism of religious beliefs, an opposition to every kind of innovation, and especially to scientific enlightenment .

5. Adhesion to archaic forms has led priesthoods to support barbarous criminal laws and slavery. Even good men do so in the belief that divine may not be the same as human Justice. But if God is conceived of as the ideal of human morality religion may be the strongest defence of Justice

6. Relation of Religion to Benevolence, and to Chastity .

7. World Religions tend to separate the spiritual from the political power

8. Attitude of Philosophy to Religion. Theism. Weakening of beliefs in Personality, Immortality, Providence . . .

9. Pantheism and Humanism. Scientific and religious standards of truth. Morals precede and may survive supernatural Religion.

\section{Chapter X.-Art and Morality}

1. The didactic and hedonic theories of Art

2. Aristotle on the functions of Art. Parallelism of Art and Morality

3. The origins of Art : its alliance with government and religion, and the decline of its power under civilisation

4. Art at the height of its influence was supermoral . .

5. Then, though seeking neither pleasure nor improvement, it was necessarily pleasurable and, in some measure, purifying and elevating .

6. From the national value and functions of Art we may explain its disinterested Purposiveness, Universality and Necessity; artistic Genius ; the forms, contents and sentiments of Art

7. - and also its Imitativeness; Idealism; Realism; and its relation to moral ideals

8. Other relations of Art to Morality $\quad . \quad+\quad . \quad+\quad$.

\section{EPILOGUE}

\section{Chapter XI.-Moral Degeneracy}

1. Moral degeneracy is closely connected with national decadence

2. Supposed causes of decadence: Climate; Luxury; relaxation of Discipline . 
SECT.

3. Effects of the geopolitical environment. Superior races, and the causes of their destruction . . . . .

4. Failure to co-operate for the public good: Parasitism'; Sterility; avoidance of Military Service; neglect of Culture ; Faction .

5. The general condition of degenerate people is failure of character, through loss of energy, want of stimulus, want of opportunity, weakening of natural illusions .

6. Difficulty of judging whether a change of national character is taking place

7. The conditions of national health 


\section{PREFACE AND INTRODUCTION}

$\S 1$. THE substance of the first five chapters (that is, the first Book) of the following work was delivered in the University of London under the University's scheme for Advanced Lectures for the Session 1808-9.

In preparing for the press I have been greatly assisted by my friends Mr. E. S. Thompson and Mr. Thomas Whittaker and another whose advice I have long had the happiness to trust. It is impossible to thank them warmly enough for their counsel and suggestions; but, of course, no one but myself has the slightest responsibility for the form, substance and details of the book as it is now published.

My indebtedness to many recent writings is acknowledged from time to time in particular passages; but there has been no opportunity of referring to certain books that have nevertheless influenced the general course of my thought and expression; and I, therefore, take this occasion to mention Mr. Graham Wallas's Human Nature in Politics and Mr. William M'Dougall's Social Psychology. They have greatly strengthened me in the endeavour to study morals as matter of fact and experience, instead of merely worrying the traditionary abstract ideas in the fashion of a scholastic age: a sort of shadow-fight that reminds me of the romances in the same age fashionable, wherein it was deemed

chief mastery to dissect

With long and tedious havoc fabled knights

In battles feigned.

In this relation my work is of a transitionary character, revising and illustrating the old philosophical Ethics in the $\mathrm{xi}$ 
light of the inductive Biology, Psychology and Anthropology that have lately been established according to the methods of physical science.

$\$ 2$. Natural and Social Morals is, in fact, a continuation of The Metaphysics of Nature, as any one may see by referring to the last chapter of that work; so that it will enable the Reader to appreciate my position if I briefly summarise the doctrines that were there recommended. ${ }^{1} \quad$ I tried to show-

(1) That the reality with which all knowledge, or science, and all actions are concerned is the World of phenomena in time and space. It is only in that World that we have definite perceptions and can make definite measurements, and these are the only sure ground of universal judgments and inferences.

Accordingly, whatever purposes we form, whatever ends (moral or otherwise) we have in view, they must be represented as possible events in the phenomenal World, the World of experience, where (if at all) they must be realised.

(2) Science is the interpretation of the World according to the principle of Causality: implying $(a)$ the continuity of all natural processes; because, should any failure of continuity occur, at that point there would be no cause ; and $(b)$ uniformity of relations in all the changes that occur; because there cannot else be any generalisation, nor any inference from the known to the unexplored. Continuity and uniformity are (within certain limits) discoverable in experience; but the rigour and necessity of them for us depend upon the nature of human understanding, or the principle of explanation; for every mode of knowledge, from the perception of particular things in space to the discovery of the most comprehensive laws of relation (such as gravitation), implies the assimilation of one fact with others. There is no other way of perceiving or knowing; so that whatever phenomena may be investigated we are compelled to consider them, whatever changes happen, as modes of

1 This Introduction is not necessary for the understanding of the book to which it is prefixed; and any one who has a distaste for metaphysics may as well pass over this and the next section $(\S 2$ and $\S 3$ ). They are inserted for the sake of those who hold that every theory of morals must have a metaphysical basis. 
the same empirical substance manifested according to the same laws : this is the persistence of matter and energy ; and nothing else satisfies the understanding. If in trying to explain any phenomenon we are led to assign a cause which further examination shows to be either less or greater than the phenomenon to be accounted for, we necessarily assume that some error has been made. Therefore, every suggestion that there may be a failure of continuity or uniformity in the course of nature is merely a talking without thinking.

It follows from this that, if morality is to be scientifically treated, it must be brought under the principle of causality : if human actions are to be explained, it must be by adequate antecedents. Explanation by purpose is no exceptional case; for purposes are amongst the antecedents of an action; and if purposes are to be realised we must have command of the means to them; that is, we must control the causes of those effects.

(3) The test of truth is the agreement of all the laws and principles that constitute knowledge-whether derived from experience or from the understanding itself-with one another and with the details of experience, that is, with observation and experiment.

Moral Science has the same test of truth and the same logical canons as the other sciences have.

(4) The next three doctrines relate to Ontology, and, therefore, are not directly involved in moral science, although they bear upon the metaphysics of Ethics. I hold that the phenomenal World is the necessary object of minds, not a thing-by-itself. To call it 'a phenomenon,' the 'object of minds,' the 'known World,' is to say that it exists in consciousness. The World in space and time is a construction in, or (more properly) a development of consciousness in its objective phase. There is also a subjective phase of consciousness, the experience of feeling and striving which is excited in us by the presence of phenomena, or by thinking about them. But neither of the two phases, object or subject, has independent existence; they are complementary differentiations of consciousness.

(5) The consciousness of each man or animal is strictly 
correlated with its body or physical organism; and this fact is utilised in Psychology to provide a substitute for the explanation of conscious processes, as if they were produced in the body by physical stimuli. But though this way of considering body and mind is a convenient device and fully justifiable for the purpose, it is utterly untrue and strictly inconceivable. Consciousness cannot be explained at all : $(a)$ not by the body certainly, for the body itself is a phenomenon in consciousness; (b) any given mental process bears no resemblance to the correlative physical process in the brain or elsewhere; $(c)$ causation is out of the question, because every physical change is completely accounted for by its physical consequences, so that it cannot be supposed to have further psychical consequences; and $(d)$, according to the doctrine of physiological automatism (quite justifiable in Physiology), the mind is of no use to the body, and cannot be inferred to have grown up as a property of it by natural selection.

Since, then, consciousness can in no way be explained (has no adequate antecedents), whilst the known World, comprising all known causes and effects, exists in consciousness; it follows that consciousness itself is necessary existence.

(6) There are, however, many reasons for thinking that consciousness, though necessary, is not absolute or without some correlative mode of Being. The World, so far as it is known, is an object in consciousness; so far as it is knowable it is a possible object; but (in our experience) a mind capable of knowlege - of perceiving, assimilating, comparing - is always associated with an animal body; whereas the planet, in some condition, certainly existed before there were any animals upon it to which it could be a phenomenon; many regions of the World are still from time to time discovered and must, in some condition, have pre-existed. That condition we can only think of as one in which there would be phenomena if a conscious organism were present; and, accordingly, we imagine remote ages of the planet, or invisible stars in the depths of space, as if we saw them. That condition of the World, then, in which there are no phenomena, because there is no organic consciousness, I call Being: it is not an object 
in consciousness; but, nevertheless, it is not without consciousness.

(7) For (to return to matters more closely bearing on moral science), since consciousness accompanies all organised bodies, but cannot have originated from them or for their sake; and since living things do not, in their chemical and physical properties, differ from the inorganic world; I infer from this (with other evidence) that, in some mode or degree, consciousness accompanies all bodies whatever-or rather, accompanies the Being of which inorganic things are phenomena; that the whole World and each part of it is a conscious thing; though I cannot be confident that distinct, comparative consciousness exists anywhere except in the higher animals, or that it attains to rational thought anywhere except in man. As a matter of natural history, the higher mental processes develop along with the higher organisation of animal bodies.

Rational thought, then, and the moral consciousness that implies rational thought are a specialisation in man of the general consciousness of the World.

(8) In the last chapters of The Metaphysics of Nature I gave an outline of the development of the human mind, and of the interpretation of Nature according to the categories or forms of judgment, as derived from experience and the principles of understanding, and I concluded with the categories of subjective activity, namely, character, will, final causes, ends and ideals, and with an indication of how the rational development of man depends upon social relations.

A glance at the Table of Contents to the present volume will show that I am here engaged in working out and illustrating the positions with which the former volume closed. Human life is the highest known development of Nature. The first condition of its maintainance is elevation and stability of character or strength of will. Will implies a purpose or end; and since we cannot discover in Nature an End that must necessarily be ours, we must ourselves choose the End. The End that deserves to be called the Chief Good is Philosophy itself, both for its own sake and because it is the condition of the fullest gratification of all our other desires. 
In realising our purposes we may find the greatest aid in one another, in Society and its institutions-the Family, the State, Religion and Fine Art. But these things, though they help, may also hinder us; and, finally, the only guide that can be trusted is reason, philosophy, or culture - the guide, the pathway and the goal.

$\S 3$. When we consider the World present to us in space, it is easy to regard the consciousness of the World as concentrated or organised at certain points in animals, and especially in men. Each man seems to himself to exist in space, because he measures all distances and directions from his own body; to which also he refers the subjective consciousness whence issue his desires. Self-localisation is the objective ground of the illusions of individuality and, therefore, of all that mutual strife which is the most conspicuous phenomenon of Evil, and the central difficulty both in the metaphysical interpretation of Nature according to purpose and also in moral philosophy.

These illusions can never be completely overcome, because we can form definite comparative judgments only about phenomena in space and time, and space and time are the very principia of individuation; so that from the clues offered us by phenomena we can never draw any other than tentative inferences or indications concerning the unity of man and living things and the World itself: it is a transcendent Idea.

By the detailed study of plants and animals we are taught that at their sources they have all the same life, are all of them temporary individualisations of one continuous germinal substance which, as it develops and gathers together materials from the rest of things, produces their bodies to be its vehicles; until, that purpose having been served and new individuals originated, the materials of the old ones are dispersed again, and they exist no longer. In the course of nature species of living beings arise, and grow more and more unlike one another, and they and their specimens endure for a longer or shorter time, but the specimens always a very short time, and then dissolution is the end of all, and all return into the great vortex. In the continuity of their generations 
they are one, and at death they return to the one World that lives for ever.

Along with the forms of life consciousness is organised, varying somewhat from species to species, but having far more that is common to all; similar avenues of sensory stimuli, and similar principles of the integration of sensations with one another, and of stimuli with reactions; from which result amongst the lower animals (as far as we can judge) similar rudimentary presentations of things, in a rudimentary space and still more rudimentary time, and dim discrimination of self from other things. This is generic consciousness, repeated in human infancy, from which selfconscious human minds emerge, and immediately forget their origin: so that the individual, though instructed by others in the history of his body, seems as to his conscious life to have an independent existence, like a self-begotten god.

This generic consciousness in some ways witnesses to the sameness of all consciousness: it comprises (as we said) very similar sense-elements in very similar forms, and without distinct awareness of individuality. On the other hand, it is fragmentary and peculiar to each animal, which knows only its own neighbourhood, very faintly the time of its own experience, very partially the qualities of a few objects; and even for human perception the World remains fragmentary. It is thought that fuses all spaces into one space, all times into one time, all phenomena into one World, and which, although at first it increases some of the illusions of individuality - such as vanity, rivalry, avarice, ambitionat last transcends them. But thought does nothing to annul the fact of individuality as it is given in perception, and it is necessary that it should have no such power; because it is only individual human organisms that manifest the conditions on which universal thought is possible, on which ideas of unity and all Philosophy depend. Individuality is not impaired by overcoming its illusions: it is only emancipated from the distraction of incompatible purposes and the weight of chance desires.

Again, by the study of human life we are taught that an 
isolated independent individual man is impossible. Men do not exist except in families and tribes; where, in some measure intentionally, but far more unintentionally, common purposes are served by the efforts of all. The essence of tribal life is co-operation in war and peace. This is its natural utility: those families that are the more capable of tribal life prosper better than those that are the less capable of it. The tribe feels its unity, and emphasises it by the theory of blood-relationship (often fictitious) and by devotion to the symbols of its unity, kings and gods. With the progress of reflection, moral philosophy discovers a further and more significant ground of unity, the ultimate dependence of fellowship and co-operation amongst mankind, and the fullest satisfaction of all their desires, upon the recognition of one End or Chief Good as the goal of all their efforts.

I follow Aristotle and Spinoza in holding that the Chief Good is Philosophy. It is true that the great majority of philosophers are in favour, according to their temperaments, of either Perfection (especially moral perfection, or Virtue) or Happiness as the End. But without Philosophy there cannot be human Happiness, nor yet Virtue : otherwise I could not take it for the Chief Good. The word 'Philosophy' has the disadvantage of suggesting too exclusively the discipline and development of intellect. But it has that limitation only when it is the pursuit of a small number of men; and it is a detestable notion that Philosophy should be the peculium of 'specialists.' Considered as the Good of Man, Philosophy requires the fullest development of human nature, the fullest activity, the fullest experience, in a word, general Culture. For this reason I sometimes substitute ' Culture' for Philosophy, as expressing the same thing in a more concrete and attractive way: only it must be understood that the essence of all Culture is thought, without which it becomes a mere miscellany of 'accomplishments,' and easily degenerates into affectation.

Now the great problem of the metaphysics of Ethics or the philosophy of Religion (which is the same thing) may be put in this way: Can a purpose be indicated in the World 
which is, on the one hand, identical with human aspirations and, on the other hand, reconcilable with the actual history of Nature and Man. We have seen that the World is a conscious Being; but what is the quality or degree of its consciousness as a Whole? Is it even by a faint analogy anthropomorphic? In The Metaphysics of Nature (c. xv. \$3) I discussed at some length the idea of a Final Cause or Purpose in the World, and concluded that in strict reasoning there is no evidence for it. That, I am sorry to say, is still my deliberate opinion. Yet, in more than one place, I have allowed myself to suggest that, inasmuch as Nature comes to Self-knowledge in Man, and Man (as far as we know) is the culmination of Nature, such Self-knowledge realised in him may be the purpose and End of Nature. Once or twice my expressions imply a belief that this is true: expressions that have not been cancelled, because in a certain mood they seem to be valid. So I make this plain statement that no one may be deceived.

If it could be shown that the End of Nature is her own self-knowledge to be realised in Man, the End of Nature and of human life would be the same, and the first part of the problem of the metaphysics of Morality would be solved. What then of the second part: is this End of Nature reconcilable with the actual history of the World? Why not? It is the evil character of history that makes us pause. As religions in the course of social development are recast under the influence of philosophy, all the particular trespasses and sins, plagues and calamities, that men have sought to expiate or avert by prayers, penances and sacrifices, coalesce and bring to birth the terrific conception of Evil haunting the very life of things, the shadow of all individual existence, and only to be expiated by an equal penance, the suffering of everything that lives, or the suffering, the death, of God Himself.

The unintelligibility of Evil is the chief moral difficulty in the recognition of Final Causes in the World. If universal strife and misery are the necessary means to the World's selfknowledge, does the End justify them? We must consider that, even were the End attained in a comprehensive science 
and metaphysics of Nature, the strife and misery of the World would not be abrogated. Philosophy might be the endowment of many men; but strife and destruction spring up from the abysses of the organic World, upon which the higher life is wholly dependent, without it must starve and perish. For mankind itself, or rather for the remote future of mankind, it is conceivable that philosophy should be a sufficient redemption. It discovers the temporary character of individuality; unmasks all the illusions of egotism; dispels the mirage in which wealth, rank, the fame of achievement or genius appears as a private good; makes it plain that nothing is our own and that the greatest amongst us is the servant of all. After this is fully known it must at last be laid to heart: the surrender of selfish claims and hopes will show the significance of the ancient divine sacrifices (as Frederick Maurice taught me), not to change the divine purpose to our own advantage but to fulfil it: acquiescing in the divine Will, or (as we say) in the necessary courses of the World; and, I suppose, with a sort of austere joy that the long warfare is accomplished.

$\S 4$. Austere indeed; for who can forget the past and the terrors of human history, worse than the carelessness and cruelty of Nature? Austere and remote; for who knows the way to Plato's City, how long it is, and what dangers beset it round? At the present hour we see the leading nations of the world preoccupied with the problems of industry, and hesitating at the proffered choice between the established system of Capitalism and the vague promises of Socialism. Neither of these plans for the organisation of industry is good for mankind; because they both require the subordination of the great body of workers to a few employers or officials. This is the principle of physiological organisation in the higher animals by which all members are subordinate to the brain. Applied to human Society the analogy is misleading, because all the members of a Society are self-conscious, and humanity requires the development-if possible the equal development - of all its members. Probably centralised organisation is the most efficient for the greater part of helpless mankind in their present condition (Capitalism far more efficient than Socialism); 
and therein lies the danger of its succeeding in one form or the other; but it contains no principle of development upon which to improve the spiritual status of the majority. That is only possible where the methods of industry are understood and the responsibility is shared by every one concerned; and these conditions are found only in Co-operation. No other system exhibits the essential conditions of human Society; no other suggests the ideal of cohesion merely through the assent and devotion of every citizen; in the end, nothing else is compatible with liberty, with the raising of the general level of our race, and with the return of Industry to the condition of instinctive interest in which, as in the Fine Arts, good workmanship becomes an end in itself. The organisation of Society upon the physiological principle would perpetuate that crude economy of Nature which stunted the common tribesman in order that he might follow his chieftain. This plan human reflection must revoke.

But it is quite useless to invite co-operation from those who have neither the ability to understand the conditions of industry, nor the character to make fair contracts and to carry them out; and of such is the greater part of mankind. In whatever direction you turn it will be found that low development of the human race is the obstacle to every kind of improvement. Therefore the raising of the average quality of the population is the condition of every other reform; and to any one who comprehends the meaning of this, dismay is excusable enough. It means practical Eugenics. In the fifth chapter I have touched upon this matter, not very hopefully. More definite proposals, together with a convincing statement of the danger of our present condition, will be found in Prof. Karl Pearson's lecture on The Problem of Practical Eugenics. ${ }^{1}$ Without a great improvement of the population there cannot be fair terms and free contract in industry, nor honesty in politics, nor rational religion, nor enlightened morality; that is to say, there cannot be any extensive attainment by individuals of the culture through which the illusions of and Co.

1 With other publications of the Francis Galton Laboratory. Dulan 
individuality are penetrated and dispelled. My ideas of what is best for mankind may be summed up in four wordseugenics, co-operation, liberty, culture.

$\S 5$. Where in the following pages I refer to questions of heredity, the Reader interested in such things may notice that the Galtonian theory is usually taken for granted. When this book was begun that theory was generally accepted. Recently another doctrine, the Mendelian, has come forward; but I must confess that, in spite of my having seen two or three striking essays upon the subject, its full power and importance were first brought home to me by the evidence set forth by Prof. Bateson in Mendel's Principles of Heredity: a work published in the spring of the present year, which did not fall into my hands until this book was already written. With earlier knowledge of it I should sometimes have expressed myself differently; but, on the whole, it has seemed to me inadvisable to make any alterations; inasmuch as no argument of mine directly relating to moral science is affected by Mendelism. It will suffice to mention the points at which it might modify certain reflections upon history and social affairs.

In discussing the influence of race, I have assumed that the formation and the stability of a race's character depend upon the length of time during which it has been relatively isolated and exposed to natural selection; and this seems to be "the old delusion that time and continued selection are needed in order to make a variety breed true" (Bateson, p. 298). Any Mendelian factor (ground of the variety) that is once present in an individual persists in the stock, unless the individual fails to breed, or unless the variation is so injurious that descendants manifesting it are eliminated by selection.

When, however, we turn to the constitution of a human race-type, such as we are concerned with in history or moral science, it is seen to depend not upon the mere presence or absence of some elementary factor, but upon the coactivity in certain proportions of a number of psychical and physical traits-say, intelligence, prudence, energy, stature-the proportions of the combination being different for each race, 
though the general traits may be common to several races; and I do not think there is yet evidence that the special and persistent correlation of such qualities, without which there is no racial character, is not dependent on time and continued selection. At any rate we can hardly help supposing that the formation of such a type takes a long time; for the variation constituting each distinctive trait must appear first in one or more individuals and be propagated thence throughout the population. Should the variation be highly advantageous, this process may in time be effected, but it must take many generations. How many generations will be needed for the formation of the complete type with all its correlated traits, must depend upon whether these traits appear at first separately or simultaneously, in one individual or in more than one. But in any case the formation of a considerable population, exhibiting a distinctive type of character, such as to justify us in calling it a race, must take a long time and depend upon natural selection; and, if so, its permanence is guaranteed by its having resulted from such selection; provided that no great changes take place in the environment. I admit that a type might be formed in a few leading families in much less time; and that the influence of these families might make a spectator suppose that their type was shared by the whole stock.

Again, for history, and indirectly for moral science, the interest of races lies a good deal in their migrations and conquests; and by such movements their environment is changed. When this happens the resistance of a racial type to modification depends upon whether any traits of the type are now directly injurious, or upon whether the adaptations necessarily undergone to the new circumstances are compatible with those traits that are considered to be racially important. But something else usually happens, namely, intermarriage between the conquerors or immigrants and the indigenous population; and I have assumed that the "blood" of the immigrants is liable to be diluted in the crossings that occur, their type of character to be "submerged" or overwhelmed; besides that the indigenous population is better adapted to the local conditions. According to Mendelism, however, "the notion that a character 
[variation, or trait of character] once appearing in an individual is in danger of obliteration by the intercrossing of that individual with other individuals lacking that character proves to be unreal, because in so far as the character depends upon factors which segregate no obliteration takes place" (Bateson, p. 288).

Still, if we further consider what traits of character are important to human race-types, it may be doubted whether they are of a kind to resist obliteration by crossing. They are not such relatively simple properties as eye-colour or the shape of hair-sections : it is admitted that "the number of factors involved in deciding human stature is large" (p. 209); and the number of factors involved in intelligence, or prudence, or enterprise may be larger. Energy, again, is entirely a matter of degree: does any one maintain that the energy of a stock cannot be obliterated by crossing it with an inferior one? For to diminish is, in this case (so far as history and morals are concerned), to obliterate. And, again, by diminishing the energy of a people most other items in the list of its virtues and vices, capacities and incapacities, lose their value; their proportional expression must be greatly changed; the type is practically extinguished. Moreover, Mendelian factors, though called units, are not, I understand, assumed to be always simple: it is enough that they behave as units in producing traits that can be observed. Ultimately, no doubt, simple physical factors will be sought; but at present the assumed factors are little else than occult causes. If the grounds upon which single traits of human character depend are unitary totals, more or less manifold, it may be supposed that they are sometimes complexes of different simple factors, sometimes compounds of larger or smaller numbers of the same factors - prudence, for example, is plainly a complex : and if complexes are liable to dissociation by intermarriage, or compounds to addition or subtraction, either change would suffice to alter a type of human character.

Finally, I have assumed in one or two places that every individual carries the qualities of all his ancestors and can transmit them to posterity, being most marked by and most liable 
to transmit the traits of his nearer ancestors. But according to the Mendelian principle of segregation this may not be true: under certain conditions of breeding, one ancestral trait (or rather its factor) descends to certain individuals, another to other individuals, whilst in a third group both are present. Nevertheless, "as describing the results to be witnessed amongst a population breeding at random," Galton's Law of Ancestral Heredity (which I have followed) yields "predictions that would frequently approximate to the truth" (Bateson, p. 129). So that since, unfortunately, human populations, with which history and moral science are concerned, may all be truthfully described as "breeding at random," I hope that in my references to heredity no serious error has resulted from neglect hitherto of Mendel's luminous and fascinating experiments. With these explanations I must leave the matter until I shall have been better instructed and have had more time to think.

In general it may be said that Mendelism gives to the conception of heredity greater definiteness than it ever had before, and that in its development it must have most important results for scientific Eugenics. Prof. Bateson's view of Eugenics, favourable to the elimination of bad qualities rather than to the direct encouragement of good ones, will be found in the sixteenth chapter of his book in a section on Sociological Applications. He utters these words of warning: "Whatever course civilisations like those of Western Europe may be disposed to pursue, there can be little doubt that before long we shall find that communities more emancipated from tradition will make a practical application of genetic principles to their own population. The power is in their hand, and they will use that power like any other with which science can endow them. The consequence of such action will be immediate and decisive. For this revolution we do well to prepare." 

BOOK I.-MORALITY NATURAL TO MAN 



\section{CHAPTER I \\ PRACTICAL AND THEORETICAL MORALITY}

\$1. Morality is natural to Man in this sense that nowhere, even in the lowest grade of savagery, do men exist without manners and customs, in relation to which some of them may be well, others ill disposed. The observance of such customs is objective morality; the disposition to observe them is subjective morality. He who on the whole observes them, is disposed to observe them and to encourage their observance in others, is a good tribesman; and he who is disposed to break or evade them is a bad tribesman. The former meets with approval, the latter with disapproval. It is true that some of the manners, customs and dispositions that are approved of and cherished by many savages may seem to us a sort of devilry, or bestiality, or lunacy; so that it may be said- " If morality be natural, so assuredly is vice." But morality is natural in Butler's sense, as that which is "stated, fixed, settled" (Analogy, c. i.); and if we take a long period of history (such as we now know to be necessary in the consideration of human affairs) it appears that bad customs cease to be customary, are condemned and can only be practised by stealth; or else that tribes in whom they remain fixed are destroyed, or fall into the background. On the other hand, amongst the customs of every tribe however savage, there is always a core of regulations having some quality of good sense-at any rate, better than no regulations at all: e.g. in connexion with property, marriage, war. And even with the devilry, bestiality, lunacy, it is generally possible to trace 
a kind of reasoning about them in the savage's mind, when we know what his beliefs are; they may sometimes be inferred to have arisen as a condition of altering earlier customs that were worse; and it may be possible to trace in outline the trans-" formation of these, or similar customs of other tribes, into something comparatively sane; so that revenge is seen to be in fact "a kind of wild justice," and the servile dread of wizards a "wild" deference to specialists. Moreover the savage's attitude towards his own manners and customs is essentially the same as we hold towards ours; and to future generations it may seem that even our manners and customs are not entirely purged of devilry, bestiality, lunacy. What will they say of war, flesh-eating, personal ornamentation, that already seemed ludicrous to Sir Thomas More when he dwelt in Utopia 400 years ago? It is well to be careful how we refuse the name of 'morality' to the manners of other people.

Morality is natural and necessary to man, because he exists in Society. It seems probable, and is now generally believed, that he always did so, that this was one condition of his differentiation from the apes. The few cases in which men have been found living in solitary, or nearly solitary, families may be put down to retrogradation. Relative permanence of the family was required by the increasing length of infancy, correlative with the growth of that great utility, intelligence. But men may be inferred to have been from the outset physically unfit to maintain themselves in solitary families as ground animals and particularly as hunters. Language, though conceivably it may have originated in the family, seems to presuppose, for any considerable development of it, the tribe or horde, and the utility of co-operation. The whole cast of human emotion is profoundly and therefore anciently social. But for social animals there must be, as W. K. Clifford expressed it, "conditions of gregariousness." Since their needs, desires, tendencies to act, may sometimes coincide, but will sometimes conflict, there must be control of some kind; and it cannot be a merely external control. Without manners and customs cohesion would be impossible; and persistent manners and customs are impossible without 
the disposition to observe and encourage them. Morality can never have been merely observance; and in this fact lies its naturalness to man, in the sense that it is necessary not merely to his existence, but to the development of all that is most distinctively human. Its own growth is such an inseparable accompaniment of the total development of human nature, and so essential to all the rest, that some philosophers have regarded it as the end for the sake of which all the rest exists: from which position they may even argue that therefore it is not natural, as being above Nature. But against this may be set the favourite philosopheme that whatever marks the perfection of each kind is its true nature.

$\S 2$. The position that Morality is natural to Man has nothing to do with the doctrine that right and wrong, good and evil, are distinctions that can be deduced from the metaphysical theories sometimes called “Naturalism." W. R. Sorley, in his logically powerful work, The Ethics of Naturalism, understands by "Naturalism " Materialism, or the mechanical theory of Nature, excluding the influence of reason and purpose; and under that limitation his argument seems to me cogent and unanswerable. It is certainly impossible to arrive at any conclusions as to what is right or good, except from practical premises. Hume was the first (I believe) to insist upon this point. In the Treatise of Human Nature (Book III. Part I. $\$ 1$ ), he says: "In every system of morality I have always remarked that the author proceeds for some time in the ordinary way of reasoning, and establishes the being of a God, or makes observations concerning human affairs; when of a sudden I am surprised to find that instead of the usual copulations of propositions, is and is not, I meet with no proposition that is not connected with an ought, or an ought not. This change is imperceptible; but is, however, of the last consequence. For as this ought or ought not expresses some new relation or affirmation, 'tis necessary that it should be observed or explained; and at the same time that a reason should be given how this new relation can be a deduction from others which are entirely different from it."

So far then, as Nature cannot be interpreted according to 
purpose, Morality cannot be deduced from Nature; but unless any one denies (as T. H. Green did) that Man is a natural growth, there is no difficulty in regarding Morality as natural to him; for to him desire, purpose and the rational co-ordination of desires are as instinct is to ants or contractility to medusae. For my part, I repudiate the use of the term 'Naturalism' as equivalent to Materialism or Mechanism. Whatever precedents may be cited for such usage, it is unjustifiable. Naturalism includes whatever principles are found in Nature. If we find there organic adaptation and reason, and if these things cannot be explained by mechanism, mechanism is not co-extensive with Nature. Nature, as every one sees, includes mechanism and organisation, and also in human affairs purpose, reason, society: and if I have coupled 'Social' with 'Natural' in the title of this book, it is to avoid misunderstanding; for I take it to be a pleonasm. To cast human affairs out of the realm of Nature is to destroy the system of the world, to despiritualise Nature, and to dismiss man to some Limbo of the non-natural, unnatural, or supernatural, which is not explicitly stated.

To return to the quotation from Hume, he overstates the case in accusing "every system of morality" of confusing obligation with abstract relation: misled, probably, by his recollections of Locke and Clarke. In Clarke's system the paralogism turns upon the word 'fitness'; which may mean (a) agreement (as when a bookcase fits into an alcove), or (b) adaptation to an end: hence he says, 'there are relations of things and therefore we ought to act accordingly.' ${ }^{1}$ The doctrines of Spinoza, Hobbes, Aristotle, are not seriously vitiated by this kind of error. It is true that Aristotle falls

1 It seems fair to Wollaston (who is attacked by Hume in a long note to the section :above quoted from) to point out that he also bases Morality on a practical principle, namely, that to aim at happiness is a duty (Rel. of Nature, Sect. viii. Prop. 9), and that when he identifies wrong-doing with falsehood, his meaning is that a wrong action implies the proposition, that such an action is a means to happiness, when in fact it is, not. He got this notion from Clarke (who says "Iniquity is the very same in action as falsity or contradiction in theory," Obligation of Nat. Rel. p. 202), but he has avoided the fundamental error of his master. In fact, Wollaston, who (I believe) was the first to give in definite outlines a mathematical analysis of feeling, is unjustly depreciated by critics and historians. 
into it in his conception of the Mean, which he tries to explain mathematically, and thereby obscures its relation to the Chief Good; for he treats it as a matter of abstract quantity instead of as that which is best in relation to the end. But in his account of the prerogatives of $\phi \rho o ́ \nu \eta \sigma \iota s$, he clearly conceives that the principle of practical syllogisms affirms an end"since such or such is the end and the chief good" (N. Eth. Book VI. c. xii.).

Still, the confusion noticed by Hume is a very common one, by no means confined to Naturalism but more characteristic of Rationalism, the chief object of Hume's attack. Whoever makes Reason the sole differentia of human nature endeavours, of course, to deduce Morality from Reason. Aristotle avoids this error by recognising that every stage in the development of the soul has its proper quality of desire. He is therefore able to declare the exercise of reason to be the chief good, and at the same time to explain that the moving power toward that good is not reason itself but its correlative desire. Aristotle's general view of the matter seems to be just; but in consistency he ought to have included not reason alone but also its correlative $\beta o u ́ \lambda \eta \sigma \iota s$ in the differentia of human nature. Morality can never be understood unless we observe that human differs from animal nature in the development of its passions and desires as much as in its faculties of intelligence. Hume shows (in the section cited) that the office of reason in morals is twofold: "either when it excites a passion by informing us of the existence of something which is a proper object of it; or when it discovers the connection of causes and effects, so as to afford us means of exerting any passion." But there is a third office, namely, to discover how all the passions may be ordered in such a way as not to frustrate one another, but converge towards the maximum advantage. Extended views of futurity and the fastening of desire upon objects remote in time are characteristic of man, and they naturally inhibit irregular impulses. The improvement of manners implies an increasing differentiation, refinement, and prospectiveness of desire, as reason discovers more and better objects of desire and the means to remoter and more comprehensive good; and 
it further implies the co-ordination of desires under dominant ideas of permanent human interests. But this would not avail without the progressive organisation of desires into stability of character, and the generation of the impassioned mood that gives nobility to life. Without stability and devotion, the idea of enduring and comprehensive good must be inoperative.

$\S 3$. Practical Morality, then, is everywhere natural to man; and, of course, its recognition and observance long presedes the rise of speculation concerning its validity and foundations. It then becomes the object of reflection, the empirical reality of human life, which must be interpreted according to principles; and we may be sure that the human mind will never rest satisfied until the principles of Morality have been taken up into one conceptual system with the totality of our knowledge.

To explain Morality: what else can it be than to find its resemblance to other things that we know, or believe that we know? The kind of explanation that is acceptable, therefore, must depend upon the age in which we live and upon the interest and culture of the interpreters. When all things are referred to the guds, Morality can be thought of in no other way. When customs and laws are regarded as of divine institution, Morality, if it can be at all distinguished from customs and laws, must be considered to have the same foundation. If the State is held to exist for the sake of some absolute good, so does Morality. A prevalent conception of world-wide law, converts Morality into the Law of Nature. The development of science extends scientific methods and concepts to Morality. Mathematics suggests a hedonistic calculus: with Physics comes the conception of social equilibrium: with Biology the insight that Morality is adaptation and a condition of personal or national survival. The master-concept of all physical and natural sciences is causation; and, therefore, Morality, if treated as a natural science, must be reduced to laws of causation, or something equivalent to them.

All this belongs to the natural and necessary working of the human mind; and superficially contrasted as such explanations must appear, they are not profoundly opposed, if we make 
allowance for the varying modes of expression that are idiomatic in different ages and countries. One man may say that Morality is of God, another that it is of Nature, and yet feel and mean much the same thing. I am surprised that Divinity should be persistently opposed to Naturalism. How is this possible to a reflective mind? There must be a reconciliation. In every one of the above suggestions toward a Philosophy or Science of Morals there seems to me to be some truth. And if with the growth of the science or sciences of human nature (of which Morality must be the chief) new methods or new concepts are established, these will not supersede but incorporate most of the earlier speculations.

The dissensions amongst Moral Philosophers (the moderns at least) seem at first to be almost entirely speculative. This follows from the fact that speculation does not arise until practical morals are well established; and that what has been established is the datum to be explained. We cannot be so deceived as to imagine that the moral rules that may seem to be conclusions in any system, are really inferences from its characteristic conceptions. With some slight qualifications, the rules are rules of Common Sense, and are the premises, the true principia, from which the theory is inferred. To agree with them on the whole is a test that no theory can ever evade. Who would listen, for example, to Utilitarianism if it did not encourage truth and honesty? or to Self-realisation, unless it were explained to mean self-devotion to the public good? Schopenhauer manages to show that suicide is forbidden by his system. Yet the Moral Philosophers sometimes argue with so much warmth, that we may reasonably suppose them to be at issue upon some practical matter of conduct. And in fact that is their belief. The differences they have in view are generally not such as can be reduced to rules, but are differences as to the spirit of conduct, the feelings of obligation that may accompany actions, and sometimes associated behaviour such as religious observances.

It cannot be denied that such feelings are essential 
qualifications of conduct. The sense of their importance is one of the conditions that deter moralists from attempting innovations in the accepted code of rules. It even prevents many of us from thinking freely upon practical moral questions. The moralist who refrains from putting forth original conclusions as to practical life, is not merely held back from an unpopular course by prudence. It is his conviction that the rule already established has the support of feelings that can only develop slowly; that what is new can have no such support; that so far as the new may conflict with the old, or even suggest its imperfection, it may impair the effectiveness of the great system of moral beliefs that is the natural growth of ages. But if such considerations should be urged against all speculation upon these subjects, it may be replied that works of moral science do not directly reach the great public; that risk attends all speculation and all action; that the capacity to endure ideas is a qualification for human life, and that it is not good to spare the elimination of those who want it; that enlightenment in morals is still very necessary, and that the graver the subject the more necessary is enlightenment; that the opposition of Moralists to one another is itself injurious and of ill example, and that it can only be overcome by attaining the conviction that different ways of feeling about conduct are natural to different kinds of serious men, and with each kind may be equally effective; and that almost any philosophical view of Morality sincerely followed out presents reasons for right conduct overwhelming to every adverse interest. As to the popular effect of any doctrine, ideas slowly filter through the social strata; but the effective propaganda of a moral message is the exemplary life.

$\S 4$. When, in view of a traditional Morality, moral reflection arises and systems or, at least, theories are formed, there are two ways of conceiving the subject. On the one hand, the connection of Morality with Custom or Law suggests that it should be treated, so far as possible, as a code of observances, rules, or duties. On the other hand, the insight that out of the heart come good and evil, that 
the essential matter is a clean heart and a right spirit, leads to the consideration of Morality as a study of character, or qualities of character, virtues and vices. The conception of virtue is more prominent in Aristotle and Hume, for example; the conception of duty or law in Butler, Bentham and Kant. But, plainly, both are necessary to a comprehensive theory: we cannot clearly separate the questions of what we ought to do, and what we ought to be; for certainly we ought to be the kind of men who gladly do such and such actions.

The evaluation of character presupposes a theory of conduct : he is the good man who does, and is confidently expected to do right actions. If we attempt to analyse his character into motives, and to classify these as good or bad, we can make no progress without inquiring what kind of actions they generally incite. Thus Bentham defines the "tutelary motives" as those that in general coincide with the public interest; the "seductive motives" as those which are apt to collide with the public interest. For him the public interest, as the standard of right conduct, determines the quality of characters or motives, as agreeing or disagreeing with it. Hume shows that all qualities of human nature are approved or disapproved according as they promote or injure general utility. The virtues described by Aristotle are those that belong to the citizen of that State in which alone the chief good can be attained.

But, again, the theory of what we ought to do cannot be separated from considerations of character and capacity. There cannot be principles of Morality irrespective of the condition of human nature, the actual or proximate scheme of conation and intelligence. The Chief Good must be something that we are at least capable of desiring: it must be useless to set public ends before a people who, in fact, are without patriotism or effective sympathy. And it is admitted that a man's responsibility is always circumscribed by his possible knowledge of the circumstances and consequences of any action: this constitutes, theoretically, his intention. Practically, his intention is further limited by his actual knowledge: 
if this is inadequate through his own fault, he is not excused; but, at any given time, ignorance puts a necessary limitation upon every one's power of doing right actions. Similarly, the bounds of human knowledge, whatever they may be, define the possible scope of moral wisdom.

A man's intention is what he chooses to do, and therefore marks his character on the whole: it is a mistake to regard his motive as a better mark. His motive is so much of the foreseen consequences of the action as he desires to bring about; and this reveals a certain trait of character: but his neglect, or comparative valuation, of the other consequences shows what sort of man he is. Suppose "that a man betrayed a trust received from a friend, because the discharge of it would fatally injure that friend," the motive is to save his friend, an amiable trait ; but the 'betrayal of trust,' though undesired, shows moral insight, to prefer a real good to formal obligation, and it implies courage to take the responsibility; and insight and courage are far more important qualities than a respect for formal obligation. At the same time, the motive must not be disregarded. Mill (Utilitarianism, c. ii.) declares that a man's intention alone determines the quality of his conduct as right or wrong, whilst his " motive has nothing to do with the morality of the action, though much with the worth of the agent." But we cannot in this way exclude the consideration of motives from the conditions of right conduct; for the consequences of the motive are amongst the consequences of the action. To act upon a motive of cruelty or greed is to strengthen its hold upon us, to confirm our character in that direction; to make it easier for us to do such actions in future and, therefore, more likely that we shall do them. All this is a part of the good or evil of every action, and by no means the least part. Still, to give prominence to intention is necessary in order to set aside the notion that a good motive, without regard to other consequences, is enough to make an action good. It is the error of sentimentalism to depreciate knowledge, foresight, circumspection, in comparison with a sweet disposition, a pious leaning, a tender heart. A good motive may make an action more amiable, more excusable, or 
more regrettable. But both a good motive and a wise intention are necessary to make it good.

The study of virtue, character, the inward life, is of profounder personal interest than a doctrine of Duty can be; for it goes to the springs of action and the secrets of experience. There life glows in its plastic origins, promising indefinite variety and richness of development; and in comparison with this a scheme of duties seems cold, finite and mechanical. The student of virtue is apt, by an effort of abstraction, to conceive of the good man as capable of existing alone, where duty would be impossible; or of duty being swallowed up in the victory of the just made perfect. The study of character moreover, leads us to the great problems of the possible change of character (or conversion) and its conditions, and of the formation of ideals in which character is glorified. But it is quite plain that this study cannot even be begun without some theory or belief as to what actions or lives are admirable or good and right, in fact, without a belief as to what we ought to do.

$\S 5$. If we turn to the historical systems of Morality, we find that for the most part they present two ways of conceiving rules of conduct; upon which ground Whewell, in his Lectures on the History of Moral Philosophy, has classified them as Independent and Dependent Systems. In the Independent Systems there is no explicit reference to any End to be attained by conduct; but either the quality of an action is supposed to be known by direct intuition (Butler); or some rule is obtained by reflection upon the nature of the case (Clarke and the Jus Naturale). In Dependent Systems, the quality of an action, or its rule or maxim, is regarded as deducible from whatever may be taken to be the End or Chief Good (Bentham). It is true that in some systems both methods of determining right conduct are recognised. Thus, according to Aristotle, the virtuous mean is directly known to the wise and experienced man; whilst it is also true that every action has an end in view, and that there is an End to which every other end is subordinate. Still, although he nowhere clearly deduces the mean from the Chief Good, it is easy to supply the missing minor premises; since all the virtues are qualities of citizens, 
upon whom depends the City that is necessary to the good life -philosophy : the virtues, therefore, are necessary means to the Chief Good. According to Kant, again, the quality of an action is determined, under the first form of the Categorical Imperative, by the universal applicability of the maxim requiring it; under the second form the quality of an action depends upon its tendency to serve the End or Chief Good, that is, Humanity itself-one's own perfection, and the happiness of others. But the perfection of a man is reason or universal thought, and the happiness of mankind can only be prosecuted by him upon universal maxims.

Such cases as these of Aristotle and Kant, if they do not fall directly into Whewell's classification, at any rate support the position for the sake of which I have drawn attention to it, which is this: that, whatever may be the conditions of our knowing what is right, no system of Morality is 'independent' in its origin and essence; however absolute a system of rules may be for us, rational rules of action imply an End which the action is to realise. Butler, though classed as an independent moralist, certainly assumes that there is such an End. I doubt, indeed, whether his caution permits him anywhere to declare the whole purpose of God's government; it is not merely the happiness of His creatures apart from their obedience, he says (Analogy, c. iii.); but, though he will not venture into such waters beyond his depth, he is certainly confident that a bottom exists. Clarke is bolder : the will of God determines itself according to Justice, Goodness and Truth, "in order to the welfare of the whole Universe" (Oblig. of Nat. Rel., Prop. I.). The Jus Naturale takes us back to the Stoic Philosophy and to the conception of Nature as expressing the wisdom and providence of Zeus. For Cudworth our knowledge of moral as of natural truth is a participation in the wisdom of God; but " it was the opinion of the wisest of the philosophers, that there is in the scale of being a nature of goodness superior to wisdom, which therefore measures and determines the wisdom of God, as His wisdom measures and determines His will." Expressing God's nature by " the mystical or enigmatical representation of an infinite circle," we say that His wisdom, which determines 
the truth of all things that his Will brings into existence, is but the periphery; the centre is Goodness (Eternal and Imm. Mor. I. iii. § 3.) It would be tedious to enter upon an exhaustive examination of moral systems upon this point; and, surely, needless: since, whether morals depend upon God or man, for a rational being moral action implies an end: or, if morals be the ordinance of Nature apart from man, it involves personification of Nature and teleology ; in fact, Nature becomes a shame-faced name for God.

Amongst the ends, however, that are regarded as determining moral action or the rules of it, we may distinguish those that lie within the scope of human understanding, desire, and effort, and those that exceed our powers. As of the former sort it seems fair to mention progress in virtue, in wisdom, in happiness. Of the latter sort is plainly Clarke's conception of "the welfare of the whole Universe." We cannot know what this is, nor therefore intelligently desire or strive after it. If the rules of Morality are really determined by an end so vast, they must be followed in some sort by faith. Similarly, when we find that Butler thinks that the end for man is, of course, happiness (private and public), but that this may not comprehend the whole purpose of moral Government, whilst nevertheless Conscience is to be obeyed on its own authority, supported merely by the probability that obedience will ensure our happiness, it is apparent that here also not the whole character and reason of Morality is to us intelligible. And much the same must be said of "naturalistic" theories of conduct, that see the true end of human action in a furthering of the process of evolution. Even this is a conception beyond our understanding, at the present stage of mental development. We cannot make it definite; we cannot judge with any confidence whether the next stage of evolution will be better or worse than the present one. Why, then, should we desire or strive after it? One of the few things we can be pretty sure of in the course of evolution is, that it will one day extinguish the human race. Few men regard this as a natural or possible object of desire : to take it for the chief good would need the faith of Tertullian, or the ferocity of Caligula. 
Now any grounds of Morality that lie beyond the scope of human understanding, desire, and effort, will be treated in this volume as lying also beyond the scope of Moral Science, and as belonging to Religion. For example, when Butler says that the constitution of human nature shows that man is designed to promote his own and the public good, and that Conscience is in fact the surest guide to that end, so much is Moral'Science; but when he suggests that conscience is the voice of God and anticipates "a higher and more effectual sentence," having reference to an end beyond our comprehension, that is Religion. Everybody, no doubt, admits the distinction. And it seems to me that if the process of evolution, or anything in Nature apart from Man, is to be made the chief good, it can only be done in the way of Religion. In this book, then, I am to treat of Morality, as far as possible, upon intelligible grounds, as a natural growth of human society: I do not contend that there is nothing in Morality that cannot be thus explained. Morality has been greatly influenced for both good and evil by Religion; that is a matter of fact which I shall discuss in Book II. c. ix. But Religion itself is not the subject of this work. I assume (referring for evidence to such works as Tylor's Primitive Culture and Frazer's Golden Bough) that most religious beliefs and observances are a natural growth of human society, but do not assert it of all of them. If at any point of my argument the position becomes a delicate and treacherous one, I will try to be candid and fair.

$\$ 6$. An imperative rule, or maxim, or positive law, requiring a certain action as means to an end, presupposes a law of uniformity, of cause and effect, or conditions and resultant, according to which the means prescribed does lead to that end, or tends to do so ; that is, it will do so, if nothing else happens to frustrate it. The imperative form of Morality, therefore (and the same is true of Legislation), is merely the mask in which it confronts the unenlightened individual who is subject to it. Whewell, indeed, says: "It is the very essence of moral truth that it implies command " (Elements of $M$. $P h$., Pref. to 2 nd ed.); but the essence of moral truth must 
be the reason on which the command is grounded. Taken generally, Morality is a practical science like Medicine or Political Economy. So far as the End is conceived (as by Butler) to lie beyond the region of Nature, the process connecting an action with that end cannot be traced; but if the End (say, human Happiness or Perfection) lies within the region of Nature, its connexion with the means is traceable by the same methods as the resultant of other natural forces in equally complex circumstances; though certainly no other circumstances are equally complex. This conception of the relation of Positive to Natural Law was latent in the Stoic ideas of a Jus Naturale, at once the Law and Reason of the World; but I believe the first clear statement of it is due to Cumberland. In his Laws of Nature (c. iv. \$1) we read, that it is not necessary that practical propositions "should be pronounced in the form of a gerund, "This, or that, ought to be done,' as some Schoolmen teach; because that fitness which is expressed by a gerund, wants explanation, which is to be fetched either from the necessary connexion of the means with the end, or from the obligation of a law. The obligation of Laws is not yet to be supposed known by those who are in quest of their original. And the necessary connexion between the means and the end, is sufficiently expressed in the connexion of them as causes with their desired effects." Bentham, again (Deontology, c. ix.), defines the ground of approbation as "the tendency of an action to produce happiness." Scientific Morality, then, is concerned with the tendencies of actions to promote the Chief Good: but, of course, popular unanalysed moral judgments are often immoral, because based on resentment, disgust, etc.; which may be merely subjective, or derived from false theories, magical or religious.

The relation of means and end implies a law of Cause and Effect, or of Conditions and Resultant: alternative phrases employed here, because I have shown in the Metaphysics of Nature (c. xiv.) that Causation can only be made definite as a strictly physical concept; whilst in Morality we are concerned with personal and social events, where the process is plainly psycho-physical. Even in inorganic Nature (as I hold) the 
process of causation is really psycho-physical; but as only the measurable physical process is open to observation and experiment, that is all we can deal with. In human affairs, however, certain factors of the psychical process are open to observation; and moral philosophers always conceive of the End or chief good as a matter of possible conscious experience. But all overt moral actions are physical actions, and, therefore, their consequences, in experience of the good, cannot be related to them by causation but only correlatively; so it may be better to say (speaking strictly) that the relation of means to end is one of conditions and resultant. Still, there is no loss of Uniformity: physical actions have physical effects; and whether the good attained be philosophy or happiness, there is a corresponding physiological modification: a law of Causation, therefore, is implied, though we are not yet able to give a complete account of it. If, then, at any time I speak of the causation of social or personal events, I hope to be understood subject to the above explanation.

As there are different conceptions of the Chief Good, each of them implies the possibility of a distinct practical science of its conditions. One set of conditions might be favourable to Perfection, and another to Happiness. In fact, however, the common maxims of Morality dictate actions that tend to secure all the recognised theoretical ends; else these Ends could never have been proposed. To speak the Truth tends to social Happiness, to human Perfection, and is certainly favourable to Philosophy. To pay one's debts has similar advantages; and so with all the other maxims; though you may observe that the tendencies are more obvious in some cases than in others. It may seem, therefore, that there is only one science for all the Ends. This is partly explained by the fact that I have already mentioned, that the maxims are the data of speculation, so that no chief good can be recommended by respectable philosophers unless the common maxims are means to it. But further explanation may be found in this, that all the conceptions of the Good put forward by philosophers are partial, one-sided abstractions, which must coincide in the ideal culmination of the moral life. Social Happiness, Per- 
fection and Philosophy in their noblest forms, are inseparable; so that it is no wonder that maxims favourable to one should be favourable to all. Nevertheless, it is not quite true that there is only one science for all the ends, as long as we maintain the abstractions. For each end (say Happiness or Perfection), so far as it comes alone into consciousness, is a differential motive which gradually affects a man's whole life. It directs attention to some things rather than to others, determines the grouping of our thoughts, and what we shall take account of, and thereby our ideas of what we ought to do. The different lives resulting gratify different tastes and characters; and this really explains the preference for different partial ends.

It may occur to some one that there is a view of the moral life to which the distinction of End and Means is inapplicable, namely, that which takes Virtue to be the End; for then every virtuous action is not merely a means but a realisation of the End itself. But on reflection it will be seen that we cannot begin with virtuous actions and the virtuous life: there must be at least a period of discipline, during which a man's actions are relatively in the nature of means. There is the oppressive doubt whether we can ever rise above this condition; and it must at least be admitted that, in the most exalted state, every action remains a means to all subsequent ones through its influence on character.

$\S 7$. One advantage of treating Morality as a science of tendencies is, that it enables us easily to overcome the difficult case of conflicting maxims that often confronts practical reflection. "To speak the truth" may seem to be opposed to the maxim "to love your neighbour as yourself"; and if these are both of them absolute commands, what shall we do? As long as the maxims remain in the imperative form, we can only avoid such difficulties by introducing qualifications-unless, or unless, or unless. But then the maxim seems to be whittled away until perhaps nothing may remain, except that we are "to speak the truth" when it is not inconvenient; and so a suspicion of illicit casuistry is aroused. As soon as we recognise that every End is obtained by a combination of means or 
forces, all difficulty disappears: we see (suppose) that "truth" is a force tending to the public welfare, but not the only force, nor one that operates exempt from counteracting forces; and that our problem is to combine all favourable forces and to exclude all opposing ones, so as to obtain the maximum resultant.

It is another advantage of viewing Morality in this way, that we avoid the hopeless problem of the historical abstract Ethics which lays down absolute rules, or inquires what the Chief Good is, and thereupon determines what the individual ought to do in order to obtain it, no matter who he is, or where, or when he lives. This method requires such evisceration of individuals that they have no individuality left; such oblivion of the actual State as to reduce it to an invention, like Plato's, or to an abstraction, like Spencer's, or to a nonentity, as with Zeno and Kant. Indeed it was whilst reflecting upon Spencer's strange misconception of scientific method and the abortive notion of an ideal State which he raises upon it (Principles of Ethics, Part I. c. xv.), that the above view of the true nature of moral laws and of their relation to the End was disclosed to me: I shall return to this subject in Chap. V. $\S 2$. The consideration that the Chief Good can only be a resultant of forces, calls our attention to the multitude of forces upon which it depends, many of which are not directly moral, but political, religious, æsthetic, industrial, and much needing to be moralised, that is, guided or eradicated; and, therefore, again, it reminds us of the many-sided nature of individuals who feel or exercise those influences amidst which a moral disposition, as it may, grows up within them. Moral Science is the most concrete of all sciences; it must survey the totality of social influences upon personal conduct in relation to the Good; and I have designed the following essay upon that great theme. 


\section{CHAPTER II}

\section{CONCEPTIONS OF THE CHIEF GOOD}

$\S 1$. Since Philosophy is far from being universally studied, the majority of men have no idea of a Chief Good, but pass their lives in a number of miscellaneous pursuits, business, sport, study, travel, according to their tastes and opportunities. With the religiously reflective it is otherwise: Religion, indeed, to them is also an all-comprehensive Philosophy, and they recognise under various names-immortal life, salvation, the glory of God-an end to which all other desires should be subordinated. And even the more reflective sort of worldlings partially generalise their activities under such concepts as wealth, distinction, power, culture and so on. Thus the way is prepared for the moralist to seek that good which Plato says that every soul pursues and believes to exist though unable to grasp it (Rep. 505 E.), an End in relation to which human life might be completely rationalised, so that no action should be done that did not tend to secure it, or that interfered with any other action tending that way. Whether such an End can be clearly determined may be doubted, beeause it may be doubted whether men are yet capable of a rational life; but it is necessary to the idea of such a life.

Now every End that can be proposed to men presupposes a spontaneous desire, and ultimately an instinct or instinctive disposition, with which it is or may be connected. Plainly such Ends as wealth, distinction, power, culture, are related to the simpler desires of self-preservation, self-display, rivalry, curiosity; and even the Ends of Religion are traceable to some 
or other of such primitive impulses. Therefore everybody can sympathise with these Ends.

Desire, however, extends not only to actions or experiences that directly satisfy it, but also to anything that may indirectly be the cause of its proper satisfaction. The love of distinction is gratified by admiration; therefore we desire to do or possess whatever is known to excite admiration, indifferent as it may otherwise be to us. A Tyrolese peasant may care nothing for flowers, and yet risk his neck for a sprig of edelweiss if, stuck in his hatband, it will draw to him the favour of the village. This capacity of desires to spread over and assimilate remote objects does more perhaps than any other trait of our nature to give not only variety but nobility to human life; and it is an important, though by no means the sole, ground of our love of family, country, and mankind. It is conceivable that the Chief Good itself should not be an object of desire for its own sake, but such a thing that by striving after it all our spontaneous desires would be satisfied in the highest degree. Thus many have supposed that Virtue is not desired for its own sake, but because it is the necessary means to the Happiness that comes of an orderly life. Or, again, the Chief Good may be the natural object of one desire and also the main condition of gratifying all the rest, which some men have thought to be the case with Wisdom.

The object of desire is always some kind of experience for oneself or others. It has been doubted whether we can desire anything for others without reference to ourselves; but it seems clear that we can desire the prosperity of our children, or country, or another country (say Italy), after we are dead and shall no longer witness or have any share in it; for we often act in ways that can only be explained by such purposes. In relation to morality the experience desired must depend upon the actions of ourselves or others, or upon co-operation. To desire that the weather may become warmer, for example, since this does not depend upon human action, cannot have any moral significance, unless with reference to activities which warmer weather would help or hinder. But the desire to read, or meet friends, or take part in some social movement, or 
that others may do such things, may have moral significance. It is therefore a misleading expression of Butler's that our affections, passions, and appetites are directed to "particular external objects" (Sermon XI.), instead of to our experience in relation to them. We do not desire a book, but to read it; nor applause, but the elation of hearing it; and so forth. It is impossible to desire objects except so far as we are to act upon them or draw experience from them. Butler's error seems to have arisen by his mistaking the object of attention for the object of desire; for it is quite true that in many cases of desire the object of attention is an external object; but it is in relation to our activities that it is interesting. The same mistake leads to a supposed opposition between the object desired and the pleasure of obtaining it; for it seems to be true that pleasure cannot be continuously attended to as an object can be, but can only be felt as accompanying other mental processes; it cannot therefore be separately desired, but only as it is involved in activities about something else; which cannot at first have been desired for the pleasure of it, for then the pleasure had not been experienced. Still, whilst pleasure seems to be quite different from 'external objects,' and easily separable from them, it is otherwise with its relation to experience. Pleasure or pain colours (with disputable exceptions) all experience; and we do not in adult life desire any experience that does not directly or indirectly promise pleasure or the relief of pain; what we desire is the pleasurable or pain-relieving experience. The hungry man, it is said, desires food, not the pleasure of eating it. In fact he desires to eat, and from that action the representation of relief or satisfaction is inseparable. Bring him to a table set with a variety of food; and, if famished, he may seize the nearest dish to allay the cravings of his stomach; but, if he can still discriminate, you will see him eat what he likes best.

The Chief Good also then must be some kind of experience : it cannot be an abstract idea or anything external to human nature: if Perfection or Wisdom is the Chief Good, it can only be as the most perfect or as the philosophical life.

$\S 2$. The discussion of the supreme End of human life has 
caused much dissension amongst philosophers ; they have argued it, not without heat and mutual reproaches; yet their teachings concerning it may be classified under a very few heads and, for the most part, may be reconciled. In fact, making allowances for misunderstandings, their agreement is notable and satisfactory, and contrasts with the endless differences of speculative metaphysicians.

Conceptions of the Summum Bonum are of course influenced by contemporary social conditions and by tradition and by the philosopher's personal temperament. Under ordinary social conditions we find two conceptions in secular opposition - Happiness and Perfection-either of which may be sought merely for oneself (Egoism) or for everybody whom one's conduct can possibly influence (Universalism). Instead of complete Perfection some one trait of it is sometimes insisted on as essential-moral virtue, charm or beauty of conduct or character, intellectual excellence or philosophy. Such doctrines may be considered healthy and normal. But during ages of social confusion, depression, degeneracy (sometimes perhaps on personal grounds), another way of conceiving the End may be seriously and even devoutly preached, tending to the discouragement of all worldly activities, under such names as Apathy, Tranquillity, Indifference, Nirvana. And these doctrines may seem to be unhealthy and abnormal, although they have been anciently and widely maintained.

I shall not now undertake the detailed criticism of ideas concerning the Good, but merely offer a few reflections upon the thoroughly natural character of them all. As for Hedonism, or the doctrine that Pleasure or Happiness is the Chief Good, we have seen that pleasure cannot be, as Hedonists assume, a separate object of desire, nor therefore the End by itself; but this objection is easily avoided by saying that a pleasurable or happy life is the End, a life of pleasurable activities and experiences. Very likely this is what Hedonists have always meant ; but, if so, it was a great mistake to be always insisting that 'Pleasure is the only possible end,' ' the sole object of desire,' and so forth. It makes an extraordinary difference to say that a happy life is the end: it gives prominence to its 
continuity and wholeness, and suggests all the interests, domestic and public, artistic and intellectual, that humanise our life; for surely all these are pleasurable. There are people (though it is little to their credit) who cannot think of pleasure except as sensual or bestial. Such a limitation of associations seems to be itself bestial. Cicero again and again taunts Epicurus with having said 'that he could not conceive of Happiness without bodily pleasures.' Well : who can? Without them there is no life, no happiness, no virtue. But are not virtue and philosophy also pleasurable?

As for the division of Hedonism into Egotistic and Universal (Utilitarianism), so far as Egotism has been supported by philosophers it was done from a mistaken view of human nature, absurdly exaggerating the individuality and independence of the Ego. Here again we avoid the delusion by saying that the End is not happiness but the happy life; for such a life is necessarily social and dependent. Practical Egotism is a moral disease: I mean in life generally. There are certain relations, such as buying and selling, in which it is normal; and it is by taking these relations as characteristic of our whole life that Common Sense seems sometimes to sanction Egotism. But in the natural life a man's affections enfold his family and friends, country and even all living things, expanding with the growth of intelligence and civilisation.

It has often been urged that the idea of Happiness cannot be made definite, and as much may be said for the idea of a happy life; but this is mere quibbling. "A maximum of satisfaction now and at every future moment:" is it not possible to try to live happily without fathoming that concept? A similar objection has been urged with as little reason against the idea of Perfection. Neither as an absolute idea a priori nor as 'adaptation to environment,' it is said, is Perfection definitely conceivable. But what sense is there in such pedantry? Morality is not merely a speculative doctrine to be deduced from concepts, but a study of human life, in order that by understanding it we may make the utmost of our lot and do the best we can. Most people who think at all have some 
notion of a life larger, purer, better, than their own, and in lucid intervals desire it. This is a relative perfection, and by reflection it is possible to make this idea clearer, steadier, more comprehensive, and in some sort worthy (for the time at least) to be the guide of our life; and every advance that we make brightens and extends the prospect. Of course, perfection is no abstract idea: it can only mean a life of the most perfect activity and experience.

In the history of Moral Philosophy, however, Perfection itself has less often been treated as the End than some quality or aspect of the perfect life. Plato and Aristotle thought that rational activity was the essence of humanity, and accordingly regarded Reason, Knowledge of the Good, the philosophical life, as the End and as the consummation of all virtue and excellence. Spinoza in his own way agrees with them; and after trying hard to consider this as a philosophic prejudice, as if a saddler should maintain that there is 'nothing like leather,' I find myself driven to submit to their authority. For although reason is not the whole essence of man, sentiment and character being equally distinctive of him, still it is the noblest and happiest of human activities, and the main condition of every other that is worth practising. To this matter I must return at the close of the chapter.

Beauty of character or conduct has never, I think, been made the End; but both Aristotle and, after him, Shaftesbury recognise its close relation to virtue. We may say that such a notion is characteristically Greek; to no other people, perhaps, does it occur spontaneously; and as with nations so with individuals, they are few who study it. Moralists too much neglect it. Beauty more than pleasure deserves the praise of Aristotle that it perfects every activity and is like the bloom of youth. Nothing is more necessary to the sweetness of life and to the commendation of virtue.

For the truth is that of all the conceptions of the Chief Good that may be called normal, Virtue is least an object of spontaneous desire. The consciousness of this is the excuse for the harsh tones in which the pursuit of it is often preached. A good deal of the writing of the Stoics and Kantians is a 
sort of bullying; and we do not like to be bullied. If Hedonism may be suspected of encouraging indulgence, the worship of virtue is too favourable to asceticism, pride and bitterness. This explains the perpetual misunderstanding of Epicureanism and Utilitarianism. The narrow devotee of virtue does not wish to understand them. We see in Aristotle's Ethics the twofold doctrine that pleasure is contrary to virtue, and that the highest virtue is the most pleasurable of all activities. The solution of the difficulty is that virtue for most of us is very hard to learn, especially if we are scrupulous, and that in the learning it is often contrary to pleasure. Those who have learnt it agree that it is fairer than the morning or the evening star; but it does not always shine cheerfully npon their foreheads. Nevertheless, some people are naturally and graciously virtuous: and whoever sees in them the charm of virtue, and reflects upon its part in human life, naturally desires virtue.

Tranquillity has its place in the experience of a happy or virtuous life; but as an exclusive aim it must be classed with the morbidness of Apathy and Indifference. Such conceptions of the Chief Good may sometimes be natural to the old or the sick or the degenerate, or to good men fallen on evil times. Their prevalence in the Eastern world may perhaps be attributed to the narrow range for self-expression and, thereupon, the thwarted energies of the priestly castes that created Hindoo Philosophy and allied doctrines. May they be far from us; but who can tell? Schopenhauer's Pessimism, if it stood alone, might be ascribed to personal temperament; but the vogue of that philosophy in Europe and America, through the writings of von Hartmann and others, shows that the disease is not merely personal. No doubt one root of Pessimism is a wide imagination and narrow means; but that is not all. The increasing difficulties of modern life, its unmanageable breadth and complexity, luxury and misery, the vanity of popular remedies, the unwillingness of impenetrable multitudes to consider the roots of evil, may excuse a man for falling back upon the resigned contemplation of what he cannot influence, and for finding a religious meaning in the jibe 
that 'the more they change everything the more is it the same.'

$\S 3$. Whilst maintaining that the philosophic ends, Perfection, Wisdom, Happiness, Beauty, Virtue, are all natural objects of desire, I have acknowledged that not everybody naturally desires them or is even aware of them. Works on Ethics do not sufficiently recognise the existence of the irrational man. Aristotle discusses $\theta \eta \rho \iota \tau^{\prime} \eta s$ (Eth. VII. v.) as the quality of a sort of zoological man, having a nature of his own, without understanding, and therefore incapable of morality. Even such men are too numerous; and yet they are few in comparison with the multitude who are capable of well-disposed observance but not of philosophical morality. In our imperfect industrial system the conditions of such a life are not obtainable by many people; and if the conditions were better, many would still be incapable of the effort of thought required by it. Hence, indeed, the proximate end of all social effort, as a condition of widely realising the Chief Good, whatever it may be, is to raise the average capacity of the nation, or indeed of the human race. But some men, at least, as they mature come spontaneously to desire, under one or another name, an End of Ends. The desire of it is favourable to that 'stated, fixed, settled' order of Society which Butler says is what we mean by ' natural,' and therefore it is natural that men should come to desire it. Since the morality of Common Sense is explained bysuch an End, the desire of it half consciously exists in many who have never reflected upon it: in this sense, that the desire often awakens in those who are devoted to conventional morality as soon as its relation to the philosophic End is pointed out; and such desire is often identical with religious devotion, being expressed symbolically as personal service, or as obedience to the commandments of One whose purpose is above our understanding.

But it may be said: "If less than all men are capable of conceiving philosophic morality, how can the study of it be a Natural Science? A zoologist is not content to study only some animals." Morality, however, is not a branch of anthropology; it is not a study of men merely as they exist or have existed, but as they may and should exist. It is a practical 
Science of means and ends; and there is nothing inconsistent in considering what is the Chief Good for human life, even if many men are incapable of desiring it; for we still inquire what are the best means of enabling them to desire it; or of obtaining a breed of men that shall be capable of it: which in fact may be the chief means to the Chief Good. Or some one may feel a repugnance to this doctrine because such a philosophic Morality cannot be taught to everybody. 'This,' it may be said, 'greatly impoverishes it in comparison with Religion, which does not despair even of the bestial man.' Very true: it is not the direct purpose of Moral Science to inculcate right conduct, but to explain it. If successful in this task, it must be very useful to those who teach morals in dealing with those whose chief need is enlightenment. But there are very many, perhaps the majority, to whom enlightenment alone is of very little use. The most rational propaganda amongst them is the exemplary life. The Christian Religion proclaims such a life; and it has other resources: art, music, solemn observances, mysterious rites, hopes and fears and consolation; which within certain limits are effective, and justifiable when they do not make people more irrational than they were by nature.

The possibility of such conceptions as these philosophical Ends, and of the corresponding lives, depends upon the development of reason and character in Society; and we may now take it for granted that reason, character, and Society with all its customs and institutions, are interdependent manifestations of human nature. If social institutions were made by contract, they might be called 'artificial'; and then, by contrast, the condition that was primitive and not made would be called 'natural'; and again, by correlative contrast, Society and whatever is due to it (e.g. Virtue) must seem unnatural to man or at least non-natural. ${ }^{1} \quad$ But if in human history there has

1 The absurdity of this was exposed by Shaftesbury in his Sensus Communis and elsewhere, evidently under the influence of Aristotle. Hume was entirely free from the delusion concerning the contractual origin of Society, which had clouded the mind of Europe for an age, and to which even Burke was still subject (see the Appeal from the New to the Old Whigs); yet Hume was so far misled by it as to call the social virtues, especially Justice, artificial (but not arbitrary, he says); and perhaps to this day the majority even of reflective people may be found to use similar language. 
been no such arbitrary change as that which the contractual theory assumes; if Society is a continuous development from prehuman conditions; all its products, language, reason, affection, co-operation, justice and all the elements of Morality are according to nature.

Without reason it would be impossible to gain the universality of view implied in the conception of an End by which the whole of human life may be regulated, or to investigate the means by which it may be attainable. Without sympathy and affection it would be impossible to desire the Happiness or Perfection of others, or to co-operate with them for the common good. I do not mean that reason, sympathy, and affection are alone enough to explain ideal morality: no simple explanation of human traits can ever be an adequate one. Many other conditions are important, but these are essential. The mere habit of acting with others in small matters is a perpetual suggestion of this greatest matter of all. That the happiness and virtue of others are useful to us is at least effective in counteracting envy and rivalry. That their approbation is important to us not only modifies our behaviour but also our dispositions. That we are incessantly dependent upon one another's services awakens gratitude. The solidarity. of family life during the youth of offspring is biologically necessary; and partly by fact, partly by fiction, the family blood-relationship was extended to the tribe. The tribe itself is biologically necessary, and becomes the ground of co-operation and comradeship. By the Stoic philosophy, too, and the nobler religions, tribal relationships have been extended to the human race, not without biological justification; and along such lines the family affections have crept out to embrace whatever can be called a brother.

Still the causes that divide mankind and check the spread of moral ideas are so many and powerful that we need not wonder if the philosophic Ends are not widely appreciated. The general condition of our life is co-operation qualified by rivalry. Differences of family, nation, race, locality, religion and class are all grounds of mutual hatred. A sort of law has been supposed to hold-that the stronger the feeling of 
cohesion within any social group, the stronger is the antipathy of its members to all outside it. Then there are the atavistic -brutal, cruel, stupid, lazy by hereditary curse; those who for want of education in either literature or liberal religion have never heard of the higher morality; those who have been stunted and hardened by unfavourable industrial or commercial circumstances; those who have been foully oppressed, or embittered by private wrongs. It is therefore easy to explain the restriction of philosophical morality to a relatively small number of people. Indeed the causes above mentioned, with others it were tedious to add, have such an anti-social tendency that cohesion would perhaps be impossible, if the failure of reason and affection were not compensated by the development of those feelings that constitute the illusion of human life.

$\$ 4$. It is well known that throughout the organic world, but especially amongst animals so far as gregarious, individuals are subject to limitations and modifications mental and bodily, which are advantageous to the species rather than to themselves, except so far as they depend upon the species. This is also true of man: August Weismann (On the Duration of Life) has maintained that even the life of the human individual is shortened for the sake of the race, as with all other animals; and this opinion is supported by A. R. Wallace. We need not wonder then that, similarly for the sake of the race, man's passions are often exaggerated and his reason blinded or hoodwinked. The passion of love, being the condition of overpopulation and selection, is the most important of all; and in its development it becomes the inspiration of everything disinterested and noble. Therefore in its immaturity it is violent and blind, and its shadow is everywhere pain and sorrow. This doctrine has been elaborated by Schopenhauer; but I leave it to the poets. Nothing is more often contrasted with love than prudence and the absorbing passion for wealth, yet these motives also soon escape control and sacrifice the individual; and if less violent than romantic love they are more lasting. The love of power and the love of fame make an able man toil even more indefatigably than the love of wealth; and the more abstract these passions are the

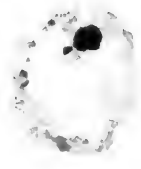


more unintelligible they seem. Accordingly, moralists have always triumphed in exposing their folly. "How little wealth," they say, "can a sane man spend upon his own desires; how insecure is power, and what an invidious possession; how empty is fame, how beset by detraction; the applause of 999 men in the 1000 is worthless, and any day may turn to censure; and the greater your fame the smaller the proportion of it that can ever be known to you." But as soon as we reflect that capital is necessary to social life, and that wealth can only be produced or reinvested by employing labour, thereby increasing the population and the materials for natural selection, it becomes evident that whilst the love of wealth is felt and conceived as an egoistic passion, it really subserves social ends. The love of power over others easily becomes diseased; is liable to be infected with disease by the very fact of its gratification; and in its diseased forms it is the devilish passion; and yet, speaking generally, the man who desires to rule, is necessary to all organisation, political, military, or industrial. As for the love of fame, it supplies leadership in war and peace, in art and science, and makes the rarest things the cheapest. Now, whereas these passions subserve social ends, why should they be felt and conceived selfishly? Since the devotee of wealth, power, fame, is really (for the most part) a social benefactor, why does he not regard himself in that way? Why does not the humblest man engaged in buying and selling, or in punching holes in brass buttons, regard himself as a public servant? For he really is one, so far as he deals honestly. Because the causes that produce opposition amongst men (and which subserve selection), have prevented the growth of social feelings in sufficient strength to sustain the requisite exertions. Until the social feelings have developed rational insight into the social consequences of his actions can be of little use to a man. Nay, it may even depress his energies; for the mutual antagonism and grudging of men is such that many would hardly work if they saw that they were helping others. They are therefore actually blinded to the simplest and most obvious considerations; as you may best see in the case of foreign trade; for 
people think they are injured by buying of the foreigner the things they need most, and that their gain by trade consists in the goods they foist off upon him; so that the finest Lancashire cottons are exported as an act of war, and commerce is regarded as a sort of vendetta.

There is another side to this: not only are some of the ablest of mankind adapted by selfish passions to the public service; but the great herd of us are also modified and limited, in such a way as to remain a herd and get the benefit of herdsmen. That the average human brain is poorly developed and always apt to become worse, is the most important of all facts to remember. Apparently the cheapest way in which a tribe may obtain advantage over others has not been by general superiority in brains, but by variability, thereby obtaining more powerful leaders-balanced, of course, by imbeciles at the other end of the scale; but, in early stages of civilisation, imbeciles do not long encumber the tribe. The result is that the civilisation of every country depends upon a small number of eminent men: a few hundreds. Remove them, and society must disintegrate and resettle upon some more stable plan ; that is, upon a plan that needs less ability to maintain it. Hence the rest of us must have instincts and dispositions impelling us to follow leaders: such as suggestibility, imitativeness, admiration. It is even probable that the early conditions of social organisation have kept down the average independence of tribesmen and subjects, in order that they may the more readily follow leaders (Galton on Human Faculty, Art. XIV.).

Suggestibility requires a want of mental resistance and agility, so that an idea suggested meets with no preformed judgment or plan and awakens no play of exception, objection, contradiction. Imitativeness is suggestibility under the most infectious conditions, when we witness the actions of others. Admiration strengthens both; and the man who under pressure of these impulses keeps the high road, resents the failure of them in other people. In every society these are the chief causes of its shallow ópóvoıa, concord or unanimity. They make people dress and behave alike, and say the same things 
and feel alike. Suggestibility and imitativeness are, though useful, nearly always laughable: they prevent men from being themselves; they make them poor copies of others, and yet (for the most part) something better than themselves. But admiration is pathetic. Very beautiful it is to see the upturned faces, the beaming eyes, the single-hearted enthusiasm of a cheering crowd; and beautiful very often is the simplicity and sincerity of the hero. There is universal gratification without second thoughts. We cannot help reflecting that, were there no such scenes, the love of fame would not exist, nor yet therefore all that toil which it sustains. We also see that if such an hour were not felt to be entirely disinterested, an end in itself, it would lose its charm and its efficacy. Therefore we are temporarily blinded to the consequences of it: temporarily and specially, for at other times we deliberately employ praise to encourage children, and public honours are openly defended on the ground that they encourage public services.

$\S 5$. Because, then, the development of social feelings in most men has not been fast enough or strong enough to support continuous exertion for philosophic ends, egotistic feelings have been so modified as to direct action to ends that are (at least) social and, therefore, a condition of the philosophical ends; and meanwhile, reason has been hoodwinked so that the real tendency of actions shall remain obscure. In other men more direct methods have been successful; their eyes have been opened, and with them effectual love of the public welfare, of the perfecting of human nature, of knowledge, beauty, virtue, have become prevailing motives. Still, with these other men, too, there may be a certain illusion in their pursuits, which is fully shared by bystanders: I mean the common belief that their life is one of self-sacrifice. Similarly, moralists often commiserate the devotee of wealth or ambition as sacrificing his life to vanity; and if their meaning is that devotion to one pursuit prevents the complete development of a man's nature, there is much truth in such lamentation; but as long as a man is successful in business or politics there is no loss of happiness. It is easy to waste one's sympathies in 
commiserating a prime minister or a millionaire. And the same thing is true of the benevolent, the virtuous, the philosophic. Their vocation often excludes them from many common enjoyments; but, speaking generally, they do not need our pity; very rarely would they change their life for any other. Still this illusion also has its use. It is some support to the exceptionally arduous life, so necessary as it is to the world, that it should be regarded as almost superhuman.

The opposition supposed to exist between Egoism and Altruism is, for the most part, an illusion caused by our not seeing another man's life from the inside. It is true, of course, that many a man is so far an Egoist that he is not consciously and intentionally much of an Altruist, although (if an honest man) he spends his life in doing services to others; but it is not true that the Altruist is not an Egoist in the sense that he does not know his life to be a continual satisfaction of his own nature. To insist upon the opposition between Egoism and Altruism, leads to that moral Dualism which puts Self-love upon the same level as Duty and Benevolence, and which has been defended by some of the greatest men: such as Bishop Butler, who says, "interest, one's own happiness is a manifest obligation" (Pref. to Sermons). If we reply with Kant that what we are necessarily inclined to cannot be an obligation, it may be said that at any rate "one's own happiness" is a rational End, and that we see it to be so. No end, of course, is in the first place rational; it must be given by or derived from spontaneous desire; the expression "egoistic reason" now so common is an impropriety. But an end may be said to be rationalised if it can be seen to have an universal character; and in the case of Self-love this may be seen in three ways; it is an affection of every man; its gratification in each of us is a condition of the universal welfare; and it is concerned with the total interest of our life, often in opposition to particular desires.

Self-love, then, is certainly a rational End; but it does not follow that it is of equal rank with Benevolence and 
Duty. Butler, however, says that "when we sit down in a cool hour, we can neither justify to ourselves the pursuit of virtue and moral rectitude, nor any other end, till we are convinced that it will be for our happiness, or at least not contrary to it" (On Love of our Neighbour). If we inquire amongst men what is generally thought of this dictum, we shall find no steady and consistent opinion. On the one hand, it is said that certainly, in the last resort, every man must care for himself: on the other hand, to undergo hardship and death for a friend, one's family, one's country, is praised as exalted virtue. But the former of these judgments may be at least partly explained by the fact that, in honest business relations, to care for one's own interests is generally the best course for everybody concerned, and that the experience of business is inconsiderately generalised to include cases which may be seen, on the slightest reflection, not to have the same character. With division of employments, every man engaged in industry and commerce becomes a specialist, of whom may be reasonably required, according to his ability, exact and comprehensive knowledge of his own work and assiduous care in carrying it out. Failure in these things is a failure in social duty. Integrity being necessary in all relations - foresight, enterprise, economy are, in business, the virtues of one's office. For the want of them impoverishment is the natural penalty, which could not be replaced by any other penalty without the most wasteful confusion. The conditions of business do not preclude men from occasionally assisting one another; but the general rule that each man must be responsible for his own affairs, is the one most conducive to public advantage. Social reasons are the justification of all commercial virtue; and therefore commercial self-regard is entirely in harmony with private and social generosity, with the promotion of culture and national welfare and, in the last resort, with unreserved self-devotion to the public good ( $c f$. C. VIII. $\$ 8$ ).

If universal welfare could possibly be attained, every condition of it, and therefore every individual's welfare, would be a necessary end; but if only a maximum be attainable, it is 
conceivable that some individuals must be sacrificed, just as in one's own life certain desires and powers must be sacrificed, in order to secure the maximum aimed at by Self-love ( $c f$. Sidgwick's Meth. of Ethics, III. xiii. §3). We cannot explain away the sacrifices made (say) in war, by saying that in the act of death a patriot has a satisfaction above all regret; for though this may be true, yet it cannot be supposed that this supreme hour is equal in happiness to all that he might have obtained by staying at home, or that merely not to have enlisted must have poisoned the rest of his life. For myself, I hope not to be put to the trial of a martyr or hero; but should that be my lot, my judgment at this cool hour is, that I ought to accept death for any noble cause. The individual has a finite value, which public interests may decisively outweigh.

If we consider what kind of life the philosophical egoist purposes with himself, it will appear in some respects inconsistent. For it is not the life of a beast or a hermit, but one

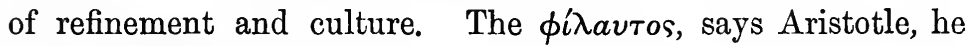
who truly loves himself, in everything gives himself the best part, that is to say, the noblest; which may be death ( $N$. Bth. Book IX. c. viii.). But what makes a man choose refinement, culture, the noblest part? The adoption of social valuations; for neither these things nor the belief that they are good does any man make for himself. His tastes and passions, his body and soul, are made by social life for social purposes; yet the social valuation of altruism he rejects. $\mathrm{He}$ says that for every man his own life is the chief good. This is pathological reasoning.

$\S 6$. But it may be said, however natural it may be to desire the philosophic Ends, and however many may desire them, were it even all of us, it would still remain to be decided whether these ends, or some of them, or perhaps others hitherto undiscovered, are truly good. That we do in fact desire them is no proof that they ought to be desired.

This objection assumes, in the first place, that there may be a chief good apart from our own choice and decision, either quite independent of us or merely not yet discovered. If the good be assumed to exist independently of our choice, it must 
be as an End set by God to His creation, or (what comes to the same thing) set by the teleology of Nature. Such an end may be sought either by interpreting the teleology of Nature or by means of a revelation; and I have shown (Metaph. of Nature, c. xv. \$ 3) that, upon merely speculative grounds, we cannot with any confidence interpret Nature teleologically; and therefore we cannot find in Nature the end of humanity; though I have allowed myself to suggest that the end of Nature may be self-knowledge, to be attained through science and philosophy in man. I can think of nothing else; but Moral Science cannot be built upon surmises. Whether the end can be known by revelation, is an inquiry beyond the range of this volume; but, if it can, and if we may judge of the result from the most accredited revelation, the end so taught is the same as, or at least includes, the philosophical ends, namely Happiness, Perfection, Virtue, the Beauty of Holiness and Wisdom. But if the chief Good is something discoverable by human reason, but not yet; knowable, but only to the loftier minds of posterity; it is plain that a condition of posterity's success is that we should persist in studying Moral Science; and meanwhile we must draw up a plan of human life as best we can for present use.

Some attempts have been made to anticipate the ideas of the future, by discovering a law of the development of moral ideas. L. T. Hobhouse (Morals in Evolution, Part II. c. viii.) after tracing the idea of the Good from the earliest conceptions of which we can obtain any evidence, through the history of religion and philosophy, finds that all lines of thought converge upon the conception of the growth of the self-directive selfregulative human spirit as the Good. Herbert Spencer, after tracing the evolution of all Nature and of human society as an expression of the same principles, foresees an ideal State in which the utmost development of individuals in mind and character shall coincide with the utmost social harmony. Except that the one lays more stress upon individuality, and the other upon the value of social effort (a difference as to the means rather than as to the end), these philosophers seem to be essentially agreed; and if they are right, the Good as 
conceived by posterity will be a reconciliation of all those ends that hitherto have divided the Schools. That they are right I hope and believe; but cannot completely put aside the suspicion that hope may be the cause of our belief. The later developments of Society and Thought have been the work almost entirely of one race of men. Everything culminates. The world has a long life before it. Other races, predominant in future times, may have other ideals-such perhaps as we should scorn. For our life is expensive spiritually as well as physically, and is carried on with an exuberance of sentiment and imagination that may not be justified by its efficiency. So courage is better than hope.

As to the suggestion that from our desiring a Good it does not follow that we ought to desire it, that is the fallacy of the endless question. Just as, speculatively whatever reason we give for a conclusion, an opponent may ask 'why,' and again 'why'; so, morally, whatever Good be assigned as the ground on which we ought to regulate our life, we may be asked, 'Why ought that Good to be pursued?' And if we are able to assign a still more comprehensive end, it is still impossible to prevent the question being repeated. Speculatively, there are principles and facts that admit of no further proof except their own agreement. And so it is in Morals: human life and human nature is a given fact of which it is absurd to ask whether it ought to be. That we ought to make the best of that life is felt by all serious people; and, therefore, we ought to pursue the ends that enable us to make the best of it to the best of our judgment. Happiness or Perfection, as we have seen, is not to be taken abstractly, but only as the co-ordination of human life; just as in speculation the axioms themselves are not science, but only the condition of co-ordinating knowledges. The philosophic End is not to be sought at the cost of human life, but as the ideal of human development. It is not limitary but liberative : it gives the freest play to energies which, without a common aim, clash and frustrate one another. Looked at in this way the Summum Bonum is itself a means to the Bonum Consummatum, the maximum realisation of human desire and activity. And 
in this way we can give a meaning to the question, 'Why ought I to seek the chief good ?'-Should this be asked by a serious and sensible man seeking enlightenment, he might be told-' because it is the condition of all human prosperity and culture'; which we may presume that he has at heart.

Still, it may be said again, there appears to be not one Philosophic End but several, or at least two: how decide between them? There is no call to decide between them. The words Happiness, Perfection, etc., are different names for the same actual life. One word commends the Good to one man, another to another, according to accidents of character; and any one of the names taken by itself indicates an impossible abstraction. Taking humanity, or any nation, as a whole, no considerable degree of Happiness, or Virtue, or Wisdom can be attained, or maintained, without the others: though, certainly, in nations or individuals, one or another attainment may be the more conspicuous or characteristic. In individuals, to a superficial glance Happiness, Virtue, Wisdom seem to be separable; but let the student of human life judge whether-if we consider the whole life, and not merely certain crises-this is not nearly always a mistake. Moreover, it is one of the aims of the moral life to reduce as much as possible the physical and social conditions that separate Happiness from Virtue.

To aim rationally at a happy life for all requires the most comprehensive knowledge and power of reflection, and it necessitates a virtuous life; but a truly virtuous life in the individual may, in some cases, be attended by a good deal of unhappiness from unfortunate circumstances, sometimes even from persecution, still more certainly from sympathy with the misery or degradation of others, and from indignation and shame at the sight of those who witness it untouched. Yet there is a self-healing power in the virtuous soul, as in the healthy body: the effort that cannot be relinquished to ameliorate the lot of others, and the occasional success : which is figured to us by the joy of Heaven over them that repent. We are clouded by the notion that the saint chooses his lot, and might have chosen otherwise. No: but he is chosen, and 
could at least no otherwise be happier. In fact, the opposition so easily assumed to exist between virtue and happiness is chiefly found in the errors of those who seek the one in indulgence and the other in restraint. But as sensuality is not happiness, neither is asceticism virtue; though in some degree the sensuous life is a necessary part of the happy life; and asceticism often enters into the discipline of virtue.

$\$ 7$. If one term must be chosen to denote the Chief Good, it seems to me (as I have said) that Philosophy or Culture is the best. It is the most definite and conceivable End, and it is easy to show that its attainment in some measure is a condition of every other good. For knowledge gives power over the physical forces, and is therefore favourable to the expansion of human life in every way, especially to the diffusion of leisure, and thereby to the development of the fine arts and gracious manners. It is the only possible remedy of poverty and disease, and it will one day discover the means of eliminating from the heredity of our race all criminal and vicious propensities and of raising the whole level of humanity. If virtue is a life according to Nature, it is only by philosophy that the laws of that life can be revealed.

The great difficulty of considering Culture as the Chief Good arises from this, that at present so few people actively desire it. Yet I cannot think that my praise of it can be a professional error, as if it were an idol of the den. Perhaps not many actively desire universal Perfection or Happiness All schoolmen are liable to the reproach of taking refuge in contemplation from a world in which they cannot compete, and scorning indulgences that they cannot afford to pay for and dare not steal. That the philosopher's life is not incompatible with poverty seems to me to be no reproach; but he is not always a recluse. Unfortunately he has sometimes set himself up as a judge of other men's lives; as Plato does in the Republic (582, 3). So does Mill in Utilitarianism (c. ii.); for he says that the rule for measuring the quality of enjoyments against quantity is "the preference felt by those who, in their opportunities of experience, to which must be added their habits of self-consciousness and self-observation, are best 
furnished with the means of comparison." But as long as the philosopher's life differs a good deal from the lives of many other men, he must acquire peculiar tastes, and lose the relish of many common activities that are still necessary to our collective welfare. To take philosophy as the Chief Good, implies no absurd design to impose it upon a reluctant world, but a belief that its acceptance would also be the best means to every other good, and that it admits of being gradually universalised; that culture and reflection are to become general amongst us, in order that all men may become enlightened judges of virtue and happiness. And it has certainly been the course of nature hitherto that the growth of intelligence has accompanied the development of organic life, in which the World's life seems to culminate.

All that Aristotle says of the philosophic life is true, namely, that it is the exercise of that which is highest in our nature, and concerned with the highest things (the being and laws of the universe); that (for those who are capable of it) it is a more enduring activity than any other; that it gives the purest enjoyment to those who sufficiently practise it; that it is less dependent than any other pursuit upon external conditions and even upon Society itself, though it may be the better for co-operation. Philosophy more than anything else is its own end and reward: it is the noblest occupation of that leisure in which human life perfects itself, in a wellordered State made possible by the practical virtues. The philosophic life is, he says, above the level of human nature; but so much the more should we aspire to it; for it is the activity furthest removed from animal life, most characteristic of man, the realisation of what is best in each one of us, wherein we come nearest to the Divine Nature. Moreover Aristotle shows that Philosophy requires for its realisation a well-ordered State and moral virtue in the citizens; so that all other forms of Good are included under it.

Such are Aristotle's sublime reflections upon his own vocation: for the most part as true now as ever they were. The accumulation of knowledge, indeed, has made co-operation more necessary; we must consult with friends upon matters 
beyond our own faculty. External conditions too are more requisite, such as laboratories and libraries; but they need not be private possessions. For multitudes the philosophic life is still too strenuous to be constantly pursued; but with better social conditions some share in it would be open to all, and its value is known to those who take but a small part in it. That it is the essential realisation of human nature is true; and that it brings us nearest to the gods may be understood to mean that in Philosophy the World attains to selfknowledge; wherein to have only a small share is no small satisfaction, no mean reward.

And all that Spinoza, in his more abstruse style sets forth is also true; and I think it is more profoundly meditated. For he says that everything in the world strives to preserve its own being, and the being of man consists essentially in reason; this therefore is what we exercise for its own sake. But finite as we are in the midst of an infinite world, we are continually distracted by the power of external causes; which is so great in comparison with our own that we can never wholly withstand them, and they disturb us in various ways, as by fear and grief and other passions. So far as we are influenced by these causes our minds are clouded, our true nature is impaired, and we suffer pain. But so far as we are able to understand the action of external causes and the disturbances they produce in us, our true nature is strengthened, and we rejoice. This is virtue, or our own power, which grows greater the more our understanding of the world increases; and since this expansion of our own nature is continually associated with the world which we interpret, it becomes a love of that world, that is, of God, whom therein we know. Now in learning to understand our passions we see that they arise from the weakness of our own nature, and therefore we cease to love or hate the particular external causes that excite them. It is no fault of the world that we are weak. The more we know of the world, the more we see the necessity of everything that happens there: we acquiesce: hope and fear subside: death is swallowed up in the everlasting life of God. In understanding the course of the world we actively participate 
in it. The passion of thought, directed to that which is universal in Nature, is stronger than the passions excited by particular things; indeed it is excited by a far greater number of particulars, and is so much the more powerful. By studying our own character and preparing principles of action for all events, we can deal securely with the accidents of life. And we shall be wise if, in striving to amend our own condition and to overcome the illusion of life, we attend to the good of everything rather than to the evil: dwell, for example, upon the right use of honour rather than upon its emptiness. Thus to grow in personal power is the natural control of passion, and therefore freedom and happiness. And the knowledge of Nature according to its universal conditions (or laws) is a knowledge of it as it necessarily exists from age to age (particular experience at any time adds nothing to this but sensation and feeling), so that nothing is gained by the duration of life; science itself is life eternal. This is blessedness, and the love of God, and the love wherewith God loves Himself.

With such reflections Spinoza's deeply-impassioned soul carries Naturalism over into Mysticism; and his mystical language means so much that no other terms can convey that I confess myself loth to alter it. For him there is but one possible End of human life: only Philosophy can satisfy our true nature. But I have tried to show that the philosophic life is, by itself, an abstraction; that human nature at its highest development, so far as we know it, involves the sentiments of Virtue and Benevolence; and that, therefore, for different temperaments, the End may also be conceived as Duty or as universal Happiness; and that the important thing for Moral Philosophy is to recognise the harmony and unity of these conceptions in the actual good life. It might be said that such a life is not so much chosen as forced upon us by the necessity of thought; but thought can only force upon us the idea of such a life. The actual life, if it is to be lived by any but the elect, must be chosen; for, clearly, other lives are possible. Let us suppose, then, that by the voices of the wisest of our race it is chosen. Humanity 
takes its fate in its own hands and chooses its own good at its own risk. There is no rational appeal from this decision : we may say in our haste with Epicurus that "there is no master over us." But indeed the risk is great. For what Spinoza says of the individual is true of mankind: it is finite amidst an infinite World, and the inhuman forces of the World are the stronger. At some time a turn must occur in the history of our planet: circumstances will thenceforward become less and less favourable to the highest human life: it will maintain itself with increasing difficulty. At last there will be no choice but between degradation and death; and Aristotle says that, when a man must choose between virtue with death and the enduring of a great calamity, there may be some excuse for weakness; but if the alternative be very vile he will prefer to die. May that hour be deferred until mankind is capable of a noble decision. Unhappily amidst the vast rhythms of Nature, to judge of the appointed time may confound the predictions of Astronomy. Should it happen now, none can doubt that a horrible descent awaits us, and that posterity in the general corruption of manners

will breed,

Perverse, all monstrous, all prodigious things. 


\section{CHAPTER III}

THE SOCIAL CHARACTER OF MORALS

$\S 1$. Some moralists hold that no action is indifferent; every action, they say, must be either right or wrong: but most men, even exponents of opposite schools, think otherwise. Spencer, for example, assumes that certain actions of a simple type need give us no concern (Prin. of Ethics, $§ 2$ ); and Whewell says, "If there be not on either side any necessary character of good or bad, a man is permitted by morality to choose one side or the other according to other considerations. . . . And undoubtedly there are, at every period of our lives, many things about us which are, as far as we can discern, morally indifferent. We cannot see that either alternative will affect our moral culture" (Elements of Morality, c. xvii. § 331). That this is the saner view follows from the consideration that responsibility cannot extend beyond the intention of our action. It may be true that in the system of the World each action has consequences different from every other; but if the different consequences cannet be foreseen by us, an error of choice is a misfortune not a fault We must, of course, according to our opportunities, seek after the greatest attainable enlightenment as to the consequences of our actions; and we must be clear as to the sincerity of our intention; but the limits of our judgment at any time are also the limits of our moral danger.

The further we go back in human history the less this is understood. The conception, derived from tribal customs, of a law comprehensive and minute, watched over by avenging powers, makes no allowance for the ignorance of agents. The fate of CEdipus and Uzzah clouds every life; and even when 
the traditional belief has been weakened, the disposition to believe is still inherited by many unfortunates, and their consciences teem with scrupulous terrors. This condition of mind is sometimes so oppressive as to amount to insanity; sometimes favours the growth of a belief in one's own supernatural impeccability; sometimes turns to disgust, or despair, or rebellion. To discover natural foundations of morality delivers us from this superstition,-an Epicurean motive, but a just one; for it is a mistake to think that moral feeling is strengthened by increasing the burden of responsibility. If we are to strive we must be allowed to hope.

In Bentham's classification of Duties, right action may be considered under Prudence, Probity or Beneficence, according as a man aims at making the best of his own life, or at not injuring others, or at helping them. But a little reflection shows that Prudence cannot be considered merely as a making the best of one's own life. This is sometimes a convenient abstraction; but every human life is a social life, lived in a social medium, dependent upon social provisions. Common Sense comes more and more to recognise this. A little while ago drunkenness was regarded as a private affair, not vicious, hardly disgusting, but at worst a sort of foolishness compensated by good fellowship. The size of families was never until recently made a moral question amongst us; considered as the work of God rather than of man, it was by no means subject to public opinion. Then arose the doctrine that it was a moral duty to have small families, in order to leave enough food for other people. Now we learn that large families are better, because they provide food for Natural Selection; or else that the 'fit' should have many children, the ' unfit' few or none, by way of anticipating Natural Selection. In any case it is a social question, not merely one of Prudence.

In short, for many years past, not only the drift of Common Sense, but also the tendency of scholastic moral reflection has been toward the conception of morality as an essentially social phenomenon. It does not follow in the opinion of Green, for example, that morality is a natural phenomenon: but it is so for those who consider all the conditions of human life to be 
natural; and, accordingly, in this volume I assume that the natural foundations of morality are discovered if its principles and conceptions are traced to the conditions of human life.

$\S 2$. Although it seems to me probable that man was always a social animal, yet the individual has never been completely socialised. No tribe has been discovered in which quarrelling and dissatisfaction were not common; in which there were not men and women who had desires and purposes that could not be fulfilled, except at the cost of others' or of the public good; or in which there were not men (though these may be rarer) who held opinions and beliefs contrary to the generally accepted traditions; and in the course of civilisation these people rapidly multiply, ranging from honest and enlightened prophets and dissenters down to criminals and lunatics. Without such recusants and disturbers of the peace there could never in any society have been any internal causes of change or improvement: nevertheless, the greater number of private desires and opinions that are in conflict with public order, far from promising any improvement, are absurd and injurious. Restraint therefore is necessary. Thereby indeed the better course will often be rejected; but in human affairs, as Imlac observed, good lies upon the right hand and upon the left; whatever is gained, something else must be foregone.

A student of the history of speculation ceases to be astonished at any extravagance; he reads with a smile the passionate declaration that all the evils of human life are due to social and political restraint:

Old Custom, legal Crime, And bloody Faith the foulest birth of Time.

He wonders where the credulous one can have lived, with whom consorted, how much he knows of his own heart; and whether the warmest imagination and sensibility could have been so much misled, if it were not for that unfortunate definition of man as a 'rational animal' and, therefore, an animal to be conceived as naturally governed by reason. Such was the fallacy that deceived the sanguine but ill-instructed Naturalism of the Eighteenth Century that culminated in the 
poetry of Shelley. It is true that many, nay, most of our private desires are only by accident opposed to one another, and that they are capable of being far more fully gratified by compromise and co-operation than by our solitary efforts. But in the immaturity of reason this cannot be seen; or, if it can be seen, in the immaturity of feeling it cannot be acted upon. It is not merely savages or barbarians who are incapable of impartial and comprehensive views of the public good, and of the skilful co-ordination of individual efforts for the attainment of a maximum satisfaction; we are still in this condition and must remain so for ages to come. In all concrete affairs, so much the more the more complex they are, and the less they admit of reduction to quantitative statements, human reason depends on the method of trial and error; and our safety depends upon our experimenting within certain limits of traditionary restraint. The earliest limits are set by Custom.

It is impossible to find the origin of custom or rational grounds of its power : it arose from causes, from natural utility and selection, not from reason. Animals have their customs, especially social animals, and are so far conscious of those customs as to punish the infraction of them. The least developed tribes of men are, of course, far more fully conscious of their customs, can describe them in language, and deliberately punish the breaking of them. Yet in direct intention and as conceived by the tribesmen, their customs may be utterly irrational, very inferior in this way to the customs of bees and ants, and some of them inexplicable except as either survivals of a former culture that have lost their meaning and yet are better than no tradition at all, or as exercises in discipline and co-operation, purposes not present to the consciousness of the tribe. Indeed, for a savage it is some gain to be doing no harm. The waste of time (many months a year) by Australians in childishly silly rites can only be made up to them by the advantage of doing anything together under a strong sense of tribal unity and necessity, of preserving any traditions rather than have none at all; or excused by the reflection that they have not enough intelligence to employ themselves better, and might easily employ themselves worse. Tribal cohesion and the 
implied observances are accepted in general by inherited disposition, because every tribe must necessarily be descended from those who followed and maintained its customs in former generations ; and, in exceptional cases, observances are enforced not only by general tribal feeling and special inflictions, but by the fear of predatory beasts and of hostile tribes, should an offender attempt to secede, and of ghosts and magic that slays at a distance: in short by the political and supernatural environment.

In time, especially with the rise of kings, aristocracies and priesthoods (which may be the same thing), customs, though never superseded, are modified and supplemented by positive laws. The development of law may have followed different lines in different societies; but we find the beginning of itat least of legislation-at a very early stage of human life. Spencer and Gillen have shown that, even amongst the native tribes of central Australia, customs are not fixed, or merely modifiable by forgetfulness and desuetude, but are exactly remembered and yet may be changed from time to time under the advice of the elders. When the conception of law, as a system of regulations capable of being adapted to every exigency of human life, has once become clear, it may be assumed, under the influence of religious or philosophical ideas, that such a system actually exists in the nature of things, though not yet worked out in detail, according to the saying of Aristotle, that whatsoever is not ordained is forbidden ( $N$. Eth. Book V. c. xi. 1). The Code of Manu aims at regulating every action of every hour, and declares that " the whole world is kept in order by punishment"; even the Gods fulfil their duties "only if they are tormented by the fear of punishment" (VII. 22-3). Under such a rule there seems to be nothing left to morality; even a disposition to obey the law is repudiated. In fact, much else must always remain; and the recognition of the impossibility of controlling every detail of life, leads Hobbes to reverse the dictum of Aristotle and declare that whatsoever is not forbidden is allowed; the liberty of the subject is the silence of the law (Leviathan, c. xxi.). Then the subject, 
politically free, remains under the law of Nature: that is to say, conduct exempt from legislation is subject to morality alone. Bentham makes the matter clearer by explaining that many actions do not admit of being defined precisely enough for legislation, or cannot be enforced by legal penalties without a loss greater than the gain.

In every religious community, actions exempt from political control are still regarded as subject to a divine law; so that, again, no room remains for pure morality except the willing acceptance of that law; indeed the more bigoted deny the possibility of a willing acceptance by a sinful man; insist that it can only happen by grace; and, instead of "pure" they speak of "mere morality" as an insolent pretence of philosophers and worldlings. Yet we find that everywhere, in spite of such claims, there grow up in the old customary way certain special tissues of observance, such as the codes of honour, of etiquette, of respectability, for the most part supplementary, but sometimes in direct opposition, to the laws of civil Government and Religion. From the earliest times, too, the reflection of independent minds upon the course of life has given rise to proverbs, maxims, gnomic verses, prophetic sentences, prescribing modes of conduct, or of feeling and disposition toward conduct, and having that character of universality and disinterestedness that is specifically moral; and at last such reflection investigates principles of conduct underlying Custom, Law, Religion, and every kind of observance, tending to explain and rationalise them, and constituting Moral Philosophy.

$\S 3$. Rules are useless and observances impossible without corresponding feelings and impulses. The Law, Religion, the codes of Honour and Public Opinion awaken in the breasts of their subjects corresponding sentiments of great power and efficacy. Those who are ruled by respectability live in a perpetual anxiety of circumspection, as ever in their great Taskmaster's eye-the eye, namely, of every imaginable onlooker. Breaches of etiquette are attended in youth by a dismal sinking of the heart, shame and confusion of face, and are remembered when mortal sins have been forgotten. To 
abide by the Law is so much a matter of course amongst those who are not criminals that if, when the Law is definitely called in question, we decide to support it, the feeling that moves us, indeed, has little specific character but coalesces with the general sense of allegiance to our country. Amongst law-breakers, on the other hand, the dread of breaking the law and of being found out is accompanied by such definite representations of pains and penalties to follow, that apart from incidental consequences to reputation and so forth, it may not differ from the ordinary alarms of prudence and bodily fear. Religion inspires the loftiest devotion, confidence and energy, or else ever-haunting dread, prostration and despair. One easily sees that in each case the feelings connected with any kind of observance take their colour from the special character of its source and sanction. If God be for us, who can be against us; and, if against us, whither shall we flee, where hide? Honour is the peculiar code of a class or calling, and varies accordingly ('Honour amongst thieves'): but most properly it is in each country the observances of the gentry. The positive sentiment of honour, inherited, disciplined and confirmed by constant example, is a specialisation of high moral feeling and the natural ally of whatever is noble in human nature; but it is most unfortunately everywhere limited by the special traditions of a class. The sense of dishonour is the most physically penetrating, thrilling and mortal of all that we know: it prognosticates the crumbling of the social basis of a man's pride, too often his only claim to distinction. But in what circumstances this feeling shall be aroused depends upon the present custom of his fellows in resenting misdeeds, and their custom is greatly influenced by class interests and prejudices; so that if they resent an action that is right by every other standard, that action is dishonourable; and if they do not resent it, though illegal, irreligious, vicious and vulgar, that action is, in fact, not dishonourable. The vagaries and perversions hence arising must astonish and dismay any observer who does not realise that the mass of mankind is still everywhere determined by custom, cannot as to common actions think or feel otherwise; that the customs 
of a class are more stringent to its members than those of the community, because its existence implies some opposition to the community; that the controlling feelings must be proportionally intense; and that since the limitation of sympathy between classes often makes their mutual antipathy worse than that of foreigners, injury to other classes may be treated more lightly than injury to enemies (especially of the same class); whilst to be outcast is worse than exile.

We may observe that in all these situations in which a man's conduct comes under the eye of others, whether of the public, or of his own class, or of God in heaven, he may be actuated by a desire to please (or not to displease), or by fear of displeasing them. Under the former motive he feels free and generous, under the latter servile and resentful. The character that is freely and generously in accord with rules and observances may be trusted to adhere to their spirit even if they cease to be enforced; and this is the character above all things to be desired. But servile submission promises Society no security without restraint; and unfortunately the general action of law and public opinion, and in a less degree of honour and religion, appeals to fear rather than to more generous sentiments. There is little scope for reward, which would be far more favourable to noble and spontaneous morals.

The sentiment especially correlative with moral conduct is Conscience or Duty, the feeling we have in saying that 'this ought to be done' or 'that ought not to be done,' and also in remorse when saying that 'that ought not to have been done,' and the satisfaction that 'that was done well.' Inasmuch as actions that ought, or ought not, to be done may also be honourable or dishonourable, legal or illegal, etc., it must often happen that moral feeling is accompanied by others of the regulative kind from which, at the time, it can hardly be distinguished. But many actions are right or wrong, that at law or in honour are indifferent; or right, though illegal or even dishonourable; so that there is no difficulty in recognising the specific character of conscience and moral Duty. And we find its character to be this, that it attaches to 
nothing but the action itself, as defined by our intention, and includes no definite representations of further indirect advantage or disadvantage to follow, whether to oneself or others in whom we are specially interested. In this it is nearer akin to sentiments of honour than to those of legality or religion.

$\$ 4$. The authoritative tone of conscience was unfortunately exaggerated by Butler in his Sermons-how it "magisterially asserts itself," and "goes on to anticipate a higher and more effectual sentence." This is a confusion of Morals with Religion; and Kant makes matters worse, identifying Duty with the command of an abstract Prussian drill-sergeant. Hence psychologists have been misled in their analysis of conscience : Bain deriving it from "education under authority" (Ethics, Part I. c. iii.), and Spencer explaining it as an abstract vestige of all other forms of control, religious, political, and social, and deriving its coerciveness especially from religious and political government (Ethics, Part I. c. vii.); so that conscience is an "ego-altruistic sentiment" (Psych. Part IX. c. vii.), representing in abstracto the feelings of others, God or man, toward ourselves in respect of any action; although true moral insight regards no such indirect, but only the direct consequences of conduct (Ethics, Part I. c. vii.). Others have considered conscience as a kind of imitation of tribal government set up in our own breasts (Fouillée); and this metaphorical character of it is plain when we first meet with the explanation of Self-control in Plato (Rep. 431).

Recent investigations of anthropologists seem to prove, however, that conscientious feeling exists amongst savages before there is any government, or anything that can properly be called religion: that is, before there are any gods. The rites of savage tribes in Australia and New Guinea, especially the rites of initiation, take place under feelings that can only be called conscientious. Religious they may seem to us, because they have been incorporated with our high religion; but they greatly differ from the terrors of early superstitious religion. Certain rites excite such feelings and maintain them, but also presuppose them; for such rites could not be established or maintained unless feelings had already grown 
up about certain beliefs as to the necessity of certain actions. The reasons sometimes given by the savages themselves for such actions are mere mythology, and attempt the imaginative explanation of observances whose origin is forgotten. To trace the particular conditions under which such beliefs and feelings originated may be impossible for want of evidence: but it seems to me, entering as well as I can into the savage mind,

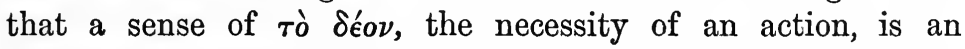
universal condition of social life. It is known that the less developed the social organisation of any people, the stricter are their customs; and it is reasonable to infer that, in former ages, the customs of tribes that we call 'primitive' were stricter than they are now; for as to time they are no more primitive than we are; their ancestry is as ancient as ours. The narrower their intelligence and experience in bygone ages, the less possible was doubt or criticism. There arose amongst them the sense of necessity in conduct. No doubt it was enforced by the tribe, but it was confirmed by natural selection; since no one could remain in the tribe who did not feel it. It was an indispensable preparation for political, religious and all regulative beliefs and feelings, which are differentiated out of it; and, therefore, it was by no means derived from them. If so, it is the easier to conceive that though all other modes of regulation should atrophy, this one may still live and reign.

How natural it is to speak of conscience ' reigning,' personifying and even hypostatising that sentiment; yet this belongs to a group of metaphorical expressions that, promising to elevate, really cloud and obscure the subject. Duty almost inevitably suggests the military life, and rhetorically this is often convenient; for fighting under the influence of ideasthe king, the hearth, the altar-is with many, perhaps with most men, the noblest action they are capable of ; and it is noble. But thus again the analytic psychologist is misled into deriving moral duty from associations with punishment; for although it is grossly erroneous to derive military duty wholly or chiefly from the fear of punishment; since in fact it is a panic inspiration depending upon special conditions of social 
co-operation; yet the liability to punishment in its harshest forms is nearly always one of those conditions, and necessary enough where all sorts of men, noble and vulgar, must act together; its influence cannot be excluded, and is therefore supposed to be equally present in what is called moral obligation. Accordingly, we read treatises on moral obligation in which, perhaps insensibly, all the conditions of military and juridical obligation are confused with the purely moral life.

Juridical or political obligation, according to Austin's analysis, implies a subject, a sovereign, a law made by that sovereign, and a sanction by which he enforces it. Religious obligation, according to popular notions, readily presents the same features; and even the codes of honour and respectability may be interpreted in the same way, if by 'sovereign' we understand men of one's own class or the great public. But in relation to moral duty there is no sovereign, nor positive law, nor sanction, nor subject; but a man chooses a good action for its own sake, as Aristotle says (N. Eth. Book II. c. iv. 3) : meaning by $\delta \iota^{\prime} a v ่ \tau a ́$ not that no reason can be given for it, but that (for whatever reasons) the action is seen to be good, and is therefore chosen and done. The influence of Aristotle's simple, natural, open-eyed view of conduct, has never been lost in moral philosophy; but being in some ways too narrowly Greek, it has been generally overcome by the Stoic, quasiSemitic doctrines, reinforced by the Scholastic identification of morality with Christian duty.' Hence we find Kant inventing a metaphysical mythology to explain what he assumes to be the fact of moral obligation; dividing a man into noumenon and phenomenon, in order to find a sovereign and a subject, discovering an unconditional law in the sense of duty, andthen the analogy completely breaks down; for he is resolved that morality must be disinterested, and therefore there can be no sanction. It is a compromise between Stoicism and Christianity, according to Kant's essentially imaginative procedure : its imaginative character being disguised from himself and his readers by the submergence of plastic images under abstract ideas.

Moral 'obligation' is a question-begging phrase, inevitably 
suggesting all that machinery of law and order, which without a sanction is meaningless. If we inquire the cause of such a confusion of ideas, it may sometimes be traceable to personal character : in some men conscience has a much more authoritative tone than in others; in Butler, for example, than in Hume: and sometimes this difference is exhibited upon a national or racial scale; as if we compare the Romans with the Greeks, the Germans with the French. Sometimes the confusion may be due to our not distinguishing the moral from the other feelings that help to determine right conduct and are practically of equal or greater importance. Berkeley speaks of disinterested virtue almost sarcastically as something above human nature (Alciphron, Dial. III.); and so it is, if any one purposes to rely upon that alone for the direction of mankind, or even of his own life ; for it is to be feared that the best of men would be unsafe if they attempted to live without law, religion, or honour. But all that has nothing to do with the philosophical question as to the nature of moral duty.

$\S 5$. Those moralists, therefore, seem to me to be in the right who maintain that moral duty, or the term 'Ought' is unanalysable: that is to say, intellectually it is unanalysable, because it is empty. As Berkeley observes, "the communicating of ideas is not the chief and only end of language, as is commonly supposed. There are other ends, as the raising of some passion, the exciting of deterring from an action, the putting the mind in some particular disposition" (Princ. of $H$. Kn. Intro. \$20). 'Duty,' 'Conscience,' 'I ought'-are terms that properly stand not for an intuition of what is good or right, but for the feeling and impulse that accompany such an intuition. Unfortunately, conscientious feelings cling not only to clear moral intuitions and judgments, but also to every sort of belief as to what is right, in whatever way such a belief may have been established; and whereas the normal and desirable adjustment is that feelings should be strong in proportion to the gravity of an action, it often happens in uncultivated minds that the strongest feeling attaches to the most insignificant actions, empty ritual and trivial observances, or 
even silly abstinence, as 'not to whistle on the Sabbath.' Such prejudices may sometimes express a predisposition to magical beliefs and practices, but usually result from the inculcation of rules and observances, whether by social tradition or direct teaching, without assigning reasonable grounds for the conduct prescribed.

The word Conscience, indeed, is legitimately used in two senses: (1) moral judgment, and (2) the sentiment of duty. The use of it in the former sense has the disadvantage of suggesting that moral judgment is a different 'faculty' from speculative judgment; which is not true; for, when it results from reasoning, it is a judgment of causation. The latter sense is prominent in Butler when he speaks of the 'manifest authority' of conscience; and he explicitly confuses the two meanings in his description of "conscience, moral reason, moral sense, or Divine reason," as "a sentiment of the understanding or a perception of the heart; or, which seems the truth, as including both" (Diss. on Virtue). ${ }^{1}$ This confusion of moral reason with moral sense has led to much further confusion in discussing the validity of conscience. The validity of moral reason is exactly the same as the validity of reason in any other department of thought; but the validity of the connexion of the sense of moral necessity with any given belief or observance depends upon whether that belief or observance is dictated by reason, or is the result of education or tradition; which may be erroneous-though supported perhaps by hereditary pre-disposition. Hence an inquiry into the origin of the connexion between this feeling and any given belief, although it does not decide the validity of the connexion, is by no means irrelevant to an inquiry into its validity.

Most of us can remember a time when we were harassed by conscientious scruples about actions indifferent, or even by moral repugnance to perfectly reasonable actions. The overcoming of such associations is necessary to any improvement in human life; but it is attended by moral danger. The

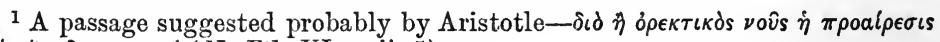

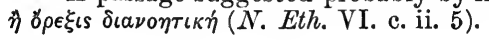


association loosened at one point is liable to become weaker everywhere. Those who are assiduous in associating moral feeling in the minds of children with beliefs and observances which they are very likely, on approaching maturity, to think false or groundless, commit a grievous error, often do a grievous wrong; such as no purity of motive can justify.

The danger attending the dissociation of moral feeling and observance, however, is not merely a personal matter: it sometimes threatens a whole nation or culture-zone. This necessarily follows upon the reduction of morality to rules and maxims, under any non-empirical sanction, whenever the conditions of life undergo an important change, so that reflection receives an unusual stimulus; for then there must be casuistry as to the application of such rules and maxims in the new circumstances, and scepticism as to their grounds. The doctrine of Comte that the progress of intelligence is the fundamental cause of social change, is obviously untrue; for the movement of intelligence depends, like sensation, upon a change of stimulus, and this change is usually supplied by social conditions. Every approximation to the 'stationary state' in social affairs is accompanied by stagnation of thought. That there may be new inferences there must be new data. New data are supplied by changes brought about chiefly by war, commerce and other means of intercourse with other nations; whence ensue changes of industry and in the balance of political forces internal and external, and therefore in government, and sometimes more direct influences on thought through foreign art and literature. Such a social movement brought Philosophy to Athens in the fifth century, and in the Sophists, Socrates, and his disciples, the consequent moral danger is apparent; by Plato acknowledged and a chief theme of all his writings. For seven centuries Philosophy saved herself: society she could not save. In modern Europe the same thing happened at the Renaissance and Reformation: marked by the casuistry of the Jesuits, and by the great renewal of science and Philosophy. I shall not boast that Philosophy saved the modern world; for I fear it has not been saved; and, at any rate, human beings cannot be saved 
merely by thinking. The change of conditions, in the classic world, introduced as one of them a great increase in the prevalence of slavery; in the modern European world it brought a decrease. So much to the good. In the modern world, again, the shock has agitated a greater mass, which offers greater resistance to disintegration. But the process goes on, and another dangerous stage of it has been reached in our own day.

What shall I believe; what must I do; how re-establish the sense that 'this is necessary'-the ancient and indispensable condition of social life and of my own inward peace? The morality of Common Sense without the support of enlightened casuistry, has become a quicksand, as we may read in the immortal third Book of Henry Sidgwick's Methods of Ethics; and if we look elsewhere we are met by the 'conflict of science and religion,' an odious canting phrase that unhappily stands for a tragic fact. Within the scope of this volume I can only fall back upon the guidance of causation, the replacing of rules and maxims of observance by the conception of the tendency of actions to bring about a certain End, and by the association of Conscience and Duty with the intention to secure that End: namely, the predominant interests of humanity; which I say that every sane man knows very well, Virtue, the Happy Life, the Beautiful Life, and Philosophy, the understanding of the world and its courses, which must be the light of our endeavour and perhaps our consolation in defeat.

$\S 6$. There are three fundamental conditions of social life. Sociality; that is, the satisfaction that men of the same tribe (or animals of the same herd) have in being together, and the loss of which with its correlative activities is felt as homesickness by any one who is separated from his tribe (Spencer, Psych. Part IX. c. v.): a sense of the necessity of observances, as we have seen; and the sympathetic disposition to refrain from mutual injury, and to help one another when help is needed. These conditions being fulfilled, we may perhaps learn by thinking how wide the tribe is and what it is necessary to do for its sake. The universality of the 
End and the sense of the necessity of pursuing it, presuppose a sufficient development of thought to appreciate the unity of mankind, and the claims that all men have upon us; and a sufficient development of affection and beneficent sympathy to make this knowledge effectual. These conditions are by no means present in all of us; adequately present in none; but hardly any one is quite destitute of such sympathy and affection.

Affection develops first within the family; it is indispensable to any kind of animal that has to protect its offspring, and must be lasting in proportion to the time during which the offspring need protection. At first identical with parental instinct, it is, no doubt, blind and automatic, but not therefore less strong; rather to that source we may trace its strength and persistence after the rise of self-consciousness. In its development, however, the disposition to help others becomes so far a self-sustaining passion that we may be eager to defend or succour in distress those toward whom we feel not merely little affection but even (in general) antipathy. In the family, affection is insured by natural selection all families and species in which it is defective must die out. And in a less degree this is true of the tribe; at least to this extent, that tribes in which the sympathetic disposition is strong have, in general, a great advantage over those in whom it is weak. Accordingly, I believe it may be said, on the whole, that by the ascendancy of tribes amongst whose members mutual help and fidelity are instinctive, benevolence increases with civilisation: but I cannot assert this confidently, because both qualities are difficult to measure; because in the decadence of civilisation effective sympathy may decline, although the external characters of civilisation are still strongly marked; because other qualities such as intelligence and energy are highly important to civilisation and are not necessarily connected with effective sympathy; and because, in some forms of civilisation, certain causes, such as war and strict demarcations of rank, check the development of regard for others.

We must distinguish passive sympathy, the mere reflection 
of another's happiness or suffering in one's own soul, from that form of sympathy which includes the effectual impulse to increase the happiness or diminish the suffering of another. The former by itself is useless, except perhaps to artists. It is sentimentality, and may be natural to some people, or acquired by habitually neglecting or suppressing the impulse to action, or by. indulging in day-dreams or romances which give no opportunity of action. We must also distinguish between emotional sympathy, the actual rejoicing or suffering with others, which is amiable, but may be ineffective, from perceptive sympathy which fully understands by symptoms the pleasure and pain, or the emotions of others, but may be accompanied by little emotional disturbance. That emotional and perceptive sympathy are separable conditions is shown by malevolence and envy; where there is a clear perception of the suffering or happiness of others, but an opposite feeling aroused in our own breast not only suppresses all compassion but impels us to increase their suffering or to destroy their happiness. The neglect of these distinctions occasions many popular fallacies. We are apt to over-value the display of passive emotional sympathy; for, as the Quaker said, 'What is the use of feeling for a man if you do not feel in your pocket?' We are apt to misinterpret the character of the actively but unemotionally sympathetic man, who is helpful without display, and to call him cold: the Scotch and the Quakers, for example, are often thought cold; but are there any better friends in time of trouble? It is a disadvantage of the theatre as a means of culture, that there the expression of feeling is exaggerated, and this gives an erroneous notion of the relation of feeling to action, obscuring the importance of that organisation of character which makes possible a great discharge of energy with little emotional disturbance. We are apt, finally, to over-value the sort of sympathetic action - namely, pity or generosity - that is excited by the immediate prospect of relieving pain or conferring pleasure, in comparison with the more abstract form of instinctive justice that is aroused by a knowledge or divination of remote conditions of wrong or injury, by the signs of political or social 
encroachment; or in comparison with that comprehensive and impersonal benevolence that embraces nations and generations in its care. The taunt is indeed common that a philanthropist may be capable of overlooking the nearest claims, however real: every sort of virtue is followed by shadows that caricature it. But the truth is that a sane regard for the welfare of mankind, or one's own country, must put a restraint upon many impulses of personal kindness, or modify their expression beyond popular recognition.

The development of thought is one condition of appreciating the universality of the End; but no speculative power alone is sufficient for it without a corresponding development of effective sympathy. Hence Aristotle wrote his Ethics for Greek gentlemen: neither the northern barbarians nor the Asiatics being fit for citizenship, nor therefore for the good life. With what mingled pain and amusement do we find the old Pagan saying, that 'no one supposes that a slave can have any part in happiness' (Book X. c. vi.); though a ray of better illumination sometimes penetrates his mind, as when he says that no one can be friends with a slave-at least as a slave, but as a man perhaps (Book VIII. c. ix.). Plato felt the need for better relations between social classes, when he insisted upon the amicableness and unity of interest between magistrates and the industrial body that were implied in their reciprocal tasks of protection and sustentation. It is the glory of the Stoics to have been the first in Europe to declare that the good life in its highest degree is open to all men, as citizens of one city and children of one Father, even Zeus, whose City is the World. But the nature of the good life they perversely misconceived and misrepresented by every illusion of rhetoric; so that they were the first to make virtue unamiable. We see that their philosophy of human life is too much in bondage to abstract ideas, and wants the imagination that is implied in true benevolence. It remained for Christianity to reconcile virtue with that simple naive happiness which is so necessary to human life, yet from which every Greek Philosophy shrank. But Christianity was less successful in its conception of life as a natural whole, and of its possible 
beauty and glory in this world, and was still more deficient in its valuation of Philosophy.

As the moral conceptions of Greece were limited by slavery, so were those of Judea by nationality. And this is a great difficulty of the present age: other nations, and still more other races, seem to lie beyond the scope of our efforts. With different races facial and gesticulatory expressions are so different, that a difference of inward experience and capacity are not improbably indicated; so that, considering the actual antagonisms that also exist, the full universality of the moral End may still for some ages remain an impracticable ideal.

$\S 7$. The social character of morality has been acknowledged more or less explicitly by nearly all philosophers; but it was repudiated by the Cyrenaics and Cynics: sects that are not extinct, nor likely soon to fail. Each philosopher or school is a type of a certain kind of man and way of thinking. The Cyrenaic is the spokesman of all worldlings who accept whatever enjoyment comes within reach, without recognising any but prudential obligations to society or having any disposition to make a fair return for their costs. The Cynic represents the morose recluses who pretend to shun the world and discard its usages, disparage the elegances of life along with its pleasures, its affections together with its forms, and its decencies rather than its vices. The Epicureans, again, confined society to the garden: a conception impossible to a circumspective mind, except in an age when slavery had given to the few a false appearance of nobility, and delivered industry over to contempt.

Some systems disguise their real social basis by substituting a divine for the human polity. But all mythologies and theologies (so far as gods are persons) can only imitate human social relationships, and are especially modelled on the institutions of government and family, generally presenting a sort of patriarchal absolutism. Other systems, again, offer abstractions from human life for the fact itself. Such are the theories of the Stoics and Kant. Manifestly their conceptions of a Law of Nature, a magisterial Conscience, an unconditional Command, are borrowed (as we have seen) from our ordinary 
experience of social government; and it may seem strange that the invèntors of such thin schemes should feel them to be more impressive than any actual kingdom, and pay them in fact a more impassioned homage. But this is why such abstractions come into existence: they collect from some area of experience whatever forces of goodness or nobility it may comprise, and drop the repugnances, the failures, the meanness, the dross. Hence the numbers and enthusiasm of the disciples who follow the idealist philosopher; for he is a type of all such men as cannot master the whole truth and must take refuge in abstractions. Alike in art and morals we see crawling at the bottom of the world unimaginative copyists, "realists," and adulators of the passing fashion of life; others we find who are aware of good and evil in all things, and endeavour by a comprehensive study of human affairs to discover the actual conditions of enhancing the good, that is to be cherished and honoured though it cannot be separated; between these groups come the fastidious or intolerant devotees of beauty or virtue, who make a narrow selection of the good and repudiate nature, for the most part self-deceived and always in danger of fanaticism. The abstract idealist follows an uncritical convention of traditionary concepts. His unconditional law is simple, unembarrassed, incorruptible, unchangeable, because it describes no actual case. It cannot be evaded nor weakened by disobedience, because it is never enforced. It infallibly distinguishes the good from the evil by sheer logic, on the principle that a stick must be straight or crooked; though, in fact, it is never straight. I do not doubt the value of Idealism to those to whom it is in a manner native, and am far from depreciating the nobility of temper displayed by many of its adherents. Indeed as a protest against crude Realism it may be indispensable in our see-saw world. But such a philosophy explains nothing, and can have little power because it is too far removed from fact and observance. The true moral ideal is not a principle or an abstraction, but a model of life, and is most effective when presented in an actual person; so that on this ground religious ethics are far more persuasive than Idealism. 
Idealism is the mere ghost of Religion, and is no more able to carry on the work of Religion than the ghost of Brunel was able to go on building railways after his physical decease. The spread of an imitative Idealism in this country since 1870 has been accompanied by a decline in politics, art, literature and every function of the spiritual life.

On the other hand, perhaps the greater number of philosophers have recognised that morality is essentially a condition and a factor of our actual social and political life. The ground of their doctrines indeed seldom deserved to be called inductive, yet it was in some measure a study of facts, of men and manners and institutions : for example, Aristotle, Hobbes, Spinoza, Hume, Bentham, Hegel, Mill and Spencer. An incongruous list it may seem; and undoubtedly some of them bear the stamp of different political circumstances, as Aristotle, Hobbes, Hegel; or like Hobbes, Hume, and Mill are strongly influenced by their temperaments. But if we are offended at Hegel's fatal subordinating of the individual to the State, we remember the needs of his age and country, and that the chief merit of all his Philosophy is its protest against the moral abstractions of Kant. If the cynicism of Hobbes irritates us, we call to mind his great doctrines, that moral laws are prior in nature to society - that is to say, they are the condition of the existence of Society; which lives to realise them, in order that human nature may be realised; and, again, that human nature differs from everything else in the world by containing the ground of civil institutions, under which alone a rational life is possible. In general, if we are dissatisfied with the tendency of any of these doctors, so far as they offer moral instruction, we must consider that the function of moral philosophy is not to inspire but to enlighten, not to teach but to explain, and that some actual social or political life such as they postulate is essential to the explanation. Morality, then, is a social manifestation, and nearly all philosophical systems recognise that fact; but in turn, the maintenance of Society and all its observances depends upon the character of its citizens. Until recently no one saw so clearly as Aristotle had seen that, in morality, everything at last depends upon 
character. But Mill and Spencer entered upon their labours with the help of the new historical method. They found that moral conceptions vary with social conditions, and that even moral duties depend upon social conditions, but that on the whole, and in the long-run, the organisation of morality in the character of individuals is the chief means of social health and progress. 


\section{CHAPTER IV}

\section{CHARACTER}

$\S 1$. THE morality of the individual depends upon character. It is not enough that his actions be right according to a rule : they must either spring from his spontaneous impulses; or be determined by the reflection that they are right, whatever else might otherwise have been preferred.

The characters possible in the human race are, no doubt, determined ultimately by natural selection operating either upon individuals or upon tribes: I mean that, in any region, certain types of character are more suited than others to the conditions of human life and, in the long-run, these must predominate; and that, in the long-run, only those tribes can be successful in which certain types of character predominate. But this consideration sheds no light upon the special complexion of characters actually existing at any time or place. We may infer from it that some degree of sociality, sympathy, regard for observances, energy, endurance, intelligence, must everywhere exist; and that in the more successful tribes there must be a more effective resultant of such qualities than in the less successful; but whether the greater success be due to more effective sympathy or to more energy, or what not, cannot be known without a particular investigation. The conditions of human life, and therefore the characters required to deal with them, vary in different regions of the world; not only geographically, as in climate, flora and fauna, and physical configuration, but politically, internally and externally; and politically they vary still more in the course of time with the development of Societies in social 
and military organisation, religion, industry, knowledge. The possible types of character, therefore, are quite impredictable. The future of the world, could it be foreseen, would perhaps exhibit types of human nature as astonishing as the animal types that are found in the mesozoic strata; though it seems to be generally assumed that the future paragon of animals can only be a smugger image of the extant philistine or church-warden.

Extant characters depend upon (a) heredity, (b) tribal education, and (c) opportunities for expression: As to $(a)$ heredity, we may take it to be generally recognised that character is inheritable, more generally perhaps than that intelligence is so; though in the crossing of families and stocks, it cannot be pretended that every quality or disposition is traceable to definite ancestors. The interest of heredity to us who are already born is manifold. If we know anything of our forefathers' virtues and vices we have clues to selfknowledge and self-control; if they were nobly-natured we may preserve the tradition and the proofs of their nobility; if they were otherwise we may be on our guard against their faults, and try to make up for their shortcomings. These are good motives. But, speculatively, the consideration that in some way we reproduce our forefathers adds little to the general consideration that all events are determined by causes. Whatever may have happened in the past, our own conduct begins with our own life. Knowledge of causes may help us to understand ourselves, and it justifies the metaphysician in forgiving us our trespasses, but can in no way affect the rational necessity of living the best life we can, such as we are, and of making the most of ourselves. With regard to future generations, the significance of heredity is much greater; since it always lies in the power of the present one to determine who shall be born at all; in other words, who shall marry. There is a growing conviction that certain strains of disease, vice, incompetence, ought to be eliminated from the human race; and that, to that end, some sort of restrictions should be put upon the marriage of the diseased, vicious, and incompetent. A branch of Anthropology, Eugenics, has been established to 
study the conditions of human heredity (cf. Chap. V. $§ 5$ ). It is needless to express fears that conclusions will be reached too hastily, and be too hastily acted upon; or, on the other hand, that whatever valuable discoveries may be made, false sentiment will prevent the taking of any action. We may be sure that the inquiry will at last be successful, that the hereditary conditions-not probably of individuality-but of types of character will be understood, and that the arrangements of human marriage will be modified in accordance with the knowledge obtained. Still there must always be limits to the power of man over his own nature, physical and social conditions that must be conformed to with the alternative of selfdestruction. We cannot breed and establish whatever types we like best, but only such as are fit for this world.

(b) Tribal education is as old as tribal life. At least, amongst some of the lowest existing savages, the Australians, nothing is more remarkable than the pains taken to inculcate traditions, customs and moral beliefs upon their youth, and to engraft them by training and impressive rites. But education, as here understood, is something much wider than direct training or schooling, namely, the influence of public opinion, sexual admiration, national art, literature and religion, and social and political institutions. The subject is so important and extensive that I purpose to devote to it the whole of the next Book. Strictly, education does not create character, but only limits it by determining behaviour; but its influence begins so early, that purely congenital character is a thing unknown; and there is so much elimination of those characters that are not plastic to tribal education, that they are rare except among the criminal and insane. Schopenhauer's dogma that character is innate and unchangeable is too crudely stated. Extreme cases of the reversion of educated savages do not prove that the normal education of a man in his own tribe cannot be radically effective. We learn to imitate not only the actions of others but their ways of thinking and feeling, and this too becomes a second nature. The truth that the dogma points to is that in many men, at least, there is something innate that gives a bias to all the results of education, so that they are 
still themselves; and that there remains in them to the last a potentiality of reaction for good and for evil unknown and incalculable.

(c) Opportunities of expression determine what characters shall flourish and what shall be perverted, stunted, or extinguished. Amongst the conditions of expression are the influences that constitute tribal education, thwarting some tendencies, and encouraging others; but there are many more conditions. The settled or migratory life of the tribe, the nature of its industries and extent of the division of labour, the length of the hours of labour, the prominence of extra-industrial careers - military, artistic, professional, - the degree of political and social freedom, the density of population, and many other things, determine a man's exercise of choice as to his general mode of life and, therefore, the satisfaction of his personal impulses : in other words the expression of his character. It is sometimes said that character is equivalent to the totality of a man's actions; but, unless the notion of congenital character is an empty one, character can only be equivalent to actions so far as a man has opportunities of acting. We may rather say that, from want of enough opportunities, a man's character is never fully expressed, nor can it be fully known. His accepted character is a sort of conventionalised product, an imperfect organisation of traits selected by the environment from the totality of his connate tendencies. This is proved by the phenomena of 'multiple personality'; or it may be inferred from the widespread roots of the ancestral tree and the numerous types that must therefore meet in each individual. The presence of "latent characters" in animals and men, and their transmission through many generations, is shown by Darwin in his Variation of Animals and Plants (c. xiii.). Perhaps a very tactful, sympathetic, penetrating judge may infer from some of a man's actions what he would do in other cases; but such inferences seem to me extremely uncertain and, when drawn by ordinary men, utterly worthless. The truth is that, for want of opportunities of acting, a man never knows his own character. Not only do most people deceive themselves grossly about their 
characters as about everything that concerns themselves, but the conscientious, scrupulous and impartial cannot possibly know how they would act in circumstances very different, or sometimes only a little different from those in which they have been tried. One may often be surprised by the change in the moral outlook presented by an actual situation, compared with one's anticipation of it. Who has not experienced this ? Manifestly, a congenital character cannot develop freely unless there is a suitable sphere for its activity. Hence it is often justly observed that the criminals of one age might have been the heroes of another. Much of the vice and folly of mankind is due to want of opportunity of innocent indulgence. Sexual perversion and gambling, for instance, and even the crowding of country folk into towns, almost inevitably result from compulsory deferring of marriage, want of occasions of enterprise, or of indulging the variety of impulses and tastes that constitute human nature. One may sometimes tolerate noise by considering it as the untimely overflow of high spirits.

$\S 2$. Character is known to others and even to oneself (so far as it is known) by constancy of reaction in given circumstances, but is essentially conceived as the expression of impulses, desires, feelings and ideas. Appreciation of another's character depends on sympathy with this subjective side of it; so that if a man's actions do not seem truthfully to express this inward life, he is regarded as playing a part. But impulses, feelings, ideas, in mere miscellaneity, do not constitute a character; that term implies such an organisation of them that a man acts with some degree of consistency for human and, therefore, not merely proximate ends. It must be assumed of course that this organisation is represented in a man's physical structure, more particularly in his nervous system. By reflecting upon this, it seems to me that we get a fuller sense of the reality of character as a directing agency in the world, and of the necessity of reckoning upon it in education, morals and politics, than by considering it only as a mental fact. Causation is a physical conception, and it is not unreasonable that physical considerations should have most weight in men's judgments. A statesman who urges legislative or administrative measures 
that are incongruous with a nation's character, may restrain his eagerness by the reflection that he is entering into a conflict with physical forces. The physiological actuality of character must qualify alike our hopes and our fears for the course of events, whether determined by individuals or by nations; it must direct our inquiries into events and guide our interpretations of history. When investigations are made into the degeneracy or improvement of national physique, the important issue is the direction in which the national character may be changing. And if it seems to be changing and we would know the causes, it may be less important to consider the direct influence of circumstances in stunting, or softening, or stupefying certain classes, than to ask whether circumstances have not changed in such a way as to be more favourable to one than to another strain of blood in the population, and to give a predominance to another stock than that which formerly directed our affairs, and by whom our physiognomy was strongly presented to mankind.

The variety of characters is inexhaustible, and the classification of them correspondingly elusive. Bain proposed to distinguish them according to the relative prominence in individuals of the active, or the emotional, or the intellectual disposition. Ribot (La Psychologie des sentiments) prefers to make the fundamental division between the active and the emotional dispositions, and to treat intellectual power as a secondary quality determining species of the chief genera according as there may be less or more of it. This seems to me an improvement upon Bain's plan: intellect is a comparatively late influence upon action, and then upon the means rather than upon the ends which indicate character. So far as the intellectual disposition gives rise to a special type of man, it is as an active impulse supported by the motive of scientific curiosity. But has not Ribot overlooked the fact that the core of every emotion is an impulse or active tendency? If this is the fact, the single basis of differences of character must be differences of active tendencies and of the groupings of such tendencies; whilst degree of feeling or emotion, like degree of intellect, can only determine varieties of the classes 
thus distinguished. Hence character is, in the first place, expressed by actions; secondly, by the emotional energy of such actions, which may decline as habits are formed; thirdly, by the intelligence with which ends are comprehended and means adjusted to them. A man's intention depends upon what he is impelled to do in circumstances that have been analysed and defined by his intelligence.

We are here concerned with the varieties of character only in relation to morals, for which purpose the following distinctions seem to me the most important:

(1) The relatively aggressive in contrast with the submissive, and the initiative in contrast with the imitative or sequacious. It is these differences that make it so absurd to suppose that in practical affairs each man can count for one.

(2) The commonest division of moral characters is into the selfish and unselfish. Its inadequacy may be supplemented by a study of Spencer's chapters on the egoistic, egoaltruistic and altruistic sentiments (Psychology, Part VIII.); for every emotional disposition, such as Spencer calls a 'sentiment,' includes an impulse (which it reinforces) to act in a certain way. And to these three kinds of motive we should, I think, add another for which there is no accepted name, public or (as I have called them) 'panic' motives, depending on the sympathetic co-operation of the Tribe. According as one or another of these kinds of motives has most influence upon a man's actions on the whole, the general type of his character is determined. Egoistic motives are directly connected with a man's own welfare, and include most of those that are usually called selfish; they range from animal appetites and the crudest impulses of self-preservation or resentment (fear and anger) to the representative sentiments (as Spencer would say) of proprietorship, liberty, and integrity. Ego-altruistic motives arise from a man's belief as to the feelings of others towards him, or from his desire to excite those feelings toward himself: such as vanity, honour, the love of fame and the sort of conscience that depends upon the belief that we are watched. Some of these are also classed 
as selfish; and so they are in intention; but, by involving the gratification of others, they secure some social control over the immediately selfish impulses. Altruistic motives, most characteristic of the 'unselfish' man, imply such a sympathetic adoption of the interests of others, as to act on their behalf even to one's own disadvantage, as in pity, generosity, benevolence. Public or panic motives are those which direct action according to the total interest of the tribe-patriotism, loyalty, religion (in its tribal form) and justice: they arise amidst the contagious excitement of a crowd animated by a common purpose; and susceptibility to such excitement is with most men, especially of a primitive sort, a condition of sociall co-operation. If we consider any action (say, a gift) in isolation and abstractly, it may be done apparently from any of these kinds of motives; but if we take the details of circumstance and expression, there is less uncertainty in assigning its true source; and when we survey an extensive context of actions, from which alone a man can be fairly judged, the dominant motives that constitute his character (so far as it has developed) may stand out clearly enough.

It is usual to describe the altruistic sentiments as if they alone were sympathetic; but we have distinguished (C. III. $\S 6$ ) between sympathy as a perception of what others feel, and effective sympathy as the disposition to act for them according to what we perceive or divine to be their interest. In altruism effective sympathy aims at the good of others as individuals; and in all forms of public spirit it is present with the consciousness of co-operation for the public good. Hence it may be thought that, in classing justice with patriotism or loyalty, I am taking it away from its true connexion with benevolence, as " negative beneficence," because we often seem to require justice for individuals ; but when we require justice for individuals it is never as such but on public grounds as the greatest of all public interests, and we assume the co-operation of the tribe, amidst whose unanimous approval or disapproval the sentiment probably originated. Perceptive sympathy, however, is implied in every form of ego-altruism; for the vain man seeks for signs that you admire him; the ambitious 
booby that you feel his 'magnetism'; and, easily diseased, these dispositions become hallucinatory. Perceptive sympathy is also involved in cruelty and malevolence; in their raw state as an egotistic gratification; then as proof of power to impress the minds of others; and, unfortunately, cruelty and malevolence break out with the most horrible violence and fanaticism when fear and rage become panic in a tribe; but in civilised adults they may now be regarded as pathological. Well : it is recognised that some men are chiefly egoistic, and some largely ego-altruistic; that others are altruistic in an unusual degree, and still others conspicuous for some mode of public or panic sentiment. It may not be enough recognised that a man of any of these classes may be a good citizen : this depending a good deal upon his intelligence; so that an enlightened egoist is far better than a stupid altruist: though the highest moral level may not be attainable in all these classes.

(3) Characters of every type differ in degree of elevation: a distinction that seems to be easiest understood as a matter of intellect, of comprehensiveness and discrimination in the moral purview; but it really involves something else. The impulses, emotions, sentiments themselves undergo evolution. Acquisitiveness is not the same feeling-impulse in a jackdaw, a peasant and a banker; the love of liberty in Hampden is something else than impatience of being in prison; the egoaltruistic conscience is a very different thing in the man who is merely afraid of being found out by his neighbour from what it becomes in him whose God is witness, and for whom therefore all worldly honour and hazard are contemptible. As to altruism, a man may be very generous but by no means benevolent and even very unjust. It is true that the development of the emotional life bears a close relation to the intellectual, especially to the intellectual imagination; it grows more abstract, more comprehensive, more sensitive to remote conditions; but the relation is very irregular. A man of high character may have a moderate intellect, and high intellect may be found in a starveling soul. In evolution I think the sentiments anticipate intelligence: surely, the 
moral consciousness precedes moral philosophy; poets and prophets utter truths whose reach and incidence they cannot possibly understand; patriots and martyrs die for causes that they cannot rationally justify. To this day the passions of liberty and justice have in some men a far-reaching sensitiveness to encroachment, to the faint premonition of encroachment, that cannot be defined or argued. Historiographers and politicians of the Flathead tribe do not appreciate this; most of the baseness of the world comes of neglecting it. Still, we see in the illusions to which youth is subject under those "dangerous guides, the feelings," that these feelings are the better for experience and understanding.

(4) Characters differ in stability: some are more trustworthy than others, and persevere to the end. This quality may seem to depend upon the presence of a dominant idea or purpose, always active (though perhaps in the background of the mind) and having a greater power to determine conduct than any other idea. But such a dominant idea itself depends upon the feelings and impulses, or tendencies to act, of which it is the co-ordinating resultant. It dominates because no other idea can give equally good co-ordination to the feelings and impulses (perhaps too numerous and often too obscure for analysis); so that, excited again and again in great variety of circumstances, it becomes habitual and may become exclusive. It is true that the plain man in 'the cool sequestered vale of life' may 'keep the even tenour of his way' and exhibit stability of character without any distinct consciousness of a dominant idea; he might disclaim anything so pretentious; and, to avoid needless subtleties, it may be admitted that a number of ideas connected with business, family, neighbourliness, religion, harmonise so well under ordinary conditions that none of them may ever need to exert a supremacy. But if discord should break out, stability of character requires that there shall not be two masters : it is possible to serve Mammon for the sake of God, or God for the sake of Mammon, but not to give them equal honour. Outside 'the mean and sure estate,' not to have a dominant idea ("goal-idea") is to be ineffective, irregular, unreliable, and at war with oneself; and the wider 
one's relations with the world the more comprehensive one's purpose must be.

Stability of character is often called strength of Will; but the word 'will' occasions more confused writing than any other used in Morals. It is a general term for volitions, that is, for those central moments of the transition from desires to action wherein it is decided (with whatever deliberation) which of certain desires shall be realised-for I take the case of competing desires to be typical. This momentary and transitional quality of volition is disguised by the fact that, when persistent action is necessary, there occur reiterated solicitations to abandon it, which have to be met by renewed decisions; but the persistence of action as such is not volition but conation-the original go of the organism; which expresses itself, at successive stages of development, as impulse, instinct, purpose. Moral volition is the determination of conduct by moral purposes and sentiments; which may be an egoistic sensitiveness about one's own integrity, or an egoaltruistic regard for honour, or else benevolence, or loyalty. For I cannot regard the higher volitions as determined wholly or chiefly by the idea of Self, or even by the self-regarding sentiment. It is true, of course, that they only take place at the level of self-consciousness; but the being aware of an action as mine by no means implies that it is done for my own sake. The idea of Self is merely a symbol of our memories, our social relations and our desires and purposes. An idea has no power, except as it excites desire; and the self-regarding sentiment cannot, without violence or misplaced ingenuity, be interpreted as including a man's devotion to the king, or to God, or to justice : these are social sentiments.

With the progressive elevation of character remote interests acquire control over our actions, because they are more favourable than the simpler ends are to human life. Spencer observes that the strength of an emotion in influencing conduct depends partly on the completeness of its organisation, and, on this ground, the more ancient and simple an emotion the stronger it is; but also on its representativeness, or the number of primitive emotions that are co-ordinated in it. Hence such 
sentiments as honour and loyalty and justice, being highly representative, can, if well established, overcome occasional impulses that are only reinforced by simple emotions. Moral sentiments constitute a special adaptation to social life; and their comparative strength in some men is no more mysterious than any other triumph of superior organisation-say, of mammalia over deinosaurs. They especially support persistent purposes stretching through long periods of time, the most characteristic trait of human life. If they are still too weak in most of us, it is because human nature is, on the average, still very imperfectly developed.

A consequence of the imperfect organisation of moral purposes and sentiments is that the carrying of them out often costs an effort. This may easily be understood by any one who has watched an ant dragging a pupa over difficult ground: nothing discourages him; his instinct can summon all his strength to the task. So can a man's purpose summon all his strength, his self-respect, or his affection, or his public spirit, when opposed by other men, or by circumstance, or by his own irregular impulses. There is an interestcircuit in human life analogous to the motor-circuit that sticks a limpet to a rock. Success in pursuing an end strengthens our interest; failure renews it. The purpose causes persistent efforts, and wins if it is the strongest power within us; nor is this peculiar to moral purpose, but often seen in the most insolent of men. The odd notion that the higher sentiments are the weaker, and that there is some mystery in their predominance, seems due to the fact that their expression is the less violent; but the reason of this is, partly, that they are fusions of several simpler emotions whose different expressions inhibit one another; partly, that they are related to remote purposes or comprehensive purposes, for which the perturbation of primitive emotions would be the reverse of useful. As a man's permanent purposes and moral sentiments embrace all interests, personal, patriotic, and impersonal, he identifies them with the reason of the World, and gives to the devil the irregular impulses that threaten to ruin his life. If he persists in well-doing and has been happy in his birth and parentage, 
the struggle against irregular impulses grows less and less severe; they occur less frequently; at last they disturb him not at all. The $\sigma \omega \phi \rho \omega \nu$, says Aristotle, has no evil desires.

$\S 3$. As qualities generally or widely prevalent amongst peoples, stability of character (the result of organic co-ordination) and elevation of character (expressing abstract and comprehensive sentiments) are late products of evolution. They therefore vary greatly in individuals and tribes, and are very liable to disease. Elevation often runs to fanaticism and Quixotry; the dominant ideas that give stability may, as "fixed" ideas, be manifested in all degrees of insanity. Still, that such qualities anywhere prevail implies a utility superior to that of the irregular impulsive type of primitive man. On stability and elevation of character depend the trustworthiness of social life, the justice of institutions, and their durability, so far as they are living and not merely customary. The persistence of the egoistic, ego-altruistic and altruistic types, again, implies that they are all useful. Everything that makes a society plastic and adaptable to new conditions is useful. To include a variety of types is therefore useful. And egoism is useful; for it leads a man to seek new openings of profit, and generally to make the best of the world for himself and his family and for all whose situation directly affects his own interests. It is true that adaptation through individuality is not the only way in which a society may be plastic. We see, for example, that the bee-society must have undergone an extensive series of adaptations entirely by natural selection of queens : but, then, bee-societies, from some very early date in their history as societies, have not depended for their maintenance upon complete individuals, since their workers are of undeveloped sex. The same is true of ants and termites. But human societies have always consisted of individuals; and the greater societies become, the more difficult it is to adapt them to the changing conditions of their existence by central regulation, or in any way except through individual initiative. Moreover, the enlightened egotist tries, not only to make the best of the world for himself, but also to make the best of himself, to the great advantage of the world. In fact, in some 
men, or in some ages, self-culture may produce their highest type of character. As for ego-altruism, it is indispensable as the only moral control of blind egoism where altruism is feeble: Spencer shows its importance in early stages of social development (Princ. of Sociology, §36). Those who do not care how their actions affect the happiness, freedom, dignity of others, must be made to care how the impulses of others recoil upon themselves. So we often see such people going as far as they dare in evil, though trembling for their honour, or cringing to their God. But in others the sentiments of honour and personal religion rise to an impassioned nobility, to a necessity of being stainless in name, faultless in fealty, in conscience void of offence.

The conditions of the growth of altruism are difficult to generalise. Outside the family, in which a great development of affection and active sympathy must necessarily - at least in the mother-go along with the lengthening of infancy, it is generally very feeble in primitive races; and so it is within the family amongst the younger children, or even sometimes in the father; but there are exceptions. It is probably repressed by the practices of hunting and war, which require the relentless infliction of pain; yet in these directions callousness may be specialised. In war a tribe must be the stronger for a confidence amongst its members that they will be succoured in danger or when wounded; and in hunting and many industrial occupations, tribal co-operation is facilitated by altruism. But it is certainly repressed by class distinctions and by family or personal rivalry. Barbarism and luxury, especially when based upon slavery, are unfavourable to it. So is any condition in which every man is a sort of spy upon his fellows, as in some absurd Utopias, and often in small towns. Aristotle in writing his Ethics had no need of the hypothesis of general benevolence; his conceptions of the virtues are essentially ego-altruistic. In a Greek City, with its factions, its personal rivalries, and its concern for the efficiency of every citizen, every one lived under supervision; it was, therefore, a forcing-bed of ability, but not a school of general benevolence. Only when the City was humbled, and 


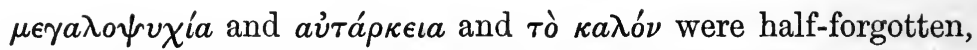
then, from amidst the wretchedness of slaves and foreigners, the altruism of Stoical and Christian morals arose. According to Plato (Rep. $462 \mathrm{~B}$ ), a society is united by being exposed to common conditions of pleasure and pain (cf. Laws, $678 \mathrm{E}$ ); and this is Spencer's theory of the beginnings of sympathy (Psychology, \$\$ 504-6). It is reasonable to suppose that as the distinctions of nationality, rank and other barriers between men are gradually effaced (of which, however, effective sympathy is itself one condition), mere intelligent recognition of our common nature is enough to identify the lot of others with our own, and to give play in wider relations to the family and tribal instinct of mutual help. Still, I think that effective sympathy beyond the family circle is also an individual variation which, under conditions that I cannot confidently assign, but at least by promoting solidarity, becomes hereditary in some families and in some tribes.

That the public or panic sentiments of patriotism and justice, loyalty and religion are necessary to human existence, is plain enough : they are the chief means of securing cohesion amongst the tribesmen, united action, submission and fidelity to leaders. It is usual, perhaps, to regard them as modes of altruism, but whereas altruism aims directly at the happiness or good of others, distributively, as persons; the public sentiments subserve the collective good instinctively, having directly in view some symbol, the hearth, the crown or king, the altar or God. They involve a simple sort of effective sympathy (justice, especially, a high degree of it), and they are very favourable to its development, but are essentially different from it in their instinctive character. Great moral difficulties arise sometimes from the conflict of public sentiments with one another; but still greater between them and personal sentiments, such as liberty and benevolence. It is the opposition of the total interests of Society considered in two different ways, distributively and collectively. The former has the clearer intelligence on its side, the latter has the stronger instinct; so that as instincts weaken in civilised life, we see men opposing military service on the ground of abstract liberty, 
or opposing their own country when at war upon the ground of universal brotherhood. I have often wondered how Butler would have resolved such knots by consulting his conscience; though some men seem to find it quite easy.

To class religion with public sentiments may seem strange in this age, when it has become chiefly a private matter; but, of course, although there was always family religion and even personal, especially in the worship of inferior gods, and connected with it an ego-altruistic sort of conscience, still, the great religion that adored and served the high gods was anciently tribal, and celebrated with public rites. The growth of empires destroyed the natural identity of religion with the tribe or nation; sometimes by fusing or intermixing the worships of subject peoples; sometimes by imposing foreign rites. Missionary enterprise has had similar results. What concerns ourselves is, that the Roman Empire, surviving in the Roman Church, spread one religion over many peoples, destroying the identity of Church and State. At the Reformation England formally restored this identity; but through the continued allegiance of some families to the Pope, and the persistent growth of Nonconformity, it has been impossible to make the restoration actual. Hence we are apt to think of religion as a personal matter ; but the history of it, its utility, its contagiousness, fierceness and animosity in many of its manifestations, cannot be understood in that way.

$\S 4$. Whilst the variety of characters is endless, and the classification of them difficult, the effect of education and imitation upon behaviour reduces the describable manifestations of character to a smaller number. A striking result of imitativeness is the formation of ideals, which are found at a very early stage of tribal development. The conditions of life anywhere give an advantage to a certain kind of man; by the principle of variation one man will sometimes appear who is better in this kind than any of his contemporaries; he rivets the attentive admiration of the rest and attracts followers. The stories told of such men form a cumulative tradition, which collects at last about some name eminent above all others: this is a hero and an ideal. A. C. Haddon in his Expedition 
to Torres Straits (vol. V.) tells us that the islanders regard as the highest virtues the warlike qualities of bravery, ferocity, endurance, and that these constitute their notion of a good man. ${ }^{1} \quad$ They are embodied in the hero Kwoiam. With the evolution of society and the differentiation of ranks, employments and individualities, several kinds of men become conspicuous in their own spheres, and may give rise to as many ideals.

Devotion to ideals is one form of that living for impassioned ends which is an important condition of distinction amongst men. It is not indeed the only condition; for if men did not spontaneously arise having direct impassioned ends, there could be no facts from which to derive the ideals : and we must not misinterpret such cases as Milton's admiration for Euripides or Alexander's admiration for Achilles, which were the effects not the causes of their genius. Original men are the greatest, but therefore they are few; and it seems to be believed that for most of us ideals are good, because in fact most of those even who stand in the higher ranks of personality are highly imitative. There is, indeed, a vast mass of us hardly self-conscious enough to have ideals, who merely follow customs; and many have ideals in youth, a sort of distinction whilst they last, but forget them. George Eliot in Middlemarch describes Rosamund Vincy as occupied "in being from morning till night her own standard of a perfect lady." She acted so well as not to know she was acting: that is to say, a histrionic life is one danger of the worshipping of ideals. And, to speak candidly, I doubt if the self-consciousness implied in ideals is always healthy; and, were I a spiritual adviser, should lay less stress upon ideals than upon the maxim, "Whatsoever thy hand findeth to do, do it with thy might." Goethe describes himself as always rising "through work a step higher, because he springs at no ideal, but lets his nature develop itself fighting and playing." Thus we grow, and, day by day, find what manner of men we

${ }^{1}$ By no means the same qualities as those inculcated at initiation for the internal peace of the tribe : namely, respect, obedience, generosity, truthfulness, manliness, not to thieve, or shirk, or gossip, or contract irregular marriage, (p. 273), 
are, without risking the fallacies of self-analysis. At any rate, ideals even when spontaneously adopted are probably misleading and limitary; for there was never a more impracticable maxim to begin with than $\gamma \nu \hat{\omega} \theta \iota$ $\sigma \epsilon a v \tau o$ ó .

National character, it has been observed, is not merely the sum, or the average of the characters of all the citizens (Lazarus); and the proposal has been made to explain this fact by supposing a sort of national oversoul, distinct from all individual minds but determining the total national life. Setting aside absurdities, we may point to the fact that national affairs are almost always directed by a small part of the people, more or less distinct from the rest, and in many cases an aristocracy or caste of different race from the main body. But, besides this, there nearly always exists a national ideal, ostensively founded on the national heroes and national achievements; traditionary and no doubt modifiable but, on the whole, of remarkable consistency, and exercising an appreciable influence upon history. Such ideals may not be actually traceable beyond a few hundred years, but probably are of much greater antiquity and possibly connected with totems. The totem, being held to be identical in blood and nature with the people who are called after it, becomes an object of imitation and in fact an ideal (A. C. Haddon, Torres Straits, V. p. 184). This is forgotten by civilised peoples; the English have forgotten that they are horses, though the fact remains. Do they not still worship their totem at their chief festivals, abstain from eating it, and pay more attention to its breeding than to their own? The power of tradition has no relation to its origin; and the character it preserves for nations may affect their life as a whole, long after the differentiation of ranks and offices has made it impossible that the same ideal should much modify the personal characters of great masses of the citizens.

$\S 5$. After the development of a certain social structure in tribes, ideals spring from institutions, and are usually personified in individuals, mythic, legendary or historical; such as Buddha, Lycurgus, Sir Philip Sidney.

(1) The greatest of all institutions is the divine royal 
family: the symbol, the unity, the identity, of the whole tribe. The dateless ancestral god and mother-god reign in heaven and animate the world, represented, or rather reincarnated, in the living king and perpetuated in his son. The divine family has been conceived differently by different peoples; some have never reached it, and in other cases the tradition of it has been obscured. But in widely-separated regions, it has been worshipped as the principle of fertility in Nature, and has been believed to be involved in the annual cycle of fertility-birth and death, resurrection and death. And to insure the succession of summer after winter, upon which the life of the tribe and of all things depends, it has been imitated by putting to death the king and installing another, or by putting to death his son (J. G. Frazer in Adonis, Attis, Osiris). The growth of humane feelings, or perhaps the weakness of the king in desiring to avoid his fate, may at some time substitute a bull or goat for the human victim, or an image for the reality, or turn the whole ceremony into a passion-play. But whilst the ancient customs lived, the king was necessarily the wonder, hope and trust of his people, because his chief function was to be a sacrifice for their welfare.

The difficulty of understanding what is called the 'pleasure,' say rather the fascination of tragedy, that has so much perplexed the critics, is easily overcome, if it be true that the tragedy of tragedies is the death of the divine king or his divine son. This was necessarily witnessed by the tribe with poignant satisfaction; though to us it seems horrible to say that-

Comfortable thoughts arise

From the bleeding sacrifice.

And hence has descended to us the conception of self-renunciation as an essential quality of every moral ideal. In our own literature the self-renunciation of the king is recorded in Beowulf, who having slain the dragon and suffered a mortal wound, gives thanks to god that by his death he has acquired great treasures for his people. With the increasing transcendency of the divine family, no longer incarnate on earth, 
the king becomes the tribe's champion; and with the further progress of positive thought the ideal is handed down to whatsoever hero is ready to die for a good cause, the knight errant, the chivalrous gentleman, the coal-miner who perishes in rescuing his fellows from their burning tomb.

(2) Originally connected with the divine family are certain types of inspired men. An early differentiation is the Priest; and he is apt to become so specialised as hardly to present a type for general morals. But he is consecrated and devoted, and so must we be. The ideal, as it has come down to us, is well described in Chaucer's "poore persoun of a toune." Unfortunately, Religion, the belief in superior beings that help those who appeal to them, is generally debased by Magic, the belief that ceremonies and formulæ have a coercive power even over the gods themselves; so that the Priest may become a sort of Magician and be separated from the tribal life. Protestantism, in one aspect, is a revolt against the magical claims of priestcraft; and Chaucer, of course, was a Wickliffite.

When a priesthood is manacled by ceremonies and formulæ, it ceases to have any original inspiration, resents progress and has no remedy for corruption: then, if there is to be any salvation, the Prophet must arise. And since of all trades a corrupt priesthood is the most devoted to the world, the flesh and the devil, as a protest against these the Saint must appear. When Prophets and Saints are persecuted they become Martyrs. Thus is established the ideal of the just Man alone with God, His spokesman and witness against principalities and powers. And, again, with the growth of positive ideas, we find the various elements of this ideal distributed between the Poet or Artist, who is in a manner inspired, and surely to a reflective mind seems a sort of sacred person; the Conscientious Man, who is not dismayed by the opposition of law, opinion or official religion; and the Philanthropist, who has other purposes than those of the world where, 
(3) Amongst the ordinary offices of citizenship, it is obvious that the Judge, Statesman and Nobleman have royal and divine traditions; and that, so far as they fulfil their offices, they live solely for the public good, as Plato would say; though he might add that they usually include the art of wages with their other accomplishments. Aristotle's virtues are an analysis of the character of the Athenian nobleman as he ought to be. In spite of self-sufficiency, he lives under the eye of his fellows for the sake of the City: a necessary consequence of the citizens' having succeeded to the responsibility of kings. No one makes such an analysis for the French, Germans or English, because, from the relative prominence of a priesthood in modern Europe, the gentry are supposed to submit to an educative code; although, in fact, the priestly code does not spring from their manners and does not inspire their life.

(4) Commerce has hardly yet produced an ideal; for the patriarchs of Hebrew epos, and their astonishing bargains with one another and with their god, do not fascinate the imagination of other races; and the Christian doctrine, by discouraging usury and encouraging almsgiving, would have prevented the development of commerce and reduced the world to beggary. In England, however, the traditions of Whittington and Gresham indicate the ideal, namely, having honestly made one's fortune and station, to behave in everything with public spirit and to use one's advantage for the public good. In connexion with Industry the Poet and Artist again find a place as perfect Artisans, and may represent the culture-heroes whom ancient tribes commemorate. Even the humblest citizen is of the kin; nay, a slave, by the universalising Christian sentiment, is of the body of our Lord; and to him also descends the tradition of service and sacrifice. According to Chaucer, the Ploughman (doubtless Piers Ploughman) was the Persoun's brother, a common thing in those days; and

A trewe swynkere and a good was he, Lyvyng in pees and perfight charitee. God lovede he best with all his hoole herte At alle tymes, though him gamede or smerte, 
And thanne his neighebour right as himselve.

He wolde threshe, and therto dyke and delve,

For Christes sake, with every poure wight,

Withouten hyre.

To him also, therefore, the art of wages is necessary.

(5) Whilst all these ideals plainly involve self-devotion, there is, on the other hand, the devotee of Self-culture, who stands for the necessary resistance of individuality to the socialising pressure that might end in uniformity and stagnation. But even this ideal is social; for unless the worth of the individual be preserved, what is the use of the Tribe?

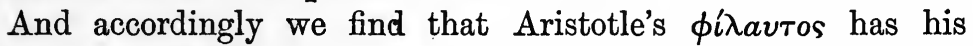
own method of renunciation; for in everything he chooses the better part for himself, even in yielding the doing of a noble action to another ( $N$. $E$. IX. viii.). To the most refined Greek egotism ego-altruism became an illusion for the fact of altruism; what was praised as noble, or rather what reflection

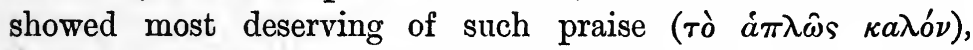
becoming itself an end, involved self-denial. We cannot escape from the service of the Tribe except by degenerating into brutes.

(6) The comparative seclusion of women's life has limited the feminine ideals. To be a good mother is the hardest task in the world and the most responsible; yet it is not enough for the ambition of some contemporary women, who in their rhetorical exercises always class the "nursery" with the "kitchen," and repudiate both as unworthy of their great powers. Other feminine ideals, though few, are well known; such as the Hostess, whom every one views with satisfaction; and the Leader of Fashion, whose function it is to deny herself the joy of outshining others, and to restrain by considerations of grace and beauty the vagaries of luxury and ostentation.

The Mother and the Virgin are united in the God-Mother of the older Christianity; and this union, though a contradiction in nature, and as such an impossible ideal, has had (I think), or may have had, a redeeming influence upon both its elements. May we not say that the virginity of the Mother, whatever sources the notion may be traced to, has refined and 
purified the idea of motherhood as it formerly prevailed, at least amongst some races; and that, on the other hand, the motherhood of the Virgin has, or may have, enlightened many as to the true meaning of virginity? As to physical virginity, every one sadly honours those women who give up the ordinary life of affectionate happiness and care, for the sake of piety and charity, and who take the world for their offspring; but no one could see, without anxiety for the human race, the modesty and dignity of womanhood refusing their heritage to posterity. Let us always remember with dread that, both in thought and feeling, whatever has been last acquired, whatever is most distinctive of our culture and most precious in human nature, is very liable to morbid perversion. The Mother, indeed, is so necessary an ideal, that we might easily suppose it to have been universal and not to have needed the sanction of heaven for its exaltation. The truth is that nothing has needed purification more than heaven itself; and that the purification of heaven and the exaltation of motherhood have happened together. The internal history of these great changes is very obscure to me; but may perhaps be traced partly to the Teutonic family, partly to Christian asceticism, and partly to the amelioration of manners in the course of civilisation.

$\S 6$. But if the morality of the individual depends upon character, for many men-nay, should I not say for all of us? - any considerable degree of morality requires a change of character, a change of heart. We have seen that tribal education, through custom, sympathy and imitation, may bring about not only in action but in thought and feeling, a change of behaviour that is not practically distinguishable from a change of character. But the moral problem is : supposing this process in my own case not to have been effectual, how can I carry it out for myself? Now this question is meaningless unless I desire to grow better; but given such a desire, it need by no means be in vain.

In the first place, in youth, there is always hope. For the doctrine that character is innate or congenital does not mean, so far as it has any scientific foundation, that the character of infancy remains throughout life; that is plainly 
absurd. It means that one is born with a disposition to develop at successive periods a system of feelings and impulses, to act and think according to a certain type. What that type is we cannot know beforehand, except by way of probable expectation, based upon a knowledge of parental and ancestral character, but admitting a wide possibility of variation in degree of energy, in special activities, and in elevation of type (higher or lower), that is, in abstractness, comprehensiveness and plasticity of the spiritual powers. When a child is growing up we can usually observe in him various family traits, but no one's character was ever predicted. The development of character, of course, like that of the body, depends partly upon the exercise of the powers that constitute it. If anything good is difficult to us, we must seek opportunities of doing it; if a bad habit fetters us, we must form a better one. The fact that we wish to improve indicates the possibility of improvement: it implies that the requisite impulses already exist; perhaps it may best be considered as a symptom that the change is taking place.

As long as there is youth there is hope: but youth means the period of development; and we do not know beforehand of any individual how long that will last. It is very variable in different people; and the youth of the mind or, if you like, the brain, is in many people a good deal longer than that of the rest of the body. We cannot assign any positive limit to the natural improvement of character. It is a fact of experience that some people grow nobler and sweeter even in old age.

But, secondly, the exercise of our powers depends upon opportunities of action. New circumstances may excite latent impulses, or increase the energy of impulses already active. To meet people with unfamiliar ideas and expressions excites new sympathies and imitations. To go to school, to leave school and enter upon business, to change one's employment, may be the beginning of a new life. Many people when they marry have no desire of children and even look forward to their coming with repugnance, yet are devoted to them when they do come. So little do we know ourselves before we are 
tried. It amuses me to hear men say they would never have done, or will never do, this or that. It is not true that the sky changes, not the mind, for those that cross the seas : many a useless Englishman has made a capital American. We must therefore seek circumstances favourable to whatever phase of character we desire to cultivate; and, of course, avoid circumstances and company in which our faults flourish.

In the third place, whilst the foregoing considerations take for granted that there is a congenital disposition to development; and that, therefore, there are limits to each man's growth, and that, of course, these limits become narrower with advancing years; it is also true that under pathological conditions a complete change of character may take place. The subject of such a moral revolution usually manifests a different cœnæsthesis or temperament, different impulses and capacities and different dominant ideas; having been grave he is now gay; instead of being a carpenter he is a soldier; no longer married but a bachelor; and he acts accordingly, and can only remember such portions of his former life as agree with his present dominant ideas. In such cases, there may after a time occur a reversion to the former personality, and back again periodically. The extent of the change, the range of mental states affected, may vary, and so may its stability. Something of the same kind happens in religious conversion. The frenzy of a Revival sometimes produces hypnosis, sometimes hysteria, alters the balance of the impulses and emotions and the dominant systems of ideas; the subject is a new creature, born again. In most cases such a change may be only the normal transition from youth to manhood, hastened and modified by religious excitement (E. D. Starbuck, The Psychology of Religion). In those who are already mature, conversion may be directly due to excitement. When such a change has taken place under the influence of the Christian religion, there is usually a marked improvement of character; but, of course, the extent of the change varies and, unfortunately, so does its stability. Time is necessary that it may be confirmed by inward growth.

Now, the pathological change, usually so-called, which may 
amount to insanity, no one will seek; and Revivals are not to be had whenever our moral condition needs one: we can, therefore, only inquire how far similar results are obtainable by our normal efforts. As to the cœnæsthesis, we come to considerations that must excite a smile; it is a fact that, on this account, we often need not a clergyman but a doctor. Many people are nuisances to their friends, incapable and of depraved character, for want of physical exercise and sensible diet. When the conæsthesis is healthy our actions are healthy, and we think healthy thoughts: what we shall remember and imagine, and in what colours it shall come before us, is determined in this way without our care. As to the establishing of new dominant ideas, if with all our hearts we desire it any idea may be made habitual. We may learn to regard ourselves as devoted to our family or our country, and really become so; as dedicated to some good social or political cause, or to art, or science, or self-culture; by reading, by meditating and by living accordingly we may confirm ourselves in such things. Still, looking around me and observing how easy and natural the good life is to some, and how difficult it is to others, I cannot wonder at the pious belief in our dependence on the grace of God, or at the sigh with which Spinoza closes his Ethics, that all excellent things are as difficult as they are rare. 
$\S 1$. EvERY philosophical inquiry takes for granted the unity and continuity of the World; and, therefore, a theory of Morality must show how it stands related to the rest of nature. Gloomy enough some of the doctrines have been concerning this matter: as that the present world is a place of punishment for the transgressions of a former life; or that it is a place of probation and preparation for a life to come; or that it is the expression or phenomenon of the moral life of souls, providing for their manifold degrees of progress or retrogression innumerable lots in all the ranks of human or animal life; or, again, that it is as a whole the blundering expression of an evil Will, witnessing by its misery the crime of its cause; or that it was originally the work of a good Will, unhappily thwarted by necessity, or by our own fault, or the devil's. All such doctrines as these, however vaguely or fantastically they may be conceived, seem to me to be, in their comprehensiveness; essentially philosophical. As much may be said for the noble teaching of Aristotle and Spinoza, that morality is implied in the development of reason, wherein man is likest God and beloved by Him. On the other hand, any study of Morality that fails to assign it a place in the universal order, cannot have that character of comprehensive explanation which is identified with Philosophy. In the present work Morality is regarded as the kind of conduct by which man, as the highest manifestation of life on this planet, may rise to a life far higher and better, becoming free, noble, serene, and wise with the self-knowledge of the World. 
Morality, therefore, as we have seen (C. I. $\S 6$ ) is a science of the means to an End, or harmonious group of Ends; which, if not very definitely, are positively conceived, and are spontaneously desired by men when clearly recognised, and serve to co-ordinate or rationalise all the actions of human life. And since the relation of means to End is merely that of causes (in our power) to an effect desired, it follows that Moral Science is a -study of causation-of psycho-physical causation-and differs from the Natural Sciences not in the quality of its laws but in the limitation of its scope by the End in view. So that it proceeds, of course, by observations of facts, and by reasoning, inductive and deductive, on the facts observed. These facts comprise, firstly, experience of human life and the results of conduct and the Natural History of Conduct, and, secondly, the conclusions of all other sciences under which human conduct in any aspect of it can be conceived. As presented by Spencer, for example (Ethics, Part I.) these data are physical because men, in the most general consideration of them, are moving bodies; biological, because men are living bodies; psychological, because men are consciously active; and sociological, because Society is necessary to human life. As for the reasoning upon these facts, it is subject to the same principles and forms as in every other investigation.

Moral Science differs from the Natural Sciences "not in the nature of its laws, but in the limitation of its scope by the End in view." Is such a proposition reconcilable with Hume's distinction between the predications of fact and obligation, is and ought? Must not the laws of Moral Science always involve the ought, and therefore differ essentially from the laws of Natural Science? No: for that would be to confuse the statement of the scientific laws with the attitude and feelings of the moral Subject. Moral Science is not a system of commands but of the rational grounds of command. The End being recognised and desired, and the Means to it stated in the usual form of indicative predication, " $\mathrm{A}$ is the cause of B," the moral Subject feels that he ought to act accordingly for the sake of the End; or if the action is to be enforced by 
a legislature or other authority, its necessity is declared along with the sanction, and we then have a command. But the feeling of the moral subject, or the command of an authority, rationally presupposes a relation of facts, that such an action is the means to the Chief Good: just as a precept of medicine presupposes the law of the action of a drug, and the patient's desire to get well. This relation of fact Moral Science must investigate, and it is always a fact of causation. But, if so, Causation must be the supreme principle, or axiom, or universal postulate of Moral Science. Henry Sidgwick, in his Methods of Ethics, collated the principles of Kant and Clarke with those of Common Sense and Utilitarianism, and discovered three fundamental axioms common to all moral systems (Book III. c. xiii. $§ \S 3,4,5$ ). The first is involved in Justice, considered as impartiality in the application of general rules: "Whatever action any of us judges to be right for himself, he implicitly judges to be right for all similar persons in similar circumstances." Or, as we may otherwise put it, "if a kind of conduct that is right (or wrong) for me is not right (or wrong) for some one else, it must be on the ground of some difference between the two cases other than the fact that I and he are different persons." A corresponding proposition "may be stated with equal truth in respect of what ought to be done to-not by-different individuals." This principle is less abstractly and accurately stated in the Golden Rule. The second principle is that of Rational Self-Love or Prudence, "impartial concern for all parts of our conscious life. We might express it concisely by saying ' that Hereafter as such is to be regarded neither less nor more than Now.'" Whether it is happiness or any other good that is to be obtained, certainty and other conditions being the same, "mere difference of priority and posteriority in time is not a reasonable ground for having more regard to the consciousness of one moment than to that of another." The third principle is involved in Benevolence: "The good of any one individual is of no more importance from the point of view (if I may say so) of the Universe, than the good of any other; unless, that is, there are special grounds for believing that more good is 


\section{PHYSICAL AND BIOLOGICAL CONDITIONS 97}

likely to be realised in the one case than in the other." These things are self-evident, immediately cognisable by abstract intuition, "the permanent basis of the common conviction that the fundamental precepts of morality are essentially reasonable."

Entirely agreeing with these passages, and recognising their importance both in the reconciling of different schools of moralists and in the logical presentment of Moral Science, it seems to me of equal importance to notice that the principles of Justice, Prudence and Benevolence, are not really distinctive principles of Moral Science but merely forms of the principle of Causation adapted to that department of reflection. For the cause being the same the effect is the same, or where there is no difference in the cause there is none in the effect. But, according to the principle of Prudence, a good has the same value in the present or the future, other conditions being the same; and that is true, because time itself is not a thing or a cause, and can make no difference to any effect. Similarly, the principles of Justice, that "what is right for one is right for all"; and of Benevolence, that "the good of one is as important as that of another," are true, because abstract individuality comprises no difference of causation, and therefore can make no difference to any effect. For the same reasons, however, these axioms stand liable to the same criticism as the principle of Causation, that in strict statement they are inapplicable to concrete cases of conduct, because cases differing only in time or in abstract individuality never occur. It is evidently impossible that any good, whether pleasure, or virtue, or wisdom, should be the same to a man ten years hence as it is now; because, although time is not a cause, it is a condition of the action of all causes, and every man with all his circumstances changes at every moment. And it is obviously untrue that an action that is right for one is right for all, or that one man's good is as important as another's"Socrates and Sambo, Judas Iscariot and Jesus Christ," as Carlyle says - as soon as we consider the differences of persons and cases. Nevertheless, these axioms in Morals and Causation in Physics have the same logical interest of formal generalisation, and the same scientific applicability, if we 
grant the necessary latitude of interpretation. The principle of Justice-that what is right for one is right for all-is especially necessary to Moral Science, as a postulate without which no generalisation, that is to say, no Science, is possible. And the practical use of all of them is, to indicate the irrationality of our disposition to prefer the present to the future merely because it is nearer, and ourselves to others merely because we are ourselves: in both cases the nearer good being the more vividly imaginable, but perhaps the greater by no means.

The moral Categories, likewise, are all defined by Causation. Free Will is the power of acting upon one's own initiative: one's own character being the decisive condition (Metaphysics of Nature, c. xv. $\$ 2$ ). Virtue is the quality of a character so far as it is the free cause of good actions. A Good action is one that is a necessary means to the Chief Good, and implies something amiable or admirable in the agent. A Right action is one that is the necessary means to the Chief Good according to a rule, but requires no more than bare integrity in the agent. A Right is a sphere of liberty or ownership, the public recognition of which is generally conducive to good or right actions. Duty is the necessity of an action in relation to the End, under a sens of obligation that presents no assignable sanction. Merit or Desert-whilst meaning primarily that the subject of them has the approval of the public, or the king or God,-is such a condition of a man that praise or reward is the appropriate means of sustaining or increasing his own efforts or (if that be needless or impossible, as it may be) those of others, in like kind, toward the End.

$\S 2$. The Laws of Moral Science, then, are all reducible to Causation; and, of course, as in other sciences we may distinguish them into Primary and Derivative. Primary Laws state the tendencies of actions of all kinds in relation to the Good, supposing the conditions to be simple and to present no counteracting forces. Derivative Laws state the results of actions when the conditions are complex and the forces conflicting or composite. 
The Primary Laws are those that people usually have in mind when they speak of moral principles and duties. Many of them fall into groups according to the great interests of life, such as Health, Property and Profession, Family, Co-operation, Public Service. Thus under Health come the laws of nutrition, ventilation, action of drugs; under the Family come the laws of eugenics and parental care; under Co-operation come conciliation, fairness in contract and profit sharing, fidelity to contracts; and so forth. Some laws are of a more general scope, such as the tendencies of truthfulness and impartiality and benevolence.

It is perhaps most usual to conceive of these laws negatively, as prohibitions: "No sensual excess," "no parental neglect," "no aggression," "no fraud," "no lying." This leads to the crude notion of "moral rules" by analogy with public laws, which cannot be enacted in any other form and which presuppose a science of conduct. Moral Science is not a system of rules, but a science of the tendencies of actions: which being known, every one must judge what he ought to do. Nothing can do more to darken the subject than to put moral rules in the above prohibitive forms, for it conceals the really important question - What is 'excess,' or 'neglect,' or ' aggression,' or 'fraud,' or 'lying'? In the light of Moral Science, to forbid such things is tautology, for they all connote injurious actions. But such confusion is the natural result of not distinguishing between Primary and Derivative moral laws. For the study of complex cases of conduct immediately shows that an action, which in simple cases is conducive to good, may cease to be so under other conditions. Some forms of constitutional weakness are cured by what would, in ordinary health, be excessive nutrition. The danger of violence may sometimes best be averted by attacking first; which under peaceful conditions would be aggression. A traitor may sometimes be foiled by saying what is not true; although to say the same thing to an honest man would be lying. In all these cases what would be wrong if we had only the direct tendency of an action to consider, becomes right in the given circumstances. 
Such relations of action and consequence are what I mean by Derivative Laws; and the study of such laws is called Casuistry. The mercenary abuse of Casuistry has discredited it; every one knows from Pascal's Lettres provinciales that, in the hands of some of its professors, it had become a study of all possible excuses for an evil life. But Casuistry is an essential part of Moral Science; for without it there is no name of any vice or virtue that can be comprehensively understood, no public guidance for any one who feels that his own conscience is baffled, no definite public standard of behaviour. The most important modern study of Casuistry that I am acquainted with is the third Book of The Methods of Ethics; an invaluable analysis of the perplexities of Common Sense in moral difficulties. Other striking investigations into cases of conscience may be found in Henry Sidgwick's Practical Ethics, in The Principles of Morals (c. vi.) by T. Fowler and J. M. Wilson, and in H. Rashdall's Theory of Good and Evil (Book III. c. v.). The general revival of this study would, no doubt, lead some inquirers into extravagance and absurdity, and display the narrow bigotry that is natural to others. Moreover, a premature formulation of doctrines (such as might perhaps result for a time) always does much harm: especially where successful performance must often depend, as it does in Art and Literature as well as in Morality, upon refinement of feeling rather than upon ratiocination. But, on the whole, general moral enlightenment would probably result. How much licentiousness is now practised and tolerated by the wholly unenlightened casuistry of private or of partizan interests (say) in finance and in politics? How much distress is now occasioned to sensitive minds by the notion of a conflict of duties, under the belief that every simple tendency toward the Good is an absolute duty; whereas one's duty can only be known by reflecting on all the circumstances of one's case and finding the resulting tendency toward the Good? It is true that this cannot always be determined; but it is a great gain to perceive that our difficulty is an objective one, that we have done our best to resolve it, and that failure is not voluntary. How much mischief is now done by the fanatical 


\section{PHYSICAL AND BIOLOGTEA CONDTIIONS' 101}

belief that we are concerned only with the primary and immediate tendencies of our actions and ought to disregard the consequences - to "act upon principle," in fact: which rightly means not to act upon some abstract rule but to act with a single eye to the moral End.

It seems to have been this distinction between Primary Tendencies and Casuistry that Spencer had in view when he opposed Absolute to Relative Ethics. $\mathrm{He}$ entertained the extraordinary notion of an Absolute Ethics which could only be known and realised in the Ideal State; although his Ideal State had no content but this, that it must present the conditions of Absolute Ethics. He compares Ethics with Astronomy and Physiology; but no one supposes that we have an Absolute Science in either case, or need for the investigation an Ideal Heaven or an Ideal Animal: It is incomprehensible to me how he could miss the more obvious scientific analogy of "abstract tendencies" and "derivative laws"; especially as Mill and J. E. Cairnes had shown that these conceptions give the clue to the logical character of Economics.

$\S 3$. As to the proof of moral laws, it presents all degrees of difficulty. Some of them have become, as formulæ, so much a matter of course that to give reasons for them may seem superfluous; but in an educated or half-educated Society, nothing is secure against attack that is not scientifically grounded. The fact is that because Morality has been taught by rule and as of supernatural derivation, there is no subject about which the majority of men, even in civilised countries, are so unenlightened. Thousands of sermons are preached every week; and even those who doubt whether oral instruction can have much direct effect upon conduct, must admit that it is a capital means of explaining a subject; yet morality is not generally understood. One wonders what all the sermons can be about. To refer Morality to conscience saves a lot of trouble; and "to follow conscience" may be at present the best practical advice to the well-nurtured; but it does not enlighten the conscience, which is one purpose of Moral Science. This is a case in which timidity checks inquiry; 
because there is a narrow-minded type of believers to whom the explanation of a tenet is equivalent to its refutation. Besides, the evil done by some actions, such as lying and dishonesty, is so obvious in simple cases that it is in some sort intuitively plain; and we readily take the same view of other cases which, under education, we are accustomed to think of as in the same class with falsehood and theft; but this is often illusory, as we become aware when asked for reasons.

At any rate, if Morals are to be rendered scientific they must be treated of by the usual scientific methods. Proof requires the combination of deduction with induction, of reasoning from the nature of the case with verification by experience; and we may proceed either by the Historical Method, collecting laws of the effects of conduct from experience, and trying to deduce them from what we learn of human nature from Biology, Psychology and Sociology; or by the Physical Method, computing the resultants of the known tendencies of actions and verifying them by experience. The laws of health and eugenics, taken from Biology, will for a long time have an increasing interest for Morality. Consider how the removal of adenoids sometimes completely changes the subject's mental and moral traits : a thing easily understood, because the metabolic process is fundamental in organic life and depends upon breathing. The operation, therefore, renders possible a fuller realisation of the subject's innate capacities. Had Napoleon Buonaparte suffered from adenoids in his youth, the whole face of the world might have been changed as effectually as if Cleopatra's nose had been a little shorter. Now probably all of us have greater capacities than we ever realise. The causes of our restricted development are largely social inhibitions; but others are physiological; and if they can be discovered, a far greater improvement may be made in individuals than has ever been wrought by education. The law of parental care is primarily biological: parental care, when once it has appeared in the world, increases with the increasing organisation of animal life; and this must be so, because the attainment of higher individuality requires longer youth and, therefore, longer protection: but the particular direction of such care in human 
life depends upon the kind or degree of culture that has been reached by different societies. The conditions of co-operation, fairness and fidelity in contract, are, as Spencer has shown (Ethics, Part I. c. viii.), both biological and social ; for everywhere in animate nature the division of functions, or of labour, demands that all work, inasmuch as it involves destruction of tissue, must be repaid in order that the structures may be repaired. Truth-speaking, again, is a transfer of knowledge; and knowledge is a condition of effective action : truthspeaking, therefore, is necessary to effective co-operation.

In such simple cases as these it is easy to find confirmation of the deductive argument in human experience; for the evil consequences of neglecting the laws of health and parental care, or of practising cheating and lying, are a matter of daily observation in a sufficient variety of circumstances. More labour is involved in investigations by the Historical Method, because of difficulties in ascertaining the facts; but tentative beginnings should be made wherever the facts are obtainable. There is an important investigation required into the correlation of moral qualities: a preliminary difficulty occurs in distinguishing and defining the qualities to be compared, then there is the work of collecting, analysing and generalising the facts, and, finally, of tracing to their psycho-physical grounds any connexions or disconnexions that may be discovered. It is not probable that groupings of good or bad qualities that show any constancy are accidental; but unless we show (as the historical method requires) why $\mathrm{A}$ and $\mathrm{B}$ are connected and $\mathrm{B}$ and $\mathrm{C}$ opposed, our results are merely empirical, and our confidence in applying them to problems of education or marriage must be feeble. Some inquiries have been made into the correlation of certain forms of misdemeanour, crime and insanity - such as drunkenness, sexual perversity, theft, fraud, violence; and it is well to begin where the facts are conspicuous, and a body of statistics is immediately obtainable.

The growth of the Natural History of Morals in such works as A. Sutherland's Origin and Growth of the Moral Instinct, and E. Westermarck's Origin and Development of Moral Ideas, is accumulating immense piles of material for 
the Historical Method. We may perhaps learn from it the correlation of moral qualities in the characters of nations. We see that no particular moral practice or belief is universal, because beliefs and practices are in each case adapted to tribal conditions. We see, too, that such conditions are often themselves other beliefs, traditions, ancestral influences, rather than present physical or political facts. Morality appears from such evidence not to depend essentially on Religion or Law; since it is rarely or never identical with them and in fact precedes both, having its own organisation of tradition and instinctive feeling. Following up the development of moral beliefs, we find that irrational forms are characteristic of barbarous societies, and that they approximate to rational forms as civilisation advances (e.g. in the infliction of punishment): a fact which seems due partly to the development of reason itself and partly to the growth of effective sympathy. As an aspect of general History, the Natural History of Morals should give us a clue to the causes of national progress or degeneration. It may enable us to trace the effect of particular virtues or vices, as well as of laws and institutions, upon the general national welfare. Perhaps by studying the whole course of historical change we may venture to forecast the future of mankind; as, for example, L. T. Hobhouse does in the closing chapters of his Morals in Evolution.

When we turn to complex cases of personal conduct, or Casuistry, the difficulty of proving any theorem concerning the relation of exceptional actions to the public welfare increases in an extraordinary degree. The method pursued hitherto has been chiefly ratiocinative. And this has been due, partly, to a mistaken imitation of legal arguments : though the conditions are quite different; since in Morals we have no settled laws and rulings upon complex questions to which to appeal, as in a Court of Justice: the case is more like legislation, and must appeal to facts. But, partly, the resort to mere ratiocination is due to the conditions of the problem; it is so difficult to find the requisite facts, or anything like ' control experiments.' The old doctors tried to strengthen their arguments by quoting authorities and pious opinions; but for us there is no resource 
but the scientific plan of analysing material evidence. The labour of research to find the evidence in history and memoirs must at first be very great; but the purpose to be served, the enlightenment of the public conscience, is proportionately great, and worthy the dedication of many lives.

$\$ 4$. Returning to the position that Moral Science is a study of psycho-physical causation, it follows that human conduct may be considered under the sciences of Nature so far as it presents the phenomena of which they severally treat. Spencer in his Principles of Ethics (Part I. c. v.) enforces with frank naturalism his own theory that Morality or Conduct exhibits the marks of every process of evolution; that it begins with actions that are relatively homogeneous, indefinite (or unspecialised) and incoherent, and tends towards a greater coherence, definiteness (or specialisation) and heterogeneity : in other words the cultivated man does a greater variety of actions than the savage, adjusts them better to their ends, and arranges them better so as to concur and not to frustrate one another. And in the course of these changes in his conduct, a man (or society of men), like every finite system of forces, advances toward a state of equilibrium : at first, and so far as he lives, toward a moving equilibrium (of the metabolic process) of ever longer duration and greater "breadth," that is, requiring a greater multiplicity of concurrent adaptations; until at last death, or temporary stable equilibrium, is reached.

It is difficult even for a hardened student of the physical sciences not to smile at this proposal to begin the discussion of Ethics by considering man as a moving body; still, as he certainly is a moving body, and a system of moving bodies, one should rather be surprised at oneself for not having already considered what must follow from that fact. Something of the kind, indeed, may be found in Cumberland's Laws of Nature, c. ii. It shocks me the less that I hold everything in the world to be psycho-physical, and nothing to be adequately described as merely a moving body. To consider man as an animal has become common enough ; and many will be ready to admit that moral conduct is an adaptation of human beings to the conditions of human life. But this zoological conception 
of human life differs little, if at all, from the mechanical; for the conditions of inorganic evolution and of organic evolution by natural selection are nearly the same. The boundless fertility that Darwin observed in plants and animals corresponds to the innumerable atoms assumed by La Place; the struggle for existence is parallel with the clash of atomic forces; organic variation is a special case of what Spencer calls the "multiplication of effects" (every force produces in its incidence more than one change); survival of the fittest is motion in the direction of least resistance; and the adaptation of an animal certainly consists in the establishing of a moving equilibrium. I cannot, indeed, perceive in inorganic bodies any adequate analogy to heredity; but, otherwise, it seems that the acceptance of a zoological theory commits us to a physical theory of human life, so far as a man is a moving body.

We shall not escape from this conclusion by urging that the special character of human life is the adapting of other things to our uses, for many animals do the same; nor by reflecting that the chief conditions of the environment to which we are adapted are to be found in society and our relations to other men, for in this too many animals have anticipated us. A great distinction of human life is its adaptation to remote conditions, especially to conditions remote in time. Some animals, it is true, provide food for the winter, and make other preparations for the future, in an instinctive way. But we lay plans for our careers, for old age, for our family and our country, and are unhappy at the thought that the final lot of the race is beyond our power of interference. It has been one of the great functions of Religion to accustom us (or some of us) to live for remote, comprehensive and obscure ends, under the guidance of animistic ideas, before it had become possible (if it is yet possible) for us to form definite ideas of the end to be attained and of the means or causes by which it is to be brought about. Still, since ideas of remote ends would effect nothing without the growth of powerful sentiments corresponding to them, such sentiments are (as I have observed) necessarily amongst the differentiæ of human nature; that is, moral sentiments. Their existence and power close the by- 
paths of caprice and depravity, and drive us on to act for remote and impersonal ends in spite of deterrent or seductive motives derived from near and vulgar suggestions ; makes such action, in fact, a path of least resistance. Hence ideas of remote ends, themselves derived from past experience, depend for their effcacy on present forces; moral forces with their physiological correlatives ; and, thus conditioned, their efficacy is by no means inconsistent with a mechanical theory of human life so far as man is a moving body. Are they not notoriously means of prolonging life, of maintaining the moving equilibrium?

Moral theory has a double interest in evolution, namely, as it concerns the individual, and as it concerns Society. To both, according to Spencer, the formula applies, that they grow in bulk with a loss of internal disturbance, pass from the homogeneous, indefinite, incoherent state to the heterogeneous, definite and coherent; and tend to establish a moving equilibrium for an ever longer time. Now, even granting this to be a natural law, it does not follow that we ought to accept it, and endeavour to carry it out. But it is not merely a physical or psycho-physical law : the tendencies described by it are well known under other names, almost universally amongst men, as exciting correlative desires. As for the "moving equilibrium" (or life), that one's days may be long in the land lies perhaps deeper in our hearts than any other hope : it has been called 'the first law of nature'; Aristotle says a complete life is necessary to happiness; and Spinoza, that to die young and immature, not yet capable of eternal thought, is lamentable. To become 'heterogeneous' (as the context shows) is nothing else than to develop all our faculties, and Kant says that this is what every rational being necessarily desires. To be 'definite' is to adjust our actions well to Ends, to be exact in the discharge of our duties, the sort of platitude that is dear to moralists. To be 'coherent' is to behave in such a way that our actions aid and do not frustrate one another, that we aid and do not frustrate the rational actions of our neighbours: it is, as Kant would say, the idea of a will universally legislative. All these tendencies, then, being necessary objects of desire to rational men, are necessary 
elements of the total Good; and there is no question whether such desires shall be entertained, but only as to the proportion in which they should be gratified: how far, for example, our desires for length of days and the development of our faculties as personal ends, are compatible with our social duties. They are certainly not inconsistent with any conception of the Good that has ever been expounded; and since we do not yet know enough of man and his future to define the Good accurately, a similar indefiniteness must be the lot of the elements of the End that seem to be indicated by the general formula of evolution.

Socially there is a parallel difficulty. For the State, also, length of life, variety, cohesion and the specialisation implied in it, are certainly desired; but in what relation they stand to wealth, virtue, culture, is not clear. Cohesion (the most essential consideration) is attained in many different ways, by police, by cajolery, by agreement of interests or by a common devotion to the Good: which is the best plan? Of the last it may be said that, physically, it involves the greatest security and the least waste of energy. It is most in favour with the philosophers; for Plato says (Rep. 590) the purpose of government is to train mankind to be friends and equal, as far as may be possible in nature; and Spinoza (Eth. IV. App. IX.) that in the State men are at first ruled by fear, but to the end that they may be led by reason; and this is also the view of Kant and of Spencer. Social cohesion, then, goes along with virtue and wisdom. The prophets are of the same mind, preaching purity of heart as the condition of the Kingdom of Heaven. And this they preach to all men, assuming, as most of the philosophers do, that ideally, or in the development of human life, all men alike are capable of it.

But if we are to draw our inferences from the facts, it must, I fear, be acknowledged that we do not know enough about the future of the world or of the human race, to be sure of the perfectibility of man, or that the tendency of history is toward an equal development of individuals, and not to a greater differentiation of superior and inferior races than has ever yet been known. And if we do not know what is 
probable, or even possible in future history, can we rationally determine what ought to happen in the evolution of the State? What ought to be the grounds of its cohesion, what the degree of specialisation in its members? In spite of a strong direction of sympathy and of my wishes in this matter, I find a difficulty in saying that that ought to happen which may be impossible. Can liberty, fraternity and equality be the conditions of equilibrium amongst citizens, if their personal forces remain unequal? And must they not remain unequal, unless by the careful breeding of mankind those people are eliminated, whose presence makes liberty impossible and equality absurd?

$\S 5$. Turning from physical to biological principles, it is plain that natural selection must in every tribe produce some sort of manners as conditions of gregariousness, and that these must (as we say) improve as tribes increase in internal complexity and cohesion. It is also plain that such manners will, on the whole, carry with them corresponding morals, or dispositions to observe them, as simpler and easier conditions of their observance than universal hypocrisy or coercion would be. It is equally plain, however, that the average manners and morals of every civilised people are very inferior to the theoretical enlightenment of its leaders; and that this theoretical enlightenment is not directly due to natural selection, but (in the first place) to the impassioned insight of prophets or moral geniuses, who see why the soul is sick and how it must be healed, and (in the second place) to analytic reflection upon the conditions of human life. Indirectly, however, natural selection bears upon theoretical enlightenment; for since natural selection operates upon advantageous variations, endemic variability in any tribe is itself advantageous (short of the point at which stability is frustrated), because it supplies the materials of selection; and one result of variability is the production of great men, amongst whom are prophets. So far, again, as a prophet's teaching is true and effectual, it probably gives an advantage to his tribe.

In the method of their development, psychologically considered, moral ideas and principles do not differ from other abstractions and generalisations ; and cosmologically they may 
possess the same significance as scientific theorems have in the rise of Nature to Self-consciousness. In their practical realisation they depend, first, upon the average susceptibility of the people to whom they are delivered; secondly, upon the degree in which tribal success is conditional upon the morality of the tribesmen and unobtainable by other means. The prophet who comes to a tribe in which the average man is sensual and worldly, will find himself most at home in the desert. If cunning, persistency and legality will ensure success, the average man may succeed in spite of the denunciations of the prophet. In every tribe there is a great inert mass of men and women (of whom the women have hitherto been much the more inert) that resists every reform. The power of a prophet to move mankind is a special case of the effect of oral teaching; and this is practically nothing, unless it can be associated with very strong feelings. A preparation for the excitement of such feelings must pre-exist, if anything great is to be done: an obscure stir of desire and impulse, which the prophet may direct by the guidance of his ideas. Such a state of things is (I believe) usually brought about by national calamities, or social distress, or glaringly bad adjustment of classes or professions: as may be seen at the times of Wesley, Rousseau, Luther. "The great prophets of the eighth and seventh centuries [B.c., in Judæa] by the spiritual ideals and the ethical fervour of their teaching had wrought a religious and moral reform perhaps unparalleled in history " (J. G. Frazer, Adonis, c. ii.). What were the tribal conditions under which this happened? In every great movement oratory, however impassioned, is vain apart from the susceptibility of those addressed. To find the conditions of this susceptibility in every case is a much-needed historical investigation.

Another equally needed investigation is, to find what connexion holds between personal or tribal morality and personal or tribal success. A positive connexion is too easily assumed by pious authors, and too flippantly repudiated bycynics. The utility of such virtues as prudence, courage, loyalty is highly probable, and it is easy to see why; but how far is tribal success connected with the general prevalence of effective sympathy, or with 
different forms of effective sympathy? No virtue is now so generally inculcated under the names of unselfishness and altruism: but it seems to me that the simpler forms of altruism-pity and generosity - however amiable, may be extremely injurious. It is clear that amongst tribes or nations an immense predominance may be obtained by one that is conspicuously wanting in some moral qualities: for example, the Romans and the Turks. But it may be said that unless a conquering people has some virtue besides courage, their success has no permanence; that the nations overcome (unless numerically very inferior) are generally the more corrupt; and that hitherto the general result of international struggles has been (so far as we can judge impartially) to establish better types of national morality. As to the future, it is often assumed that the spread of peoples and of their influence by war and conquest will soon cease; and that, instead, their predominance will depend upon success in industry and commerce. It is also assumed that with the decline of militancy, the heart of man will be so purified that industrial unfairness and knavery of every kind will also come to an end. Why? For my own part, except in such general terms as that, in the long-run, there must be an advantage in the system of policy or industry that works with most economy and least friction, and therefore excludes aggression and knavery, I will not venture upon any forecast. We seem not to have the knowledge or the resources of method that might justify one in trying to anticipate events; but it is my persuasion (though I cannot justify it) that, for a long time to come, the lot of mankind will exhibit changes as rapid and as astonishing as any that have ever been endured.

The practical lessons to be drawn from Natural Selection with a view to moral improvement are (1) to make such social arrangements that integrity and magnanimity may prosper, whilst sensuality, parasitism, fraud and violence may be discouraged; (2) to give more care to the breeding of mankind. The first plan is carried out very imperfectly by sumptuary laws and police administration; but the essential method is to secure a steady improvement of the environment. 
Town or country life or prevailing kinds of industry may be favourable to the higher or to the lower strain of national character; and so to the prevailing mental and moral qualities. Above all, liberty is favourable to enterprise and self-reliance. But as in Nature certain conditions are favourable to parasitism and predatoriness, so some states of Society are favourable to paupers, do-nothings, impostors, thieves. This depends partly upon general education and enlightenment, partly upon the average character; for sometimes thoughtless pity and generosity and mistaken piety encourage begging and laziness; sometimes there is even a widespread sympathy with criminals. Such sympathy is sometimes due to the long prevalence of bad laws, sometimes to a low average of personal development that can hardly be cured by any devices hitherto accepted.

The second plan, to give more care to the breeding of mankind, was long ago recommended by Plato, and has been practised by many barbarous tribes, though in ways that we should think brutal or licentious. It may proceed positively, by endeavouring to propagate and encourage what are considered to be good strains of blood, and this has been called Eugenics, or negatively, by the extirpation of what are considered to be bad strains; or in both ways. The difficulties of both theoretical and practical Eugenics are too obvious. According to some proposals, youths who are probably vehicles of good blood should be endowed and encouraged to marry and propagate; but (not to say that the ability to make one's own living is a promising quality) this course, involving expenditure of public money, requires in England an appeal to Parliament, which at present would certainly reject it. Opinion must first be influenced; and the chief means of influencing it, politicians' speeches and the newspapers, will give no help. They care for no schemes that do not hold out hope of immediate tangible gain: very few amongst their audiences can appreciate anything else : and this they call being 'practical.' Incorrigible blindness to remote ends, or perversity in rejecting them, is characteristic of low development; and this is why the human race has fallen under the power of mythological 
and social illusions that often secure remote ends without our desiring them : it is the same root that nourishes most of the vices. In default of parliamentary intervention, it has been proposed to appeal to a more select audience, to influence those who are immediately interested by the superiority of their own blood. Lists are to be made out of families distinguished for their achievements, the ability of those now living and the record of their ancestors and correlatives. The belief is to be inculcated that their blood is a racial possession to be sacredly guarded and only transmitted by intermarriage with their equals. There is nothing impossible in this proposal; such a sentiment has prevailed and been, for a time, effectual with every aristocracy. The eugenists merely want to alter the traditionary meaning of "aristocracy," and fall back upon the derivation; but powerful and numerous are the interests opposed to such a change. Not only those noodles of rank and fashion who have no claims to superiority except fashion and rank, but the great democracy will resent it. Democracy suffers extant aristocracies, sanctioned by possession, tradition and remote reverberations of old religion, with wonderful patience and humility, nay, with round-eyed, open-mouthed admiration, pathetic to contemplate. If offended, Democracy can laugh and say, "After all, what a sham it is!" But a new aristocracy of the "twice-born," based not upon office, wealth or titles but upon personal superiority! The less disputable, the more insufferable. Did you ever hear of "the intellectuals," and consider how that phrase of scorn signifies the resurgence of everything vulgar, stupid and brutal in the baser sort? Let the "intellectuals" beware: they are very few.

Practically, I think it will be the wiser course, at first, to disseminate unostentatiously the ideas of Eugenics, in the hope that they will take root in the minds of promising youth, and gradually form a rational distaste for moral mésalliance. In particular cases one may perhaps venture to say: "Who is her mother, my boy? Would you have married her?" or "My dear, have you considered young Hopeful's father?" and so forth. "You suppose, no doubt, that you are to marry an individual: there is no such thing. That is an 
illusion brought upon you by Nature, because she wants to have you married anyhow, hoping to kill your offspring if they happen to be failures, caring not at all. Really you marry a family, and take not only their social odour, but their pedigree, and that not a mere heraldic list of names, but series of actual rogues and fools, or (by the grace of heaven) something better; who, though their 'peripheries' be underground, are (believe me) no more dead than yourselves."

As time goes on and a scientific theory of heredity is defined and established, any nation that earnestly desires its own welfare will, no doubt, make reasonable marriage laws. Francis Galton has shown in how many ages and countries laws of marriage that seem to us strange or oppressive have been accepted with subjective conviction under "immaterial motives" (Sociological Papers, 1905). It has been objected that such motives are religious and out of date; but I should say that the power of religious motives, apart from political and social sanctions, is difficult to estimate, and has generally been over-rated.

Theoretically, many objections have been raised against Eugenics: as, for example, that its ideas are still worked out very imperfectly : which is true, but irrelevant, unless some one proposes immediately to act upon them. Any one who doubts that they will be worked out, must be very dense. It is said, again, that the best type of man to breed cannot yet be known. But it would be an absurd misunderstanding of Biology to propose to breed one type of man; there must be many varieties. And this leads me to say that the evidence hitherto adduced in support of the inheritance of ability, may perhaps give the public a false impression, having been drawn chiefly from official, literary, scientific families because the facts in their case are the most easily ascertainable. Surely, the greater part of the ability of this country is absorbed by industry and commerce, and that ought to be made plain to everybody. Others have urged that qualities are so intermixed in human nature that the problem of breeding to improve certain qualities, as we do with dogs or horses, is incomparably complex. But this is to misconceive the present 
purpose of Eugenics: which is, to preserve the riches of human nature now existing. To attempt to breed for special qualities may be left to future generations, if they see fit. Here again, perhaps, the critics have been misled by the prominence given in eugenic discussions to literary and scientific families that display special qualities. There is more force in the objection that, from the great complexity of human nature, any caste artificially produced must be very unstable. When we consider how easily domesticated animals revert to the original stock, it is discouraging to think for how many generations a eugenic policy must be maintained in order to establish secure results. The risk of crossing with families not "twice born" must also be very great: the importance of isolation, if selection is to work effectually, is well recognised.

On the whole, I should say that positive attempts to improve the breed, unsupported by extensive elimination, would be quite useless. It could at most produce a caste; and the merits of that are not worth arguing. Elimination means the segregation or sterilisation of 'the unfit,' carried out persistently upon a considerable scale. The proposal has been made to begin by segregating for life criminals and paupers, just as we do lunatics (a class which ought to include many imbeciles now at large): and if we had the sense of a dodo we should set about this at once. Besides protecting.future generations, it would give immediate social relief. It follows, indeed, from the laws of variation and of reversion to the mean, that the purgation of the breed by such methods would not be as rapid as was once hoped for ; but it would be real and, with due persistence, would become more and more effectual. As for practical difficulties, the above proposals would be received by the outcry of that sort of pity and generosity that never sees beyond the present object; not to mention the feelings of the Unfit and their relatives, many of them electors. I do not believe, however, that such opposition is insuperable; there are already signs of its giving way. Few can hear patiently the declaration that it is inhumane to check the breeding of vice and imbecility; or that the feeblest or worst of mankind have a right to bring 
children into a world where they are sure to be miserable and likely to be vicious. Such doctrines are immoral; by some Society, and probably before long, they will be put aside; and everlasting honour is reserved for the Society that sets the example. Although redemption is a religious idea, it is a moral problem; and here Biology may do more for mankind than Moral Philosophy has ever accomplished.

$\$ 6$. Spencer thought it essential to his theory of morals that success in life, longer, wider life, should coincide with pleasure and increase of pleasure (Ethics, Part I. c. iii.); and Aristotle said it was vain to argue whether pleasure or life should be preferred, because they are inseparable (Nic. Eth. X. iv.). Their inseparability is cardinal for Utilitarians; since, otherwise, the first principle, "to seek the greatest Happiness," may be in conflict with that fundamental instinct the love of life. Any doctrine, however rational it might seem, that threatened to shorten life would certainly be unpopular. To avoid actual pain a good many people might be willing to die prematurely; but if the evidence only pointed to this, that the shorter life would give the maximum of pleasure, it would be impossible to argue them out of a single fortnight. "Never mind the maximum, good Moralist" (they would say); "deduct, if you like, something from the sum that you know so exactly how to calculate ; but let me breathe the Spring again, and yet once more let me hear the thrushes singing in the rain."

It seems to be generally assumed that healthy life, on the whole, coincides with pleasure; but Schopenhauer and the other Pessimists declare this to be an illusion. Life, they say, is a continual repetition of the vital series-desire, effort, satisfaction or failure; desire is painful, effort is painful, failure is painful; and satisfaction is at best a momentary relief, followed by disappointment. Desire and effort are blindly instinctive with the incurable folly of hope; the relief that follows upon their success is called pleasure but in fact is an empty negation. You may tell these philosophers that in your experience pleasure is qualitatively different from pain and equally positive; but they will content themselves with pointing out that their theory of illusion gives a sufficient 
account of what you call your "experience." The most thorough examination that has ever been made of this doctrine may be found in James Sully's Pessimism; and to that work I must refer any one who is inclined to think Schopenhauer's doctrine plausible; contenting myself with addressing those who share my illusion that pleasure is a positive feeling and generally predominates over pain in a normal life. We shall probably agree that desire is pleasurable unless it is thwarted, that effort to a considerable degree is thoroughly enjoyable, and that the satisfaction of success is as good as we deserve; whilst thwarted desires, overstrained efforts and dull satiety belong to the ill-adjusted life, too common certainly but by no means universal.

Spencer's arguments in favour of the coincidence, or the tendency to coincidence, of pleasure with life, are three. First, pleasure accompanies the increase, pain the decrease, of vitality. It is interesting to observe how many speculative thinkers have assumed this connexion (e.g. Descartes, Hobbes, Spinoza, Kant), which now seems to have been experimentally established. On the ground of experience it is an ultimate fact of the correlation of mental and bodily processes. To be sure, essential vital processes-breathing, circulation, digestion-go forward, increase or diminish, without any distinct consciousness of them as either pleasurable or painful, except in certain states that are painful. But although there is little distinct pleasure or pain accompanying normal changes of breathing, circulation, digestion, yet the cœnæsthesis is affected-our general sense of well-being or distress-and the connexion between this and all our other pleasures and pains is decisive. Our consciousness of the visceral processes by way of feeling is much greater than by way of sensation; and a persistently disagreeable cœnæsthesis is mortal.

Secondly, says Spencer (Psychology, §§ 124, 126), since throughout the animal kingdom pleasurable activities are sought and painful ones avoided, if the pleasurable were not favourable and the painful injurious to life, animals would be formed for their own destruction. It follows, therefore, from natural selection that those living creatures in whom pleasure 
accompanies useful, and pain injurious actions have a great advantage over any in which the reverse relations hold, and must overcome them in the struggle for existence. There must be, then, an universal tendency for the good life to be a happy one. But against this doctrine Henry Sidgwick argued in his Lectures on the Ethics of Spencer (L. II.) that, a priori, we can only infer that preservative actions must be less painful than injurious ones: the animal kingdom might have been governed by pain only: it is not, therefore, necessary that pleasure should coincide with life, or even exist at all. A just argument, it seems to me, against any claim to work out a hedonist system by non-empirical methods, but having very little bearing upon the relation between pleasure and life for those who admit that, as a matter of fact, there is not merely a choice between more or less pain, since pleasure is a positive experience. Especially, whoever accepts the law of self-conservation-so far at least as that 'pain accompanies decrease of vitality'-must admit that, if there were only degrees of pain in experience, even could life begin in such a world it must immediately decline and soon perish.

It has also been urged by William M'Dougall (Phys. Psych. c. viii.) that, at any rate, Spencer's argument requires the admission that consciousness is a mode of energy (which, in fact, was Spencer's opinion); for unless the appetition of pleasure and aversion from pain are actual causes, the physiological processes concerned would have been just as certainly favoured or suppressed by natural selection as furthering or impairing life, even though the favourable processes should "have been painful and the injurious pleasurable, and although in that case the progress of organisation would have brought a constant increase of misery. Therefore, if we derive the connexion between life and happiness from natural selection, we must admit that consciousness (at least in the modes of pleasure and pain) is an equivalent of physical energy; or, as the only alternative, regard the connexion as the work of a benevolent Creator. Now, for my part, I accept the argument against the derivation from natural selection of any connexion between physical and mental processes: consciousness, in 
my view, is not a mode of energy, and therefore cannot be explained by any physical hypothesis. But neither can any explanation be given by a supernatural hypothesis. Whilst holding that the least assumption we can make in Metaphysics is, that pleasure and pain, like all modes of consciousness, are actualities of the transcendent Being of which an organised body is the phenomenon, still, if asked for scientific evidence, I regard the detailed correlation between physiological and psychical processes as merely a matter of fact and induction. Not to be able to deduce the connexion between pleasure and life seems a failure of method only through our not observing that (strictly) deduction from physical laws such as natural selection is possible only in the region of physical phenomena. That Spencer overlooked this limit to his method does not, however, impair the inductive evidence as to the general coincidence of pleasure with life-serving activities: a connexion which is indisputable in the case of all animals except man.

Thirdly, Spencer argues that if useful actions are not pleasurable, they tend to become so by practice and heredity (Ethics, § 33). The biological dispute raised by this last word 'heredity' (that is, whether the effects of practice can be inherited) need not delay us; since, assuming that the pleasure that comes with practice is the correlative of smoother working, it is evident that offspring, varying in such a way as to fall most easily into the same habits, must have an advantage, and a more pleasurable life than others. It is chiefly (or most conspicuously) in human life that this case presents itself. The useful and even necessary actions that are painful to us are chiefly connected with industry, and are due, as Spencer explains (Ethics, $\$ 35$ ), to the rapid change of industrial conditions that in recent years has affected a great part of the world and especially our own race. In little more than a thousand years we have passed from outdoor, irregular occupations, to which we were well adapted, to indoor (for most of us) and regular occupations of too long hours. There has not been time enough for organic adaptation to take place nor, therefore, for the correlative change of feelings, without 
which the new conditions of industry cannot be pleasurable. By degrees this disorganisation may be cured; but meanwhile many people must look for the reward of labour in its consequences, without obtaining normal enjoyment from the labour itself.

We must, then, qualify the principle 'that life-serving activity tends to be pleasurable' by admitting that it may not become so if the correspondence is disturbed by rapid changes in the environment. These operate from one side, as ill health may operate from the other. But Sidgwick says (op. cit.): Suppose that the changes of industrial conditions continue. Then, plainly, there can be no settled adaptation and no correlative happiness. In fact, the re-establishment of equilibrium, such that the working of the psycho-physical organism shall be smooth and normally pleasurable, requires some approach to what J. S. Mill called "the stationary state," and that such a state of society shall last, as the old hunting state lasted, for thousands of years. But Sidgwick's argument merely raises the improbability of this occurrence (the advent of a stationary state); it makes nothing against the tendency to adaptation alleged by Spencer. And as to the actual future of industry, the adaptation to it of the industrial classes will depend less upon the kind of industry-more or less machinery, or even more or less indoor or outdoor-than upon the demand it may make for regularity, persistency and energy. Now regularity is already required (though not always given) in a high degree; and throughout the Teutonic countries, at least, the tendency at present is to shorten the hours of labour and diminish the physical task. But the continued realisation of this tendency depends upon whether Socialism is to prevail (for this, in my judgment, would put everything back), upon the progress of inventions and upon the exhaustibility of the planet's raw material.

One cause that intensifies all industrial difficulties and originates many of them, is the pressure of population. Of this Spencer says that it tends to disappear as the organic level of the human race rises: because it is a law of animal life that fecundity varies inversely as individual development 
(Biology, Part VI. c. xiii.). But, certainly, the establishment of equilibrium between population and industrial productive power must be very remote, as long as Society refuses to undertake a rigorous elimination of the unfit. And, meanwhile, the fact that the intellectual classes limit their own families defers the attainment of a natural balance, because the increase of population comes from the lower strata of personal development, and especially from those who have the strongest sexual impulses.

As to other cases, besides the industrial, in which there is a non-coincidence of pleasure and pain respectively with useful and injurious actions, such as indulgence in alcohol and injurious drugs, it has been shown by Archdall Reid that, under free conditions and given a sufficient time, natural selection eliminates those who do not acquire an organic distaste for excess in the use of alcohol. But, of course, if indulgence is prevented by sumptuary laws, natural selection cannot operate; and again, to take a minor case, if injurious objects are so rare in nature that there are not enough occasions of eliminating those who like them (arsenic, for example, happens to be sweet), there is no remedy but to learn their properties and abstain prudentially.

By way of objection to Spencer's sanguine expectations of future happiness for mankind, it has been said that, since in the progress of organisation there is a tendency for conscious processes to become reflex or automatic, human life may at last become mechanical, suffering neither pleasure nor pain. But this suggestion is hardly serious; we know no case of any animal becoming thus mechanically adapted, and in our own organisation of habits there is no loss of consciousness, for the perfecting of a habit liberates consciousness in other activities. The gradual desiccation of the planet, the elevation and subsidence of lands, the weathering down of all mountains, the lengthening of summer and winter alternately in opposite hemispheres, with other geological and astronomical changes, will keep us awake for a long time to come: to say nothing of social and racial changes that will keep mankind in lively occupation for many a century. We may suppose that the 
planet will at some hour enter upon the conditions that are most favourable to human culture, and thereafter deteriorate; and that posterity must then degenerate, or cease to marry, or maintain a struggle increasingly painful in ever dwindling bands; until the light of reason, which then perhaps will nowhere else illumine the solar system, shall go out, and leave it to primeval darkness and mystery.

Well, Spencer's argument is so far effectual as to show that the normal life, the well-adapted life, is generally a pleasurable life and, still more, that the tendency of organisation is to make the normal life pleasurable; and such a pleasurable life is necessarily desired. If so, a relative perfection or adaptation to the conditions of life (which for man are chiefly social) and the pleasure that accompanies adaptation must be factors of the total Good; the Good Life must be conceived to be pleasurable. So far the Hedonists are justified, though not in identifying pleasure with good.

In fact, the relation of pleasure to the Good was better understood by Spinoza than by Bentham. Spinoza says, "We never strive after, wish for, long for or desire anything because we deem it good, but we deem a thing good because we strive after it, wish, long for or desire it"; for will or appetite is "the essence of man, from the nature of which essence those things necessarily follow which tend to his conservation, and which therefore he has been determined to perform" (Ethics, III. 9). Here we have a thoroughly biological idea: no species can persist in living that does not desire the things that conserve it: the species that has arrived at self-consciousness calls such things good. The desire to understand is peculiarly the essence of man, according to Spinoza; hence, with those in whom this desire predominates, to understand is especially deemed good. But what each man deems good depends upon his character, that is, upon his predominant desires and the ideas by which they are coordinated: sensuality, wealth, honour, public interests, and so forth. In the same things he normally finds pleasure so far as his activities about them are successful or seem likely to be successful : in Spinoza's quaint language, pleasure 
is the transition to a greater perfection, pain to a less perfection.

The physiological correlatives of pleasure and mental pain (for which we have no appropriate word) are very obscure. Pleasure seems to reinforce the activities that it accompanies, and some have supposed that it therefore depends upon the occurrence of additional nervous discharges: but it may be merely the consciousness of the free and harmonious convergence of cerebral energies upon the activity that is being carried out, especially perhaps the rapid repair of the waste and destruction involved in such activity. But at any rate it presupposes such activity and its object. That the prospect of pleasure originally determines the activity, is an error of the older empirical doctrine that overlooked the necessary and connate structure and functions of the organism, upon whose activity the possibility of pleasure depends. It is true, however, that when any desire has been gratified and pleasure has accompanied it, in future the rise of that desire is accompanied and reinforced by remembrance of the pleasure of its former gratification. Hence, as Plato and Aristotle teach, moral education depends upon associating good actions with pleasure, and bad actions with pain. But the strength of a desire bears no constant proportion to the pleasurableness of its gratification: in the formation of a habit desire may increase, whilst the pleasure of its gratification decreases, except so far as the activity of a habit is itself pleasurable.

Desires are psycho-physical dispositions of the organism varying in direction and strength with the species and the individual; and amongst men the direction and proportionate strength of desires determine what I have called "moral species" (Metaphysics of Nature, c. xv. $\S 4$ ). What we take pleasure in, what we deem good, depends upon what kind of men we are. And the effective morality of any nation depends upon the sort of men who constitute or lead that nation. Upon them depend the laws and social arrangements that may make virtue self-rewarding and vice self-destructive. There cannot be a nobler life than that which we desire or are capable of earnestly desiring. In short, the improvement 
of morality requires the improvement of mankind, not merely of those now living, but by purgation of the nation's blood, generation after generation; without which preaching is indeed foolishness and Moral Philosophy exists in vain. If, however, with all our hearts we desire this thing, it can be attained. 
BOOK II.-MORALITY AND INSTITUTIONS 



\section{CHAPTER VI}

\section{THE INFLUENCE OF CUSTOM}

$\S 1$. IT is too much the practice of those who philosophise on Morality to consider their subject as a study of principles, whether Ends or Imperatives, equally good for all men in all circumstances : a sublime conception, but essentially scholastic; depending on the traditionary definition of man as a "rational animal "; ignoring even the general character of men, let alone their particular conditions. In fact this kind of moral doctrine glories in being unconditional: "Thou shalt__," no matter who or what thou art. But the blank is difficult to fill. For nearly all men in any country such doctrine is unreal; their effective sentiments do not respond to it; at most they acknowledge its claims when they are specially withdrawn from the affairs of life, as at a sermon or a tragedy. Unconditionality is non-existent; therefore its morality has no content; in aiming at everybody, it reaches nobody; because everybody lives under concrete conditions, which must be considered in every action. The only universal is the tendency of an action: whether the action is right or wrong depends upon the conditions under which that tendency operates.

From such scholastic emptiness Aristotle was saved by his Hellenism; and hence the Ethics contains more matter of fact and human nature than any other moral treatise that ever was written. $\mathrm{He}$ holds, indeed, that there must be natural justice, but recognises that actual regulations everywhere differ. The disruption of Greek society, however, the inroads of slaves and Semites upon Philosophy, the rise of the Macedonian Empire and, later, the spread of Roman authority, 
gave rise to a cosmopolitan conception of morality, Law of Nature, Law of Reason, the Stoic system of abstractions. And it may seem that Christianity gave support to this evisceration of social duties; but that is to overlook the special quality of the primitive Christian mission to a World about to end. The coming destruction of all this World's institutions made possible the unconditionality of Christian precepts. When it was realised that the Church was to live in the midst of the World, two disciplines were established, the monastic and the secular. The maladaptation of this system to human nature, emphasised by casuistry, was a principal cause of Protestantism: in which we witness uncompromising professions of belief in moral precepts, that few people bear in mind for half the day and the majority wholly neglect.

The chief modern exponent of unconditional morality is Kant, who revived the Stoical system as a kind of abstract Protestantism. Hegel's chief service to Philosophy was his exposure of the hollowness of Morals without Institutions. But he failed to reconcile the two, and the efforts in that direction of his disciples have been still feebler. It was, I believe, Thomas Green's declaration (Prolegomena, IV. ii.) that Moral Philosophy delivers no practical principles, but has for its chief function the elucidation of the absolute Good and the encouragement of aspiration, that completed my dissatisfaction with abstract Ethics.

But, it may be said, 'whatever the merits of Aristotle's Ethics, surely in relation to Philosophy his Hellenism is a narrowness and an imperfection. So far the Stoical universalising of Morality was more philosophical; it was an advance of human thought.' That is true; but the advance was made upon such a method that no results could be obtained. It was not an advance by induction, the hopeful line of procedure in Aristotle; but by deduction from a concept-Reason. No deduction from a conventional concept -whether "rational" or "sensitive"-can ever constitute Moral Philosophy, because no such concept is adequate to any man or any class of men. The Baconian, not the Scholastic method, must be followed. Seeing this, my first 
design, when preparing to write this book, was to collect the phenomena of human morals. Alas, how little I comprehended the greatness of that task-impossible without abandoning every other employment. But, happily, similar ideas had occurred to others; and I see with gratitude several works appearing on this great subject far better than I could have produced. I mention as having been especially useful to me: Alexander Sutherland's Origin and Growth of the Moral Instinct, and Edward Westermarck's profound investigations of Human Marriage and of The Origin and Development of Moral Ideas. Compared with such works the following chapters of this Book can only be essays. We have there some preparation for Moral Philosophy on a basis of knowledge; whereas the older sort, though illumined here and there by insight derived from prophets, was in the main a development of prejudices or abstractions.

This acknowledgment compels me to add, that I find it impossible to accept all the explanations and conclusions offered by these explorers of the moral world; and upon one point I must protest, as the alternative to abandoning Moral Philosophy. Westermarck argues that moral judgments are based on emotional reactions; " a certain mode of conduct has a tendency to evoke in us moral indignation or moral approval" (Moral Ideas, vol. I. p. 17); and such judgments are subjective. Therefore, there are no general moral truths; "the object of scientific ethics cannot be to fix rules for human conduct," but "to study the moral consciousness as a fact" (18). Nevertheless, moral emotion "has a certain flavour of generality"; a moral judgment is not a merely individual estimate; it refers not only to one's own feelings, but to feelings which one believes that others would share if they knew the act and its circumstances equally well and had equally refined emotions (104-5). This results from the fact that the moral consciousness was born in Society and "that tribal custom was the first rule of duty" (117-18).

But, if it be granted that moral judgments (at least upon others) were originally based on emotional reactions; that certain kinds of conduct were resented or applauded by the 
tribe before rules were generalised (which must surely be true); it does not follow that these judgments have not in time acquired another character. Certain modes of conduct being customary and approved, or breaches of custom and disapproved, analysis - at first obscurely conscious, at last methodical-shows that such modes of conduct have certain common characters, and that in relation to the Good (however conceived) they further or frustrate its realisation, stand as causes of that effect. Such analysis and classification of actions approved or disapproved, discloses general moral truths, the tendencies of conduct, that were hidden from the quasi-instinctive judgments of earlier men; and to do this is the object of scientific ethics, in contrast with that natural history of the moral consciousness which Westermarck so admirably investigates. Approval and disapproval are transferred by cumulative association and reflective identification to whatever furthers or hinders the Good. We must distinguish even in civilised life between instinctive and reflective approval. For instance, a man of refined emotions may have a strong instinctive approval of duelling (say) in some cases of family honour, and yet may bring himself to disapprove of it, if reflection convinces him that it is not the best way of securing the ends of social life.

\$2. "Tribal custom was the first rule of duty." It is true that we cannot directly know anything of primitive man. The savages whom we are apt to call primitive, such as the Bushmans, Andamanese, Australians, are presumably of as long descent as ourselves-some hundreds of thousands of years from Apedom. Still there is good reason to believe that their manner of life is more like that of primitive man than our own, because we have evidence that our own forefathers lived much more nearly as they do. Such savages, then, live by custom; and they have no other rule of life, no law, government, or definite religion. All social animals, again, have customs; so that we naturally infer that our ancestors became human under the influence of custom, and were from the first subdued to custom, or the observance of that which to them seemed necessary. 
The view that custom itself was derived from the sentences and decisions of kings has been abandoned. It really needed the assumption that the king's sentences were either immediately inspired by a god or dictated by an innate moral sense. For unless his office was to declare the already established Custom, there could have been, in the absence of any settled mode of life, no other ground for his saying one thing rather than another, and no assurance that he would be consistent in his adjudications. Besides, why should his decisions have been accepted? The custom of obeying him at least must be presupposed. In fact there is abundant evidence that Elders, Kings, Judges, were at first the interpreters of Custom, and, for the most part, that has always been their function.

Custom, then, was the first ground of all restraint upon individual caprice in action or in the expression of opinions and beliefs, of all observance and uniformity of behaviour. It is the ground of the family, of government, of law, of religion, forms of art and morals. The necessity of it lay in the dependence of our remote forefathers upon society for defence against other animals and other tribes, and the advantage of it in a better livelihood-the same necessity and advantage that gave rise to language. It was the condition of peace within the tribe or horde, and of co-operation. And it remains the essential condition of these things and of all our institutions. We are adapted to it by imitativeness, suggestibility, sympathy, and the love of being together in crowds. It moulds all our feelings and judgments about social affairs. This is why one people cannot adopt another's institutions without modifying them in accordance with their own traditions. Neither our character nor our intelligence is well enough developed to preserve morals, or art, or religion, or law, or government, or the family, without custom. To enforce this truth was one of the chief merits of Burke's political philosophy, in opposition to a very premature worship of reason.

If indeed in any tribe, custom were undeviatingly followed by every one there could be no morality because no immorality: such a condition would be antecedent to "the origin of evil." 
It is not likely that such a state of things ever existed: human beings are too variable; there must always have occurred some of those irreconcilables in whom every suggestion or example excites the opposite reaction. Even social animals sometimes break their customs. Spencer describes several kinds of savage that fail to form tribes through excess of independence (Principles of Sociology, $\S 35$ ); though whether their present condition has not resulted from the destruction of some earlier organisation may deserve inquiry. For it may be said to be probable that the nearer a tribe approaches to primitive conditions the more strictly its customs are observed. The tribesman for the most part follows custom as a matter of course; if it ever occurs to him to deviate, custom becomes coercive through the attitude of his fellows. Hence, that feeling, established during hundreds of thousands of yearsthat 'this must be done' - which seems to me to be the essence of moral sentiment. His fellows resent the breach of custom, approve adhesion to it; and these feelings give rise in him, through perceptive sympathy, to the ego-altruistic conscience and, by active sympathy and imitation, to the reflex sentiments, remorse or self-approval. Both the egoaltruistic and the reflective conscience require greater mental development than the sense that 'this must be done'; yet even now (to judge from my own experience) the sense that 'this must be done' may be morally determining without any representations of approval or disapproval by oneself or others.

I cannot then agree with Westermarck that the moral emotions are entirely derived from resentment, hostile or kindly, toward those who break or observe custom; nor, again, that the moral judgment is in the first place passed upon others. But he has excellently shown how moral feeling and judgment acquire the three great qualities of generality, disinterestedness and impartiality: such, in fact, are the characteristics of custom itself (Moral Ideas, p. 120). Custom is general: every one in the same circumstances does the same thing, expects others to do it, knows that it is expected of himself. Custom is impersonal: under its influence the feel- 
ing arises not so much that ' $I$ must do this' as that 'this must be done'; so that it may be coercive apart from the idea of obligation or responsibility to others. Custom is impartial: and I blame whoever fails, others or myself alike. Custom is impartial, that is, to all who are in the same circumstances; though not, of course, to those in different circumstances; since there may be one custom for elders or chieftains, another for common tribesmen, or for women, or for slaves.

$\S 3$. Custom has the great moral inadequacy of governing only external actions; and, therefore, of being, in the first instance, the ground of feelings and judgments relating only to external actions. A man who has failed in some customary observance feels guilty, though the fault occurred without intention, by oversight, or even by some physical impossibility of performance: who has not experienced this? And he judges in the same way the shortcomings of his fellows. Tribes still exist in whom self-consciousness is so little developed that they make no distinction between intentional and unintentional breach of custom (Westermarck, Moral Ideas, c. ix.). Yet whoever is capable of remembering as a whole the situation in which he has acted, must feel differently according as he says: "I meant it," or "I did not mean it"; though in both cases he may feel effectually guilty. By degrees this difference in a man's feelings toward himself affects his feeling toward others and his judgment of them as apparently intending or not intending any fault: at least, as soon as men arise who are capable in some measure of independent reflection. For such a change of view as to the essence of an action, distinguishing the will from the deed, must begin in some individual. It is an act of private judgment; and custom inhibits private judgment and especially the communication of it, upon which the influence of any bolder mind depends. In fact, it is difficult to see how the emancipation of action or thought could be realised if customs themselves did not change.

In the course of time, however, the customs of a tribe, even at a very low stage of culture, such as some of the Australians 
(Spencer and Gillen, Tribes of Central Australia, c. i.), do undergo changes; so that it is reasonable to suppose that, in the vast period of their forgotten past, all their customs have altered over and over again. In progressive Societies the process is more rapid. A change of habitat from mountain to plain, or of industry from hunting to agriculture involves new customs; so does the differentiation of ranks and employments, both in the regulations of the new groups and in the relations of one group to another. Any change of custom will be followed by different members of the tribe with various degrees of unwillingness and must occasion some conflict of opinion. We read in the Icelandic Sagas how the women cherished the traditionary blood-feud and frustrated the efforts of the men to establish a law of commutation. With the growth of reflection the sense of the coerciveness of custom becomes weaker as the advantage appears of freely adapting actions to ends; customs are then evaded for the sake of purposes; but such reflection on the part of individuals cannot be effective, unless the power of custom has already been broken by stress of circumstances.

Adaptation is the general cause of change of customs, as it is of the development of organic life. Indeed change of custom is an essential phenomenon of the development of human life, as necessary to human progress as the formation of customs was to human origins. Wherever there is active competition of tribes, any one that has inferior customs, and cannot change them, perishes. At all levels of intelligence there may be deliberate innovation, from the childish meddling of Arunta elders to the solemn 'trial and error' of modern legislatures. The coalescence of tribes, by conquest or otherwise, produces a conflict of their customs and consequent modifications of them. A new religion, whether of indigenous growth or accepted from invading missionaries, has far-reaching effects. Commercial intercourse with foreigners necessitates endless concessions and compromises as to property and exchange, and may lead to direct imitation of their institutions, as recently on the part of the Japanese. At last the power of custom is weakened by the mere knowledge that 
other people have different customs and perhaps think ours as absurd as we do theirs.

In our day, with its diversity of religious and political sects, led or followed by their giddy or sentimental newspapers, the simple confidence of customary judgments is for the most part lost. Private judgment has long been preached and begins to be practised. There is the inestimable gain that you may follow reason if you have any. But it is not altogether advantageous to the young and the ignorant, the weak and the passionate who, without custom to guide them, are capable of the utmost vagaries of vanity, self-will and infatuation.

$\S 4$. Custom and public opinion are so closely related, that it may seem difficult to judge which of them is antecedent to the other; for, no doubt, certain actions may be regularly practised because they seem good to the tribe; though, for the most part, actions seem good because they have been constantly practised. If we consider public opinion to depend on the use of language (which may be disputed), we may infer that custom was the earlier and the first ground of public opinion. But, at any rate, as social life grows plastic, custom depends more and more upon public opinion for its sanction and enforcement. As there are primary customs of doing and abstaining, so there are secondary customs of resenting the failure to do or abstain, and if resentment ceases to be felt and expressed, these secondary customs fall into desuetude; then the primary customs also lose their hold upon the tribe. In the same way laws, political and religious, though remaining nominally obligatory, become obsolete when public opinion no longer supports their execution. There are such laws amongst ourselves.

Public opinion sometimes enforces custom by the general action of the tribe-a spontaneous lynching; oftener it has some recognised organ, a council of elders or the chief; who, again, having decided the matter, may appoint some one or some body of men to carry out the penalty; or if the offence be a personal injury, may surrender the culprit to the injured party, or to his kin, to take revenge. But even in the last 
case the intervention of the tribe acts as a restraint upon revenge, substitutes a customary penalty for the "indistinguished scope" of personal fury, necessarily modifies the feelings of the avenger, and transforms revenge into punishment. This must be considered one of the greatest steps in human culture, if not the greatest of all, however hideous the penalty may be or rationally unjustifiable.

But we have seen that custom is concerned, in the first instance, with the overt action; so that motive, intention, inadvertence and even disability may be disregarded or very irregularly allowed for. It is further incident to the enforcement of custom that public opinion, on which it depends, is liable to be moved by suspicions, influenced by prejudice, and misled by superstition. The savage mind is in any case little capable of carrying out comparisons; under excitement it is quite incapable. It exists in a state of primary dissociation, or incoordination; that is, its organisation is naturally so imperfect that one train of ideas does not arouse another one with which it seems to us to have a close logical connexion. Perhaps we can understand this condition best by considering its analogy with the secondary dissociation, or discoordination, produced by hypnotism; whereby the subject accepts any absurd suggestion, because the great body of sense and knowledge is temporarily shut off which, in his normal waking state, would make him reject it. Such is the way in which suspicions and superstitions work in a savage's mind: suspicion is its own evidence, and the most absurd belief of animism or magic is more powerful than the evidence of the senses. The state in which suspicion is its own evidence remains too common amongst those whom we call civilised or even cultured.

After the development of Laws, political and religious, Custom, besides supporting these its offspring, retains a certain extensive province of its own, where observances, positive and negative, that cannot be or, for some cause, have not been defined by law, are left to public opinion. Public opinion enforces them very irregularly and capriciously by such penalties as Coventry, Boycott, loss of respectability, even 
mobbing or stoning, in circumstances that prevent the identification of an assailant or the proving of his offence. It is usual to laud public opinion, though it is hardly modest to do so, as it is partly our own creation. Since it cannot be got rid of, we ought to make the best of it; and that requires that its action should be greatly amended. On public affairs, opinion has in Parliament and Press organs of public discussion, and yet in such matters grave injustice is often done and long persisted in. In private affairs there is no organ of expression or tribunal; men are tried at tea-tables or in smoking-rooms, without being openly accused or/ having any opportunity of defence, and suspicion, prejudice, superstition have full sway. Under the exciting suggestions of suspicion the mind of many an excellent citizen reverts to the savage level. We are especially liable to such reversion under the influence of fashions and panics that every now and again take possession of society, and from which many of us will hardly escape even by reflecting upon the absurdity of accepting suspicions for evidence, exaggerations for truths and prejudices for principles, and upon the indignity of being the victims of suggestion, imitation and dissociation.

The knowledge of Customs we may suppose to be the first form of Common Sense; and, as in tribes where Customs are determined by a Council of Elders not every man can be supposed to have an equal knowledge of them, so it is with Common Sense. In the development of society and reflection Common Sense begins to be opposed to any Customs that are merely survivals and encumbrances without adaptation to present wants. Practical thought finds amidst a variety of customs the common qualities of those that are approved by competent men. The manifest advantages of friendly co-operation and proportionate sharing suggest such maxims as 'Love thy neighbour' and 'Do unto others as you would have them do to you.' Upon this foundation of recognised practical judgments, Moral Philosophy is raised in the effort of Reason to systematise the social conditions of life. As Henry Sidgwick observes, Common Sense is "a body of moral truth warranted to be such by the consensus of mankind-or at least of that 
portion of mankind which combines adequate intellectual enlightenment with a serious concern for morality" (Meth. of Eth. III. c. i. $§ 5$ ). He has shown that this body of moral truth, though (as an independent system) defective in definiteness, has attained to a certain degree of enlightenment and of the worthier sort of casuistry. This is the unwritten law that ought to be known to, and administered by, Public Opinion; but how many members of that judicial body have read Henry Sidgwick's immortal third book, or could read it? The great majority of the public and the published organs of their opinion have no sufficient sense of their task, or of the duty of preparing for it, because there is no one to whom they are responsible. It is power without responsibility that is apt to make a democracy (of which public opinion is the most perfect example), in the language of Burke, "the most shameless thing in the world."

$\$ 5$. From the general customs of a tribe or nation must be distinguished the special customs of a caste, profession or trade, which may remain of a barbarous character and profoundly immoral long after general customs have been extensively purified. The reason of this is that such special customs often have an anti-social bias. Growing up through the efforts of a differentiated group of tribesmen to protect their own interests, they take no account of the general interests of the nation, gradually become hostile to the public interest, exclusive, secret, dishonest. The narrower and more exclusive such a group, the more secret and the more liable to corruption; and the stronger its internal cohesion, the greater its opposition to the commonwealth.

Commissions of inquiry, or the Law Courts, sometimes bring trade-secrets to light. It then appears perhaps that 'Havana' cigar means a cigar of a certain shape, with no reference to the place where the tobacco may have been grown or manufactured; or, again, that 'linen' shirt means 'not paper.' We laugh and blush, and perhaps do not reflect that the same spirit that gives rise to such tricks, the spirit of commercial conspiracy, is apt to operate universally in setting corporations, associations, groups, upon a tacit understanding 
against the country: that it is the soul of all monopolies, schemes of 'protection,' and campaigns of contractors who, during a war, shout for patriotism and loyalty whilst swindling their country and their king.

The knowledge that secret customs-such as 'making work' or accepting commissions-exist in many trades and professions, attaches a certain suspicion to every member of them-in some of them much more than in others. Lawyers and pawnbrokers are favourite objects of popular suspicion: no doubt, from the impressive circumstances that bring people into contact with them. Stories to their discredit being current, the liar or thief excuses himself, on the ground that the practices of those who pretend to respectability are no better than his own. A member of any profession that carries a bad name has, from that very fact, weaker motives to refrain from base transactions. For this reason one ought never to speak with contempt of any profession as a whole-of horsedealers, for example, or ballet-girls. The more honourable members of any group, unless exceptionally placed, have a constant struggle to resist the growth of evil practices that cannot be abstained from without accepting some economic disadvantage. Every secret understanding is necessarily elastic, and stretches indefinitely under pressure of the most cunning and vulgar people who hope to gain by it. The consciences of most of us are highly modifiable by the sentiments of others: what all our colleagues say may well seem right; or, at least, to dissent from it may imply a questionable degree of self-sufficiency; though perhaps their unanimity is due to suggestion and to the imitation of one confident rogue. Who has not experienced a weakening conviction of the villainy of an action when another has 'put the case' in new phraseology?

$\$ 6$. The customs of a people imply the habits of each individual, and to alter them involves the well-known difficulty of the breaking of habits. But they are much more than habits; for, being general practices, they involve the adaptation of each man's actions to those of his neighbours; therefore, they cannot be broken without general consent or 
general confusion. But, still further, customs are regarded as right and as conferring rights; very often they are regarded as sacred and sanctioned by the gods; so that to depart from them is opposed by conscience and by supernatural fear. The lower the level of intelligence in any people, the harder it is to change its customs. So far as women are concerned, their influence is almost entirely on the side of ancient usage; though, once shaken out of it, there may be no limit to their deviation; since reliance on custom and feebleness of private judgment are reciprocal.

Hence the prevalence of Custom hinders every sort of alteration in Law, Religion, Art and Morals, whether for better or worse. It is well known that a principal means of reconciling a conquered people is to leave them to their Customs and Laws: the latter being little else than declared Customs. Custom then appears as the right of the weaker, and preserves for him much the same life as he had led before. But the result is that, in a few generations, the conqueror is absorbed into the mass of the population, and dissipates his blood, without making any atonement by way of civilisation for all his temporary violence and tyranny. The difficulty of altering customs is ludicrously shown by the fate of all proposals to change English spelling or weights and measures, though we are supposed to be an intelligent people. A change of Religion is only possible when it has stagnated or corrupted and lost its hold; as happened at the introduction of Christianity and at the Reformation. Even when such a change has taken place its influence is often very superficial: the South Europeans, with their saints and Madonnas, have always been polytheists; and the North Europeans, in their ways of thinking and feeling, have remained much the same as in the reign of Woden and Thor. Religious observances that have themselves become customs are the most lasting of all; litanies are recited for hundreds of years in languages that none of the worshippers understand, and victims are slain with stone knives for ages after the introduction of bronze or iron. Even in Science and Philosophy customary formulæ and beliefs hinder the acceptance 
of rational explanation. Phrases persist, such as "centrifugal force," "action of a law," "sufficient reason," which are meaningless or misleading. A profusion of technical terms preserves a system however vain, because they can be learnt and repeated by disciples who cannot understand them but delight to hold fast by a form of sound words. And since worn-out customs, laws, religions, philosophies are adapted to a certain type of mind, by no means extinct but merely subordinated in the movement of society, at any period of fatigue, weakness or disruption that type reasserts itself, and we see a reaction, or the revival of obsolete ways of feeling and thinking, with the old practices, the old ritual, the old formulæ. Recently there has been a revival of the retributive theory of punishment. We hear the cry- "Back to Aristotle," "Back to Kant." Ghosts, too, again walk at large; magic is widely practised, and Astrology has numerous devotees.

As for Morality, since it requires the thoughtful adaptation of every action (that is not indifferent) to each special case, according to the circumstances and persons concerned, nothing can now be more opposed to it than the prevalence of Custom. Custom in quiet times enables men to live in security who are incapable of thinking. But it encourages no man to think: it hinders thinking. If anywhere there is a custom of smuggling, perjury, bribery, he is a rare free-thinker who sees much harm in those practices. If it is the custom to treat a man as superior to a woman, a freeman to a slave, a native to a foreigner, it is difficult for most people to understand that in any circumstances the woman, or the slave, or the foreigner may deserve the greater respect.

Custom hinders the reconciliation of self-interest with public utility; because, if custom is contrary to utility, even though the useful action in itself should not be contrary to self-interest, custom makes it so; for public opinion is in favour of the custom, and even one's own conscience is apt to be subdued by it. Custom is the great enemy of moral courage; it strangles virtue in the birth. It sometimes requires us to connive at wrong-doing, and sometimes to do wrong. This has often been illustrated in forms of politeness, 
which may mask deceit or compel hypocrisy. Custom may make it impossible that conduct should be purely felicific: to break it may be a material injury to others; as if in the public interest one should refuse an office to an incompetent man who happens to be next on the roster: or even a moral injury; for any bold departure from custom shocks the conscience of many good people and disturbs the rule of life for many others. 


\section{CHAPTER VII}

\section{THE FAMILY}

$\S 1$. THE origin and development of the Family are obscure. Amongst existing tribes and nations there is great diversity in the customary relationships of the sexes, and in the consequent tracing of kindred. As history takes us back only a few thousand years, it brings us no nearer the beginnings of human life: it shows us a few more varieties of marriage, and records some changes that have occurred in certain nations as to their family systems; but such changes, instead of throwing a light upon the character of the primitive family, make us reflect how many other changes may have been passed through during the hundreds of thousands of years now allowed for the development of the human race.

In endeavouring to unravel the history of the family there are two starting points: (1) the customs of existing and historical peoples; (2) the customs of the higher mammalia and especially the anthropoid apes.

Taking existing and historical peoples, we distinguish roughly certain grades of culture, and assume (generally) that the lower grades represent (approximately) earlier stages of development. This assumption is supported by historical evidence that existing nations of the highest grade have passed through conditions corresponding, in the main, with those under which other nations of inferior culture are still found to live; and that nations in the higher grades still maintain, in a form more or less atrophied, various ideas or practices that can be best explained as vestiges of a lower condition, and therefore point to this when there may be no record of it. 
Reasoning in this way, it seems to have been made out $(a)$ that strict monogamy, as we understand it, is a modern custom; (b) that in former times polygamy was everywhere permissible though, in practice, confined in every tribe to the few who could afford it; (c) that patronymy, or the tracing of descent through the father, is almost everywhere preceded by metronymy, or the tracing of descent through the mother; $(d)$ that metronymy is generally associated with polyandry, or with some form of group-marriage, or practices indicating group-marriage. From this it has been inferred that metronymy was based on the impossibility of identifying the father, and that a still earlier condition probably existed in which there was no marriage at all, but entire promiscuity prevailed.

But all the arguments of this kind carry us back a very little way-shall we say 20,000 years? - so that we get no nearer the condition of primitive man. Existing savages, being of as ancient descent as ourselves, have had time to deviate in all directions, and probably many tribes of them are degenerate. The rise of metronymy is compatible with an original monogamy, if we suppose that, either to economise the food supply, or to disencumber the tribe of non-combatants, female infanticide was adopted, or that in any other way women became scarce; for this would have led to polyandry, and so to problematic paternity. Westermarck indeed gives other reasons for the naming of children after their mother (Human Marriage, c. v.). Modern monogamy may thus be a return to the primitive condition, rendered possible by better economic conditious and relative decline of hostility, and favoured by the growth of feelings and ideas concerning the family which are characteristic of our civilisation.

Turning to the argument from the customs of the higher mammalia, Sutherland has shown (Moral Instincts, c. v.) that as the length of youth increases in various species there is some tendency toward permanence in the companionship of the parents. The greater the individual development in the members of any species, the longer their youth; and, therefore, the more lasting parental care must be. The only directly significant consideration, however, is the state of things amongst 
anthropoid apes; and what we know of this is at least compatible with the hypothesis that pithecanthropus was monogamous, or at least lived in distinct families. Whilst reports are conflicting as to the orangutan, it is agreed that our still nearer kin, the chimpanzee and gorilla, live in families: see the citations by Westermarck (Human Marriage, c. i.). It is plain that this plan is the most favourable to the survival of the offspring, especially considering their early helplessness and prolonged youth, not attaining maturity before the fourteenth or fifteenth year. The reasonable inference is that the human species before its great differentiation occurred, had the same custom ; and the long period that has since elapsed, together with wanderings all over the world, has given plenty of time and plenty of occasion for every known or surmised deviation from primitive conditions. The Australian aborigines, for example, are among the rudest tribes now extant; and their marriage customs, of a complexity to baffle the trained intelligence of a herald or a Quaker, must have taken a long age to elaborate. But if some of their traits seem to be interpretable as the vestiges of an earlier custom of group-marriage, it is easily conceivable that, in ages still more remote, group-marriage arose from the degradation or, possibly, by the improvement of more primitive conditions: a degradation of monogamy, but an improvement upon any state in which the males took no share in caring for the offspring.

$\S 2$. It has to be considered whether the distinctness of families is incompatible with the combination of them in larger groups, if it should seem probable that the ancestor of man was more gregarious than the other apes. It is said that orangs are not sociable, and that whilst generally living in families - father, mother and children-the male or female is often found solitary; or the female may have one or two young ones with her. Gibbons often go in troops. Gorillas wander in family parties - father, mother, and one or two young ones; according to some statements polygamy sometimes occurs. They may occasionally assemble in larger numbers, but cannot be called gregarious. Chimpanzees also wander in families : I find no report of polygamy amongst them. Sometimes three or 
four families are found together, but such association does not amount to gregariousness. This usual separation of families Westermarck attributes to the difficulty of obtaining food in the same locality for greater numbers, and infers that the ancestor of man at the ape-stage of development also lived in separate families (p. 43).

But the evidence shows that in gibbons, chimpanzees, and even in gorillas there is some tendency to association: they present in fact degrees of variation in this character; and the results show that man must have had a greater variability than any of them. Why may not one of his variations have taken the direction of greater sociability? One of his variations certainly was to become extensively carnivorous. What effect would this have had upon his sociability? Westermarck quotes Spencer to show that " an animal of a predatory kind, which has prey that can be caught and killed without help, profits by living alone." But whilst it is true that the cats are on the whole solitary (though not in the rearing of their cubs), there are also the wolves and dogs to be considered. Now is man in character more like a cat or a dog? Is it certain that primitive man preyed chiefly upon animals that could be "caught and killed without help"? Westermarck compares man to the chimpanzee in "his comparatively slight strength and courage" (p. 43). But such a constitution would not have been favourable to a solitary carnivore. Whatever the manape's strength, he was probably more courageous and aggressive than the chimpanzee; but probably, again, his courage would have been greatly supported by companionship, as happens with the wolf. We shall hardly discover what his earliest prey was ; some chimpanzees are known to eat birds and birds' eggs; and in this way our ape may have first acquired his taste for flesh; but it must have been other game that led him to become a ground animal, independent of the trees and forests. Ancient remains of man have been found in association with the bones of large and powerful animals, which he seems to have slain and eaten; but such remains are of man, not of the man-ape. The man-ape had no weapons : he must have hunted first and then, by slow degrees, devised weapons to assist 
him : unless we suppose they were invented only to fight his fellows. He must therefore have hunted beasts against which weapons gave a great advantage. In such a life his courage must have been developed by natural selection; but is it probable that he undertook the chase alone?

Nothing can be more useless to prove that man was not originally gregarious, than to cite instances of existing savages who live almost in single families and yet subsist mainly by hunting: they all have elaborate weapons; are all of them people of immemorial culture such as it is. Westermarck cites, as instances of people who live even now "rather in separate families than in tribes" and "belong to the very rudest races of the world," the Veddahs, Fuegians, some West Australians, Bushmans, certain Indians of Brazil and of $\mathrm{N}$. America, Eskimaux (Human Marriage, pp. 43-9). But none of these are entirely without tribal association; some of them are plainly degenerate, beaten and broken peoples, driven into hills and peninsulas and desert lands; all of them have wandered further than Ahasuerus. The Indians of Brazil, how came they there; and what probability is there that, after the adventures of hundreds of thousands of years, they have any resemblance to our ancestors even half-way back to the ape?

I suggest, then, that our remote ancestors, when they became carnivorous, hunted in packs - a sort of wolf-ape (Metaphysics of Nature, c. xv. $§ 3$ ). Westermarck supposes that gregariousness resulted from an increasing food supply (Moral Ideas, vol. II. p. 195). But for a frugivorous ape in the tropical forest, whence came this increase? For a hunting ape, however, gregariousness might very well cause an increased supply of food. Gregariousness, like other acquisitions, was established by its utility. Early carnivorousness easily explains the development of the legs to run, of the hands to make and use weapons, the erect attitude, curvature of spine, poise of head, shortening of the alimentary canal, and other physical features. How could any of these characters have been acquired whilst our ape remained chiefly frugivorous? Life in the pack, again, is a better occasion 
of the growth of language than merely family life can be: else why do not chimpanzees talk? The pack explains the sociality of man as he is most generally known, if the Veddahs and Bushmans will excuse my saying so. Man, in fact, is in character more like a dog than he is like a cat; and that is the basis of the psychology of his whole emotional nature.

But if man was originally a social animal, does it follow that his sexual relations were, at first, promiscuous? I do not see that the formation of a horde is incompatible with the distinctness of families. Some writers seem to assume that in the horde the strongest male claimed all the females, and drove away all other males as soon as they came of age. But such a plan, though advantageous with some herbivores, which thus breed only by the most powerful males, would have been very inefficient for a hunting animal. Does any such thing happen in packs of wild dogs or wolves? A horde including many adult males, as with them, is plainly the most efficient for hunting. Had each male, then, his own wife and children? Wolves are believed to pair, and, when not united in a pack, usually go in pairs. Much more may the wolf-ape have done so with his greater intelligence and with the much longer infancy of his offspring. I accept, therefore, Westermarck's conclusion that "human marriage appears to be an inheritance from some ape-like progenitor." No doubt it had to be jealously defended vi et armis; and, accordingly, conjugal jealousy is connate in men and women of most nations. It was impossible, however, in the endless vicissitudes of tribes, wandering league by league over all the world, that marriage should be preserved from every sort of corruption. For one thing, when a horde became permanent, not (as with wolves) occasional, the care of each father for his own children may have been less essential; just as would now happen under Communism. We shall presently see other causes of corruption.

$\S 3$. Without being accused of prejudice, Europeans may boast that monogamy is the best means of perpetuating the human race that, in spite of all experiments, has yet been discovered. If it was first established amongst the apes by 
natural selection, it may be said to reassert itself under the same sanction. It seems needless to compare the moral advantages and disadvantages of group-marriage, polyandry, polygyny and monogamy. In his Sociology (\$ 315) Spencer has shown a general connexion between militancy and polygyny on the one hand, and on the other between monogamy and industrialism. Without dwelling on the greater natural cohesion of the monogamous family, its greater freedom from jealousies and internal strife, it is enough that this form alone is compatible with the free personal development of women, that is, of half the human race; with the reasonable apportioning of rights, and the acceptance of obligation by both women and men; with the noblest sentiments of mutual affection, and with the cultivation of chastity by both as a disposition and not merely as a physical observance.

The way in which chastity as a physical observance gained a place amongst many barbarous tribes, may be read in Sutherland's Moral Instinct (cc. viii.-ix.). It seems to have depended generally upon the regarding of women as property, whose value was depreciated by prenuptial intercourse: even, therefore, when exacted of women it was not expected of men; and we see the plain marks of this state of things in the lives and feelings of the most civilised nations. Chastity, as a disposition, so far as it exists at all amongst men, seems to have resulted partly from conjugal sympathy, as Sutherland says ; partly from moral reflection, which easily shows that of all qualities it is the most conducive to happiness and personal development; partly, therefore, by natural selection - for if the virtue is to be practised, the disposition to it is a psychological economy, freeing the mind from incessant distraction; partly, again, from religious ideas concerning cleanness and uncleanness and the predominant claims of the spiritual life.

It is said that polygynists regard monogamy as a practically impossible condition of life, since it imposes upon men periods of enforced continence, only avoidable by irregular relations. But in the present state of human nature many similar objections might be raised as, for example, that the love of variety is incompatible with monogamy, or with any 
sort of limitation upon appetite. Such objections prove too much. Many savages practise the abstinence implied in monogamy (Westermarck, Human Marriage, c. xxi.); and the normal civilised man, though far from the ideal of chastity, is not so entirely the victim of his passions as to be incapable of selfrestraint according to custom. And if we reflect upon the nature of the sexual passion, as it obviously exists to ensure the perpetuation of the species, so according to the ideal of human life it has that purpose only. That its indulgence for this purpose only should become in everybody's mind a matter of course, or even instinctive-being otherwise submerged by the predominance of other purposes-is true chastity. This supposes far greater subordination of sexual desire than is imposed by the conditions of monogamy, which, however, seem to be a necessary preparation for chastity.

The preparation will take a long time. Amongst most wild animals the utmost violence of the sexual instinct is compatible with a regular and healthy life, because it is only active at certain seasons. They may be said to live as morality would require, in the sense that indulgence is no more than necessary to the end of the species: the season over, their minds are free from this scourge of flame. And Westermarck has shown that the evidence points to the former existence of seasonal marriage in the human race (Human Marriage, c. ii.); but, unhappily for our peace of mind, this good old custom has been lost. In this way, more conspicuously than in any other, human nature suffered a fall in its differentiation from the animal stock. Several causes may be assigned for this sinister change of sexual constitution. In the first place, the use of seasonal marriage is to ensure the birth of offspring about the time when food is most plentiful. But men have slowly but steadily brought about such conditions that food is normally obtainable with nearly equal certainty all the year round. Accordingly, most domestic animals provided for by man have also lost their seasonal instinct. In the second place, the lengthening of the period of gestation (in comparison with the anthropoids) by about three months would have required a corresponding putting back of the period of rut; and 
such a corresponding variation of male and female physiology needs long and severe natural selection to arrange. In the third place, the extensive migrations of tribes, frequently altering their kinds of food and the climatic conditions of supply, especially so far as they still depended upon vegetables, must have prevented the establishing of any new coincidence of seasonal birth with special abundance of food.

The result of this is that the sexual instinct in man is profoundly deranged even amongst savages, and exhibits the symptoms of derangement: extensive. variability from one individual to another and extreme liability to disease. All degrees of erotomania and depravity extend from the asylum to the normal disposition, and beyond that all degrees of aversion and caprice down to the fanatic who identifies sexuality with original sin. The intoxication of sexual passion has been heightened by the practice of marriage by capture and by the treatment of women in war, which have associated indulgence with triumph; by the admired practice of polygyny by kings, and thence by gods; by innumerable rites reinforcing lust with the needless incentive of religious zeal ; and even by the antidote of profane jesting. Nevertheless, to this passion we owe a large share of all the emulation that there is in the world, and therefore of every improvement of our lot; much of the motive of Poetry, Music and plastic Art; and the life of the family that nurses all that is amiable in our world. And here and there in the world, but more especially in these later ages, the coarseness and egotism of this passion has been hidden from many of us, when most necessary that it should be hidden, by the glorious illusion of romantic love: for our eyes were not yet open. Who knows the significance of marriage? Who sees the illimitable train of events that wait upon marriage? It is something in which we ourselves are least of all concerned.

$\S 4$. The Family, as it has developed in all branches of the Caucasian or Aryo-semitic race, seems to have passed through a stage of which the Roman family with its patria potestas was the extreme form. The family might comprise 
merely father, mother and children, or several married children and relatives, besides slaves, approaching in numbers to a clan. The father of the family is described as having power to slay or sell his children, or to give them in marriage; but this was subject to various tribal and local customs and often to the consent of the elder sons. He alone had a public status, representing the family in all legal or political transactions with other families of the City or State; his household being responsible only to him. He was also the priest and intercessor with the gods, the most important of whom were his ancestors and amongst whom he himself would one day be numbered. But such an organisation of the Family is incompatible with the organisation of the State, when the central government begins to claim direct control over all citizens as individuals; as becomes necessary in order to put an end to feuds and tumults caused by the support given to every quarrelsome man by his relatives. At the same time the cohesion of the patriarchal family ceases to be necessary for the protection of its members. It is also weakened by migrations, by intercourse with foreigners, by all the causes that dislocate customs, and by the progress of reflection which tends to discredit polytheism and ancestor-worship. Hence in modern Europe the complex forms of the family are almost everywhere superseded by what we generally regard as the ultimate unit, the family of father, mother and children; and even within this group the patria potestas is reduced to a slight authority exercised during the nonage of the children and subject in almost everything to the interference of the State.

Still, the father of the modern family is-or till recently was-responsible for the maintenance of his family with shelter and food and for educating his children and putting them in the way of getting their own living. The children, again, were responsible for the maintenance of their parents in sickness and old age. Thus the essential moral relations of the family remained, and in some respects were more favourable than formerly to the moral life. For the rigidity of status in the old family was unfavourable to the development of personality; the strictness of authority was unfavourable to 
the growth of affection. Internal cohesion generated external hostilities. It was a stern world, a world of duty rather than affection. For political life, too, the old family was unadaptable to changing conditions: such large units wanted the plasticity of the modern family, in which each man, as he comes of age, adopts any career that seems best on the whole.

But it has now become apparent that the feeling of the direct relationship of every individual to the State grows more and more powerful in many peoples' minds, and enfeebles the sense of the family solidarity and responsibility. The growth of benevolent feelings makes many of us willing to share the responsibilities of other people; and the decline of the sense of duty leaves them willing that we should do so. To take the case of England, we know that, already in the sixteenth century, great social and economic changes brought into existence large numbers of broken men without definite means of livelihood. Their needs were partly met by Poor Laws, which were modified from time to time to provide them shelter and food and sometimes employment, and were found in 1834 to have done incomparably more harm than good. Since then there has been a certain superficial improvement, reducing the numbers of those who receive public relief in proportion to the total population; but at the same time there has been a prodigious increase in the numbers of those in the next rank of poverty frequently needing or on the verge of needing help. It is not merely individuals but numerous families that live in this condition, about ten per cent of the population.

In the midst of this spreading poverty, the nation awoke to the need that everybody should be educated. The bulk of the poorer classes had never regarded, nor had been taught to regard, any sort of scholastic education as necessary for their children. When an Act of Parliament required all parents to send their children to school it appeared that many families had no means to pay for it. It was for them a new expense, and there was no cause of a rise of wages to meet it. Education therefore had to be made free. Next it is found that many children come to school without breakfast; and it is absurd to try to teach them when they are physically incap- 
able of learning. Breakfast, therefore, must be given free. But, alas! they have no shoes and insufficient clothes: Logic requires that these also should be provided. There are various social reformers who declare it to be their intention to make the State responsible for everything - for the "children of the State."

What will then become of the Family? In the beginning it arose, and throughout its changing history it has persisted, as the means of rearing offspring: group-marriage, polyandry, polygyny, monogamy, all have existed upon the sole condition that they brought up the children. The economic use of the family to this day is the rearing of children and the fitting of them to take their places in the world. No form of marriage is necessary for the procreation of children. Buthe will of procerate

But the economic use of the family, it may be said, is not the only one: it is the great school of morals and nurse of the affections. It is indeed-at least, hitherto it has been. But what sort of moral school will that family be in which the children see their parents leave to other people the expense of rearing them? And what affection will they bear to parents to whom they owe nothing but bare existence? Nay, what affection will parents continue to feel for children for whom they are no longer responsible? No doubt, for some generations to come, many parents, especially mothers, will still have instinctive affection for their offspring. But the ground of every instinct is utility; and the utility of this instinct is the faithful care and rearing of offspring. Natural selection ensures it; for those who have it not perish with their race. Arrange that their race shall not perish, and what is there to prevent the degeneration of the instinct? But in fact human affections are not merely instinctive; their development depends upon exercise. The exercise of parental affection is care and labour for the sake of the children: in that care and labour affection grows strong. Toil and fatigue lose their bitterness to the man whose thoughts are at home. No task depresses, no danger dismays him whom affection and duty incite. For him gain and ambition lose their selfishness and greediness, and every hour of life is ennobled and redeemed. 
When Plato deprived his soldiers and magistrates of all economic interests he also abolished the family amongst them; in Utopia, More supposes the community of goods to be compatible with the warmest family affections. Contrasted with the Greek, the Englishman is full of good intentions and bad reasoning. But in fact nothing is so bad as bad reasoning. It is by bad reasoning, failing to follow out the consequences of their actions, warmly indulging their amiable desires, contenting themselves with what seem to be immediate results, that well-meaning people often become more mischievous than criminals. Whoever did more harm than those benevolent people who altered the Poor Laws in 1782 and 1815? If on reflection it should appear that the gradual diminution of parental responsibility must destroy the monogamous Family, probably many people would cease to support movements that tend in that direction, even if thereby they did not give immediate ease to some of their less fortunate countrymen.

A social state in which the solidarity and responsibility of the Family no longer existed, would differ so much from our own that we cannot form the least image of it. I do not say that it could not be better than ours; but it would be most iniquitous to desire, or help to realise, something of which I do not know whether it would be good or evil. Its value will one day be known, for it will be tried. Our restless race will try all social experiments. Wanting rational power to predict, we shall try whatever flatters our hopes. We shall try again and again, like an animal shaking the bars of its cage; for not even experience can immediately create understanding. Consider what our race has gone through in this one matter of marriage; consider how much longer our race has to exist, and how much faster future changes will be; consider that out of $1,500,000,000$ people in the world only about $300,000,000$ are even nominally civilised; and then guess, if you can, what is going to happen to us.

$\S 5$. Fresh from these considerations, I cannot suppress a smile on approaching the "problem of population," the most dismal problem of the "dismal science." The future of the world may not be much affected by the following paragraphs: 
I hear the laughter of the Earth-spirit: but we must try to think. The basis of the problem of population is the Malthusian Law, that our race tends to increase faster than the means of life can be increased by our efforts. This gives rise to competition and to elimination of the incompetent, and has been a chief condition of human development. The difference between ourselves and plants and other animals under the law is that we alone can do something to increase the means of life; and that therefore there is selection of those peoples who by superior intelligence, prudence, energy and co-operation are most successful in industry. It is now admitted by Economists that an improvement in the quality of the population enables an equal number, with similar external conditions, to live better than before; and plainly improvement in the personal factors of industry is, for the most part, a moral improvement. Still, whether we shall be permanently better off for any industrial advance depends upon our ability to take advantage of it; and this always requires at last some limitation of the increase of population.

Spencer (as I have mentioned in C. V. $\$ 5$ ) infers from a survey of the animal kingdom and from the conditions of generation, that there is an opposition between personal development and fecundity; so that if the conditions of life remain favourable to personal development, such a decline of the birth-rate may be expected that, even supposing every one to marry, it will at last just balance the death-rate. We may suppose that such a state of things will coincide with the rise of that instinctive chastity spoken of above in $\$ 3$. For my part, I do not see enough ground for confidence that the conditions of life will always be favourable to personal development; since it is possible that the movement of society will be towards the formation of such organisations as we see amongst bees and ants, depending upon a total efficiency of the group, and compatible in human beings with a high specialisation of classes along with a decrease in the breadth of personal development. A balance of population might then be reached through the sterility of certain classes of the group, whilst sufficient offspring were obtained by the increased fecundity 
of others. We do not enough consider how many things are possible and how short-sighted we are in social affairs.

At any rate, Spencer's solution of this problem is practically so remote of attainment for $1,500,000,000$ people mostly barbarous-say in 1,000,000 years-that the social reformer eagerly seeks some readier way out; and the most obvious way is the prudential restriction of the numbers of each family according to its means. This course, suggested by Malthus' observation that the positive or destructive checks upon population tend to operate inversely as the preventive checks, so that choice lies between a high death-rate and a low birth-rate, was much in favour fifty years ago with the disciples of Mill. Apparently, however, it is not a device in which people need philosophic instruction, since it is everywhere adopted by people who reach a certain standard of comfort, and see their comfort encroached upon by every addition to the family. It prevails in New England, Australia and amongst peasant-proprietors everywhere, and was known in several ancient States. It spreads from the well-to-do downwards as far as there is anything that can be called comfort. Everywhere the old custom of families is to have as many children as can be born. Especially, as long as ancestorworship prevails, every one desires to have children who may celebrate his funeral rites, and maintain the traditionary sacrifices for the peace of his own ghost and of all his forefathers. As customs lose their power and religion relaxes its hold upon life and reflection intervenes, men see the consequences of a large family to property, and women to their own health and leisure. The love of offspring is strong, but not stronger than all the other desires of life with which, in fact, it comes into competition. Besides, one motive for limiting the family is to do the best for those that are already born; another is to have some opportunity of "selfrealisation." The egotism involved in "neo-malthusianism" need not be without excuse. But the excessive love of comfort, which plays a large part in it, is a moral disease. One result is that a smaller proportion of children come in each generation from those classes that have the greater 
intelligence, character and health, and a larger proportion from those that are every way inferior. Comfort increases in the wealthier classes and the death-rate falls, but the average quality of the population deteriorates. During the nineteenth century the average quality fell, because great industrial and vehicular inventions, combined with freedom of commerce, facilitated a rapid increase of population; which multiplied by three; whereas the former rate of increase since Doomsday Book was a doubling in two hundred years $(1050$, about $1,000,000 ; 1400$, about $2,000,000$ - the Black Death having lately destroyed about one-half;-1600, 5,000,000; 1800, 10,000,000 for England and Wales; $1900,30,000,000)$. Such an increase can only be explained by many being born of parents and grandparents who in sterner times would have been eliminated; therefore there was a fall of the average quality. And this is now being followed by another fall in the effort to preserve the comfort that has been attained.

Moreover, the limitation of families is partly due to a deferring of the age of marriage; whilst there is an increase of those who do not marry at all. But statistics show that an increase of celibacy is accompanied by an increase of prostitution. And it is obvious that since those who restrain their sexual propensity are either those in whom it is weak, or those who have unusual self-control, the increase of population may chiefly proceed from those in whom it is stronger or unrestrained; so that the scourge of lust will continually bite deeper.

It may be urged on the other hand (1) that if the birthrate is higher in the poorer classes, so is the death-rate; and it is true that the net degeneration is for this reason less than it otherwise would be. (2) That since the remote ancestors of the nation are on the whole the same people, there is a general tendency for the offspring alike of superior and inferior parents to revert to the average; so that the children of the weaker classes, especially the survivors of them, will at least be better than their parents. This is the Law of Regression, pointed out by Galton (Natural Inheritance, c. vii.). 
Other consoling considerations are not equally sound: as that the difference between the children of different classes lies mainly in nutrition, hygiene, education: so the sentimental newspapers tell us. It is foolish to disparage the power of heredity. And it is useless to exaggerate it, as in some of the proposed eugenic plans-to breed from selected couples in order to improve the blood of $1,500,000,000$ people, mostly barbarous. If we learn anything from Biology it is that there can be no improvement without elimination. As long as a considerable proportion of births are of inferior quality, a high death-rate or strict segregation of failures is necessary to progress. Formerly elimination resulted from competition; and the love of comfort which seeks to evade competition, as in Australia and New Zealand, is a moral disease.

Whether anything can be done to weed the population by permanently segregating criminals and quasi-lunatics and imbeciles, by preventing marriage amongst certain classes of invalids and hereditary suspects, by euthanasia of certain idiots and incurable sufferers, time will show. Even the Laws of Manu teach the avoidance of marriage where there is hereditary or personal disease (III. 7-8). And the wide prevalence of infanticide indicates, at least, what human beings are capable of in extremity.

§6. A sensitive mind shrinks from imagining any great change in the life of the Family. We know that many detestable things have been held right and honourable by barbarians and strange outlandish people; but that the family of our love, having once been established, should ever be abandoned by our own children's children is an intolerable suggestion. In fact, it is impossible really to imagine it: we cannot construct any relationships to replace the present ones with any definiteness or confidence as to their grounds in causation; much less can we clothe any hypothetical relationships with corresponding feelings and affections. Hence it is impossible not to wish that the family may remain much as it is, in order that we may retain some sympathy with the future of the world.

The family with its traditionary customs is the great 
nurse of the moral life. Whatever is good and right we are taught there under the inseparable sanctions of affection and duty. Even if we are taught in the name of religion, still the sanction of religion is set before us in the image of the Family, as the highest that we can understand and the sure way to reach our hearts. Truthfulness, honesty, kindness, generosity, justice, are all taught not only by precepts but in the necessary experience of association with our parents and brothers and sisters. In this society our perceptive sympathy develops: we soon come to know what every one else feels about our own actions and about every event that happens: thus our personality is in some sort merged in that of others, or theirs in ours. More slowly our emotional and active sympathies develop: we feel as the others feel and share their desires and resentments. To be gladly taken into their life is our chief happiness; to offend them, to be thrust away from them, is an intolerable bitterness. In fact there is danger in the closeness of a child's family life; if the ideas of the family are unenlightened, if its feelings are perverse or ill-balanced, he may never get over it. But everybody knows that this early nurture far more than anything else in our lives, determines our moral beliefs and sentiments. Naturally it falls in with our inherited dispositions; and the events of our after life, however impressive, even a change of religious belief, generally leave the essentials of our early convictions unaltered. It is this aptitude of the monogamous family to be the great nursery of morals that gives it its hold upon the world, and which by conferring a superiority upon every nation that maintains it, may well ensure its permanence.

The fact of education within the family being known to every one, we find it almost incredible that Kant should have rested morality exclusively on a command of reason; and that Schopenhauer should have ascribed it entirely to sympathy. Why, when the whole fact is before their eyes, will people insist upon only one side of it? It may be said, by way of excuse, that Kant was a lonely old man who had no family of his own and had neglected intercourse with his parents' family. Still, he was once a child. For Schopenhauer it 
may be said that sympathy had been sadly lacking in his own nurture, and so may have seemed to him the one thing needful. But, plainly, morality is not merely sympathy, but involves duty; and, again, so far as we are good, it is not merely through duty but through affection. Reverential duty is derived from patriarchal authority; and in family life sympathy and affection coincide with reverence. Undoubtedly the proportion of these elements in the moral life has varied; probably the further back we go in the patriarchal tradition the more prominent authority was; sympathy and affection have become more important as the cohesion of the family more depends upon them. There has been a parallel change in our religious feelings. A decline of the reverential spirit in youth inevitably follows the alteration of patriarchal conditions; and it becomes increasingly difficult to preserve the noble tone of life.

It is true, of course, that not every family provides its children with the conditions of moral development. In what circumstances children as they grow up may be justified in escaping from their families; in what circumstances public authority may be justified in taking children away from their parents, I shall not discuss; but the breaking up of the family by separation of husband and wife is a matter that cannot be passed by. Divorce is permitted by our civil law for adultery on the woman's side; on the man's for adultery with cruelty and desertion. To make sex a ground of such differences is a revolting partiality in public law. The moral justifiability of divorce for any of the above causes is plain on the simple consideration that adultery, cruelty and desertion are in fact acts of divorce by the guilty party, and that the legal judgment is a formal declaration of it. This truth is disguised by the procedure which makes it appear that divorce is the act of the innocent party. Religious opposition to divorce rests upon the same grounds as religious disparagement of marriage. The sexually diseased mind of a priesthood, that condemns the natural conditions of human life, only tolerates marriage under supernatural sanctions whose obligation is necessarily unlimited. 
Milton argued that divorce should also be permitted for " disproportion, contrariety, or numbness of mind." “ Among Christian writers touching matrimony; there be three chief ends thereof agreed on; godly society, next civil, and thirdly that of the marriage bed. Of these the first in name to be the highest and most excellent, no baptised man can deny, nor that idolatry smites directly against this prime end; nor that such as the violated end is, such is the violation: but he who affirms adultery to be the highest breach, affirms the bed to be the highest of marriage, which is in truth a gross and boorish opinion, how common soever; as far from the countenance of Scripture, as from the light of all clean philosophy and civil nature. And out of question the cheerful help that may be in marriage toward sanctity of life, is the purest, and so the noblest end of that contract: but if the particular of each person be considered, then of these three ends which God appointed, that to him is greatest which is most necessary; and marriage is then most broken to him when he utterly wants the fruition of that which he most sought therein, whether it were religious, civil, or corporal society. Of which wants to do him right by divorce only for the last and meanest is a perverse injury" (Doctrine and Dicipline of Divorce, Book I. c. ix.). Milton specifies idolatry, as the context shows, merely as an extreme case of mental or moral incompatibility.

Now whether this argument is conclusive or not, depends upon how high we rate the claims of the individual. If we put them very high, as Milton did, his conclusion is indisputable: a marriage that frustrates personal development fails of one chief purpose. But if we consider that the human individual always depends upon society, and that the higher his culture the greater is his debt, it may appear that even his claims to personal development must sometimes give way to social claims. Our life is by no means in our own control; besides contracts of specific obligation, there are many customs and understandings which we observe contrary to our personal interests. Marriage is an extreme case not only of specific contract, but also of universal custom and understanding (in 
this country) that its duration shall be life-long. The moral grounds of this are, first, that it springs from love mutual, impassioned and unconditional ; secondly, that it is an expanding, strengthening, and ennobling of life; and, thirdly, that the interest of future generations infinitely outweighs our own. It is admitted to make a great difference whether there are children of the marriage and how old they are; but suppose there are none, it affects the particular marriage, but not the significance of the institution. The difficulty is that the moral grounds of marriage are idealised from the natural institution, but are often forgotten in actual contracts.

If in any nation a strong feeling should prevail in favour of divorce for incompatibility, so that separations actually took place upon this ground and met with public sympathy, it might be unwise to try to oppose it by legislation and thereby incur the terrible evil of public disapproval of the law. The judicial separations now often arranged seem to me to be in the nature of a very unsatisfactory compromise. It is urged that to grant divorce in such cases would enable the offending party to marry again; but if punishment in such cases is desirable, some other means of enforcing it should be found. For this particular punishment has hardly any deterrent effect, and may be expected to give rise to further irregular connexions. As to whether second marriages are justifiable at all, or whether we should not emulate certain noble birds that cannot forget, the occasions and motives of marriage amongst us are still so far from being (in many cases) justifiable by moral reflection, that it is useless to attempt the casuistry of questions of great refinement.

Similarly with the legalisation of marriage, it may seem unreasonable to condemn all attempts to dispense with it, if affection and fidelity in fact exist. But one cannot help seeing that on the woman's side the risk is unfairly great; and that the man ought to consider that he does not know his own character well enough to be safe in all contingencies, and that the depth of ignobility is to allow others to incur danger for oneself. Or, again, it may be said that ' marriage and parental responsibility do not involve cohabitation and domestic life. 
Why should people be condemned to domestic life if they do not like it? Go as you please.' But they are not condemned to domestic life, but only to keep their contracts. If they choose to agree to live separately they can ; and can even, if they like, pay for the care of their children in other families : behaving even then better than cuckoos. Or further, 'since some women like to make love and have children but not the worry of rearing them, whilst others have less amativeness (as the phrenologists say) but a passion for nursing; why not take advantage of this natural basis for the division of labour?' Because it would result in a great increase of amativeness amongst us and a corresponding decrease of maternal affection; whereas there is already quite enough amativeness in the world, but not enough maternal affection.

$\S 7$. Our feelings and judgments concerning morals are chiefly formed in youth by family life; and thence, with the extension of knowledge and sympathy they spread to all other social relations. But the Family is not the sole source of morality. In the active selection of savage and barbarous life, affection and duty must in successful tribes become instinctive in other than merely domestic relations: to resent the breaking of customs; to succour the wounded; to follow and defend the chief. Sutherland draws too strictly the division between morality and law when he writes: "From the usages that grew up within the family sprang morality; from those that grew up between the families sprang law" (Moral Instinct, c. xix.). Law he traces entirely to attempts to restrain the blood-feud (c. xx.). But the relations of families, or even of tribes, barbarous or even savage, are not uniformly hostile. Marriages are often arranged otherwise than by capture; rights of hospitality are widely recognised; commerce sometimes exists between remote tribes of low culture; alliances of tribes are sometimes formed, as by the Iroquois; and the custom of observing the conditions of all these peaceful relations generates moral feeling. Nay, surely, the feelings and ideas that support and are maintained by the blood-feud and the wer, or compensation, must be called moral, however much we may disapprove of them; and though 
themselves rude and destructive they contribute largely to our sentiments of justice. In some degree, intercourse and effective sympathy are met with outside the family circle even amongst savage peoples.

It must be acknowledged, indeed, that the influence of the family upon general morals is not always beneficial. The very force of internal cohesion in the family seems to generate repulsions between different families, and similarly between different tribes. The force of internal cohesion survives into our own time in the phenomena of nepotism. Too strong even for publicly educated men, it is generally believed to be still more active in women. In defence of them Mill (taking no account of heredity) says: "All the education that women receive from society inculcates in them the feeling that the individuals connected with them are the only ones to whom they owe any duty-the only ones whose interest they are called upon to care for; while as far as education is concerned they are left strangers even to the elementary ideas which are presupposed in any intelligent regard for larger interests or higher moral objects. The complaint against them resolves itself merely into this, that they fulfil only too faithfully the sole duty which they are taught, and almost the only one which they are permitted to practise" (Subjection of Women, c. iii.). They seem in former days to have been the most persistent upholders of the blood-feud, as I have mentioned. Confined to the family, women are the last to be touched by the movement of ideas, so that everywhere-in France, for example-their minds are the strongholds of superstition. Spencer, again, observes that, in one respect, the family and the external relations of men are rightly ruled by opposite principles. In all cases of sharing outside the family the maxim is-" to each according to his efficiency," inside the family - " to each according to his needs" (Sociology, § 322). The transfer of the family maxim to the industrial and financial relations of the outside world, is the essence of sentimental communism.

Nevertheless, the extension of the idea of the Family to include the tribe and at last the whole world has had an 
immeasurable influence upon political and religious ideals. The family is early conceived as having a quasi-mystic unity, and the same idea incorporates the tribe as, either by tradition or by rites of adoption, all its members are conceived of as one in blood. To confer the title of Father upon chief or king qualifies with affection the most revolting tyrannies; so that one witnesses the pathetic spectacle of a nation condoning the brutality of a line of Tzars with the name of "Little Father." From kings the name of Father is acquired by gods; and with the rise of a supreme god, Zeus or Odin, or of One God, the title of All-Father conferred upon Him unites mankind, and prepares the way for family affections, in the form of universal benevolence, to cast down the barriers of tribe and caste and colour.

But here, again, we see how the influence of family ideas beyond their original limits may be highly injurious; for tribe and caste and colour may stand for profound differences of personality that cannot be obliterated without a loss far greater than the gain. 


\section{CHAPTER VIII}

INFLUENCE OF THE STATE ON MORALS

$\S 1$. THE considerations upon which we are about to enter are so complex and far reaching that every section of the present chapter might give occasion to a volume. Yet they have been generally neglected; and my chief hope is that by jotting down the heads of a few essays upon the moral influence of the State, I may draw attention to the matter. Whilst there is a valuable suggestion in Plato's doctrine that the State takes its character from its citizens, the important qualification must be made that citizens, by being such, are not independent individuals, and that their relations to the State and to one another determine their character.

Three questions concerning the State have been long and warmly debated: its origin, its End or final Good, and the ground of its stability. If we knew the origin of the State it might be expected to throw some light upon its relations to the individual, upon the antiquity and hereditary and traditionary character of this adaptation to others, or upon the difficulty of reconciling its claims with his. If, for example, we knew that the State was always founded upon conquest, this might be thought to explain the irreconcilability of many men to its claims more easily than if it could be shown to have resulted from an agreement, or to have developed from the Family. But, in fact, whatever the origin, it occurred so long ago that, whatever the perfection of the earliest adjustment between State and individual, there have since happened changes enough to explain at least as much disaffection as we see in the world. 
By a State I mean a body of people amongst whom Government exists with power to enforce internal order and to direct its military resources in defence or aggression; but how far such government must be permanently vested in a definite organ cannot be exactly defined. The States that we now see around us have not all had the same proximate origin. The Governments of England, France, and Spain are founded on conquests that happened a good while ago; the United States of America and the German Empire more recently upon deliberate agreements. But in these cases the conquering or constituent powers had governments of their own; and if we try to trace back all the States we know it will be difficult to find any that were not either established by conquest or essentially modified by a conquest at some critical point of their history. Nevertheless, some forms of the State having existed long before the beginning of history, and all known savages and barbariaus having certainly diverged from the original common condition of mankind (if there ever was such a thing), it is plain that the origin of States can only be a matter of hazardous speculation; and therefore it is a relief to consider that our conclusions about it could have little or no effect upon morals. This was not the opinion of philosophers two or three hundred years ago. They hoped to draw from their theories of the origin of the State reasons in favour of most social observances, especially allegiance and responsibility. It is very instructive to observe in men of the greatest calibre-Hooker, Hobbes, Locke-what a feeble sense they have of the cogency of arguments; as thus-" the act of a publick Society of men done five hundred years sithence standeth as theirs who presently are of the same Societies, because Corporations are immortal; we were then alive in our predecessors, and they in their successors do live still " (Eccl. Pol. I. x.). Similar fictions satisfy Milton and Locke; but to see how high they stood above their age, compare their reasoning with the pedantic fatuosity of Filmer or Salmasius. Such fictions, too, seem to satisfy Hobbes; but I do not think that he believed the Contract to be historical; and in general there is a utilitarian ground for his argu- 
ments, which is disguised and weakened by the fashionable hypothesis.

The contractual theory is a confusion of ideas concerning hereditary obligation, derived from the ages of status, with ideas of the superior equity and moral validity of contract derived from an age of individual emancipation; and a fusion of the Stoical theory of Laws of Nature with the Epicurean doctrine of a fortuitous assemblage of human atoms. When it flourished there was little that could properly be called history, no sense of antiquity ; the scanty records of a few hundred years carried everything back into a thick mist, in which the positing of some notion of creation or of a mechanical concourse must account for everything as best it could. Men from our earliest knowledge of them appeared to have been in some measure rational, at least as rational as Hooker's contemporaries. Why, then, should they not have made a contract? He did not perceive how far his contemporaries were from being rational: who does? And, of course, he could not surmise anything of the still less rational "Preadamites," to whom we are accustomed to trace everything that interests us. Modern history is a construction upon methods, and often with data, derived from the physical sciences, on whose simple phenomena method had first to be practised. In the same school we have learnt to follow the connexion of ideas with a closeness that makes the old acceptance of legal and moral fictions almost incredible. Yet the contractual theory with its crude assumptions was almost inevitable to an enlightened mind during the period from Hooker to Locke, and may best be considered as expressing the conviction that social and political conditions ought to be such as a just man would consent to.

At present two hypotheses as to the origin of Government are much in favour. First, the patriarchal: if we suppose that our forefathers, after they became recognisably human, still existed in independent families, we have here the necessary origin of a certain kind of government; for the father of the family must rule at least during the nonage of his children; and we know that in several branches of the race his rule might continue not only over his sons but his sons' sons. And it is 
easily conceivable that if several families united, one of them might obtain a predominance, its name might be accepted by the rest, and its head might exercise a patriarchal sway over the whole clan thus formed. But if we think that from the first a human society consisted of a number of families united for the purposes of hunting, implying possible war for the defence or extension of their hunting-grounds, it seems more reasonable to adopt the second view; that government resulted from the persistent leadership of the most distinguished man of the horde, whether his distinction lay in hunting and fighting, or in oratory, or in magic, or in all these faculties. That only by a rare accident could such personal ascendency be perpetuated in such a way as to establish hereditary chieftainship, is no objection; because there were hundreds of thousands of years to experiment in. It was necessary that there should not only be a perpetuation of personal ascendency, but also such a modification of the members of the horde as to make them devoted to their leader. Without this a horde could never become a tribe. It is the second hypothesis that commends itself to me; and I think the patriarchal families may in most cases have grown up within the tribe or State at a certain stage of its development, being, indeed, the households of the chief's or king's companions, or of the principal owners of land or other property. Still, as I have said before, it is probably a mistake to insist that any of our institutions had only one origin. Possibly the State originated in some cases from the Family, in others from the Horde. In either case the extension of its limits and the growth of royal power seems to have depended chiefly on conquests ; and this, undoubtedly, has had important moral consequences.

But we may be sure that, in whatever way a State was formed, it was never with any clear view of all that was involved in it. The early consolidation of a patriarchal family or chief-led tribe must be considered, in relation to the small foresight and circumspection of primitive men, as an accidental variation favoured by natural selection. If, later, a State is extended by conquest, there is doubtless the motive to obtain a full, free life at the expense of inferiors ; if by agree- 
ment, the desire of safety or peace or military predominance may have been active. But the conception of an End or Chief Good for which the State exists is, to this day, the property of a few speculative minds; though it is true that, in certain periods of national exaltation, ideas concerning the national purpose or destiny are widely propagated. The moral significance of such a conception is manifest: it may either control or subserve morality. If, for example, the State exists for its own aggrandisement or glory, or (to be more colourless) its own development, as an End in itself, the moral ends of the individual are limited by this purpose. Since there cannot be a rational conflict of Ends, the End of the State must be the moral End; and we may sometimes meet with enthusiasts for this doctrine; which, like all impassioned abstract ideas, has a certain unselfishness and ennobling power, but is apt to narrow our vision to some special interest, such as war or trade, and to blind us to the actual complex conditions of human life. On the other hand, if the State exists to promote the greatest happiness, or personal development, or culture, these are recognised moral Ends, and the State becomes an organ of moral improvement. If the End of the State cannot be shown to have been predetermined by Nature or Providence, it may be possible for us to determine it for the good of mankind, if we can agree as to that. But if Nature or Providence has secretly appointed the End, we must suppose that it will be realised whether we like it or not.

But even if the origin of the State and its true End are alike obscure, we may perhaps discern the present source of its strength and durability. The old doctrines of Divine Right and of the obligations of an original Contract having been abandoned, many people believe that its durability depends on nothing else than force-military or police; others say it is not force but Will. ' 'Will,' however, must mean consent, since else it could only be effective by force; and this consent is represented as the element of truth in the old doctrine of a contract. Yet it cannot be said that in Russia or in some provinces of Austria, the State exists by consent; and, in fact, seeing how many disaffected people have sometimes been found 
in India or Ireland or even nearer Westminster, it is plain that force has everywhere something to do with political stability. But granting that where force is resorted to or relied on, it must have the consent of the majority, or at least of some important or effective body with their dependents and admirers; still, why do they consent? The grounds of consent are the real grounds of government; and those grounds, according to Hume, are the same for allegiance to government, and for keeping contracts and for all justice, namely, Utility : of which he conceived, of course, in the old-fashioned way as an easily intelligible interest in public order. But, in fact, the matter is conceived of in this way by very few. The stability of the State has the same grounds as the practice of morality : gregariousness and other instincts, customs and customary judgments : such instincts and customs having been fostered by the biological utility of the State. Being a condition of better co-operation, nutrition, safety, and of increasing populousness and power, the State exists because those adapted to live in it have an immeasurable advantage over all others. Those who cannot adapt themselves to the State perish, or linger wretchedly in desert places. The instincts and customs involved in the life of the State are sociality, effective sympathy, approbation and disapprobation, loyalty, religion, justice: in short, the greater part of the moral life; so that it must be of the utmost interest to the moral life, whether the form, administration and other conditions of the State tend to develop or pervert these instincts and customs. They and the State grew up together before their significance was understood, and still it is not clearly understood.

$\S 2$. We may consider first how morality is affected by the mere size of States: whether through the tendencies favoured in the population by large or small States respectively, or by the general development of personality. Of course the distinction between large and small States is a relative one; and so many other differences, political, geographical, etc., besides size, are effective, that all generalisations will be approximate and tentative. We may obtain some relief from these difficulties by attending chiefly to civilised 
States, and by observing that by "small States" may generally be understood either City States, like those of ancient Greece or of Lombardy in the later middle ages, or others such as Holland in the seventeenth century where the influence of cities is predominant.

A small State is narrowly circumscribed by neighbours, toward whom antipathy is almost constant, and open hostility frequent. This fact bears upon all the internal relationships of citizens. In every small community a principal occupation of leisure hours with most people is criticism of others, the spread of information and hypothesis concerning their ancestry, character and condition. In a small State, where every citizen is important to the whole as a soldier and politician, such criticism is more active and penetrating, and every citizen must be keenly aware of it. He knows that he walks down the street under the commentary of all who see him. This may not produce dissimulation or hypocrisy, if the conditions of life are otherwise favourable to virility; but it can hardly fail to produce 'ego-altruism,' the disposition to judge one's own person and actions according to the effect they are believed to have upon the feelings and judgments of others: the sense of their fellows' approbation or disapprobation, in the forms of vanity, respectability, honour. And this spirit is immortalised in $\tau \dot{o} \kappa a \lambda o ́ \nu$, the motive of all practical virtue, according to Aristotle, reflecting the common sentiment of Greeks.

The constant antagonism of neighbouring States intensifies a narrow patriotism, with the stupid prejudices which are its shadow, but also with the enthusiastic devotion that may give it splendour. In such an atmosphere the State may become a redeeming ideal; and it is usually much needed. For the incessant intercourse and mutual knowledge of citizens intensify and embitter the divisions of interest that everywhere exist, and give rise not only to personal jealousy but to outrageous faction. These factions indeed may become so insane that each side (aristocratic or democratic) feels itself to have more in common with the corresponding body even in the rival Cities than with its domestic opposite and, if defeated, may 
call in the enemy. (It must be admitted that this sometimes happens also in Country States.)

The incessant intercourse of citizens tends to develop amongst them the arts of expression, facial, gesticulatory, vocal, and with the arts of expression the perceptive sympathy that interprets expression. In such a Society every man knows instinctively what is passing in the mind of others, and the ego-altruistic spirit is greatly subtilised. The consciousness of this ought to discourage dissimulation, but may impel one to greater refinements in acting a part. Incessant intercourse also develops general intelligence and taste; and intelligence is the principal condition of moral criticism and of the generalisation or unification of virtue, as Aristotle observes; and taste is closely related to morals, especially of the ego-altruistic kind, as the conception $\tau \dot{o} \kappa a \lambda o ́ \nu$ witnesses.

Finally, the spirit of patriotism and the ego-altruistic spirit, together with personal rivalries and the opportunity offered by a small State for the individual to produce an important effect upon affairs, all unite to spur men on to distinguish themselves. This is what makes the City State a forcing-bed of ability, and it helps to explain the disproportionate numbers of remarkable men whom they produce in comparison with Kingdoms and Empires. For the same reason, in such a State, the pressure of public opinion in Democracies has not the effect, feared by Mill, of reducing personality to a uniform type: life is too active, and variety is involved in efficiency.

In a big country State, whilst the metropolis may share some of the features of a City State, there are great areas in which indeed local characters abound and a great reserve of personal strength often exists, but where there are no influences to force the growth of efficiency, taste or intelligence. Gossip is less continuous, but hardly less malicious, and it is unenlightened by public interests. Faction is less rife, except amongst leading families. Patriotism is duller but steadier. Morals remain customary. The general conditions of life are favourable to egotism outside the family; 
but this is less repressive of compassion and active sympathy than ego-altruism, which diverts our attention in relation to others from what they feel and how they are concerned for themselves, to how they feel or are concerned toward us. Moreover, in spite of parochial jealousies, the remoteness of foreign countries and faintness of faction give less occasion in obscure localities for the repression of active sympathy. Hospitality flourishes. Perhaps the sense of belonging to a great power is favourable to magnanimity.

In a small State the private citizen comes into contact with the Sovran Power both as subject and as participant; and this sovran power is responsible and enlightened in comparison with the ignorant and mean official life which is too common in country districts. Direct contact with the supreme government is above all things stimulating. Sovran legislation, finance, the control of peace and war: these functions may be seen to lend a sort of distinction to commonplace men; they have the latest information, the best advice, the instruction of traditionary tone. No lesser sphere, such as a County Council, has the same efficacy. It is a great detraction from the merits, whatever they are, of World-States, that the central Government supplants or overshadows the local powers and therefore diminishes the opportunities for the highest distinction. If all the English Counties were sovran States they would produce hundreds of statesmen and generals, hundreds of poets, historians and other desirable persons, many of them as capable and destined to be as illustrious, as the few who now attract the plaudits or the brick-bats of a London crowd. A paucity of merit exists amongst us not for want of men but for want of opportunity and incentive. And what is true of citizens is true of Cities. In a WorldState there is but one metropolis: this attracts ability and gives recognition; other cities are impoverished and obscured.

Sometimes the predominance of one interest in a State discourages the development of individuals in other directions and tends to produce a monotony of manifestation. Art was favoured in the Italian Renaissance, and is discouraged by the trading spirit of Holland and America. It appears by statistics 
that from Hampshire are derived more distinguished men of letters than from Yorkshire: doubtless because in Yorkshire there is something else to do.

The influence of a State upon its citizens depends upon its standing in relation to others, especially to neighbours. The foremost States are the most stimulating, and all States produce their greatest men and their noblest character at those epochs during which they rank highest: as may be read in the histories of Portugal and Spain and Holland. It is not that great individuals then aggrandise the State, since its greatness may be traced to general causes. Nor do they merely present the illusion of men magnified upon a platform. At such times they are really greater than they could be at any other: partly from the stimulus of their position; partly from sitting at the receipt of ideas and in the focus of the most vitalising public feeling; partly because the greatness and security of their place makes it less necessary to be scrupulous about the interests and designs of others, removes innumerable inhibitions, and so gives that release of all faculties which is essential to the manifestation of genius.

$\$ 3$. Concerning the influence of forms of Government upon character there are many commonplaces: as that in a Despotism only one is supposed to be free, and that his freedom is merely passion and caprice; that an Oligarchy is favourable to personal development in the higher ranks, but also to avarice, and to pride masked perhaps by politeness; that under both forms the mass of mankind is reduced to servility and inured to deceit and cowardice; whilst in Democracies you find indeed great popular activity but also jealousy, license and inconstancy. To me it seems impossible to generalise in this way with much confidence, seeing what variety of constitutions is concealed under these titles, Despotism, Oligarchy, Democracy. For Despotism may be modified by the presence of families holding hereditary ranks and offices, or by organised priesthoods that are the real depositories of power; Oligarchies differ according to the sources of their wealth, or their military character, or as they are limited by customs, or divided by faction; Despot- 
isms or Oligarchies may be dependent on bureaucracies of more or less ability, honestly paid, or left to cheat and plunder; the exploited classes may exist in various degrees of poverty, degrees of servility. Democracies, having hitherto had few examples, and having been of comparatively short duration, may excuse their faults on the ground of their inexperience of power, the violence of their revolutionary birth, the dispositions derived by their citizens from the earlier political state; and they vary in extent and constitution. It would need a volume to trace the moral consequences of all these modifications.

On the whole, the abuses of Despotism have not been painted in too gloomy colours: there are long ages of history that one cannot think of without horror, shame, burning resentment. History has been represented as a continuous revelation of God: but to me, on the contrary, it conveys the strongest suggestions that the course of this World is not determined by moral Ends. All the ravin of the lower regions of Nature is morally insignificant compared with ten years of misrule in Russia.

If we inquire into the origin of political rank, it seems traceable to three conditions-(1) the appearance of exceptional individuals who lead others; (2) on the part of others, admiration, and a willingness to follow leaders; (3) the advantages to a tribe of the united action thus obtained. These advantages are so great that to secure them (as Galton suggests) a low average of ability and independence of character may have been bred in tribes, in order that the majority might be easily led, provided there remained also the variability requisite to provide exceptional leaders. But merely negative qualities, such as low ability and lack of independence, are not enough ; there must be devotion to the leader if any lasting result is to be obtained. When leadership becomes hereditary in royal or noble families, rank is established, as distinguished from seniority or personal eminence. The further differentiation of ranks need not be discussed.

The natural history of royal and noble families has not 
yet been adequately written: there are many species and varieties of them, according to the different conditions of their development. The kind that has most significance for morality is that in which the King or noble is regarded as descended from the gods, and also as the head, representative, or essence of his tribe by a sort of incarnation of its ideal blood-relationship. To this position belong the sentiments of mutual devotion: the king to his people, the people to their king. It cannot be understood by legal notions of contract or trust, to which it is long antecedent. Of kingship and loyalty we may say what Aristotle says of friendship, that they imply justice but make it needless. This is the nursery of valour, liberality, magnanimity, fidelity, all impassioned virtues: without which the world is a horrible place. Such kingship is not a private good, nor is it a disparagement of any man to follow such a king.

That which ruins kingship, often turning it into despotism, and nobility, converting it into oligarchy, is the founding of them upon conquest. Then the imagination of tribal blood-relationship is lost and the common people are scorned. Rank becomes a private good, existing not for the sake of the people but against them; who, therefore, are degraded by it. It is a pitiful thing to read in history how this revolution was sometimes imitated, as in Germany and Scotland, where there had been no conquest, through the adoption of feudalism by families that might have perpetuated the ancient life.

As rank everywhere carries wealth it gives occasion to luxury, that is, to the development of the arts of life, building, costume, cookery: things promoted in the consanguineous tribe by every tribesman without grudging, as touching the honour of all. The fine arts, too, flourish at the court, and poets glorify the divine and heroic traditions of the house and promise immortal fame. But when rank is founded on conquest luxury takes a different character, the character that has made it the aversion of popular moralists, ostentatious extravagance, cruel arrogance, sensual indulgence; but the worst of it is that it involves the degradation of servants, slaves, mountebanks and women, and that their degradation 
reacts with terrific force to debauch, corrupt and brutalise the masters.

However, when amongst tribes of men character has been established by long breeding under simple conditions, it is not easily broken down; so that even when rank has changed its basis something of the old feelings between princes and people remains, and is extended to new relations. The spirit and traditions of chivalry still surviving are a proof of this. The effect of rank is nearly always to raise the moral feeling of some families. In them disparity of conditions stimulates reflection upon the true grounds of personal worth; and even injustice quickens the sense of justice; in short, there is progress from instinctive to conscious morality. But the special sentiment of rank, namely, honour, though indispensable, has many shortcomings. It is indispensable because many judgments of conduct must be determined by opinion; and the opinion most keenly felt, and often the only opinion that need be weighed at all, is that of one's own class. Since without uniformity of practical judgment no body of men can hold together, the code and sentiment of honour necessarily arise. But then (as we have seen) the opinion of a class is limited by its interests, and conduct that seems to lie in the interest of the majority, or of an influential party, cannot be condemned. Hence no code of honour was ever an adequate substitute for common morality. Still, here again the sentiment admits of extension, and in fact many a gentleman adopts the common morality into his code of honour; and common morality might be greatly improved by taking example of the spirit of honour.

As rank carries power, the spectacle of it inflames and directs that passion for leadership which is natural to some men; ambition and, associated with it, the love of fame. Of course, ambition is no proof of ability. In every generation thousands of boys and girls have an instinctive disposition to distinguish themselves in poetry or the fine arts; but not one in a hundred has capacity. So it is with leadership; and the willingness to 'take responsibility' that we often hear praised, is, in most cases of incompetence, an impudent disregard of 
public interests. Still, there may be nothing for it but to let them try: we have no measure of youthful promise; and the need men have of leaders is plain enough. Ambition is a variation that occurs persistently in successful tribes, because successful tribes are those in whom it occurs. Moralists, understanding nothing of its nature and functions, usually condemn it, and demonstrate its irrationality to the satisfaction of the unambitious. It is in fact egoistically irrational, if we exclude from consideration the satisfaction of the instinct itself: this is its illusion. As to the mischief done by ambitious lunatics and failures, it is no doubt great. To counteract it there is no course but to cure the suggestibility and sheepishness of mankind whereby they are duped: that is, to educate the present generation as well as possible, and try unremittingly to breed a better one.

The distinction of ranks, so far as it involves political, economic and social opposition, when dignity implies indignity, gives occasion to class feelings and class prejudices, suspicion and jealousy. Complaints concerning such feelings are oftenest heard from the wealthier classes, though it is in them that such feelings are strongest. It is indeed wonderful how little illwill toward the rich or educated is felt by the great mass of the poor. Those who are near the border line are sometimes envious of those on the higher side of it; and ambitious men, whose birth hinders them in rising, must be exceptionally amiable or philosophical if they do not resent the privileges of men who have only accidental claims to superiority. But the ordinary labourer seems to take his lot with irreflective dumb submission: he is used to it and, being down, need fear no fall. It is otherwise with those who have accidental claims to superiority: they may not always be able to make them good. When rank has been hereditary for generations under approximately settled and peaceful conditions, so that there has been no active elimination of the unfit, it must happen that many men of rank are of inferior personal worth, and that the average men of the privileged classes are very little above the general average of the people. This fact, when competition occurs, is brought home to them, and they then cling the more 
tenaciously to birth, to some special stamp of education, manners or other marks of superiority: especially, if possible, to Race with its associations of ancient hatreds, and they regard with more and more bitterness and scorn every attempt at competition from the world below. Moreover, the position of many of them becomes economically insecure, partly from direct impoverishment, partly from the relative increase of plebeian wealth.

The class antipathies of rank easily become cruel because full of fear; those of the ambitious climber mean, because involving an acknowledgment of inferiority. Manifested on a large scale, these antipathies produce class-wars: in by-gone times, insurrections ; nowadays, a perpetual struggle to cast the burden of national taxation upon the other party. It is the plain intention of certain groups to impose upon the middle and wealthy classes the cost of maintaining all the moral and physical failures in the country. Those who have earned and saved anything are to pay for all the children whom those who can earn nothing, or will save nothing, choose to beget and then refuse to feed or clothe or educate. The wealthier classes think this grossly immoral, and so it is; but let them remember the Statute of Labourers, the laws that made Trades Unions conspiracy, the Corn Laws, the enclosures of commons-let them remember, and then say if they are not now being rewarded according to their deeds. Injustice perpetuates itself, and descends as a national curse from generation to generation.

One of the evils of the class system is that it prevents the growth of friendship between many people who else would naturally be friends. Aristotle complains of the difficulty of being friends either with a social superior (who morally, he says, is rarely good enough), or with a slave, who, as such, is a mere tool, and has to be considered in the abstract as a man before one can be reconciled to friendship with him. In fact, the difficulty is felt almost entirely by the inferior, who, unless of a very simple and magnanimous nature, cannot help being somewhat hampered and put out by the associations which the other cannot help bringing along with him. 
$\S 4$. The ideal of Democracy requires liberty, equality, and fraternity: conditions that must be understood in some sense in which they are compatible and not quite impracticable. As for equality, I suppose that no one desires to attain personal equality by eliminating all individuals that deviate from the average ; but to attain it by "levelling up," by raising the average and all below it to a level with the ablest individuals that we know, would need hundreds or thousands of generations of severely selective breeding. Meanwhile a democracy, like any other community of men, must depend upon the eminence of its leaders. The great man, as I have elsewhere observed, organises, directs, inspires and is, therefore, indispensable. The dispute as to his importance in History turns upon a difference of conception as to the scale upon which History is to be written. Taking History socially and for long periods, the influence of a given individual may count for little: first, because "no man is necessary"that is, a substitute for any one would soon be forthcoming; and, secondly, because the causes of great movements are ultimately such as climate and geography, population and disease, and the condition of neighbouring nations-facts over which the individual has no control. The causation of great movements (as recently) by mechanical inventions is exceptional ; but plainly these inventions needed no extraordinary genius for which a substitute could not have been found. But in political or military events, and during short periods, the great man is often decisive; and however insignificant such things may seem to the speculative historian or sociologist, a democracy competing with a rival power is not likely to undervalue them. It is not true that History is the biographies of great men; but it is almost exclusively the record of nations that produce great men.

The occurrence of great men in any nation seems to depend upon such conditions as these, others being equal: the numbers of the population; its diffusion with varying circumstances of habitat and industry; mixture of races, so far as it is favourable to variation. Moreover, in any generation, men of distinction are likely to be born if amongst the 
same people such men have been born in former generations, provided there have been no causes enfeebling its heredity: such as religious persecution, celibacy, war, or emigration of the most enterprising men (Galton, Hereditary Genius). A fall of the average by too great ease of getting a livelihood will decrease the proportion of distinguished men. Hard times, or even a plague, by eliminating weaklings, may raise the average heredity and increase the proportion of the able. The success of great men when they have been born, depends further upon whether the circumstances of the age suit them; for Shakespeare would have been wasted a hundred years earlier: whether their fellow-countrymen are willing and able to support them; for what became of Hannibal?-whether a career is open to them in the actual circumstances of their birth; for, as a Corsican only, what could Napoleon have achieved? This last consideration-I mean the open career - gives advantage to democracy over any other form of government in the production of leaders, provided that it interprets the principle of equality to mean equality of opportunity.

In a democracy capable of wisely selecting its leaders and of honouring them, all those virtues may still flourish which we have seen grow up under natural kingship, namely, loyalty, fidelity, reverence and unforced co-operation. Moreover, the same conditions that give opportunity to political and military leaders are also favourable to the birth and expression of all other original and independent minds : men of science, poets, artists and prophets; I mean those men of moral insight who are as necessary to the renewing or preservation as to the discovery and propagation of moral truth.

A democracy that secures equality of opportunity to all its citizens is likely to obtain the ablest leaders, because it draws upon the widest area of population; and, in the industrial sphere, we see this theorem verified in the north of England, in Australia, and North America. And it is reasonable to expect that at the same time such equality should diminish jealousies and increase active sympathy and harmony. There seems indeed to be some truth in the 
accusation that in democracies the masses are jealous of every sort of distinction, patrician families, "intellectuals," even people whose virtue is more than others wish to emulate, and in a particular way of those who have risen from the ranks. But there has never yet been any democratic society that was not deeply scored with the traces of oligarchy, which necessarily keep jealousy alive. Sometimes perhaps jealousy is less excited by unfair distinctions to which we are accustomed (so that to the vulgar they seem fair), than by fair distinctions earned by those who began in the same position as ourselves. I am not whitewashing my species. No doubt the existence of any manifest differences amongst men, such as colour, nationality, rank, or ability, hinders the spread of effective sympathy. Equality of opportunity removes what is most invidious in rank, and so far it seems favourable to harmonious co-operation. There are indeed certain kinds of effective sympathy, as in ministration to the poor, which, in certain circumstances, are dependent upon differences of rank, and I shall not depreciate the good feeling displayed in such ways. But I have pointed out the superiority of sympathy with men's rights and remote interests over a regard for their immediate wants (C. III. $\S 6$ ); and it is obvious that no democracy is healthy or secure in which there exists a class in need of alms:

Equality of opportunity is a great part of liberty; which in general must, of course, be understood under the limitations necessary to protect the liberty of others : liberty is always in fact a compromise; I shall not attempt to define it. So far as liberty exists amongst a healthy people it is favourable to energy and originality and, therefore, to individuality, which is encouraged in modern life by the great variety of circumstances in which men can maintain themselves. For the same reason it is favourable to adaptability. Adaptability is the same thing as life itself; and, when obtained by energetic striving, it is the same thing as progress. To the lazy and sensual liberty allows degeneration; but coercion has never helped the souls of such people. When a healthy people is free, each man takes the course that seems advantageous to 
him, and so the whole community is gradually adjusted point by point to every change of circumstances. Liberty is favourable to co-operation; because co-operation is natural to men, and liberty does not prevent it. It is favourable to the growth of characters that need no external restraint, because those who do need restraint fall and are eliminated. But the adaptation of character to co-operation without coercion is the essence of civilisation: which can be defined, I believe, in no other way. Where, however, liberty is not universal but the privilege of a class or race, the noble spirit of the free man is liable to be corrupted by scorn of inferiors and defiance of equals: a temper destructive of the co-operative spirit, and easily allying itself with arrogance and greed.

Since most men must live by industry, democratic liberty, under which each man chooses for himself, makes industry honourable: provided there be not a large class so weak and cheap and poor and miserable as to have no choice what they shall do. With such a class no democracy is healthy or safe. For the most part an oligarchy makes industry dishonourable, because its existence depends upon the predominance of the military life; and in fact it is favourable to coercion and servile labour or even slavery, and therefore to bad workmanship. But liberty makes industry more efficient, because each labours according to his own bent and for his own ends. With industry go the virtues of perseverance, patience, foresight, regularity and honesty, which are necessary to its success. Liberty is also more favourable than any other condition to patriotism; for, so far as patriotism is instinctive, there is nothing in liberty to impair it; and so far as it grows by experience of advantage, liberty is for the mass of people the only condition upon which patriotism can flourish at all. In fact, so far as manliness is a synonym of virtue, liberty is favourable to all virtue.

Life in Towns, though not necessary to democracy, is perhaps characteristic of it; and it is commonly supposed to be injurious to the race. It need not be; but the abominable condition and habits of the poorer quarters in most of our towns in fact make it so. The unhealthy physical 
conditions can be remedied by any State that is in earnest about it. Intellectually, a town is stimulating: all ideas originate in towns : but it may be exhausting. Morally it seems to be not inferior to the country, when we have made allowance for all the failures that have come from the country. Country life is favourable to hardiness, and therefore has been supposed favourable to courage. But courage is a racial quality which, once inbred, will remain unless causes supervene that breed it out. There is nothing in a town that need have this effect: nearly all industry requires a certain courage, especially under conditions of liberty which oblige every man to take risks.

All those devices, socialist or what not, that seek to save us from risk, except by our own foresight, are most injurious to manhood. The ideal that prefers comfort, ease and safety to liberty and independence will ruin every nation that adopts it. Socialism, so far as I can understand its conflicting utterances, is in every way the opposite of democratic liberty, and would have the opposite consequences. In the same kind is the spread of government regulation in every department of life, and the multiplication of officials who think that their employment is superior to private enterprise. Whatever disparages private enterprise in comparison with official business lessens the incentives to civic courage and independence, and checks the flow of that energy which through personal efforts is always adapting a free people to the changing conditions of its life.

The great vice of a democracy, no doubt, is the aptness of a crowd to rush all one way and then the other way. This has lately become a special study, but has been effectively known and practised upon by popular leaders ever since a crowd existed; it is the main reliance of demagogues, witchdoctors and thaumaturgists. The closer people are gathered together and the more of them there are, and the more talkative and gesticulative they are, the more they are liable to sympathetic panic; all impressed with the same belief and ready to act upon it. When the majority of a State lives in one city, it is especially prone to such obsessions: hence the 
fickleness traditionally ascribed to democracies, since the historical democracies were City-States. A State with a considerable country population is less liable to it; but even there the want of close personal suggestion is now in some measure made up for by newspapers, and we recognise the phenomenon amongst ourselves as the "swing of the pendulum." The fashions of polite society have the same character, not only in dress but in amusements and opinions, and are accompanied by intolerance of dissent : partly under the absurd notion that "what all think must be true"; but more from an uneasiness as to the truth of that assumption, a consciousness on the part of many that they are not thinking and acting upon their own convictions but in subservience to a power not themselves, and a resentment that any one else should be so self-sufficient as to go his own way.

$\S 5$. In free commonwealths, as Burke shows in the Discontents, parties naturally arise and especially in parliamentary life. He defines a Party as " a body of men united, for promoting by their common endeavours the national interest, upon some particular principle upon which they are all agreed." In contrast with such legitimate Parties, we may suppose that the Factions which are found in despotisms and oligarchies and often enough, too, in free commonwealths, are bodies of men united for some other end that the national interest and not limited by any principle in the means they adopt. But in actual politics the distinction is liable to be obliterated: a beaten faction, indeed, as we see in history, has no patriotism; and a beaten party is apt to degenerate into a faction. We have again to consider the effect of aggregates upon the morality of individuals; and for the most part, what is true of parties is also true of factions, and further, of public and private corporations within any State: in fact, the moral phenomena of groups.

No man dares profess opposition to "the national interest"; but in practice it turns out that the national interest is a vast complex of interests, all of which are in some sort national, yet of such a nature that some men are much more concerned in them than others, or in which men are even concerned in 
opposite ways. For example, loyalty, patriotism, religion, property, are all national interests in which all are concerned: but some regard loyalty as a matter of personal reverence; others treat the person of the Crown as a symbol of national life, so that many men have been devotedly loyal to kings whom they despised: to some men patriotism is an exclusive sentiment involving antagonism to other States; whilst others regard justice and benevolence to foreign States as the greatest honour of their own nation: some men hold that religion involves public rites in which the whole nation ought to join; whilst others think that religion is a disposition of each man's heart, and that any public sign of it that is not voluntary is insulting to God and man: as to property, some think it is most useful when accumulated in few hands; others that nothing but diffusion can save it from corruption; and whilst the former regard philanthropy as essentially personal aid and alms-giving, the latter consider it a national disgrace that any one should need alms, and urge that the only philanthropy that can be finally justified is the effort to raise every man to independence. Now the citizen who is full of personal loyalty to the exalted in church and state, a patriot who hates a foreigner, a punctilious church-goer who hates a nonconformist, a great respecter of property in bulk and not unwilling to part with some percentage of his own to dependents who acknowledge his superiority, is a recognisable type, sometimes not unamiable, but much out of date. There is a less recognisable type composed of the opposite tendencies.

Again, all are concerned in property, but there is opposition between the holders of monopolies and those who need their goods; all are concerned in religion, but for centuries Anglicans and Nonconformists have been divided as to the best means of promoting it; all are concerned in temperance, but the brewer and the teetotaler are for encouraging it in different ways; every one desires public order, but some would entrust its maintenance entirely to authority, whilst others think that to increase every man's interest in it is the only satisfactory course. Now the monopolist of land (or what not) who is an Anglican, favourable to promoting temperance by improving 
beer, and to keeping order by authority, is a recognisable type; and so is the other man. Hence, men being naturally, cooperative, and "to cantonise" being (as Shaftesbury says) natural to man, parties are formed to promote the various interests that enter into the national good according as some men think that one course and others another is most conducive to that end; and in proportion as any interest, such as property, is liable to become the concern of some men in opposition to, or even to the injury of, others (as with monopolies), there is always a danger that the private will obscure the public interest and that party will degenerate into faction.

We must also consider that the national interest is such a vast object that few can form a nearly adequate idea of it, especially as to the proportions of its elements. To few is the idea of it, such as they have, a dominant one, except perhaps occasionally in critical times. Many men hardly think of their country except as a place to make the best of for themselves and families. Their political opinions depend partly upon their family and connexions, partly on personal sympathies and antipathies whose origin is a particular problem in each case.

Men who act together are influenced by common wishes as to the end and as to the means. These wishes decide what considerations they shall attend to, and (whenever it is a question of evidence) what facts or arguments they shall attend to, and what weight shall be attached to this evidence or to that. We cannot will to believe, but we can will to act, and that makes us believe whatever is favourable to the action. Then there is always some one to take the lead. $\mathrm{He}$ may be the man of strongest, clearest purpose, whether honest or dishonest; or he may be an actor who has chosen this part as the one in which he is most likely to shine, either because there is a paucity of rivals for it, or because he believes that it will most surely concentrate the tendencies of the crowd behind him; or even an actor who has not chosen for himself, but been thrust forward by clearer-headed men who mean to exploit his histrionic abilities. This man may be followed by honest men because they agree with his 
plans and believe him to be honest; but even then it sometimes happens, and in other cases it is seen more clearly, that his leadership depends upon "magnetism ": which property may be due to a belief on the part of others that he will succeed and that therefore it must be profitable to follow him ; or, again, may consist in the power of suggestion, operating upon the crowds of people whose wishes make them suggestible, or who have been bred to be suggestible in order that they may be led. Around the leaders cluster many able men who know what they are about; then follows the great herd governed by suggestion, imitation, habits of association and sympathetic contagion; some who are less suggestible or more scrupulous fall in with the procession rather than be singular, or seem disloyal, or disappoint their friends; and for similar reasons others of the party, who disapprove the present action, offer no active opposition. Hence such a party, once organised, has a life of its own very little controllable by its members, often not even by its ostensive leaders; and although its actions may be directed to the public good, they may, on the contrary, be inferior in honesty and intelligence to what any average member of the party would propose if left to judge for himself. In acting with their party men do not reflect that its political action is a moral action to every individual who supports it.

One reason why moral judgment is obscured, even amongst the more reflective members of a party, is that the interests of the party, if not exactly national, form so large a part of the national interest as to be easily confounded with it. Moreover most men, and their ancestors for many generations, have been less accustomed to judge of public than of private conduct. Another reason is that few men's consciences have much independence, much power of disapproval, without the support of external sanctions. But the legal sanction can rarely be invoked in political party questions. The religious sanction by itself is with most people not very strong; and what a man hears of it, if anything, generally depends upon what party he belongs to ; and, except amongst Romanists, it is thought hardly good manners of the clergy to interfere as 
such with individuals. As for the social sanction, it can only be efficacious when a culprit is exposed to the disapproval of an offended public; but the partizan herds chiefly with his own party, who are not likely to discourage him. If he meets the other side, it may seem to them unfair to visit upon one an offence adopted by a party; politeness forbids severity; and in fact there is a sort of convention that political conduct shall not be judged upon moral principles; and it seems difficult to follow any other plan if the existence of political parties is to be compatible with social amenities. But a good many simple-minded men, deficient perhaps in worldliness, do not highly value this convention.

If we allow ourselves to judge of other men's actions at all, it seems plain that, in a political propaganda, speakers and writers often grossly misstate the facts, fraudulently suppress those that are inconvenient, and resort in argument to every kind of sophistry. We may assume this to be true, because each party accuses the other of it. The end of oratory is to persuade; but most speeches and leading articles are not really addressed to any one that needs to be persuaded, but are designed to present a plausible case for some measure that is to be carried forward for very different reasons. In this service a man may utter falsehoods publicly without shame and without penalty, whilst making for his own party exclusive claims to honesty, patriotism and religion. The abuse is traditionary. Milton cites Shakespeare as "so mindful of decorum as to put never more pious words in the mouth of any person than of a tyrant" (Eikonoklastes, c. i.). Politics has always been too much a sort of civil war in disguise; and as deceit was allowed in war, so in policy. And as long as politics were in the hands of a few people - some nobles and officials, the keeper of the king's conscience and a bishop or two-the moral contagion was not extensive. But as interest and participation in politics has spread, now that every man is a politician, apparently every man may be a liar without sin or shame, on the mere profession of speaking politically. Is it worth while to continue the practice of an art that every one can learn? For, clearly, the newer 
sort of politician can mislead as brazenly and as effectively as any gentleman that ever forswore himself.

That the end justifies the means is a maxim in ill odour; probably many people repudiate it, whilst others act upon it, without understanding it. Every Dependent System of morals assumes not only that the end justifies the means, but that it is the sole measure of the means' validity; but then it also assumes that the end is really the universal Good and that the means to it are necessary and adopted for that purpose. It is another matter when the end, in which justification is sought, is not an universal Good, or when the means are not the necessary but only the most convenient. A politician, if brought to account for some piece of misrepresentation, might defend it on the ground that it served the purpose of his party; but to be morally justified he must also show that the purpose of his party is the national interest (at least), and that this misrepresentation was the necessary means of securing it.

There is no space to examine the conduct of other associations: what is true of political parties is often true of them; but their affairs are less public. On the whole, it seems plain that the conduct of political parties, besides the occasional bitterness it brings into private life, is a demoralising example and tends to make men think lightly of truth, honesty and honour. But the worst of all their deeds is to pass an unjust law, thereby impairing the foundations of society, corrupting the source of security and disfiguring the ideal of public morals.

$\$ 6$. The influence of Law upon Morality is so great that some have held it to be the sole source of Morality. In fact, law, like moral observance, is derived chiefly from. custom. As I have already observed (c. iii. $\$ 2$ ), Aristotle thought that law is, or ought to be, co-extensive with Morality, for he says that "whatever is not commanded is forbidden"; but the reasonable view is better represented by Hobbes, who says that "whatever is not forbidden is allowed"; that is, it is left to morality. For Hobbes thought that law is the ground not of morality but of effectual obligation; since eternal and 
immutable morality is obligatory in foro interno prior to law and where no law is known but, without law, cannot be enforced (Lev. c. xv.). Yet Hegel seems to have concurred with Aristotle; for he thought that moral freedom consists in the intelligent acceptance by the individual of the decisions of universal (=collective) reason as expressed in laws and institutions.

It seems to be agreed, however, that laws concerning human actions can only be wisely enacted so far as their subject-matter can be precisely defined, so that we have no laws against general insult; and only so far as breaches of them can be proved without introducing a greater evil (as by espionage), so that we have no law against unchastity; and only so far as a sufficient motive does not exist without them, so that we have no laws against imprudence. Hence a considerable number of actions that are mala in se are left to morality alone; and, on the other hand, the law renders many actions mala prohibita that are only immoral because they involve a breach of the law and the consequences of itas smuggling throws an unfair share of taxation upon other people. Finally, law can only take account of deeds : it has little hold upon dispositions, and it is with these that Morality is chiefly concerned; so that it is often important to distinguish, in any action that comes under the law, its legal aspect as observance, and its moral aspect as expressing character.

As to the importance of Law to Morality, we may say that without law or custom there could be, outside the family, no Morality: it is a mere dream of the reign of Saturn to suppose that truth, justice and benevolence would be practised, or that there could be any disposition to practise them, if there were no security, no confidence with regard to the conduct of others. But the law of any action, having been declared, although it require only the minimum of moral observance, is apt with many people to be regarded as prescribing the maximum: it is said to have this effect with inferior men who become lawyers, and it is of course tempting and perverting to all ungenerous citizens; and nothing 
is so deadly to morality as to substitute legality for it, to substitute a grudging and enforced observance for free and conscientious choice.

Nevertheless it is an important function of law to be the great exemplar of justice to every citizen. Blackstone praises those lawyers who are "so copious in their encomiums on the common law, that they tell us that the law is the perfection of reason, that it always intends to conform thereto and that what is not reason is not law" (Commentaries, Intr. \$3). This is the ideal of law, and so far as it fails of this there must be some moral injury to those who live under it. Every one knows that needless violence in administration, needless severity in punishment, deprave and brutalise the population; that the employment of spies destroys social confidence and encourages treachery; that class legislation puts all other classes in opposition not only to the oppressive class but to the State itself, sets an example of injustice and provokes retaliation; and that this effect is seen at its worst when laws, opposed for generations to the sentiments of the bulk of the people, produce, as in Ireland, a general detestation of government and sympathy with every one who defies it. Such an attitude toward government may even be brought about by laws imposed with good intentions by a majority, if the impulses to be restrained are really irrepressible; as happens, for example, under laws prohibiting the manufacture and sale of alcoholic liquors. Not only are the laws evaded to the encouragement of secrecy, fraud and conspiracy, but the contempt for law in general that ensues is a far greater evil than drunkenness. The worst of bigots is the moral bigot. Laws contrary to the national feeling, that are needless, or cruel, or otherwise unjust, may nearly always be found where Government has been recently imposed by conquest. Elsewhere, since laws are altered slowly, the vices of government reflect the ignorance, stupidity and cruelty of the population a little while ago, and foster whatever remains of those qualities. Until recently English law presented frightful instances of this evil.

The manifest injustice of laws and of the constitution of 
government in most countries, raises the conception of Rights belonging universally to persons, which though they may be encroached upon by governments can never be annulled: such as the Right of Self-defence, of Liberty, of Property, to Subsistence, to Labour, and (as the necessary guarantee of all of them) the Right, in the last resort, to resist the government with arms. These terms stand for abstract ideas illdefined and varying from age to age and from nation to nation; and after the great social and political amelioration of last century, there grew up amongst some men of letters and political reasoners the fashion of regarding them as little better than popular blunders. Thus we find Matthew Arnold speaking of liberty as only 'machinery,' and classing it with coal and railroads (Culture and Anarchy), as if it were not a necessary element of all human good.

Historically, the conception of abstract Right is connected with the belief in natural Society antecedent to the State, and in a Law of Nature. This belief was derived from Roman Law, which in turn derived it from the Stoic Philosophy: it flourished especially in the seventeenth century. The whole philosophy of that century worked with uncriticised concepts, of which these are examples; but it is absurd to blame the philosophers for using the forms and materials of construction that lay to their hands. It is unreasonable to require that Baconian principles should at once have been applied to moral investigations: the historical and psychological data for such a method did not yet exist. When, however, Hooker, Milton, and Locke assumed a Law of Nature antecedent to the State, they did not (like Hobbes and Spinoza) regard men as living in issolation under it: the condition of Nature was to them a Divine State, and the rights prevailing there were conferred by God. They did not, therefore, suppose that rights existed apart from Society, but only that when the State was formed, the rights of the natural divinely-governed Society were necessary limitations upon the newly-appointed government. Others, no doubt, conceived of rights as having independent claims merely as abstract ideas: this, as Comte showed, is a natural transition from theological to "positive" thinking. When, 
in the eighteenth century, Utilitarianism arose, we find Hutcheson defining a Right as "such a faculty of doing, demanding, or possessing anything as, if universally allowed in certain circumstances, would on the whole tend to the general good." And similarly Hume (as I have said) explains that government, the obligation of promises, justice, all have the same ground-Utility.

Turning to the history of Society, the notion of Rights, as distinct from Custom and Law and possibly opposed to them, so far from being primitive, is evidently the acquisition of a late civilisation and of a refined philosophy. It does not follow that the rights in question are improperly called 'natural,' if Society and the development of human nature are natural. The ideas of them appear when such ideas are needed to ensure that development, and no Society can continue to improve-that is, to make the End of our being more and more realisable-that does not recognise them. They are not derived from Society; Society and the Rights of the Subject have the same basis, the furtherance of the good life. Rights always have to be vindicated by individuals supported by their own power and by the help of others; who, partly by a sense of common interests, partly by sympathy, are moved to support them. The conception of rights has been of inestimable value not only in the creation of the Roman Law, but in the amelioration of the laws and governments of modern Europe. In the absence of any clear view of the End of human life, and therefore of the power of deducing its conditions, these ideas have operated with the force of instincts. It is a mistake to suppose that abstractions are always cold: that is at most true of those that are remote from practical life; such as those of Logic, which, however, arouse strong feelings in logicians. But if abstract ideas of human life were cold how could Shelley write such lines as these?-

To suffer woes which Hope thinks infinite;

To forgive wrongs darker than death or night;

To defy Power which seems omnipotent.

Such words have all the force of the experiences from which their ideas are abstracted ; and in fact nothing so much inflames 
the mind as abstract ideas. If any one thinks that politics can be carried forward without men's minds being inflamed, I am sorry for him; and I hope that the ideas of Liberty, Equality, Loyalty, Duty, will maintain their force for many an age; that is, that the instincts of our life will endure until, in the maturity of moral reason, their half-enlightened impulses shall become needless. It is not desirable to weaken the sentiments associated with such ideas, but only to explain their relation to human development, and therefore their limitation by that End. He who insists much upon his rights is apt to forget that rights, if not created by Society, yet exist for the good of all and could not be maintained without the sanction of Society, and that therefore they imply a trust upon his part not to abuse them, as rights of property and liberty are very liable to abuse. But rights that exist for the good of all also imply a duty to defend them; and there was never a time when passionate devotion to the rights of personal liberty was more necessary than it is at present, when the specious claims of a democratic majority are substituted for the divine right of a despot, and threaten to be more intrusive on privacy and more despotic in every department of human life.

As for the right of resistance, it underlies all other rights, and without it they are empty phrases. Even Hobbes held that Self-preservation, being that for the sake of which men entered the State, remained a right that could not be abrogated; so that if a man were in danger of his life from Leviathan, he might defend himself with arms, and might unite with others in like case; and this was no rebellion. But what is the use of life without the liberty of personal expansion? Resistance, however, is one of those things which, as Burke says, are not fit to be much talked about. Plainly, no one who does not mean to take an active part in it can, without cowardice, recommend it to others in any particular case-like the editor of a paper who incites other people to go to war. Nor does it seem possible to lay down general principles for it, One may say that it can only be justified by a grievance greater than the evils of resistance. But who can make the 
necessary calculation; and what great cause would ever have succeeded, if there had not been something else than calculation at the back of it? There is a spirit that feels injustice worse than death; and it is a wretched country in which many do not feel so. One may say that resistance should not be undertaken without a sufficient probability of success. But this would be a condemnation of every heroic enterprise. The matter must be decided in every case by those concerned. It is not likely that we shall ever be called upon to decide it; the more ought we to honour those whose agony has delivered us from the need of deciding.

$\$ 7$. Of all forms of political influence upon morality, Punishment and Reward are the most direct; and Punishment is the more constantly employed. It seems to be agreed that punishment is derived from retaliation, which, through the idea of the unity of a family (or clan), becomes an affair of the family, so that vengeance may be taken upon a member of the offender's family as well as upon himself, and by some or any member of the family of the injured person. Retaliation is first defined by the lex talionis, and in many races has been organised in the hereditary vendetta. In the settlement of social order, it is further limited and qualified by the State. When the State at last takes retaliation out of the hands of private persons, or of families (which with the progress of civilisation lose their independence and solidarity), and makes it a matter of public justice, it is then properly called punishment. But it retains strong marks of its origin ; being at first, whether as an infliction similar to the offence, or some commutation of it, so arranged as to gratify the resentment of the injured person, or his ghost, or his family; and remaining to this day an infliction of some kind of pain or loss, which is viewed by most of the public with satisfaction as something deserved and as 'serving him right.'

But meanwhile the growth of moral feeling and reflection has given rise to maxims conflicting with the principle of punishment, especially that we should 'forgive our enemies.' The emergence of such an astonishing doctrine may be explained in several ways, as it may in fact have had various 
origins: as in resignation when the enemy is too strong and revenge impossible-supported perhaps by a belief that God will be quits with him ; or from considering the enemy as an effect of the world-process, and his malice as no other than the scratching of thorns; or by extending to mankind the idea of the family, and regarding the offender as, in some families, an injurious brother would be regarded. In any case the opinion will then form itself in some minds that punishment, if allowed at all, must have some other meaning than the return of evil for evil. We may try to avoid the difficulty by the ludicrous subterfuge that, though we must forgive injuries to ourselves, it is right to resent injuries to other people. Or we may set up the State as a sort of divine being exempt from the rules of human morals, and declare that all offences are really committed against the State, which may avenge its violated dignity. But the State is an abstraction of a peculiarly vile kind: it differs from abstract rights in this, that whilst liberty, dignity, etc., are real conditions of the individual's development, the State, thus deified, obliterates individuality and very really sacrifices persons to machinery. In fact all offences are committed against persons, either individually or as a body; and on that ground they are punished.

But, again, when we analyse any act of retaliation, even amongst animals, we see that it involves much more than resentment and 'tit for tat.' Handle the cat too roughly, and she scratches you: that is retaliation. But then you remember not to do it again: that is reformation. If some one else is looking on, he learns the same lesson : that is determent. We see further that if all men were thus reformed or deterred, there would be universal repression or extirpation of the offence: which is the consummation to be desired. Seeing all this, we may consider which of all the consequences is rationally to be aimed at, or in what order or what proportion they should be aimed at, when it comes to the deliberate infliction or threatening of punishment. For if they are all to be pursued, yet some rather than others, our choice amongst them will affect the kinds and amounts of punishment. Capital punish- 
ment, for example, cannot reform, though it gratifies resentment and may be deterrent: solitary confinement is so difficult to imagine without experience, that it does not gratify resentment nor deter many people; and I suppose it rarely reforms anybody.

Some gratification of the feelings of resentment in the injured party or in the sympathetic or alarmed public, is probably at present, as Bentham observed, a necessary element in punishment, in order to maintain the common sense of justice. Still, this is due to the backward condition of human nature: resentment is instinctive but entirely irrational : for how (apart from the gratification of resentment itself) am I the better, or is any one the better, for another man's suffering pain or loss? If human nature is to improve, some other way must be found of curing its ills, and we must learn to feel differently toward evil-doers.

E. Westermarck, in the early chapters of his great work on Moral Ideas, shows that punishment originates in resentment, and that it still retains that quality; and he seems to argue that this is right, not merely inevitable. Hence he sets himself to refute the deterrent and reformatory theories of punishment, as if their adherents regarded reform or determent as the whole import of punishment. Now, plainly, as long as punishment is inflicted there cannot be determent without retaliation. But there may well be retaliation without resentment; for I say that no sane man who understands the nature of the ordinary criminal, his breeding and nurture, can possibly feel resentment toward him, except as the insurrection of an instinct during the lapse of understanding. For what Spinoza says of pity may be said of resentment, that it is an error, because it is painful, and because it is possible to do the same actions from reason alone. Westermarck's arguments for the value of resentment all depend upon taking the deterrent purpose as entirely abstract : thus-Why not then punish a man's children, or other innocent persons : since this might deter (p. 82)? We are supposed to entirely disregard the feelings, or the rights, of the innocent. Again (p. 83), "the heaviest punishment should be threatened when the strongest motive is needed to restrain," 
as where there is great temptation or passion. But great temptation and passion exclude the consideration of other motives; so that threats are useless. Again (p. 200), "Why should the attempt to commit a crime, when its failure obviously depends upon mere chance, be punished less severely than the accomplished crime, if not because the indignation it arouses is less intense?" A reason can be given; namely, that the purpose of an attempt is much less easy to prove to the public satisfaction than the fact of a crime: defined in general terms, it may not be "obvious." Otherwise, I should say that such leniency is a mistake, or at least a regrettable concession to vulgar feeling only to be excused by extreme expediency. As for reformation, we are told that if that were the purpose of punishment the "absolutely incorrigible" ought not to be punished at all (p. 83): as if determent and repression should count for nothing. It is sometimes urged by other retaliationists that if determent were the object, the commonest crimes should be the most severely punished: as if experience had not proved severity to be useless in deterring from common crimes, and sure to excite sympathy with the criminals; or as if the needless cruelty of such punishment should be disregarded. And, again, it is urged that, for the purpose of determent, the insane should be punished like normal people, since the example would be the same: as if it were reasonable to punish only deeds and take no account of intentions.

Retaliation seems simple, and resentment capable of being measured by equality, as long as men attend merely to the deed apart from causes and circumstances. As soon as we consider circumstances, we see that the same injury to person or property can never be equally felt by different persons or families; and as soon as we trace the deed to its sources in character and breeding, the notion of equality between offence and punishment becomes quite meaningless. The notion of equality or proportion cannot be separated from such maxims as 'to be quits' with the culprit, 'to give him his due,' to 'serve him right'; but religion is justified in commanding me ' not to judge another,' not to pretend to evalue his moral guilt: for in fact the necessary evidence is never before me. 
The clinging to retribution as the essence of punishment is partly the result of theological ideas (which, however, unless God's prerogative has been usurped by priests, reserve vengeance to Him alone); partly of illusory instinct which, under the disguise of a personal object, obtains a social end before this can be understood and appreciated; partly the inbred tradition of the vendetta. For organised retaliation between families abolished the reformatory and preventive consequences of punishment. No one supposed that, as long as any members of both families survived, any act of retaliation would be the last: no one therefore attended to anything else. Hence the difficulty of civilising mankind into a sense of the importance of those reformatory and preventive consequences that attend upon retaliation even amongst animals.

That the reformation of criminals is a necessary object of humanity, if it can be attained, no one, I suppose, will deny. Unfortunately the kinds of punishment that have hitherto been in vogue have had no effect or even tendency in that direction. The first condition of reforming criminals is that they should be treated as human beings; which may then, for the first time, happen to them after their conviction. And lately some attempts have been made to teach them trades and even to allow them some degree of liberty. Trust, industry, moral responsibility, are indispensable conditions of human life. But the difficulties of reformatory discipline are great: not the least being to obtain a constant supply of capable overseers. And as long as punishment continues to be the chief means of enforcing the criminal law, it must be said that the reformation of individual offenders is less socially important than the determent of others by their example.

The deterrent power of punishment is plain to any reflective mind, and was sporadically and half-consciously recognised long before it was given a foremost place in the philosophy of Beccaria and Bentham. The deterrent power of retaliation (if not, as in the vendetta, systematically counteracted) is so well known to Nature that many highly noxious animals, apt to retaliate, have warning colours (of course, for their own protection); and others, quite innocent, acquire an imitative 
coloration. However old resentment may be in anthropology, determent is as old as reflex action. The chief foundation of social order is the interest in order that is felt by the great body of normal men, many of whom never seriously entertain the thought of departing from honesty or practising violence, whether from its obvious impolicy or because such is their breeding; but that many of us are restrained by a knowledge of legal penalties and of their pretty regular infliction is hardly open to dispute. This gives confidence and freedom of mind in all honest pursuits; and it is probably reformatory to many people who might else become criminals, by giving a constant turn to their consideration of how to get a living, and by strengthening the tone of authority in feeble consciences.

Still it cannot be said that punishment is a successful institution. Its infliction by different magistrates, its relation to different sorts of offences, and its incidence upon different persons, are notoriously inequitable; and its abuse by barbarous and despotic governments is the chief manifestation of the Devil in history. Hence its justifiability is often disputed, and the defence of it is not always convincing. Thomas Green, greatly improving upon his sources, says that the idea of punishment implies (1) that the patient practically understands the nature of rights as founded on the public good; (2) that he has committed an actual violation of right which might have been avoided; (3) that the punishment is necessary for the maintenance of real rights. When these conditions are fulfilled the criminal sees his punishment as his own act returning upon himself, the necessary outcome of his act in a society governed by the conception of rights, to which conception he does involuntary reverence (on Political Obligation, $\$ \S 185-6)$. But it is as useless to discuss Politics as to discuss Chemistry solely from concepts without regard to the facts. On the above principles most criminals at present could not be justly punished, (1) because they do not even 'practically' understand the nature of rights, (2) because in the circumstances they could not have acted otherwise, (3) because it is doubtful whether their punishment is the necessary means of maintaining right. It is also impossible for a 
criminal to see that punishment is the necessary consequence of his act, because many crimes go unpunished; and therefore he cannot see it as his own act returning upon himself, because it was never any part of his purpose-he meant to escape.

According to Hegel crime is a nullity, because right, considered as the general Will, has no external existence and is inviolable. Punishment is the negation of a negation, and so somehow restores the right; which, however, could not be displaced (Philosophy of Law, §§ 97-8). We have also been told that a criminal has a right to be punished in order that his crime may be annihilated and he himself rendered guiltless. But how is it possible to annihilate a deed that has once existed, or how can punishment frustrate the endless consequences of that deed? Or if a man's crime is an index to his character, how can punishment, as such, make him guiltless? Nay, alas, even if it should produce repentance, how can it free him from suspicion? For we are as bad judges of repentance as of guilt. Other such accounts of punishment may be read in books written whilst lately it was fashionable to suffer from indigestion of Hegel. But whether Hegel really held the retaliatory theory of punishment may, like every other doctrine ascribed to him, be fairly disputed. See J. Ellis M'Taggart's defence of Hegel in his Hegelian Cosmology, c. v.

In fact, punishment has the same justification as Society, because hitherto it has been necessarily included in social development. But its perpetuation is another matter. When criminal psychology is understood it will be seen that punishment cannot have much effect in deterring the worse kinds of criminals; because the state of mind in which they go about their business is the obsession of a fixed idea, which directs them steadily to its realisation, and excludes all consideration of whatever consequences are irreconcilable with it and with its associated desires. When this is recognised it will be impossible any longer to trust for the maintenance of order chiefly to punishment. Instead we shall endeavour (1) to reform the social conditions that encourage crime-bad education, bad conditions of employment, bad hygiene; and (2) to 
purge mankind by segregating criminals. The segregation of any criminals (life-imprisonment under certain conditions) is (1) completely repressive as far as they are concerned, (2) prevents them from tempting and educating others, (3) weakens the tradition and the force of approving opinion amidst which criminals live, (4) puts an end to their heredity.

Reward has consequences parallel with those of punishment: (a) the gratification of some one from a motive which, by a little stretch of meaning, may be called a kind of resentment; (b) further exertions on his part as long as there is anything to hope for; (c) general encouragement to all witnesses. It is certainly as natural to reward as to punish. But reward is less resorted to (1) because the greater part of men's actions are nearly right, and we cannot be always rewarding them; (2) because such actions 'bring their own reward' merely by success. Hence rewards are not, like punishments, assigned under laws; but are left either to popular movements, which result in triumphal arches, addresses in silver caskets, and so forth ; or to the sovereign or his delegates; and are reserved for exceptional deeds that stimulate an appropriate 'resentment.' The conferring of rewards, therefore, always depends upon the initiative of some individuals, and is irregular and capricious. So far as they are bestowed by the Sovereign, the real fountain of honour is the Ministry; which, being partizan, does not always distinguish between benefactors of its own party and public benefactors, who alone ought to be publicly honoured. There seems to be no cure for such things but the placing of this branch of the prerogative with some impartial body. Whenever a partizan is unfairly rewarded it can only be at the public expense: if he receives a pension it comes from the taxes; if he receives a degree of dignity, it involves a correlative lowering of all other dignities. You smile: but those who give way to such partiality do all the harm they can and vitiate the public standards of fairness and merit. When this partiality goes the length of giving hereditary titles and power to men of no personal distinction, merely rich or importunate men, or even men whom it is inconvenient not to gratify, the acquiescence of the 
British is remarkable. As the Americans, living under different institutions (superficially different), seem to sympathise with us in these matters, we may derive our feelings from the early adaptation of the race to leadership: the race retains its sentiments of admiration for distinguished men, but has lost the power of discriminating between the genuine and the shoddy. Men distinguished in art or science rarely receive hereditary honours; so that their blood, though of the utmost interest to the country, goes undistinguished; whilst power and prestige descend to the sons and grandsons of nonentities who are mingled from time to time with that great pot-pourri, the British peerage.

Since honour requires popular recognition, it cannot be conferred effectively except in forms that already have popular prestige, and these are all political or military. The granting of military titles "upon carpet consideration" results in incongruities which, again, the public contemplates with a remarkably serious countenance. The Order of Merit, a noble conception, is, on the other hand, to the multitude unintelligible - how much below the Garter, valued by one of its ornaments for having "no merit about it"! The Chinese ambassador thought that Herbert Spencer ought to have been made a duke: in China perhaps he would have been; but as he would certainly have refused the distinction, one shudders to think what might next have happened.

Aristotle says that the chief use of honour is to secure the recognition of virtue: he does not mention the gratification of one's wife. Bentham, as was to be expected, took a very practical view of the matter; we may read in his Rationale of Reward that he thought emulation was the greatest spur to activity; and no doubt honours excite emulation. But is there really any moral or political interest in stimulating emulation? In itself it is not an uniting but a disuniting motive; although certainly in our country success or defeat in emulation is taken in a sporting spirit as part of the fun; so that it causes little disunion. Still, it is a poor thing to be content with surpassing others. And I believe that the part of emulation in our life is overestimated. In art and science 
certainly, but I believe also in professional life and industry, the greatest men are interested chiefly in their work, and would do their best for love.

\$ 8. Industry, next to family life, is the chief foundation of civilised morality. The greatest change in human character is connected with the transition from the predatory or military to the industrial state; but as the change is gradual, traits of militarism have persisted hitherto under industrialism; which, indeed, is very imperfectly established; so that we do not yet see the full consequences of the change. It seems to have taken place generally through a condition, more or less prolonged, of slavery or servile labour; which may be said to have tamed mankind at a frightful cost, not only in suffering, but in a debasement of certain qualities of character, intelligence, and physical ability, from which some nations seem unable to recover.

Slavery was brought about chiefly by conquest, in a less degree by laws of debt. Wherever it prevailed the dominant class remained military or in alliance with military power; and as serfdom ceased in Europe not long ago, the prestige of slave-holding survives; many people would still like to have slaves, and they behave to their dependents in the spirit of slave-holders so far as they dare; and a contempt for manual labour is everywhere entertained. Excuses for slavery have always been daring, quite in the military spirit: as that God created the negroes to be slaves, or (what comes to the same thing) that barbarians are by nature slaves to the Greeks. The delusion has not yet been dissipated that slavery was necessary to the leisure of Greek citizens, in order that they might be free to cultivate their minds: though surely everybody knows that slave-labour gives more trouble, needs more oversight, and is less profitable than free labour. Is it not a relief to reflect that Greek Art and Philosophy did not depend upon slavery; or would you rather think that they did? It is indeed admitted that slavery was an important cause of the decline of classic civilisation; that slaves supplanted the poorer citizens and led to their pauperisation; that it diminished the military power of cities, and corrupted the whole of the 
superior race. A slave-holding race becomes parasitical, and all parasites degenerate. The existence of slavery, indeed, exalts the self-consciousness of free citizens; and this has different consequences in different men. To one it occurs by autosuggestion to say: "I am superior, and must think and act accordingly." This is the nobler temper of a noble class. But another says: "I am superior, and can do as I please." The latter sort is the more numerous.

Where labour is free different kinds of industry have very different moral effects. Agriculture generally needs less regularity than manufacture, less persistent voluntary application to one task, but more hardihood in the form of physical endurance. The natural processes involved in agriculture are in many ways not open to observation, and they depend upon the weather; hence are favourable to superstition rather than to a belief in causation. But in handicrafts the whole process is carried out, not indeed with insight into all the physical relations involved (say, in making fire), but with a clearer perception than in agriculture of the conditions of success; so that they are great teachers of the uniformity of cause and effect, and upon this all intelligent appreciation of morality depends. Efficiency can be more exactly estimated in handicraft than in agriculture; and, therefore, 'finish,' which is the stamp of efficiency. Hence, all primitive handicraft tends to be artistic; which is the redeeming glory of labour, and nourishes the disinterested love of doing one's best.

Division of employments and of labour is necessary to handicraft, and therefore so are exchange and contract. These are at first determined within the tribe by custom; but when customs break up, or where they do not apply (as in trading with strangers), strong temptation to fraud and deceit is felt. Speculation as to the future relations of demand and supply introduces further difficulties: for which the best cure is a large open market. The connexions of cause and effect then become so intricate and sometimes remote, that it may be long before the maxim that "honesty is the best policy" is clearly understood. Still, nearly everywhere this difficult induction is made at last, though many clever people are not yet con- 
vinced of it. In the 'City article' of a respectable paper I find the following argument for not avoiding Argentine securities: "A dishonest tradesman may thrive where an honest tradesman may be ruined; and this may be the same with nations. If some municipal corporations in England could not meet their obligations, the consequences would be limited; they would not bring a sudden end to the prosperity of the United Kingdom. Prosperity is not dependent upon mere financial morality of this order, but upon conditions and events far more intricate than plain dealing between debtor and creditor. We may deplore unprincipled actions, but economic laws work independently of individual or collective ethical conduct." Here is a man in a position of trust, requiring at least common sense, who thinks (1) that if a dishonest tradesman thrives, so may a community of such men; (2) that to fail in meeting obligations is the same thing as dishonesty; (3) that mysterious things called "economic laws" may bring prosperity though people do not even mean to pay their debts, individually or collectively; and (4) that it may be wise to trust your capital to a prosperous rogue in the hope of sharing his plunder. If such beliefs were common amongst those who really conduct affairs in the city, London would soon be as deserted as Nineveh. The truth is that in civilised countries nearly all men of business practise honesty; and that no community can prosper upon any other terms. It is the general practice of honesty and the confidence based upon it that give sporadic cheats their opportunity. Consider only the time that must be wasted, if punctual payment and the consequent confidence were not almost universal.

Honest observance, at least, is a necessary condition of extensive trade; and those trade with least inward conflict and effort who are actuated by an honest disposition. Trade requires prudence, foresight, exact calculation of means. All economic undertaking involves present effort, self-restraint, loss or destruction of means for the sake of a greater remote advantage; and the qualities of character thereby disciplined are essential to all moral conduct. In moral conduct, indeed, the gain is often not clearly in view; but scientific morality aims 
at bringing it into view; and exact finish of -products, exact measurement of materials, exact comparison of values, exact calculations of means to ends, which are learnt in industry and commerce, are the chief origin of scientific thought. The reason why clever youths sometimes think that trade is exempt from moral principle is, that it is said to be based upon "selfinterest"; and this they identify with selfishness. But it is very different: for (1) the interest that a man pursues in business is not merely his own but his family's; (2) he considers his partners; (3) he usually has friendly and confidential connexions with other firms; (4) he often considers his employees; and (5) if he succeeds by improving his goods, or by economising processes and lowering prices, there is a gain of utility to the whole community. Therefore, to regard his conduct as selfish is a gratuitous degradation of commercial and industrial life.

For the Family, as long as it retained its solidarity, prudence and independence were necessary virtues: in which the individual shared without personally needing them, because shelter and subsistence in old age were generally ensured to him, though in different tribes under very different conditions. Now that by the wandering away of children to various places and occupations, the family has partially broken up, prudence and independence have become personal virtues of the highest value to the nation; and it is remarkable how in our own country they persist in spite of the emasculating Poor Laws that prevailed from 1782 to 1834 . But in a good many people they have failed; and no wonder, when we consider the wretched margin for saving that is afforded by the wages of unskilled labour, and the low rate of interest obtainable. Hence the demand for old-age pensions, and sympathy with those who claim the "right to labour" or to subsistence. The State is called upon to take the place of the old Family; but it can only do so in an external way; since it must take ages for any equivalent of the family feelings to grow up in the State under modern conditions of life. The rights of labour and subsistence should be recognised for the sake of humanity; provided that all means be adopted to ensure the gradual purging 


\section{INFLUENCE OF THE STATE ON MORALS 211}

of the population of all members whose labour during a certain period of efficiency is normally not worth paying for. Otherwise, to concede these claims of "humanity" will only make the misery of the residuary population continually worse.

Property, formerly vested in the Family, has for the most part passed into the hands of individuals. The old speculations concerning the origin of property and the attempts to find moral grounds for it were made in ignorance of its history. I cannot here discuss the moral bearing of different kinds of property-land, industrial investments, government loansor the theories of transfer, inheritance, and taxation. But as to private property in general, its justification is contained in its necessariness for the preservation and development of individuality; because it is the chief condition of a man's independence and of the enlargement of his free activities.

The present state of industry, with its too noticeable division between those who are chiefly interested in labour and those who are chiefly interested in capital, can only be transitional. The opposition of economic forces, intensified by the hostile feelings inherited by the persons concerned from military ages, and exaggerated by journalists and demagogues who always describe even negotiations in terms of war, is too wasteful to continue. Safer conditions of equilibrium will somehow be attained; and probably the future lies either with Co-operation or with Socialism. The difficulty of Cooperation seems to be that the requisite intelligence and effective sympathy are not widely enough diffused amongst us. Capitalism is served by high intelligence at very high rates of pay: intelligence, enterprise and centralised management render Capitalism in the highest degree adaptable to the diversified and ever-changing conditions of industry. Co-operators either cannot afford to pay such high wages of management; or will not, because either the pre-eminence of particular men or their exceptional rate of wages is incompatible with the notions and feelings of partnership upon which Co-operation is founded. It is conceivable, however, that able men may become ready to carry on co-operative concerns for less remuneration or for remuneration of a different kind. They may perceive the 
deceptiveness of great fortunes; they may cease to regard industry as merely a private affair, and see it as (what all honest industry is) a public service; or they may be more and more attracted by interest in industry itself. We still regard industry, for the most part, as a thing not to be undertaken for its own sake; but the opposite feeling will probably grow up until Industry acquires the same attraction as the Fine Arts have.

Since Co-operation is voluntary, it gives free play to individuality in the choice of occupation, and leaves the individual his property and the sphere of privacy and liberty that property maintains. Choice of occupation is the chief condition of the adaptability of industry, since it is determined partly by subjective preference and partly by demand; and demand shows in what direction industry is needed. Privacy and liberty are the conditions of individuality and, therefore, of the development of human nature. Socialism, in my judgment, if it should prevail, must lead to Communism. All the old arguments against it are sound; they have never been refuted: they are merely met by socialists with determined inattention. The fact is that merely negative arguments addressed to them can avail nothing. Gustave le Bon has shown that Socialism has certain features of a religion: fixed ideas, eager desires, violent emotions, panic of the herd. A great social and industrial change is certain to come about; and this movement expresses the fixed desire that it shall come soon. Now desire can never be refuted; it can only be enlightened and guided by a more intelligent movement, a better reconstructive policy. But the commonplace opponents of Socialism have no plan but to maintain the present order: which always means the interests of these very opponents: whom the gods have blinded. Thus one desire is opposed to another; and unless they can be reconciled we live in ' a state of war' present or prospective. There can be no reconciliation except by some plan that gives to each party as great satisfaction as it can reasonably expect. May not industrial Co-operation supply the grounds of compromise? But a compromise calls for reasonableness and mutual 
concessions: failing which there remains the 'state of war.'

Socialism seems to me to care very little for liberty. Its notions of brotherhood are confused because of class wars and internal factions. But it desires equality; not, however, equality of opportunity, since that implies liberty; nor yet merely impartial treatment in law, or in politeness, or in moral consideration-all which are reasonable; but personal equality, which is absurd. Its great idea, however, is general comfort: and comfort, as an End, is the antithesis of every active virtue. Yet what a natural object of desire to the multitudes by whom at present it is unattainable! And how easy it seems to get it: the rich are few; it is needless to steal their property; for we are many, and can vote them out of it. Did not the rich in their day vote for enclosures and corn laws? But Communism will extinguish property, liberty, and individuality, and will increase the general poverty through the inadaptability of industry in the hands of a bureaucracy. With individuality must go all hope of the nobler development of human nature; for Society can only be realised in its citizens.

I may be asked why individuality seems so precious to me, seeing that in the Metaphysics of Nature (c. xv.) I have declared it to be an illusion. The reason is that differentiation, which is the basis of the illusion, is the condition of all development of organic life. Its illusoriness is due to this, that before the rise of self-consciousness (say, three years of age) differentiation from the species has already taken place; so that to selfconsciousness nothing but the individual is ever known. This becomes the nurse of all other illusions; of all the vices of self-seeking; of all the absurdities of vanity and ostentation (which yet are an acknowledgment of others); and of all those strivings after wealth, power, fame that, though often disappointing to oneself, are necessary to the leadership of the tribe during the immaturity of reason and active sympathy. The only way to overcome this illusion is to preserve the conditions of the further development of the individual; for reason and active sympathy can come to maturity only in him; and only in the maturity of reason and active sympathy 
can the illusion of individuality be dissipated and co-operation in industry, and especially in culture, become universal.

Whether the future of mankind lies with Socialism or Co-operation we cannot yet foresee. Co-operation alone subserves the End of nature and man (if there be an End), the rise of the World to self-consciousness, and it has the adaptability which hitherto has been the ground of success for every organism. But Socialism, by getting hold of governments and municipalities, may establish such an organisation as to have power, for a time at least, to degrade the human race.

$\S 9$. The external activities of a State, diplomacy and war, react strongly on the character of its citizens. International relations are distinguished from personal in many ways. They are not controlled by authoritative laws. Whereas private morals presuppose society and laws protecting the well-behaved, a nation that is truthful and honest has no guarantee that it will not be cheated and robbed, except so far as other nations are afraid, or may think themselves otherwise interested in being truthful and honest. (2) The social sanction, that is, the opinion of nations generally (or the effective expression of it) is also, for the most part, determined by their interests and weakened by the opposing views of internal parties or hired newspapers. We may see courteous and even friendly relations maintained by all other countries with a government that violates every principle of humanity. (3) As for the religious sanction, we often see conflicting nations praying with equal fervour to the same God. 'Tis a noticeable thing that whoever makes war, however unjustly, seems always to expect the favour of God; declares, indeed, that that is what he chiefly trusts in; and, until defeated, he never remembers that he is a miserable sinner and that it is time to fast and pray. And (4) the natural sanction, that is, the reaction of an evil deed in its consequences, is in national affairs hardly ever understood or seriously thought of; often cannot be perceived until too late. In fact men's consciences have never been trained in these relations; only a few score people in the world have ever had, nor have their near ancestors had, 
any responsible contact with foreign affairs; and even these few have felt responsibility only to their own nations, or perhaps merely to some despot. Hence, when we try to judge conscientiously of foreign affairs, there is no educated sense, no traditionary guidance, except from the moral sentiments that have been developed within the Family and the State; and to trust these under totally different conditions is absurd. Then, if we try to reason upon the case, we are obliged to consider, that the interest of our own nation is a very important part of the interest of the world; that it is almost the only interest that our own action can effectively further; and that, if we should consent to subordinate our national interest to what we judge to be a moral principle, there could be no security that our example would be followed, or that it would do anything to establish a rule, or even that it would not be put down to cowardice.

Diplomacy, therefore, must often be embarrassing, and the popular belief is that, as an art, it consists entirely in skilful deception, and can be no further truthful than may seem necessary to make falsehood credible. For my own part, I find it impossible to believe this of our own diplomatists; although in the opinion of foreigners our diplomacy is (so they say) signally 'perfidious.' But, studying the diplomacy of some other nations, I am forced to judge that deceit is the essence of it. At any rate, since the effect upon popular moral beliefs depends not upon what diplomacy is but upon what it is supposed to be, there can be no doubt that the effect of it is to spread the conviction that "where there is no law there is no injustice" nor any sort of moral obligation.

It might be assumed that the influence of war must be still worse; and so it is upon the more brutal part of the population, who read the newspapers and revel vicariously in blood and glory; but it is not so with the average citizen. Whether the deceiving or the slaying of our enemies be the greater misfortune, slaying certainly excites more reflection, and is generally regretted as a 'necessary evil.' Few of my countrymen would ever consent to go to war, if foreigners were not (as we think) so unreasonable or so outrageously wicked; 
and foreigners generally say the same on behalf of their own countrymen. Hence, in fact, more has been done in the case of war than in any other international relations towards establishing customs and agreements favourable to humanity that make some approach to the force of law. War in its nature (apart from such understandings) dissolves all moral ties between the combatants. It is exactly the opposite of trade, which consists in mutual services and for its full development requires truthfulness and honesty. Indeed the tradition and contagion of war infects with its own vices the vulgar conception of trade; so that many regard it as a mutual cheating restricted by suspicion and ill-will. It is the tradition of savages. However, it would be absurd to set forth anything so well known as the evils of war; or, on the other hand, to explain at length how, against all that, we are bound to set the good effect of war upon relations within the tribe; how devotion to leaders and comrades, to hearth and home, valour, endurance, and all the virile virtues have been developed in the ancient wars of mankind.

When the whole tribe went to battle and fought at close quarters, war was favourably selective, since the weak and cowardly fell. But under modern conditions of war those fall who are most exposed, and they probably are not the least brave; whilst the proportionate mortality of officers necessarily increases. Even now if, under conscription, the whole nation marched out, disease and exhaustion would tell most upon the weak; but to send only the flower of the nation to be destroyed is the foolishest thing in the world. Through conquest war has been the cause of slavery and of other evils mentioned above; but it has also spread the superior races over the earth. If, however, a conquering tribe is not numerous enough to colonise and make its own society, it sinks sooner or later into the common population that it has already debased. Foreign conquest may even afflict the home country with unexpected vengeance; and the fates of Rome and Spain have been the burden of many a sermon. As for the fate of the conquered, I cannot think of a single case in which they have permanently benefited. Where there has 
been no enslavement, but only protection and control, peace has been dearly bought with effeminacy. In India we have for a long time done all we could to preserve order, to administer justice, to educate, without severity or intolerance; we have checked the periodic ravages of plague and famine, though unable to extirpate the disease or prevent much suffering from hunger; so that during last century the population advanced from 200 millions to 300 millions. But far from regarding this as evidence of prosperity, I fear it implies the survival of feebler people than formerly and a decrease of vitality and ability in the average man. At any rate, it is very fortunate for us that India is thousands of miles away.

Whilst, then, the State is indispensable to human development it restricts in many ways that development of the individual which we call morality, the disposition to act freely and sincerely for the greatest good attainable for man. It unites us in tribes and nations, but divides us in ranks and parties. It makes laws to do justice, and thereby often sets the example of injustice. It enables a livelihood to be easier earned, and thereby preserves inferior people. It exercises an external control, and thereby makes the inward moral disposition less necessary to social life. But we have still to consider the moral influence of two of the State's greatest means of maintaining itself, namely, Religion and Art. 


\section{CHAPTER IX}

\section{RELIGION AND MORALS}

$\S 1$. How man came to believe in supernatural powers must always be a matter of hypothesis, because no records remain of many, many thousands of years in our early life. Such belief is peculiar to man, in spite of the symptoms of dread that Romanes observed in his dog and thought it possible to interpret in analogy with our fear of ghosts. In children, whatever instinctive tendencies they may have to superstition, their actual fears and fancies are always due to instruction and suggestion. As for existing savages, the most "primitive" we know are as old as we are, and have probably outlived many mythologies. Still, we must hope to learn something by examining their minds; and we find everywhere amongst them two forms of supernaturalism, namely, Animism and Magic; and in all developed religions there are animist and magical elements. Really, for the purposes of this chapter, we are not much concerned about the origin of such beliefs; but perhaps, to make my position clear, I should say that, to the best of my judgment, they have three chief sources.

In the first place, into the movements and strains of natural things we necessarily read sensations of effort or force, in analogy with the kinæsthesis or sensation of our own exertions. This does not amount, as many suppose, even on the part of children or savages, to a belief that rocks or waterfalls are, like ourselves, alive: normally, the difference between animals and other objects is plain to them. It does indeed make savages and children ready to accept any suggestion that rocks, waterfalls, etc., are living agents, or to 
feign them to be so in play. But apart from suggestion, there are only impersonal force-things for them in the greater part of nature; and although nature is overgrown in certain states of culture with animism and mythology, a time comes when these accretions are stript off again, and the conception of an underlying impersonal force remains as the ground of mechanical explanation, or of Pantheism.

Secondly, at an early date man began to believe in ghosts : I refer to Tylor (Primitive Culture, c. xi.), and Spencer (Sociology, Part I.) for the explanation of how sleep, dreams, shadows, reflections, echoes, epileptic fits, excite the crude reasoning powers of savages to construct a theory of ghosts or spirits inhabiting and actuating our bodies; sometimes supposed to have pre-existed and to have taken possession of us at birth; to be attached to the body but capable under certain conditions of a separate existence ; generally to survive its decease, but not always its destruction; to hold intercourse with living men, aiding or injuring them; to be offended, or propitiated by prayer and sacrifice, or coerced by rites.

Thirdly, savages are apt to take connexions of ideas as equivalent to physical connexions amongst things : their ideas are strongly pictorial, and the determination of one idea by another, through association in their minds, is regarded (as Hume says of cause and effect) as a necessary connexion of the things themselves as they are imagined. From such a source probably originates their belief in contagious and in mimetic Magic : that whatever thing has formed part of, or has belonged to, or has been connected with a man ever after retains its connexion with him, and can be used to influence him; and that whatever resembles him may be substituted for him in all rites and incantations, so that the result will be the same as if he himself had been operated upon; or, generally, that whatever is a resemblance or a sign or a reminder of anything is, as to influence or suffering, the same as the thing itself.

Belief in ghosts, I suppose, in course of time gives rise to hero-worship or ancestor-worship; the growth of the patriarchal family tends to concentrate worship on the deceased father or 
some forefather of unusual reputation; and the development of the tribe is favourable to the worship of deceased chiefs or kings, who may be considered to attain to the rank of gods. But Nature-worship, as of the sun and moon, trees and mountains, depends, in the first place, on the imagining of everything in Nature as having one animating quality-what we call 'force,' by savages less abstractly conceived; and, secondly, upon the confusion in a savage's mind, amounting to identification, of all things that may be called by the same name: so that if a man should be called after the oak tree, and die leaving the memory of distinguished exploits, these exploits and his ghost, as personal recollection of him fades, are attributed to the tree, and to the tree prayer and sacrifice are addressed. The confusion of animals with human ancestors through names is still easier to understand. This theory of Spencer's seems to me more probable than the direct personification of natural objects. According to E. Westermarck, indeed (Moral Ideas, c. xlvii.), "the origin of Animism is the conceiving of inanimate things as volitional and emotional because they are deemed the originators of startling events." Anything unfamiliar excites awe and a sense of the supernatural, he says; but he does not explain why such things give rise in some cases to a belief in supernatural mechanics (or Magic) and in other cases to a belief in supernatural volition (or Animism). These latter cases, in my judgment, presuppose the ghost-theory. It may be argued, then, that all ethnic gods are heroes or ancestors. That gods are known whom their worshippers declare never to have been ancestors or even human, counts for little or nothing. Gods need not be very old amongst many tribes for their relationship to be forgotten, and the antiquity of such gods is often shown by their having few or no functions. At most, it points to the mythology of an earlier generation living under different conditions, or to the influence of a conquering or a conquered race.

That Animism is not a theory of Nature independently of a belief in ghosts is shown by primitive Magic; which at first is the art of controlling impersonal forces: for were all things personified at the lowest stage of culture, no such art could 
then exist. Magic supposes that powers reside in things and are, in some sort, extensible beyond them so as to operate at a distance. The wind is a familiar type of invisible force; words, as spoken and heard, are types of intangible communication, the flight of ideas may have no character of place. That things do so operate to the advantage or injury of men is a belief born of desires and passionate wishes, and confirmed by coincidences and by fears.

As to the origin of the belief in Magic, there are, indeed, already several hypotheses; but as no better kind of explanation seems now procurable I may be allowed to offer one more. It occurs to me that it may have arisen during the transition from the stage at which our remote forefathers could only operate upon things by direct manipulation to the stage at which weapons and tools were employed with intelligent appreciation of their working. In passing from direct manipulation to the use of indirect means, such as weapons, traps, tools, the latter cannot at first have been clearly understood, and they were clumsy and often ineffective. A strong desire must have seized the savage to make his sticks and stones and traps as certain in their effects as his direct manipulation had formerly been. And if upon a successful cast he noticed anything in the neighbourhood-a snake or a queer-shaped stone-this took its place in the total picture of his action and may have stuck in his mind as the obvious condition of its effectiveness. Thence would grow the practice of keeping the stone or snake (or its skin) or of carrying it about with him (as we say) for luck. That every object is perceived as a force-thing prepares it for becoming a magic-thing, and association of ideas does the rest. Nothing is more common than the charming of tools and weapons. The tacit generalisations concerning the power of contagion and the substitutability of similars are, no doubt, of slow growth. And the conversion of a magic-thing into a Fetish, controlled by a spirit, may be possible only after the rise of the ghost-theory. That irrelevant objects may be believed, through mere casual association, to be connected with success or failure is intimately known to most of us who 
remember our own childhood, or even perhaps our later years. To explain every detail of magical superstition is as hopeless as to exhaust the possibilities of personal caprice. But the power of anything, such as a pebble or a bone, having been assumed, the belief in its working depends upon the strong desire that it shall work, which calls up an image of the end as if attained. This subjective ground of the belief in Magic is indicated by the objects employed in nefarious Magic-an image of the person assailed, his name, a garment of his, or lock of hair-whatever enters into the aggregate idea of him; and by the words and gestures that accompany magic rites, which always make the idea of their success more forcible.

Religion is understood to be the worship and propitiation of a god, to avert his anger or obtain his favour and aid, according to his free will; and primitive Magic may be distinguished from Religion, not only by not implying the power of a god, but by the compulsive power it is supposed to exert upon the persons or things to which it is directed. But a fusion generally takes place between these ideas: for they are alike mysterious, implying the attainment of ends by means that have no perceivable connexion with them. On the one hand, Magic is wrought by the means of divine, especially of malevolent powers; amongst the Todas, for example, the use of spells "leaves little room to doubt that it is through the active intervention of the gods that a sorcerer is believed to work" (W. H. R. Rivers, The Todas, p. 270). On the other hand, religious rites are regarded as having a magical operation, and even the direct actions of the god may be considered not as exertions of free will, but as the obligatory fulfilment of a contract after the rites of his worship have been accomplished (Maspero, The Dawn of Civilisation, c. ii.: other cases in Westermarck's Moral Ideas, c. xlix.). In the latter case, Religion is emptied of personal relationships; and since the rites must be performed to the letter, the most indifferent actions are put on a level of necessary obligation with the most essential morals or even made superior to them; and the power of the priesthood is enhanced since they alone know the exact rites and formulæ. In the former case, where Magic 
depends upon the aid of gods or demons, new methods of crime may be discovered in all the variety of necromancy and devilworship, and, therefore, new grounds of suspicion and persecution exist. After the worship of high gods has been established, Magic becomes unlicensed thaumaturgy, exciting fear of power invisible by rites not allowed.

Still, Magic is in many ways useful. By giving confidence it may steady a bowman's hand. It enforces taboos upon property, and protects the weak and strangers, who may have unknown powers. "The belief in the power of charms produces not only honesty, but a great amount of gentle dealing," says Livingstone (Travels in South Africa). "The powerful are often restrained in their despotism from a fear that the weak and helpless may injure them by their medical knowledge."

On the other hand, the suggestion that Magic was the matrix of Science does it too much honour. Magic, indeed, involves a belief in uniform connexions of events; but so do all our ordinary actions and inferences. Such pseudoscientific systems as Astrology and Cheiromancy prove not the origin of Science in these fanciful schemes, but the architectonic tendency of the human mind, which can (as we know) make systems out of all sorts of nonsense, and is more honourably active in epic poems and theogonies. Systems arise instinctively because they economise memory and thought and give each of their parts the credibility of that part which is most assuredly believed. Mimetic Magic assumes that if any object be substituted for one that it resembles, the same results may be expected; and Science certainly proceeds upon resemblances: but Magic is content with any resemblance, and this is the very opposite of the scientific demand for exact resemblance. Magic, like Science, proceeds upon hypotheses; but, unlike Science, never tries to verify them. Magic, like Science, believes in connexions of remote events; but, unlike Science, never tries to discover the links of causation that unite them. The most that can be said is that Magic and Science have been differentiated from a common ground. Magic and Animism, alike credulous and 
uncritical, are the natural enemies of Science. Science springs from instinctive curiosity (by no means confined to wonderful or mysterious things) and is elaborated by the architectonic faculty; it is supported by the utility as well as the delight of knowledge, and learns the necessity of a precise comparison and concatenation of phenomena from the practice of men of genius whose understandings nothing else will satisfy, and from the lessons of war, industry, and commerce. If early scientific discoveries and inventions were regarded as supernatural, if the discoverers themselves were believed to exert supernatural powers and sometimes connived at the delusion, these were inevitable consequences of the pre-existence of magical systems and the great reputation of wizards and thaumaturgists.

$\S 2$. The nature of religious belief presents a very curious problem. Sometimes it seems to be the strongest of all modes of belief; for see what sacrifices of property, happiness and life are made under its influence. At other times it seems to lose all power; for in spite of the most frightful threats men disregard it, and consider it as fit only for the feeble-minded, sick and dying. Being a comparatively new mental growth, it has but shallow roots in most people, is chiefly effective in support of older instincts, and depends for its activity upon general consent and public observances. Hume was so much struck by this fact in the middle of the eighteenth century, that he compares such belief to dramatic illusion, ascribing the general incredulity to the faint idea we form of our future condition, and the faintness of the idea to the want of resemblance of that condition to the present life rather than to its remoteness. "In matters of religion men take a pleasure in being terrified, and no preachers are so popular as those who excite the most dismal and gloomy passions. In the common affairs of life, where we feel and are penetrated by the solidity of the subject, nothing can be more disagreeable than fear and terror; and it is only in dramatic performances, and in religious discourses, that they ever give pleasure" (Treatise, Book I. Part iii. $\S 9$ ). Is it, then, entirely an affair of tradition, imagination and panic excitement; 
where the facts are never presented and no verification is possible?

The evidence seems to show that in the beginning both religious and magical beliefs are a mixture of simple credulity, self-deception and deliberate deception in minds for whom truth and falsehood have not the distinctness that they have for us. See the accounts of Australian wizards by Spencer and Gillan (Central Australians, c. xvi.) : a wizard may believe in his own power, and yet pretend to cure a disease by extracting from the sick man's body a stone which he has brought with him for the purpose. In some Christian countries miracles are still publicly performed by priests who cannot possibly believe in them; and, surely, neither can many of the worshippers. But there is a disposition to believe such things. We see many who have given up belief in the reputable dogmas of the Church, so uncomfortable that they resort to spirit-rappers and astrologers, seeking to renew their faith at the primitive sources of ghost-stories and conjuring. They have ceased to believe, not through the force of other convictions but from mere weakness and incapacity to grasp anything so comprehensive and philosophical as Christian Theology. High Religion is always announced by prophets and elaborated by philosophers, so that the full appreciation of it is only possible to elevated minds; but being everywhere taught by priests of all grades of intelligence, according to their ability, it becomes everywhere adapted to the prevailing grade of intelligence, often by including the superstitions of an earlier cult; so that all sorts of absurdities and superstitions pass under the name of Buddhism or Christianity, and are not contradicted because the process of corruption is too widespread and subtle to be watched and because it is inconvenient to contradict them. Nominally the high Religion is generally accepted as long as it is customary, as long as no irreconcilable dissensions break out amongst the leaders of opinion, or as long as such dissensions can be kept secret. When dissensions concerning the faith not only exist amongst the leaders of opinion, but (as at present) become notorious, the ground of popular assent collapses, and men settle down upon primitive superstitions. The average 
mind in what we call civilised countries is little, if at all, above the savage level, and owes all its superficial superiority to the leadership of great men. Hence all the high Religions (as J. G. Frazer has observed) have a limited life and not a very long one; and now it may be impossible to reconstruct such a thing; but Magic and Animism of every sort, from Devil-worship to Faith-healing, have perennial sources in human nature.

In history, Religion, in spite of many drawbacks, has been so useful that families and tribes have been selected by their addiction to it; so that it has become an inherited instinct, or instinctive disposition. But being of relatively recent origin (biologically), it is highly variable in different men and subject to disease-easily allying itself with hallucination and insanity. Nearly every one feels its power at some period of his life, and is especially liable to its influence amidst the contagion of popular excitement. It is essentially a social phenomenon, propagated amongst the collective observances of the family and the tribe, and retaining a contagious, panic character. This explains the occasional intensity of religious enthusiasm and its relation to dramatic illusion. Social religion, as it is organised by priesthoods and usually connected with government, is the chief subject of the present chapter. Upon the value of personal religion I shall at present be content to refer to the remarkable work of William James, Varieties of Religious Experience. Personal religion is an offshoot of the social ; for although Animism must have originated in the imaginations of individuals, I do not call the fear of ghosts religion. For religion there must be gods, and gods are of the tribe not of the individual. But, once established, personal relations arise between them and all members of the tribe, though often closer with priests or other sacred persons than with the rest. So far as their rites or the duties enforced by them are the concern of any individual, failure on his part is an act of disloyalty calling for repentance and reconciliation. The disloyalty is felt to be greater in-as-much as the god is greater than the king, and so much the more an occasion of dread or remorse.

Where, again, the god is guardian of the moral laws, the 
breach of such laws becomes sinful; and thus personal religion reinforces morality with the enthusiastic self-immolating sentiments of tribal worship. Hence William James feels able to say that " the best fruits of religious experience are the best things that history has to show - the highest flights of charity, devotion, trust, patience, bravery" (op. cit. p. 259). To be sure, his investigation into the value of saintliness faintly justifies this praise; and after an inductive inquiry into the fruits of family affection or patriotism, he might be disposed to qualify it. But it seems true that with very many people the highest reaches of the moral life are only possible under the influence of religion. "The saints, with their extravagance of human tenderness, are the great torch-bearers of this belief [in the sacredness of every man]. Like the single drops that sparkle in the sun as they are flung far ahead of the advancing edge of a wave crest or of a flood, they show the way and are forerunners. The world is not yet with them, so they often seem in the midst of the world's affairs to be preposterous. Yet they are impregnators of the world, vivifiers of potentialities of goodness which but for them would lie for ever dormant. It is not possible to be quite as mean as we naturally are, when they have passed before us. One fire kindles another; and without that overtrust in human worth which they show, the rest of us would lie in spiritual stagnancy" (op. cit. p. 358).

The fact that religion is, in the first place, a tribal institution, and that a high religion, above the comprehension of the crowd, depends for its authority upon the unanimity of leaders, makes it important to suppress heresy and dissent, and so leads to persecution. This has now so much decreased that it is chiefly represented by the confusion of mind in which many people go to church-to worship God and to be respected of men. We have forgotten the state of Europe only three or four hundred years ago. Since the Reformation, persecution has declined; though this was not due to the reformers: Luther, Calvin, and Knox were not the men to suffer a difference of opinion, if they could save your soul at the cost of your body. But divisions amongst clergy and politicans paralysed all parties. The support given to polity by faith having been 
greatly weakened, it has been necessary to find other foundations for it by the amendment of social conditions and public justice. Yet we often hear pious Liberals wishing for a return to unity in religion: not reflecting that without extensive changes in our religious ideas nothing else could so effectually hinder civilisation.

$\$ 3$. Religion is such a comprehensive term that it may be difficult to find many propositions that are true of everything that it includes. Gods, demons, spirits innumerable of every quality and shape have been objects of worship and propitiation : of such different qualities that to bring the worship of all of them under one name must sometimes be painful or even offensive. Birds, beasts and reptiles do not swarm in generations more prolific than this fauna of the human imagination. How many theologies and mythologies we are acquainted with! how many more can be traced in strata of customs and folklore by comparison with better known beliefs ! and yet by far the greater number must have irretrievably perished with their worshippers. So far as known, gods and spirits are classifiable and their relationships are pretty clearly traceable ; and though their origin, like that of animals, may not yet have been discovered, they everywhere exhibit more or less adaptation to the conditions of their existence, and their continued existence depends upon such adaptation. The chief condition of their continued normal existence is utility to their worshippers; but they may enjoy a secondary parasitic life by being useful to priests and politicians.

Adherents of the more enlightened religions are apt to suppose that only their own supernatural beliefs are useful, and that the beliefs (or "superstitions") of peasants, barbarians, and savages, far from being useful, are debasing and pernicious, because they are false : at least, all who hold that the will of the god is the ground of morals can give no other reason, but must acknowledge that if a pagan religion were true it could not be depraving. And it is not to be disputed that many religious doctrines and practices even of civilised peoples have been debasing and pernicious, and have been seen to be so by eminent individuals nurtured in them, such as Plato and 
Lucretius in classical antiquity. But it must increase our belief in the general utility of a religion that it is capable of existing for ages in spite of such drawbacks. It happens here with particular doctrines or practices as with a good many organs in animal bodies that have become useless and injurious; they survive through their connexions with the rest. And as for the falsity of a whole religion in its peculiar doctrines, that (I fear we must admit) does not necessarily render it debasing or pernicious ; for we have here an extreme case of that astonishing phenomenon in human life, the utility of illusion. No one will deny (1) that pagau religions are literally false, or (2) that they could not have flourished at such frightful cost (in some cases) of blood and wealth, such terror, such bestiality, unless they had comprised some overwhelming advantage. What that advantage was it may not always be in our power to discover, but it is easy to see some things that may have contributed to it.

Beliefs concerning gods and spirits, in the first place, enhance and define the self-consciousness of tribal life by becoming the ground of stories concerning its origin, history and relation to other tribes: as may be seen in the crude myths of the Central Australians about the 'alcheringa,' the period of mythical ancestors, at a stage of development when religion can hardly be said yet to exist. Mythology is the matrix of history, poetry and philosophy: it reconciles every tribesman to his place in the world, gratifies his nascent wonder at everything that is unintelligible, explains and sanctions the tribal customs. The primitive growth of intelligence in the form of picture-thinking produces a volume of ideas much too great and various to be absorbed by the direct utility of anticipating events, or by the simple preparation for events in the making of weapons, etc. The savage's mind is active when he is not actively employed; and his otherwise redundant ideas are then indirectly utilised in the creation of mythology. This can only take coherent form in stories about the tribe, its customs, its memories, the common objects of its habitat; and such stories can become permanent only by obtaining the tribe's acceptance. 
When the progress of tribal organisation has instituted chiefs and kings, the utility of mythology is often increased by the account it gives of the king's divine descent and of his representative relation to the tribe. It may seem to a rationalist that belief in kinship and the fact of mutual aid must be the strongest ground of unity amongst tribesmen; but it is not so: from very early times human beings are controlled by symbols and theories (often groundless), as most of them are to this day ; because the direct relationships of men are so much troubled by antagonisms that illusions are necessary. How usual it is to be appealed to for consideration toward another man not on the ground that he is 'our own flesh and blood' and naturally excites our sympathy, or that timely aid will restore him to useful citizenship, but that 'he too is God's creature,' 'our brother in the Lord,' and so forth: such also are the thoughts of a remote antiquity. Moreover, whilst generations of kings succeed one another and pass away, the gods remain from age to age, presiding at burials, births and accessions, filling every interval of history and conferring upon the tribe the unity of an immortal being.

In peace gods protect the customs of the tribe, nourish the crops, make good the labours of the potter and of those that grind the corn; in war they go before the host to battle, guide the arrow and the spear and receive the souls of the valiant. Alike in peace and war a power without whose aid the efforts of men and kings are vain, the king of kings is looked up to with an exalted loyalty: such is the spirit of religious devotion; which can hardly be explained as a "binary compound of fear and affection." A profound impersonal awe, derived from ancient tribal rites ; fear (of a certain weird and mysterious kind) derived from ghost-lore; these, no doubt, had a place in religious sentiment; and so has affection when a god is regarded as the source of fertility and nutrition and security; but it is devotion to the divine chieftain, judge and lord of war, in a word, loyalty that is the ennobling power of religion. These ideas and feelings are a chief means of taming mankind : they increase the loyalty of freemen and the submissiveness of slaves. Under certain conditions the submissiveness 
of vast populations is amazing; emasculating and bloodthirsty tyranny prevails for ages unresisted; always under terrific religious sanctions. Force of arms could never obtain such submission; but men are ruled by ideas; ideas make physical compulsion unnecessary, and that is the use of them. For all political organisation, even the most barbarous, has a certain natural utility; it preserves some sort of internal peace and industry, and is therefore favourable to population. Those tribes that are susceptible to such ideas, and therefore capable of such organisation, become more numerous than others; and the ideas with their corresponding organisations prosper, until they are overthrown by other ideas connected with more effective organisations. There may have been cases in which ruling ideas have become insane, and have directly caused the destruction of all the conditions of national prosperity; but it will often be found that when one nation is overthrown by another, the conqueror had better ideas concerning God, and that successful revolutions are supported by new theories concerning the nature and purposes of God. Hence the antipathy of timid rulers to all such theories.

Whilst the subserving of political organisation is an essential utility of religious ideas, they are also necessary to the higher culture in philosophy and art. In various waysby conquest, by incalculable accident and caprice, perhaps by the hyperbole of prophets, universalising their tribal god, or by the human mind's acquiring greater powers of comparisonfrom the host of gods and demons one at last emerges supreme, and therewith a condition favourable to the recognition of the unity of nature and of natural law. But for many ages more important is the function of religious ideas in inspiring poetry and the arts. In praising kings and ancestral gods, the ideal of human nature is necessarily exalted; for gods are exalted men, or are exalted in the likeness of men, and not even beast-gods are beasts. It is true that the arts in praising the gods may exalt them merely by the exaggeration of power, without any regard to moral virtue; but, in fact, with the progress of culture the ideal is moralised. The connexion of God with the national customs and laws; his court of 
justice analogous to the king's but without some of its temptations to abuse and subornation: these things gradually determine his character. But the conception of a god who administers a moral law profoundly modifies human morality. Religious beliefs become symbolic of social necessities; and since imagination cannot yet adequately represent the importance of conduct in all its consequences, the penalties or rewards of God are substituted. Moreover, it is the defect of all custom and law that they can require no more than observance, and that this can never amount to morality unless it proceeds from a sincere will. But to mortal judges the will can never be known: only the spiritual judge can read the heart, it is the eye of God that penetrates the conscience. I do not, indeed, think it originates but it greatly enhances the power of conscience. And this is the greatest utility of religion to mankind. With conscience awakens moral reflection, and moral reflection revises the law and purifies the ideal of God, until conscience is enthroned in heaven.

$\$ 4$. Although religious beliefs have been necessary to the support of government, and government is necessary to social development, the close alliance of government with religion has, nevertheless, many injurious consequences, especially to morality. With the division of social functions there grows up a priestly caste or profession, sometimes an organised hierarchy, with exclusive access to the higher education and very wealthy, exercising greater powers than any other tissue of the state. Every organised class incessantly strives to increase its influence; and therefore a priesthood strives to extend the control of religious beliefs over every action of human life, and to strengthen their hold upon men by continually aggravating the sanctions of religious hopes and fears that enforce observance. The tendency of this process is to introduce rigidity into the whole course of life, to substitute observance for moral discrimination, and to hinder the growth of morality by diverting men's consideration from the personal and social effects of conduct and insisting upon religious rewards and punishments or other supernatural motives. Henry 
Maine says of the religious oligarchies of Asia, "Their complete monopoly of legal knowledge appears to have enabled them to put off on the world collections, not so much of the rules actually observed, as of the rules which the priestly order considered proper to be observed." "Prohibitions and ordinances, originally confined, for good reasons, to a single description of acts, are made to apply to all acts of the same class, because a man menaced with the anger of the gods for doing one thing, feels a natural terror in doing any other thing which is remotely like it. After one kind of food has been interdicted for sanitary reasons the prohibition is extended to all food resembling it ... a wise provision for insuring general cleanliness dictates in time long routines of ceremonial ablution" (Ancient Law, c. i.). Thus every action becomes a religious rite that cannot be modified without fear and trembling.

The traditionary character of religious belief is necessarily opposed to innovations, unless they proceed from the priesthood itself in extending its power or defining its doctrines. When indeed new Religions arise they are not merely innovatory but revolutionary. The strongest opposition to them comes, of course, from the old Religions; but after a few generations, if successful, they in turn become fixed and obstructive. This influence is felt in all departments of human life, justice, benevolence, temperance, but perhaps most conspicuously in relation to truth. Religious beliefs represent the condition of the human mind in some past age: in the great Worldreligions they are embodied in ancient books and authoritative writings that claim to be direct revelations. So far as such writings consist of simple teachings concerning God or morality, they may for ages lose little or nothing of their value; but legends and propositions concerning history and physical fact are apt to become incredible, if social conditions are otherwise favourable to intellectual enlightenment. The barbarous Greek mythology became intolerable to philosophers even from the sixth century B.C., and the attempts that were made to allegorise its fables seem to us ridiculous. It is the misfortune of Christianity to be encumbered with legendary 
histories, stories of miracles and a crude cosmology; which, being contained in the same books as its sublime theism and inspiring morals, seem to have the same authority; and the confusion has been confirmed by the decisions of Councils and acknowledged doctors, extending down to our own day. Hence the "opposition between Religion and Science."

This opposition has occasioned frightful animosities; the grossest physical and moral cruelty on the part of those who had the power, scoffing and blasphemy on the part of those who had no other weapons; but the undermining of truthfulness may be a more injurious, though a less conspicuous evil than the violation of charity. Truthfulness demands not merely that we should not lie or prevaricate, but also that we should study the nature of evidence, and inquire into the evidence for opinions opposed to our own before condemning them; that we should not allow our wishes to pervert our judgment, as to the weight of evidence and the nature of argument; and that we should acknowledge our errors when we become aware of them. Falsehood may be set aside; but as to the other demands of truth, the zeal of religion and the interests of a priesthood are unfavourable to their fulfilment. The first attitude of a Church towards scientific results that conflict with dogma is to deny them authoritatively and try to repress them by force, without any inquiry into the evidence for them. Entirely conscientious such conduct may sometimes be; nevertheless. it springs from the root of the whole evil, namely, a bigoted satisfaction with dogmas, the ideas of a professional crowd, and ignorance of the nature of truth where matters of fact are in question. As knowledge of the evidence, and therewith acceptance of the scientific conclusions, spreads, denial becomes absurd and repression impossible. Attempts may be made at reconciliation; alleging, for example, that the 'six days' assigned in Genesis for the creation of the World really meant periods, thousands of years, or millions, or as much as you please. Then there are Adam and the Deluge, and old-fashioned Astronomy, and numerous miracles that "may be due to a higher law"; in other words, no miracles: all very harmless, and interesting to the student of Folk-lore, but fatal traps for the 
ingenious apologist. I shall not recall the excuses that I have seen for these things, but cannot forget the feeling that such work was not good for those who wrote or for those who read it. At the stage which this issue has now reached, the more enlightened part of the public understands that, whilst the Roman Church remains irreconcilable, certain doctors of the Anglican Church accept the scientific results both in cosmology and in biblical criticism; no official protest is made against their teaching, but neither is there any official recognition of it; and meanwhile the bulk of the clergy are allowed to go on teaching to the uneducated and to children dogmas that are known to be untrue. It may not be desirable that archaic doctrines should be explicitly recanted; but on no excuse should they be actively taught. Untaught for two or three generations, they would fall into the background, and be understood in their true character.

Connivance at obscurantism carries other moral dangers of a very serious kind. Many of those who are mistaught will, when they grow up, necessarily learn things that have become matters of popular information; they must then find out how they were treated in childhood; and what will they then think of those who mistaught them? But further, if the teaching of barbarous dogmas is associated as strongly as possible with divine and moral instruction, is there not a great danger that when the dogmas are rejected, the divinity and morality will be rudely shaken? How many of us have had this experience!

Recently, attempts have been made to discredit science in the supposed interests of faith, by showing how imperfect the sciences at present are. It has been fully proved, and ( $\mathrm{I}$ believe) is admitted, that the theory of the evolution of the World is very incomplete, that many conclusions of scientific men are contradictory, that what passes for evidence is really dependent on hypotheses, approximations and other devices that give it no claim to the rigour that is often ascribed to it. We are expected to conclude from this that the case for science is imperfect, just like that for religion. But on a little reflection a very different conclusion follows. Were it urged that 
just as those who work at science are convinced by their very labours, so those who live in religious faith are convinced by their experience, I think very few men of science would care to say a word of dissent. But when it is said that, judged by rigorous tests, the evidence for scientific theories is imperfect, the terrific reply follows that for traditionary dogmas, tried by such tests, there is no evidence at all.

The reasonable course for religious men would be to accept frankly all scientific conclusions, so far as they seem to be true-just as they freely use all sorts of inventions that depend upon scientific principles - to accept the well-ascertained as practically certain, the probable as probable, and devote themselves to the uniting of scientific truth with personal experience in the interpretation of jpure divinity and in the elevation of human life. Whether Theism admits of "proof" or not, it is at least a very natural way of thinking; nine-tenths of mankind never question it; and morality can be proved and may be wisely propagated.

$\$ 5$. The influence of Religion upon Justice depends partly upon its intrinsic character, partly on its alliance with government. Its traditionary basis inclines religion to support whatever is ancient or established, however barbarous. Its connexion with government, if dependent on government for power and wealth, inclines it to support the authority of government however despotic, and proprietary rights however unjust. Westermarck observes (Moral Ideas, c. vii.) that " the chief explanation of the great severity of certain criminal codes lies in their connexion with despotism or religion or both." Laws established by despotic rulers, or ascribed to divine law-givers, "have a tendency to treat criminals not only as offenders against the individuals whom they injure or against society at large, but as rebels against their sovereign or their God." There is, therefore, no known limit to the punishment that may be annexed to such transgression. The barbarous argument-in fact, a mere verbal jingle-is familiar, that a crime must be measured by the greatness of the power against which it is committed and that, therefore, if against an infinite Being it is an infinite crime and 
requires an infinite penalty: notwithstanding the obvious retort that an infinite crime cannot be committed by a finite creature. In An Analysis of the Influence of Natural Religion by Philip Beauchamp (pseudonym) it is pointed out that, inasmuch as the force of all sanctions differs according to intensity, duration, certainty and propinquity, and the sanctions of religion are defective in certainty and propinquity, to make up for this, "the pleasures and pains anticipated in a future life are intense and durable to the utmost extent." He adds that, since the penalties remain purely imaginary, their efficacy is after all not great. Still, the confusion of mind that such teachings produce with regard to the nature and grounds of justice is not much relieved by their ineffectiveness. Even greater perhaps is the moral perversity of the doctrine of vicarious atonement as it is vulgarly taught. I feel bound to say, however, that the confusion of moral ideas thus created is not, in practice, so great as we might expect, because of the popular distinction between divine and human justice. This enables pious men to act with the most enlightened justice in human relationships, whilst it renders quite meaningless all the moral predicates with which they praise the Lord. To Berkeley the conceiving of the divine attributes in a non-human sense seemed equivalent to atheism (Alciphron, Dial. iv.); and to J. S. Mill even worse (on Hamilton, c. vii.).

How rulers and politicians have been accustomed to abuse Religion in the defence of injustice is notorious. "The deepest policy of a tyrant hath been ever to counterfeit religious," says Milton (Eikonoklastes). Machiavelli appreciates Ferdinand of Arragon as "always making Religion his pretence, and exterminating the Jews by a sort of devout cruelty" (Il Principe, c. xxi.). Burke has the most simple-minded expression of this practice in his Reflections on the French Revolution: "The body of the people must labour to obtain what by labour can be obtained; and when they find, as they commonly do, the success disproportionate to the endeavour, they must be taught their consolation in the final proportions of eternal justice." Obviously, the same excuse may be made 
for slavery; and, accordingly, no Religions have condemned slavery. They have differed in the degree to which they required masters to be kind to slaves, and in this respect Buddhism is the most humane. It was the Stoic Philosophy that first made manifest the injustice and unnaturalness of slavery; unless we ascribe this insight rather to those predecessors of the Stoics against whom Aristotle argued that slavery is according to nature. The Christian Church, as a body, never repudiated slavery; although from time to time some enlightened doctor declared it to be contrary to the spirit of our religion-especially to make slaves of fellow-Christians. As for serfs, the Church was the greatest serf-holder in Europe, and in France remained so until the outbreak of the Revolution. In America the clergy of all denominations were almost unanimously in favour of the "domestic institution." (See the chapter (xxvii.) on slavery in Westermarck's Moral Ideas.) All this is easy to understand without ascribing to the clergy more than their share of original sin, if we remember that they must consistently regard this life as but a moment in comparison with immortality, for which it is a preparation; that therefore the dignity or comfort of our station here must be insignificant in comparison with the task of filling that station well; and that perhaps it may be more meritorious (if merit may be weighed) to be a good slave than to be a good master, and likely to obtain a higher reward "in the final proportions of eternal justice." Very fine!-as long as such considerations are not made an excuse for conniving at the oppression of worldly powers, or for gratifying one's own desires for power and profit, for hardening our hearts and stopping our ears, and turning our faces away from misery.

The fact is that justice, if it is not to be ascribed to God in the same sense as to man, cannot be called a religious virtue. Mercy may be a religious virtue, but justice knows no measure but the law, whatever it may be, in each religion; in every old religion an archaic law. Order rather than justice is the ideal of religious authority; and religion inculcates every quality that is favourable to order, especially 
obedience; so that the origin of evil is popularly traced to the breaking of an absurd taboo upon a certain apple-tree.

On the other hand, if pious men think of God as the ideal of human morality, religion may become the strongest defence of justice and liberty; as happened when Cromwell vindicated them in England, and later when the conscience of New England awoke from sleep.

$\$ 6$. In contrast with the theory that human nature is essentially selfish, it can (I believe) be shown that Benevolence is the most widely diffused of all virtues. It is true that a great deal of alms-giving is egotistic, a sort of sacrifice, a way of laying up treasure in heaven, or even of avoiding curses ; and that religions commonly promise rewards to those who are open-handed to the poor. But reward is a much more prominent motive in the Old Testament and in vulgar preachings than in the New Testament; neither Christianity nor Buddhism in its purest form can be charged with bribing men to be good, or even with urging us to give for the love of God, or for our own ennobling by self-denial, rather than for love of our fellows. It is more reasonable to complain that the highest religions by their characteristic way of thinking push benevolence to excess, and turn virtue into folly. This they do, first, because in their eyes all worldly things, and therefore wealth, are relatively insignificant; secondly, because these things, such as they are, really belong to God, not to any creature; and thirdly, because dependence on prophetic insight (of the founder or some other) leaves a religion with no measure of any virtue except the prophet's words-always universalising and poetical. The conception of a divine family, in which all men, or all believers, are brethren, is, though very noble, extremely misleading in practice; because, in fact, the conditions of a family do not hold good of civil life in this world. Now, without a measure justice does not exist at all; but benevolence may flourish and do much more harm than good. In fact, alms-giving has gone far to ruin a great part of Europe. To Utilitarianism one must turn for principles which at once recommend benevolence and assign its limits; and for the practical development of them with 
reference to pecuniary liberality our best guide is Economic Science.

Chastity is as rare amongst mankind as benevolence is common; the most unchaste are often benevolent. Religions have treated chastity in every possible way, from positively discouraging it, generally or periodically, to erecting it into a virtue above the conditions of human nature. Buddhism and Romanism have treated sexual relations as essentially impure, only admissible under religious rites and incompatible with a holy life. From savage superstitions foul notions of the impurity of women are derived, and these have been consecrated and authoritatively established. The earliest Christians who encouraged such inhumanity may be excused by their belief in the approaching end of the World; but before this illusion was dissipated the doctrine of celibacy had been confirmed by a false asceticism. Here we see again that Religion knows no measure in its teachings; everything tends to a morbid exaggeration. What evil has been caused in Christendom (though not amongst Protestant Communions), first, by the disparagement of the marriage-state, and then by the diseases of celibacy; self-tormenting scruples lest the ideal of inward chastity should not have been attained, leading often to hysteria and insanity, and when complete failure occurs, ending in sanctimonious hypocrisy or nameless depravitythese things are well known. It is only of late years that we have learnt the still greater injury done to the human race by cutting off the transmission of spiritual qualities from thousands of the noblest of mankind. Ascetic celibacy is only compatible with Pessimism, as in the religion of Buddha: on no other theory is it chastity at all. Chastity is that life of the sexual relations which is most favourable to the improvement of mankind. Apart from special conditions of some individuals, marriage is a manifest duty of the nobler part of mankind, and the greater their superiority the stronger is the obligation.

$\$ 7$. The rise of World-religions-Buddhism, Christianity, Islamism-that is, religions free from merely territorial or national associations-marks an important movement of thought with regard to the unity and spiritual dependence of 
the World. Not that these religions originated the ideas of one World and one God, which in fact are due to philosophy; in India to the Brahmanic philosophy; and in Europe to a line of Greek thinkers, culminating in the teachings of Stoicism : but it was the religions that popularised such conceptions. The conception of one World, whether an emanation or creation of one God or the expression of one Law, imbues a reflective mind with a sense of the utter weakness and dependence of every individual; and with this root the ideas of humility, equality, brotherhood of all creatures are naturally connected. At the same time, in our relation to the World, whether as children of God as in Christianity, or sharers in the eternal Consciousness as in Brahminism, or bearing the responsibility of perpetuating the desires and sorrows of finite existence as in Buddhism: in any of these ways we are exalted and ennobled, and incited to carry out in our own lives the redeeming principles of humility and charity.

These sublime ideas, however, so significant for personal religion, do not seem to have had much moral influence upon religious institutions: in which every revelation must be vulgarised by a professional interpretation. It would be impossible, I think, to show that within Christendom the acknowledgment of one God, to whom all equally owe allegiance, has done anything (for example) to mitigate international animosities. It has often been the interest of the Church to keep alive jealousies and to aggravate quarrels, and its own interest has been relentlessly pursued. Moreover, each nation has always regarded Jehovah as its own God. How naïvely Milton says that " the favour and the love of Heaven, we have great argument to think in a peculiar manner propitious and propending towards us. . . . What does $\mathrm{He}$ then but reveal himself to his servants, and as his manner is, first to his Englishmen?" (Areopagitica). It would have seemed to us very incongruous to hear of 'God's Frenchmen.' But the King of France was the Most Christian King; the King of Spain the Most Catholic King. When Christian nations have united it has not always been in a wise or righteous cause. No one looks back upon the Crusades or the Holy Alliance as 
honourable to Christendom. But the hatred of Christians against unbelievers, a trait which they have in common with Mohammedans, if sometimes artificially inflamed, follows in a barbarous mind not unnaturally from the theory of a Worldreligion; since its adherents must regard the whole World as God's lawful realm, and therefore all its inhabitants who do not acknowledge his authority as infidels and rebels. That religious wars have ceased, and that the sufferings and cruelty of war have been restrained, must be ascribed to the prevalence of humane considerations rather than to the offices of religion. We owe more to Grotius than to all the Popes. But still, in the declaration or prosecution of any war, no European power would make any difference on the ground that its adversary was or was not Christian.

In estimating the value of World-religions, in which Church and State cease to be conterminous, I am inclined to give a foremost place to their tendency to separate the spiritual from the political power. Having different centres of influence and different functions, these powers are sure to fall at variance with one another. True that, for ages in Christendom, the power of the Church, with its vast wealth, strong organisation, and exclusive possession of the higher culture, so successfully controlled the ignorant and superstitious barbarians who possessed the temporal power, as to make them the servants or tools of oppression. But even then a conflict of authority between soldier and priest was not rare; and as soon as the barbarous ages began to be illumined by civilisation, and educated statesmen could be found amongst the laity, the tendency to an opposition between spiritual and political power was gradually realised, and its effects may now be seen in the State's independence of the Church throughout the greater part of Europe. This great change, accompanied by divisions within the Church itself, has been a necessary condition of the resurrection of justice, liberty and philosophy. For although philosophy prepared the way for the World-religions, and prophecy initiated them, they were no sooner formed and brought under the control of priesthoods than they became depraved by adopting superstitions from the ethnic religions they had 
superseded, and by developing rites and dogmas incompatible with spiritual originality and rational reflection. Superstitions were adopted and consecrated because it was easier than to dispel them, and the Church became parasitic upon the heathen imagination. Thus religion remained in opposition to philosophy. In the history of Christianity this opposition produced numerous heresies; but in about five centuries the heresies all seemed to be suppressed and philosophy with them, and the system that we know as Romanism was established. Still, philosophy and heresy are natural growths of the human mind not easy to extirpate: they appeared again from time to time, provoking all the devilry of the priesthood, and the blood of their martyrs splashed the face of Rome with scarlet stains that can never be purged or forgotten. At last the conspiracy of ages broke down, and spiritual originality and rational reflection were again emancipated. This has been attended by a conspicuous improvement in the morality of a large part of Europe: an improvement in which the clergy have shared not less than other sections of the community; for, in general, an official religion takes the colour of the Society it lives upon.

$\S 8$. Leaving off our discussion of the influence of religious institutions, we ought perhaps to consider finally what might be the effect upon morality should disbelief in religion become general, so that men had no guidance but philosophy and the necessities of their natural and social conditions. I have tried to show above in the first Book that natural and social conditions are a sufficient ground of the moral life. The relation of philosophy to religious belief may be negative or apologetic, or reformatory. The negative attitude is taken by Materialism, and by Deism in its extreme form: I mean the theory of the World that assigns to God merely the position of a First Cause that, having constituted a system of secondary causes, leaves them to work according to their nature: the difference between this and Materialism seems to me entirely verbal. Now, as to the bearing of these doctrines upon morals, Bacon observes in his Essay on Superstition, that "Atheism leaves a man to sense, to philosophy, to natural piety, to laws, to 
reputation; all which may be guides to an outward moral virtue, though religion were not." And this is true, with the qualification that the word "outward" erroneously implies that belief in God is necessary to the sustentation of conscience : which does not follow from the hypothesis that conscience has been reinforced by thinking of God; and, in fact, it seems to be quite untrue. Conscience is now a permanent acquisition of the human mind, and may even be the purer for having no witness. There is no reason why the Materialist or Deist should not recognise that out of the heart come forth good and evil ; nor why he should not be inspired by humanitarian enthusiasm; nor why he should not contemplate the World with religious awe.

In its apologetic relation to religion philosophy may assume three attitudes: first, to endeavour its full defence and justification, as with Malebranche and Berkeley; or, secondly, to reconcile some theory with religious beliefswhich, with different degrees of sincerity, is the practice of Descartes and Locke-and thereby, at the same time, to give a certain support to religion, at least in its central doctrines. In this way a good many philosophical controversies, such as those about "innate ideas," the explanation of conscience, "free will," are upon one side of them apologetic; and this explains the undue warmth with which they are sometimes waged. But, thirdly, the attempt may be made to reconcile religion with philosophy by preserving its spirit whilst reinterpreting its dogmas : this is characteristic of Kant, and is hardly to be distinguished from the reformatory relation of philosophy to religion.

The effort of philosophy to reform religion may halt at Unitarianism: or at a kind of Platonising Mysticism, like Maurice's; or may run its natural course into Theism and Pantheism, such as Emerson's.

Kant said that the Deist believes in a god, but the Theist in a living God; and Theism differs from Pantheism, by regarding God as not fully expressed in the phenomenal world and its consciousness, not wholly immanent, but in some sense above without being apart from it. Between the conceptions of 
popular religion and Pantheism there are possible many doctrines that may be called Theism; but we may say in general that Theism strives to maintain a belief in the personality of God, the immortality of the soul, providence and the moral government of the world; whereas none of these beliefs, in any definite form, is necessary to Pantheism.

To extend the conception of personality to the divine Being we must begin with human personality; and then we find that the emotions and impulses of 'love,' 'justice,' ' mercy,' have grown up in social relations and are correlative with our organic life; that our 'reason' and 'purpose' are discursive and experimental ; 'individuality' implies others upon an equal footing; memory and expectation can hardly belong to the eternal; and even subjectivity, besides its primitive somatic quality (organic feelings), implies an opposition to the World, which is natural enough in a being who, like ourselves, finds himself within a World, but must be entirely different for the Universal Consciousness. In fact, it is hard in this connexion to avoid language that is manifestly improper; in spite of Berkeley's disapproval, we feel driven to say that 'justice, 'reason,' 'purpose,' 'personality,' are with reference to God symbolical; that we hold them to be more true than any other terms, but that we must deliberately refrain from giving them a definite significance. But, then, the less definite the idea of personality is, the weaker are its functions. In his essay Of Atheism Bacon says: "Man, when he resteth and assureth himself upon divine protection and favour, gathereth a force and faith which human nature in itself could not obtain." Where will be his rest and assurance if the divine attributes are symbolical, he dare not say of what? On the other hand, there is a gain of moral freedom in being released from that juridical view of morals which, if not a necessary inference from the idea of a personal God, is at least very naturally associated with it. It leaves mankind to agree upon the End of actions; and in relation thereto, to determine the means (that is, moral rules), like other truths, by induction.

An inductive morality cannot be influenced by such sanc- 
tions as rewards and punishments in a future life, and has nothing to fear from the indistinctness that gradually gathers about the belief in immortality. The imaginations of our forefathers were based on the old cosmology: it was with a premonitory instinct that the Roman Church persecuted Galileo. Listen to the simplicity of Chaucer's great inarticulate contemporary :-

As I behelde into the est, an hiegh to the sonne,

I seigh a toure on a toft, trielich ymaked;

A depe dale binethe a dongeon thereinne, With depe dyches and derke and dredful of sight.

A faire felde ful of foke fonde I there bytwene, Of alle maner of men the mene and the riche, Worchying and wandryng as the world asketh.

This description of Heaven, Hell and Earth is truer to popular beliefs, and more poetical (it seems to me) than the learned elaboration of Dante. Milton, by a sublime construction, tried to rescue the regions of heaven and hell from the limitations of this visible world, but left his conceptions so obscure that they have been rarely understood and have had no influence. Still, it could not have mattered: it is impossible with our modern ideas to assign any locality or employment to departed souls; and to declare that their world is not in space at all, is to destroy all imagery and imperil the last remnant of belief. It is therefore of the last urgency not to connect such beliefs with the sanctions of morality. How much influence they had 500 years ago it is extremely difficult to say, when we consider the fluctuating character of supernatural beliefs, coming on at night and disappearing at sunrise; intensified or dissipated by a crowd, according to the humour of that crowd; emaseulated by the delusion that one may repent and be saved at the last hour; corrupted by the instruction that one may buy indulgence or forgiveness with alms. A few, whose station is above the fear of men, may be emboldened to evil by the discrediting of Hell; and their opponents may look forward less hopefully to the future, but will lose nothing if they obtain satisfaction whilst the rascals' flesh is warm. Judged by records of the Middle Ages, the ages of Faith, the 
power of Hell and other eschatological motives over the healthy was then very small. I should say that supernatural beliefs have been more important to tribes than to individuals; and influential through hopes and fears for this world rather than for another; that their value has declined with the rise of individualism, but that they have always increased the seriousness of serious men; that they enabled good men to give reasons for well-doing which to narrow and egotistic souls seemed more persuasive than the natural motives of human welfare; but that their efficacy depended greatly on the support of ritual-not only the ritual of public services (which is drama), but personal and domestic rites, such as a pious Hindoo practises above all men; which, if not quite mechanical, strengthen religious belief, and colour with solemn hues the interspaces of profaner hours, and at any rate, whilst a man is engaged in their observance, prevent his doing anything worse.

If Theism accepts the scientific postulates of conservation, continuity and uniformity, the belief in a particular providence and in the objective efficacy of prayer can hardly be maintained. In fact, the numerous adaptations of religion to human weakness become greatly diminished. But if we cannot by prayer obtain protection for others against the evils of the world, we can be more careful of their breeding and nurture; if they fail, and it is useless to beg the forgiveness of God, we can be more wisely considerate of them ourselves, and not persist in the barbarity of retribution; if our friends are not to be shielded from disaster by metaphysical aid, or to be met again when they lay down this life, is it not possible to be more helpful and more affectionate whilst we have them? And perhaps greater fortitude may be necessary. None of these things will impoverish our nature. And for himself a man may say with Matthew Arnold-

\section{Hath man no second life? Pitch this one high!}

Free will, if we understand it in a personal way-that is, my power to act, being such as I am, and as I find myself on coming to self-consciousness - is in no way incompatible with 
the scientific postulates. To the explanation of this matter given in The Metaphysics of Nature (c. xv. $\$ 2$; cp. 2nd Ed., App. D.), namely, that we are free in the sense that we exert our own powers according to our own charactersit has been objected that, nevertheless, there is no real freedom, because our character as we find it on coming to self-consciousness must be regarded as preformed, and that therefore all our actions are predetermined. This, of course, is true; but it is irrelevant to the personal issue. For the preformation of his character no man is responsible: his responsibility and his freedom grow up together with his selfconsciousness. If, indeed, there are some people who feel no responsibility, society must deal with them as wisely as it can: there are asylums and reformatories; and these may still be used, or something better may be substituted. But for all responsible men there is a free moral life: on every occasion we may choose and follow the course that seems to ourselves the best. And this is all that we are concerned about: morality has nothing to do with cosmological freedom.

It is some compensation for the loss of a belief in providence, that the same considerations that impair it also destroy the belief in Fate: the predetermination of particular events, however much they may seem in our power, and whatever efforts we make to control them. For this is the true antithesis of personal freedom.

$\S 9$. As the conceptions of divine personality, of the posthumous individuality of souls, of prayer and providence grow indistinct, Theism fades into Pantheism; and Pantheism finds its greatest difficulty in the reconciliation of the rest of Nature with Humanity. In the hands of some teachers Stoic morality suffered by unwise interpretations of the maxim 'to follow Nature.' If laws of Nature, such as heredity and selection, are to be applied to human life, it must be done in a very different way from that which we see in the animal kingdom. Although the human world has arisen out of the animal world, still with the growth of self-consciousness a great gulf has opened between them. And this ought to make us consider whether Pantheism can be a religion, or whether Humanity must not 
seek a religion in itself. And we must not allow the question to be prejudiced by the injudicious self-sufficiency of a philosopher of the last age. Consider how the problem of evil is affected by Pantheism. Evil, conceived as Sin-a kind of polluting matter or force, like a disease or curse, that can be washed off in Jordan or Ganges, or laid on the head of a goat and carried into the wilderness, one of the notions familiar to barbarous magic and therapeutics-has grown indistinct along with other religious ideas, and is repudiated by enlightened divinity. But Pantheism can hardly refuse to recognise evil in Nature; and cannot, of course, account for it by the fall of Eve or of Lucifer; and to put it down to necessity, or to a negation in the Absolute, is either to trust to words only or to invoke Ahriman; it cannot be ascribed, as by Theism it may, to a defect of power in God (J. S. Mill on Theism). Now in Nature, evil, such as it is (imperfect adaptation and consequent pain), is incurable; but in human life we can conceive of its being reduced, by the scientific elimination of physical and moral disease, to the single fact of natural death; which, with the progress of reflection, may cease to be considered an evil. The best that can be said for the World as a whole is that, in spite of all its ravin and deceit, it is one in which the love of Virtue and Wisdom does at last necessarily emerge.

Scientific postulates having been accepted, Religion will adopt the scientific method of investigation and standard of truth. A standard of truth is a system of ideas and experiences with which all phenomena, as they occur, are assimilated, and whereby they are said to be explained. The scientific standard is the great body of judgments called 'laws of nature,' connected on the one hand with the postulates of conservation, continuity, uniformity, and on the other hand with facts of observation made as definite as they can be. Such judgments or laws of Nature are all in the form of Cause and Effect, conceived as measurable antecedent and consequent. When any phenomenon, having been definitely observed, can be assimilated with those laws, it is said to be explained; for instance, a thunderstorm is explained by the laws of electricity. This scientific standard is by no means complete or perfect; 
but it is always improving, and its characteristics are universality, definiteness, coherence. A definite religious standard of truth cannot, perhaps, be fairly stated; but there is a great body of beliefs concerning the acts of God, or of supernatural beings, and of experiences assimilated to those beliefs. Such actions are not restrained to the ordinary course of Nature, and they are interpreted according to the form of Purpose or Final Causes. When any event excites our interest, in a religious way of thinking, we classify it with this great body of beliefs, and feel as if we had explained it. A thunderstorm, for instance, is explained as a discharge of fire by some angry being that controls the winds and clouds. The peace of mind that follows upon a good action is explained scientifically as the satisfaction of our social nature; religiously, as an influence of heavenly grace, like the whispering of a friend. When we examine the religious explanation of the thunderstorm, we find that the fact itself has not been precisely observed, that no continuity is traceable in the supposed cause, and not even an intelligible purpose, since the lightning strikes the just and the unjust; and, in fact, the explanation consists merely in the vague pictorial assimilation of the thunderstorm with an angry man throwing a firebrand. Such a system readily assimilates in the same indefinite way any number of miracles and marvels; nothing can happen for which a recognised precedent cannot be found and a sketchy picture substituted; but in no case can such explanations be said to give an understanding of our experience. In the early vigour of such systems miracles are welcomed and seem to confirm one another; but they become a sad encumbrance when at a later date a separate proof is required for each of them.

Ignorance of the scientific method may excuse any one for not adopting it; but those who have been trained in it often find it difficult to understand how others, who are at least acquainted with it, nevertheless cling to the religious system, or explain some things by one system, others by the other. But there is no need to interpret such cases by selfinterest, deference to opinion, or other form of insincerity, if 
we remember the force of education, the force of affection, and the imperfect organisation of the human mind. Such a case - as that of Faraday, for example, approximates the pathological condition of double personality. Still, explanation by the religious system, however personally sincere, is itself the very principle of delusion; and, surely, it must at least tend to hinder the development of the sense of truth; though in many noble natures it has not succeeded. In fact, the habit of supernatural explanation may excuse, in a religious treatise, many poor arguments which, in a scientific work, would be disgraceful. But it is a very undesirable state of mind; and when it leads its victims to disparage scientific results, and even the inductive method itself, some consciousness of insecurity may be suspected, as inciting opposition to a standard of truth whose superiority is half acknowledged. We see the same thing in the idealist philosophers who are in subsympathetic relations with theology. The existence of the religious system is a hindrance to the ascendency of induction; but look around upon mankind, and consider whether a very gradual correction of the religious system is not more to be desired than a hasty triumph of the scientific. In the present state of mankind a rapid and enduring ascendancy of the scientific spirit would certainly be impossible.

The definite teaching of morals seems to have preceded any belief in gods: at least, moral rules are taught amongst Australians and Melanesians, though none of the spirits they believe in can be called gods; and without the worship of gods there does not exist what I mean by religion. Instruction in morality, however, is given by elders during the rites of initiation, under conditions of social rapport and solemnity which many would call religious. Possibly, therefore, both morality and religious feeling (as distinct from worship) may be considered to originate independently of any supernatural sanction; and, if so, it is not unreasonable to expect that they will outlive it. When morality is taken under the sanctions of a god some of its motives are strengthened, especially in circumstances of social contagion. The motives vary between devotion to the divine king and father of the tribe and the 
most craven fear and self-seeking; but they admit of complete purification, as we see in the highest forms of Christianity. As to the substance of moral teaching, religion, once established, becomes stationary and even retrogressive, and often exhibits more archaic features than law (see Westermarck's Moral Ideas, c. ix.). It is apt to confound morality with the ritual observances which are essential to its general influence. It frequently corrupts the moral ideal by the praise of evil deities. As it exaggerates such praise, so it exaggerates the scope of every virtue for want of any definite measure. By alliance with the State, religion has promoted the growth of kingdoms, and has suffered corruption by pandering to worldly powers; but has sometimes atoned for this by vindicating against them the supremacy of Heaven. Political connexion makes it respectable, and exposes the shallowness in mind and heart of the mob of people who from this motive pretend to worship God. Religion stimulated the conscience and intensified reverence; but we must not suppose that the good religious man is good merely or chiefly by religion. That is an educational association and hereditary disposition; but his goodness lies in a character adapted to family and civil life. With the spread of civilisation the religious spirit declines, because so much strength of character exists as to make civilisation possible; because the frivolous feel safe in cities and forget to pray; and because commerce exacts order, and excludes miracles, and supplies ordinary motives for ordinary conduct to ordinary men. 


\section{CHAPTER X}

\section{ART AND MORALITY}

§ 1. "THEY who will not grant me," says Dryden, in his Discourse on Satire, "that Pleasure is one of the ends of Poetry, but that it is only a means of compassing the only end, which is instruction, must yet allow that without the means of Pleasure, the Instruction is but a bare and dry Philosophy." This was the utmost that he could venture to claim in an age which, in spite of two or three exceptional men, witnessed the collapse of both art and thought. You may understand why he dared claim no more by turning to the smug imbecility of Addison, who tells us, in the Spectator (411-21) that the pleasures of Imagination arise from contemplating the Great, the Uncommon and the Beautiful, and that the final causes of these pleasures are as follows: as to the Great, to draw the soul to the idea of God; as to the Uncommon, to encourage the pursuit of knowledge; and as to the Beautiful, to promote marriage. Look around you, and judge whether anything could be more discouraging to marriage than a sense of the Beautiful. The didactic theory of Art is usually traceable to moral timidity, or moral fanaticism, or incapacity to think; not to mention hypocrisy. But what shall we say of Plato from whom this doctrine, as a philosopheme, is derived? I cannot ascribe his attitude toward Art to irony, or pique, or genuine fanaticism, nor to his hostility to Art as the glorification of polytheism, but rather to the artistic mood itself; into which, of course, he worked himself in order to set forth his inventions to the best advantage : a mood which, in proportion to its stability, excludes all incompatible ideas, 
and, therefore, the glory of Art when you set yourself up as a moral pædagogue. For in its natural development Plato's theory of Art would have sprung from the same root as his theory of love; namely, that sensuous beauty is a manifestation of the idea of Beauty; so that as the lover, if himself of the right quality, passes from the beloved to the apprehension of Beauty in all things, and finally to the Self-beautiful, the artist also is on the way to philosophy; for what Aristotle says of Poetry is certainly true of all Art, that it is more universal and significant than any record or copy of matter of fact can be.

The opposite doctrine, the hedonic theory of Art, is a shallow but honest and rather courageous generalisation, based upon the consideration that all works of Art do somehow please somebody, that by mere direct inspection of the facts it is difficult to say anything more about them universally; whilst, as to a good many of them, it costs some subtlety to show how they edify, and many others are conspicuously unedifying. To exclude these last on the ground that they are not 'true' Art is obviously to beg the question, and is repugnant to the honesty of the hedonic school. Their view also agrees best with the spirit in which the artist works, like the poet-

With eager thought warbling his Doric lay;

for even when the artist has a purpose it is forgotten in the very act of expressing it. And this, perhaps, explains why Coleridge, rather to our surprise, defines a poem as "opposed to works of Science by proposing for its immediate object pleasure, not truth" (Biog. Lit. c. xiv.). How can any one be satisfied with the position that King Lear is opposed to Euclid's Elements by 'proposing for its immediate object pleasure, not truth'? It might, no doubt, be sincerely argued that both ends are wonderfully attained by both works; but all that I shall urge is that 'aiming at pleasure' is an inadequate account of the purpose of King Lear. It must be possible, surely, to discover a theory which will enable us to say more about it.

The error of the didactic theory of Art is that it is not an 
analysis of the facts at all, but a deduction of what Art ought to be from the propositions, first, that every justifiable work of man contributes to the Good, and, secondly, that the Good is wholly comprehended by the moral good. The method is wrong: it is the old blind treacherous way of assuning that we already have whatever conceptions are necessary to solve the problem, and need look no further: a way along which no truth has ever been reached. The error of the hedonic theory is that, whilst appealing to the facts, it takes them too simply and indiscriminately; it takes them altogether, in the same plane, without regard to their kinds, or their causes, or their various functions; not reflecting that whatever may be said of them all, in this way, may be really unimportant with regard to any one. The hedonic theory is too flattering to the boorish insensibility of Philistines; for it puts Art upon the same footing as wine and gambling. "Quantity of pleasure being equal," says Bentham, "push-pin is as good as poetry": push-pin, I believe, is a kind of gambling game. Or, again, "By arts and sciences of amusement I mean those that are usually called the Fine Arts" (Rationale of Reward, III. i.).

$\S 2$. Aristotle, in the fifth Book of his Politics, describes three functions of Music: first, recreative amusement, a preparation for serious employment; secondly, the noble enjoyment of leisure-an end in itself, for the sake of which, youth should be instructed in music; and, thirdly, that refinement of feeling and character which is obtained by $\kappa a ́ \theta a \rho \sigma \iota s$. None of these functions is adequately described as giving pleasure; though, if well carried out, they will all be pleasurable, because every activity is perfected in pleasure. The only other Art that Aristotle discusses at any length is Poetry; but all the Arts have in some measure the same three functions, though most manifestly music, poetry and dancing as anciently understood; for music, as he says, is a better imitation or expression of emotion and character than painting can be. As to the meaning of $\kappa a ́ \theta a \rho \sigma \varsigma$, any reader might well turn the page if he thought that I was about to add one to the many discussions of it. But we may hope that it is 
now agreed that in Aristotle's view, the passions, especially pity and dread, are purified under the influence of music and poetry by the very fact of indulgence. Not by exhaustion as in orgiastic rites, which leave the spirit disturbed and needing to be soothed by sacred airs, but by some action proper to the nature of Art. Twining seems to me to have come nearest to an explanation of what this action is when he concludes Note 45 on the Poetics by observing, that "the modern truth of the doctrine would perhaps amount only to this - that the habitual exercise of the passions by works of imagination in general of the serious and pathetic kind (such as Tragedies, Novels, etc.) has a tendency to soften and refine those passions, when excited by real objects in common life."

As I have observed in the Metaphysics of Nature (c. xii. $\S 3$ ), all our emotions may be aroused in two different forms; either in their primary form as motives; or in a secondary form, related to the instinctive attitude of play, in which their indulgence is, in part or altogether, the end of our present activity. The capacity of entirely serious makebelieve is a condition of strenuous play and Art, and has been developed because of the importance of play for the life of the higher animals, and of play and Art for human life. How the passions differ in Art and in ordinary life, we may not be able to say: it is not merely in degree of intensity; they are felt differently, and in the play of imagination they are not acted out. In this lies a moral danger of enervating the will. So far, again, as Art is social, the same feelings are aroused in common throughout an assembly, and as their expression reverberates in many imperceptible ways, and is imitated and reacts as in panic, they lose their personal character, become sympathetic and comformable to a common type. Under the influence of music, poetry and dancing, the passions are further regulated by rhythms, which do not so much moderate the excitement as give grace and a kind of tranquillity even in excess and frenzy. But, finally, if the Art which we witness or share in is the work of a Master, in following it we follow him, and learn to think and feel in his noble and comprehensive way; for to feel originally, 
profoundly, and nobly upon whatever enters into the artistic mood is the prerogative of the Master.

Certainly the purification of the passions is favourable to moral deliberation and decision and virtue, though Art has no such end in view, and Aristotle does not propose it. There were other ways in which his moral conceptions were unconsciously influenced by æsthetic ideas. As I have observed (c. viii. $\$ 2$ ), the life of the City State is especially favourable to the development of what Spencer calls the ego-altruistic sentiments; that is to say, sentiments which reflect the feelings of other people towards ourselves. Amongst a people of sensitive taste, like the Greeks, the feelings of others towards us must necessarily arise in great measure from judgments of æsthetic value; and therefore the individual must come to think of himself as weighed and criticised like a work of Art, and therefore will in that spirit regulate not only his appearance but his conduct. This way of thinking is perhaps most conspicuous in the Greek conception of Oratory; but, generally, тò $\kappa a \lambda o ́ \nu$ was a conception common to Art and Morality; every virtue was cultivated for the sake of the nobility of the thing; conduct was the Fine Art of living. There are, in fact, many parallels between Aristotle's ideas of Morality and of Art so far as we know them. For, generalising what he says of Tragedy, we see that Art and Virtue both express character in action; and that not merely as it is or seems, but as it ought to be; that whereas Art imitates no particular fact but the universal of human life, so it is the universal nature of man that is realised in virtue; though, indeed, for given men virtue is an imitation of that Wise Man whom after ages sought in vain. The tragic hero, again, is a man of high birth and personal greatness; and of course, according to this old heathen, virtue is not a thing for slaves. The purification of passion by Art is a preparation for virtue ; both Art and virtue are in a mean; they aim at the noble and the good that is chosen for its own sake; and even more than Art, Philosophy, the highest virtue, is the rational enjoyment of leisure.

Some such parallel as this between the theories of Art 
and Morals might be traced in other philosophical systems. According to Kant, for instance, both æsthetical and ethical judgments are disinterested, universal, determine means to an end that is never directly knowable, and are felt to be necessary though the æsthetic cannot be reduced to any definite rule. Shaftesbury and Hutcheson were struck by such resemblances between Art and Morals; and I strongly suspect that Kant learnt a good deal from Hutcheson's Inquiry into the Original of our Ideas of Beauty and Virtue, which had been translated into German by J. H. Merck. In view of this parallelism we might expect to find a greater agreement between Art and Virtue than in fact anywhere exists. But the ground of the parallelism is that, when we reflect upon their nature, they both appear to aim at an ideal; though, in fact, this is a result of their evolution, and was not to be found in their origins. Aiming at an ideal of ours, they are necessarily concerned with human character, and of course, in its universality, above all particular persons or interests: an exaltation that excludes defect, but cannot be satisfied by mere exaggeration: presenting a purpose that cannot be defined, but ever recedes as we advance. We have, therefore, to explain from the origins how it is that many people even regard Art and Virtue as opposed to one another; how it is that the lives of the saint and the artist are often very different; that a great deal of Art is indifferent to morality or even antinomian; that some theorists claim absolute independence for Art, and that even those who hold that Art must be subject to moral law, yet consider that subjection cannot be enforced without danger to the vitality of Art.

$\S 3$. If we turn to "the origins of Art," which have been so delightfully expounded by Yrjö Hirn, we find that they are often traceable to definite purposes: drama to expressional gesture; poetry and sculpture to commemoration; poetry and decoration to amative solicitation; and that there are other uses in industry, war and magic. In this way many activities are aroused and in some measure trained, many things are made and begin to be admired, before the true 
artistic nature has been developed. But whatever is an important means to an important end becomes interesting in itself, as we see in the making of weapons, pottery, apparel. Hence, if dancing, singing, painting is useful for any universal end, it becomes intrinsically interesting to dance, sing or paint. Moreover, to make something is so necessary to human life that the constructive impulse is an instinctive disposition. All our intelligent activities are specialised from some indefinite impulse, as speech is specialised from babbling; and the Arts are specialisations of the constructive impulse in certain forms that have been determined by historical conditions.

Fully to comprehend the utility of Art, not merely in its beginnings but in its whole career, we must consider not only the conscious purposes that may be present to the worker's mind, but also the advantages that may result to the tribe. If there is any advantage in highly finished weapons or utensils, such things can be made best by those who have the best developed hands, and the greatest power of prolonged attention, and the most definite ideas of what is to be done; and these are conditions of nearly all success. It is even worth observing that whilst a man is decorating a club he cannot be breaking his neighbour's head: industry and order are necessarily allied, and in primitive society occasional industry is generally pleasurable; the differentiation of Art from Handicraft has not then taken place, and cannot take place until powers of compulsion have been acquired by some men over the labour of others. Indeed, even the idea of an end and of means to it cannot, at first, be what it is to us, but must be relatively obscure. But it is in the progress of society that indirect purposes, of which the artist is not aware, become predominant in Art, namely, in preserving order by enhancing the power of government and religion, and subduing mankind through their imagination.

Although mankind was always social, and co-operative in hunting and war, the disposition to steady industry and to co-operation in industry had to be acquired. It had to be 
acquired because any tribe that did acquire it had an advantage over others, by increasing the food supply and therefore the numbers of the tribe, and so obtaining that density of population which is such an important condition of stability and power in relations with competing tribes. By what various means habits of steady industry and order arose it may be useless to inquire; the evidence before us indicates that often it came about by the subordination of some men to others, of the many to the few, either by conquest, or by submission to certain families who obtained a predominance by leadership in war, or by oratory, or perhaps by a reputation for magic. In the course of hundreds of thousands of years, by degrees and probably after innumerable failures, kingdoms and great empires were formed. By a correlative movement, religions were imagined, their rites established, and priesthoods organised; and the religions and priesthoods generally supported, though they often trenched upon, the authority of empires. A third process parallel with these was the development of the Arts in the service of empires and religions. Religion and the Arts combine to subdue mankind through imagination. By force alone the power of conquering or aristocratic families could not be maintained. At least, the only way would have been to breed down the average level of ability in the subject classes, until they were almost a different species and liable to serve like dogs or horses ; and a limit is set to this variation by the uselessness of such a population either for industry or war. But religion introduced an imaginative control by bringing the gods to sanction the social order and, in the most conspicuous cases known to us, by representing the gods as ancestors of the ruling families, sometimes bestowing divine honours on the reigning king. Thus submission was obtained sometimes with a noble loyalty, sometimes in servile and superstitious fear. And the Arts, adopted and cultivated by priesthoods, or artists in their employ, worked toward the same end: building temples and palaces, decorating them with painting and sculpture, presenting service or ceremony of dancing, music and song with grace and magnificence. Reverence 
and humility sank into the breast of the spectator: he worshipped and obeyed.

The beginnings of Art seem to have been sporadic and personal; and in some directions, such as love-poetry and self-decoration, it remained personal; but we are more interested in observing how it became organised in tribal dances and poetical traditions and styles of architecture and ornament. For its full development, Art needs the support of great wealth and great interests, that artists may be specialised and their conceptions carried out on a titanic scale. The Arts are then depersonalised, and (in their chief manifestations, at least) become national or religious, which under such conditions are much the same thing; they become more and more elaborate, costly and impressive; until at last a certain pitch is reached at which the labour employed upon them is at a maximum, as at Babylon or Egyptian Thebes; so that their works produce the greatest awe, without necessarily having the greatest æsthetic value; and thereafter a decline sets in and, age by age, Art becomes denationalised and personal. There is a similar rise and fall in the power of Religion. If we could trace curves above the abcissa of time, having measured upon ordinates, from age to age, the intensity of Art, Religion and Despotism, they might be found approximately to coincide. But there is a difficulty in settling the meaning of 'intensity': is it to be defined by the numbers controlled or by the amount of sacrifice exacted? By the measure of sacrifice exacted, Religion culminates in such a State as Dahomey, forty years ago (though, in the history of culture, far older than Babylon); but certainly the Arts do not culminate in such a State; and perhaps it should be considered pathological; for, no doubt, there have been many insane States. Or else we may consider that Art is a means of mitigating the horrors of Religion; and that a superstition with milder rites, when supported by the charm and magnificence of Art, may be better suited to the control of a greater population. If so the curves of Despotism and Religion may culminate and begin to decline, whilst for some time the curve of Art continues to rise, until its utmost pitch of power and 
historical significance is reached. It then exercises its greatest control over human life, indirectly through the Religion and Government it glorifies; but it is not a moral control.

It took hundreds of thousands of years for Government, Religion and Art to arrive at their maximum power, during which time Religion and Art were in great measure nationalised and depersonalised. Then, during times comparatively recent, their power has fallen (though with many reactions), and in great measure they have been personalised and denationalised: that is to say, with the most civilised peoples they have lost public authority and become means of personal consolation and culture. The reason for their loss of power can be nothing but loss of utility. Their original use on a national scale was to subdue mankind to Order, and thereby to industrial co-operation; but this task has been so far accomplished that their place has been taken by other motives, some moral, some self-interested, which are sufficient to maintain order. Thus considered, Religion and Art appear as imaginative by-products of social evolution, which grow whilst they serve an adequate purpose, and decline when that purpose has been served. That they fell so much more rapidly than they rose, may be explained, partly, by the conservative character of Religion, which maintained its external forms of control long after they had lost the utility that upheld them; and, partly, to the increasing acceleration that seems to follow upon combining the forces of civilised life. We must not assume that this acceleration will continue; for the low average quality of the population sets a limit to the reliance of society and institutions upon the self-control of individuals. It may certainly happen that Religion and Art, one or both of them, may revive in support of a new social order. But it may happen that that order will trust to something worse and baser, without glory or reverence, with neither imagination nor joy. The most interesting forecast that I have seen of the future of Art is given by Auguste Comte in his General View of Positivism, c. v. ; adapted, of course, to his own doctrines concerning the future of Society.

$\S 4$. Art, then, considered historically, is indirectly a con- 
trolling power in human life, by enhancing the impressiveness of Religion and Government; but it is not a power of moral control; on the contrary, the need of it, and therefore its ascendancy, depends on the weakness of morality. Morality, indeed, if we may argue from some extant savages, was not wanting in primitive men, that is, the disposition freely to observe the customs of the tribe and the simpler amenities of fellowship; and it has reappeared in modern life enriched by experience and reflection. But in barbarous and despotic ages Morality, except in a ruling caste, survives one knows not how; for it is in incessant conflict with predominant usages and beliefs. The weak have no refuge but deceit; injustice and cruelty flourish; and submission to them is a sort of cowardice that can only be excused because men's imaginations have been subjugated by Art and Religion. In that conflict, it is true, the deepest moral insight is attained; for it was in the midst of barbarism that those prophets appeared whose sayings the whole world acknowledges and shall ever acknowledge. In a fanciful way of thinking, I compare the ages in which Despotism, Religion and Art overshadowed the world, and Morality was but a feeble thing, with the geologic ages when the huge reptiles, dinosaurs and theromorphs, oppressed the earth, and the mammalia were but a feeble folk: who now, by dint of mere brains, have spread everywhere, and exterminated the whole enormous brood. In a long agony fair dealing and mutual consideration have proved themselves to be surer grounds of social stability than force and illusion; charity and magnanimity and common honesty have overcome the lust of the eye, and the pride of life. Hence, on the one side, we can understand the antipathy of Puritanism to Art, suspecting its alliances, and trusting to other conditions of public order: and, on the other side, we can understand the claims of Art to be exempt from moral control; for it inherits them from a power that once stood far above Morality amidst the things of this world that pass away.

But, further, Art at the height of its glory was, before all else, the building and adorning of temples and the praise of the gods that dwelt there. Gods good and evil, but for the most 
part above law, if not above Fate ; who were praised sometimes for justice and beneficence, but especially for power; even the best of them for power homicidal, power revengeful, power generative; nay, power digestive and cachinnatory; for it was a praise to eat, drink, and laugh more than mortals. Hence, from whatever forgotten data, the imagination of all those astonishing achievements that are celebrated in epic poetry and carved upon the walls of temples. Such things, however, in their original form, were supermoral not immoral ; for the divine agents were exempt from law and from all the conditions of human obligation ; and, therefore, Plato probably exaggerated the immoral influence of such examples. They were not considered as examples; for the spectator never conceived of himself as on a footing with the gods or, like them, irresponsible and uncontrolled: at least, whilst yet the gods lived and reigned. But when they were dethroned and perished, their records acquired a different significance, and went to swell the vast traditionary literature of homicide and adultery, the swash-buckler romance and the epic of Priapus in 100,000 fyttes. In this way a part of the divine tradition comes into conflict with moral ideas; and, indeed, the conflict begins much earlier; since for some men, such as Plato, the old gods are already dead, though they still live for centuries in popular belief.

At the same time, other parts of the divine tradition enter into alliance with moral ideas and set forth types of heroism and self-sacrifice; so that in favourable circumstances there may come about a complete reconstruction of the dominant religious conceptions. Possibly the selection exercised by public taste upon different elements of the divine tradition, according as it favoured the purification or debasement of that tradition, may have had no little influence upon the rise or fall of nations. In the free development of Art there are certain phases that excuse the Puritans' antipathy to it, and other phases that make him appear brutally insensible and perverse; but, in either case, the result is secondary and incidental, no part of the original purpose.

$\S 5$. It appears, then, that Art at the height of its power 
was neither moral nor immoral: it was not didactic; but neither was it intentionally hedonic in relation to the bystander. It was not addressed to him, but to the king or the god. And as for the Artist, he worked at his task because it was his vocation and his office, not merely for the pleasure of it, much less for his own improvement. And yet the conditions were such that it could not fail to be universally pleasurable or (with more propriety) rapturous, and also in some ways edifying and ennobling. Art was then a great public interest: from its present condition we can understand concerning it nothing at all. Art no longer exalts any nation. Suppose the Chancellor of the Exchequer should suggest the spending of some millions upon Art-say 50! How many people grudge the few thousands now spent upon statues and monuments! And, for that matter, so do I. But in those days, Art being one of the bases of order and solidarity, devotion to Art gave one nation an advantage over others. This we may say was its purpose in Nature. But the conscious purpose of all who took part in it was to praise God and the king: that is to say, it is one of the many cases of instinctive illusion in which men, pursuing one end with all their hearts, achieve another and far more important one, according to natural laws of which they have no conception. Had not such devotion been pleasurable, of course it could not have arisen or have been maintained; but it is in itself an absorbing and rapturous thing to praise God, and for the most part it is ennobling; for, if not, the religion that once exalted the nation is destroying it.

The massive awe of temples rich with colour and carvings held the eye of the worshipper and his breath; his soul dilated and his egotism collapsed. Pleasure certainly bore no proportion to his interest; for this was a fascination: he could not choose but gaze and wonder. Whoever does not feel that this must have been so, has wandered far from home in desert paths. Antiquarianism can never revive the past; in our hearts we must renew it, and learn there that the generations that created temples lived by them, and that our perceptions in revisiting them are as faded and grey as their neglected walls. But greater than the temple itself were its ceremonies and 
celebrations, the drama of sacrifice and the choral dance and song. In such rites, at certain seasons, everybody joined and abandoned himself to enthusiasm. The rhythms of movernent and sound were an intoxication; for no one really dances or comprehends dancing whom dancing does not inebriate. But the excitement of the individual was swallowed up in the contagious frenzy of the crowd: a panic inspiration, exalting every feeling, reinforcing every action, and maintaining their transports beyond (as we might suppose) the endurance of human nature.

How shall such things be brought home to this civilised generation? When the Salvation Army danced in the streets, though without the support of traditionary methods or artistic invention, and even under public ridicule, still it was a lesson in anthropology. Or do you remember Mafeking, and the public rejoicings? Vast swarms of people swaying hither and thither and shouting, divided from time to time by irregular marchings, huddling and shouting hour after hour; elated certainly and happy, and attaining no doubt such purgation as follows upon exhaustion: but the baser sort predominated, and there was nothing to refine the vulgarity and raw boasting of worthless loafers. Here was a great opportunity wasted for want of traditionary forms and artistic leadership. Or join a Welsh revival, or the service of a ritualist church where the whole assembly sings the hymns: yielding unresistingly, of course, to the enthusiasm that throbs around you. You may then learn in the depths of your soul what Art once was. Or, offering less opportunity for participation, there are cathedral services and military funerals; which, indeed, may represent an unbroken tradition of many thousands of years.

We infer, therefore, that the purpose of Art is neither pleasure nor edification, and it never was. As with all the great interests of human life, its end is not to be sought merely in its effect upon individuals; even the end as it is conceived is not the true one. The purpose in Nature was the increase of life through national order and solidarity; the conscious purpose was to praise God and honour the king. Yet certainly Art was always pleasurable or rapturous, and often purifying 
and elevating: at least, we may hope that it is in some measure purifying and elevating; but we must consider that the state of dissociation produced by intense Art-akin to hypnosis or somnambulism-may prevent it from having much direct influence upon our normal condition; and many biographies, and perhaps our own experiences, strengthen this doubt. However, although Art at its height of power exercised a social function, still, any one who had taken part in celebrations might well look forward to them again; and for him, in a secondary way, either pleasure or purification or both would become an end. And similarly with the artist himself: he delights in his work and may appreciate its bearing upon government or, at least, upon religion; and when moral reflection arises he is often willing to regard his work as favourable to morals. That depends, no doubt, upon the sort of man he is. Aristophanes in The Frogs represents Aschylus and Euripides as agreeing that the purpose of their art is to improve the citizens; Ariosto and Tasso pretend to have an allegoric intention in their great poems; Spenser tells Raleigh that he writes the Faery Queene to form a gentleman in virtue and noble manners; Shelley confesses that he has a passion for reforming the world. Many such declarations might be quoted; but they belong to ages of reflection, if not of sophistication, when in most cases the personalisation of Art is far advanced; nor need we suppose that even great artists are clearly aware of their own purposes and methods. Especially we must distinguish between the ideas of their leisure hours (when they are open to suggestions from the world without) and the mental conditions of actual composition - a dissociated absorption in the work itself. A study of this psychological isolation provides the best excuse for the perverse tenet that Art exists for its own sake.

$\$ 6$. It may corroborate our hypothesis if we show that the contents and characteristics of Art are deducible from its conditions as we have described them. Thus Art is disinterested because it expresses loyalty and devotion. It is quite true that in its beginnings Art, so far as it is personal, is in many of its manifestations dependent on private motives; and so is Religion. 
Personal Religion at first seeks the favour of the gods, or averts their hostility, by invocations, sacrifices, vows, rites, penances; and I cannot say that such motives and means have ever been discarded by the mass of mankind; but national Religion indisputably in some men, and in some measure in all, raises loyalty and worship to an unqualified devotion. And so it is with Art in its alliance with loyalty and religion. And where Art is necessary to the tribe or nation men must be born addicted to it, and capable of absorption in it without further designs. Again, when Art has become disinterested, it retains the form of purposiveness, although the actual, original purpose may have been forgotten, or subordinated to the performance itself. Then, as long as Art is truly national, judgments concerning it are apt to be universal, because in fact the practice is universal. Subjects and methods of treatment, slowly evolved, are by continual trial adjusted to the national ideas and sentiments, and may remain unchanged for many subsequent generations. And, again, such judgments, being universal, are felt to be necessary: particularly when subjects and methods of treatment have been consecrated by Religion.

But if from any cause the power of Religion over Art relaxes, the necessity of traditionary subjects and methods ceases to be felt; a new era of experimentation begins under the guidance of personal taste. That such or such work is necessarily right or adequate by universal consent, then becomes a subjective conviction, which tries to justify itself by reasoning, but cannot discover an adequate logic. Two such eras are well known : one in Greece during the fifth century B.c., when the City undertook the patronage of the Arts for the glory of the City and its deities, and the priesthood was not powerful enough to control their development; the other in Western Europe, about 1450-1550, when the leaders of the priesthood still exercised a decisive authority, but partly by worldly corruption, partly by uncontrollable sympathy with the tide of new ideas and aspirations, became patrons of a humanist movement that gratified their own tastes, but betrayed their official interests.

As the Fine Arts become personalised, they afford the 
means of independent professional livelihoods, and are more and more free from official control and patronage; and to those who practise the Arts for a livelihood, the task can no longer be disinterested, except in the case of a few who have other means of living, or who are by birthright such devotees of the ideal that they can think of nothing else, or so happily adapted to the public taste that they can please without condescension. In those Arts indeed that require the presence of the artist, such as comedy and other public performances, we may suppose that the eagerness to exhibit his own skill or grace, a recognised motive of some primitive Arts, was never wholly absent, though in certain cases, necessarily restrained by official forms; and this motive has, no doubt, greatly increased in power as success has depended more and more on personal gifts, graces and dexterities; and, in fact, it has thus added the most astonishing chapter to the distressful history of vanity and jealousy. At this point devotees of poetry and the plastic Arts are less exposed to temptation; and in spite of the argument of Karl Groos in his entertaining works on The Play of Animals, and The Play of Man, and of others who agree with him, I venture to think that in these Arts, and sometimes even on the stage, the greatest artists are influenced little, or not at all, by the motive of self-display. It is useless to ask artists for their opinions about it; but consider that an instinctive passion for the ideal is capable of submerging all other motives; then put yourself in the place of the great artist, and you will see that what is possible is real. Such devotion constitutes the morality of the artist, so far as he is an artist ; for no man's genius is his own, nor to be used for his own ends. Mill's saying that Poetry is a kind of soliloquy is erroneous in so far as all Art is social; and yet has a certain truth in the unanimous rapport of tribal celebration: since in the orgiastic abandonment there is no longer any spectator.

The universality, necessity and disinterested purposiveness of the Arts, and also the decline of those characteristics, are easily understood in the light of history ; but if we consider the Arts merely as they exist amongst us now, it would be impossible to understand how they can have such qualities. 
We may be referred to "genius" for an explanation of them, but genius itself needs an explanation; which can only be that it is the inheritance of powers selected by the conditions of the great ages of Art, because necessary at that time to the structure of social life. And this enables us to understand why to this day so many people in each generation are born with artistic dispositions in various degrees of strength; of whom most turn away from the artist's life with a glance and a sigh; some thousands give it up after a bitter failure; some hundreds go on and starve; some scores make a living, and a handful make a fortune. It is just like the Kingdom of Heaven : many are called, and few are chosen. And the reason is that, as division of labour is the condition of social life, any variation of faculty that was favourable to some branch of necessary labour has been selected and become endemic; that the artistic disposition is such a faculty, and that having been once established in the germ-plasm of the race, it cannot be bred out until long after its utility has declined. Age after age, after that decline has set in, it buds into life as if to adorn the Spring, and meets a perpetual Winter. The suffering thus inflicted upon individuals, what arithmetic can sum! If you try to see it on the inside, you may suppose it enough to split the planet: but the planet does not split: and our consolation must be that still greater numbers are born with an inclination to cultivate their garden or to mind their sheep, or with what Adam Smith calls the "propensity to truck and barter."

As almost every great nation has at some time depended upon its poets, musicians and artists (though not in equal measure), we may assume that the potentiality of such genius is widely diffused, and that every generation produces nearly the same amount of it: yet its manifestation varies greatly from age to age. To understand this we must consider that artistic genius is a special direction of the constructive instinct, concurring with certain modes of feeling and powers of intellect. The instinct, feeling and intellect may combine in very different proportions, but the essential thing for art is the special direction of the instinct. Every instinct develops unless it is inhibited by direct repression, or by want of stimulus and 
opportunity, or by the predominant strength of some other impulse. Artistic genius in a Quaker 200 years ago would have met with direct repression; in general at that time, there was a want of stimulus and opportunity; if 100 years ago our poets had all been attracted into the army, what an impoverishment of literature! A great enemy of all genius is repression by conventions; a still greater, perhaps, the vulgar tastes, or dull insensibility of the public; but in certain happy ages there has been a general release of the human mind from tyranny, convention, censoriousness and every sort of dread; and then genius of every kind obtains the fullest expression; as at Athens after the Persian War, in Italy at the Renaissance, in England after the Armada, and widely in Europe at the close of the eighteenth century. At other times, less glorious yet noble results have been attained when stimulus and opportunity have been given by those who had the power, such as Ptolemy, Augustus, Louis XIV. And perhaps even now, in spite of the censure of popular newspapers and the parsimony of the Exchequer, there might be a greater manifestation of artistic genius than we see around us, if it were not for the seductions of electrical engineering and the Stock Exchange.

Well: as we have accounted for the general characters of Art and for artistic genius, in a similar way from historical conditions we may deduce the contents of artistic work and the forms into which they are cast. Plainly, the original contents are myths and legends concerning gods and kings: these are engraved, painted, sung and danced. The forms of plastic art, of pantomime, of epic, drama, ode, can all be traced back to religious sources. With the democratisation of society the original heroes, gods and kings, give place to earls and baronets, soldiers and millionaires, until we come to people distinguished by some merely personal quality or humour. We must except from such derivation the crude ghost-story and gossip-tale (or fabliau) in literature, with corresponding forms in other arts ; which, being adapted to the simplest social conditions, have persisted unchanged for hundreds of thousands of years; just as some living things, adapted to the simplest physical conditions, have persisted for millions of years in the 
deep sea. Meanwhile, divine myths branched off from the ghost-story in some remote age, and unfolded into the higher forms of Art.

The artistic sentiments have the same origin and history. The sentiment of Beauty, indeed, developes late, and is attained by few poets; but sublimity and pathos are the terror, exaltation, affliction of those who celebrated the victories and tragedies of the gods, and of those who witnessed as if they performed, with all their souls ; comic humour is the exuberance, abandonment and good fellowship of religious revellers. How can these things be understood in the present condition of the Arts? How is it possible for mere fiction to arouse such interest and distress? It can only be the renewal of a state of dissociated imagination for which, in former days, fiction was truth; and, being such a renewal, it is something far less intense than the original ; compared with which our liveliest æsthetic experience is like age remembering the joys of love. For in the æsthetic mood at its height there was no consciousness of make-believe or wavering of belief: it is easiest for us to understand through the absorption of children's games or of hunting. In this connexion, too, the strongly expressive quality of joy and grief must be explained; for they are in some ways injurious: joy on the part of any individual excites envy and hostility, grief shows weakness and excites contempt: but no expression can be too marked and violent for the orgiastic indulgence of national triumph or lamentation. Joy and grief have developed from indefinite elation and depression into specific emotions under the sanction of tribal utility.

$\$ 7$. Further, because Art is social, it must be addressed to the eye or ear, that a whole assembly may witness it at once. But the value of colours and tones with their harmonies and contrasts, though great (especially in the case of tones), is much less than the kinæsthetic significance of their arrangement in form and rhythm: I mean the movements they suggest. In Architecture, Sculpture and even Painting the retinal effect is unimportant in comparison with the eyemovements that are excited, and the movements of the arm 
and whole body that are correlative with movements of the eye ; and in the rhythmic Arts of Dancing, Music and Poetry, the interest of the kinæsthesis is overwhelming both for the individual and for the harmony of the choir or ballet. That odours have such indefinite connexion with movements in man is one reason why there can be no fine art of odours. Originality of rhythms is the surest test of musical or poetic genius. The power of Art cannot be understood unless we realise that, on its sensuous level, it possesses the whole body, and that this is only possible through the excitation (express or nascent) of bodily activities.

But Art at the height of its power is essentially imaginative, and the part of sensuous excitement is to inflame and sustain the imagination and to reify its ideas. These ideas are chiefly concerned with loyalty and devotion, the enhancement of the glory of kings and gods by building and adorning their habitations and rehearsing their acts and sufferings. Art, therefore, is imitative of human life ; for though a god be perceived as a beast, or a mountain, or the sun, his acts and sufferings can only be imagined as those of the human spirit. But as the impulse is to exalt his glory, his actions are expressed with exaggeration, sometimes monstrous; with a selective emphasis, according to the interest of his cult; with a suppression or subordination of whatever is irrelevant or inconsistent with it: and this constitutes ideality. The universal significance of such religious actions is greatest at that period at which the king and his ancestors are conceived of as identical with the Tribe itself. The imitation also becomes conventionalised: Sculpture, Painting and Poetry, which are capable of free natural expression, become conventionalised under a priesthood, or when the creative spirit flags, or when in a given state of culture the limits of technique are reached; whilst dancing and music, which express not action itself but the character and feeling of it, seem necessarily to set in certain schemes and figures that become traditionary-less true, of course, of modern music, separated from dancing and personalised.

Art that idealises those gods who are conceived of under 
moral ideas is an exaltation of human nature and of morality. At first it is too enormous, abstract and remote to have much influence; but with the democratisation of Society, the hero (as we have seen) is gradually reduced to more sympathetic proportions; he is then conceived with greater detail, and so the change from Idealism to Realism gradually takes place. Sometimes the change goes further, and the meanness and bestiality of human nature becomes the subject of Banalism: astonishing phenomenon! If there is any substance in Spencer's explanation of the delights of picnicing as a return to the open-air life,

When wild in woods the noble savage ran,

Banalism may be interpreted as an imaginative indulgence of instincts derived from the bestial savagery of other ancestors.

The Greeks were fortunate in being able at the height of their civilisation to find subjects of tragedy in their own heroic age, and thereby to attain the noblest Idealism that the world has ever seen. In English literature this phase, unhappily, is wanting, because of the destruction of our ancestral gods; so that it passed with little preparation from crude religious dramas and stiff naive allegories to the mature Realism of Shakespeare: in which the universal significance of an action is retained whilst it is brought as close as possible to experience: a perfection that can only be reached and briefly held at rare and happy epochs. It is, perhaps, at this stage that Art has the most direct influence upon Morality. The hero of a Shakespearean drama is not so remote as not to be identifiable with the spectators; his fate is a passage of experience, and the representative character of his career is an implicit "criticism" of every individual life But nothing is more fatal to both Art and Morality than the intentionally didactic tone, especially the subjection of drama to the principle of poetic justice, as if Art existed to correct the visible dispensations of providence. To reward virtue with worldly prosperity is a falsification and an anti-climax. It misrepresents the truth of spiritual triumph, and strengthens 
the confidence of the vulgar man in vulgar gains. If all is well, what becomes of courage and sacrifice? Life is robbed of its heroism, and of that mysterious connexion with the divine which is witnessed to in the derivation of tragedy from the sacrifice of God.

The epic or drama of the Divine Hero has always been chaunted or written by the greatest men, and cherished as the essence of national life. It is certainly a literary misfortune that the civilisation of North Europe involved the banishment of our ancestral gods, and left us with no heroic ideals truly expressing our character. But you may see in the Sagas that the old gods were dying a natural death; and how could they survive who prophesied their own destruction? The knighterrants were an impossible substitute, products of a superficial culture, necessarily transient phantoms, though they have left some impress of themselves on our sentiment and imagination. The distinction between 'sacred' and 'secular' literature is now too deeply marked: so that the former, in spite of the sublimity and profound pathos of the better part of it, is less and less read every year. The more the nations of Europe recover their individuality after the chaos of the Middle Ages, the less regard they have for the religion that was associated with those ages. The present purpose of Literature and Art, according to nature, though generally otherwise conceived by us, is the maintenance of national life by the diffusion of social beliefs and ideals. The purpose must fail if our beliefs and ideals are misrepresented, whether by the attempt to diffuse beliefs that are impossible, and ideals that never were and never will be ours; or by the falling of literature out of the hands of the greatest men. Only by them can the interest and nobility of Art and Literature be maintained, and social beliefs and ideals be realised in forms of beauty to the rapture and purification of all beholders.

$\S 8$. As it is better for a savage to be carving a totem on his war-club than to be breaking his friend's head with it; so it may be better to be reading a silly novel than to be conducting a sordid intrigue or talking scandal about one's neighbour; but whether as instruction or discipline novel- 
reading is in general very inferior to wood-carving. Incessant novel-reading is the resource of those who have not enough fancy or energy to invent their own day-dreams; but daydreaming and novel-reading have the same fault, the divorce of sentiment from action.

In general it is a mistake to criticise Art, however illregulated, upon moral grounds. Should there ever be some chance of Morality's becoming the chief power in the world, certainly everything else must be subject to it. But it does not follow that direct attempts to enforce subjection are the most effective. In the first place, we are still so ignorant of what is moral in its total consequences, that it is easy to make gross blunders by the prejudiced condemnation of innocent things. Moreover, those who undertake to enforce moral judgments may be the most detestable Pharisees, or people too weak or timid to resist the Pharisee's demands. But, secondly, there is nearly always a better way of determining the limits of Art than by invoking a moral judgment, namely, by appealing to the nature of Art itself. For inasmuch as Art is disinterested, and universal in its appeal, it does not excite appetite or selfish desires; and inasmuch as it excludes all painful effects that cannot be either redeemed or so subordinated as merely to intensify the total effect, it is incompatible with coarseness, or horror, or whatever causes such physical disgust as to overpower the imagination. These considerations are sufficient to determine the limits of comedy and tragedy; and they have neither the irritating nor the paralysing quality of moral censure, which stirs one artist to frenzy and reduces another to imbecility.

The worst possibility of Art is its perversion by luxury to serve and adorn the passions by enhancing the charm of life and manners in a corrupt society. It was a strange thing of Burke to suppose that under any conditions "vice itself could be shorn of half its evil by losing all its grossness." The best of Art now, besides the joy of it, is to enable us to see and feel what is noble and what is base, without the dull and ineffective method of being told about it; to reanimate a nation with the 
admiration of heroes, and with a willingness to follow them as we were wont to do. Art is anciently and intimately related to Religion; and although theologians have reduced religious beliefs into systems of philosophy, Matthew Arnold seems to have been justified in holding that with Poetry they have a profounder and more fruitful alliance. 

EPILOGUE 



\section{CHAPTER XI}

\section{MORAL DEGENERACY}

$\S 1$. That the processes of the World, whether physical or organic, are not necessarily conducive to progress, to improvement in the conditions or activities of human life, has long been recognised. That there is an end to all human glory has often been declared to be the decree of Fate. The highways of history run through the ruins of empires. The modern theory of evolution fills the reflective man with gloom, when he considers that dissolution is as good a name for it; that natural selection is essentially a process of world-wide destruction : from amidst which, here and there, survivors emerge and enjoy a temporary triumph; whilst in remote vista there is only one end, the same end for the slayer and the slain. The great multitude without any effort avoids such reflections; and those to whom such reflections occur, for the most part, without effort set them aside as too remote for any practical purpose, or even as injurious to the active life that is only nourished by hope. Passionate Desire has ears only for her flatterers; and is everywhere intent upon the immortality of the nation, the language, the literature, the memory of heroes and their deeds. The cry that there is one end of all things is less resented than ignored. Moreover if only death were threatened, and if it would come quickly and let all be over, we might confront it with resignation or with scorn : but there is worse than death. Degeneracy is worse: to fall short of our forefathers and not to know it, to know it and yet deny it; not to care; to have lost the sense of shame and be reconciled to corruption; to boast of deeds that we can no 
longer emulate; to be suffered in our insignificance by the magnanimity of those who honour what we have lost, even lost the power of understanding. Again and again, this lot has befallen nations.

Why should a nation fail and disintegrate? For in this respect it seems to present no essential analogy to the individual. With the individual after some years the power of nutrition decreases, the waste of active life can no longer be fully repaired; the tissues lose their vigour, and soon the end comes : but we know of no necessary limit to the power of a nation to repair the waste of its life, no inherent restriction upon the succession of generations. The individual, again, soon completes a definite anatomy, that does not admit of much original adaptation if the conditions of life should rapidly change-as, fortunately, they do not. The conditions of a nation's life now change rapidly; but although every nation has a certain structure of institutions and customs comparable with an animal's anatomy, yet that structure is not obviously so definite or fixed as not to allow of extensive changes and adaptations. Possibly the analogy between organic and social life now so commonly appealed to, may be fallacious. I shall not argue the matter, nor rest any weight upon it, but merely take the prevalent view as a starting-point: not pretending to anticipate the principles of the next age, nor yet to fetch explanations from Aquinas or Plato or the reign of Saturn. It will not be disputed that every nation, in order to preserve or enhance its life, must preserve order, or avoid extreme disorder amongst its own citizens, whatever their rank, occupation or culture ; must get food and shelter under certain physical and economic conditions; must keep terms with its neighbours whether friendly or hostile: nor will it be disputed that the conditions of maintaining peace and of sustentation are liable to change, and that the same is true of the power and spirit of neighbouring nations. In some ages of the world change of any sort has been very slow; for the last few thousand years it has been increasingly rapid, and there is no prospect of a slackening pace. Whatever changes happen in the conditions of a nation's life, internal or external, they must be met by 
some corresponding change in that nation's activities. Such a responsive change of activities is adaptation, the power of making it is adaptability; and as long as there is adequate adaptability a nation will live, though whether better or worse cannot in general terms be predicted. For as parasitic animals show us, adaptation is compatible with degeneracy. A nation may adapt itself to a subordinate place or even to slavery.

It is not obvious that any nation's structure of institutions and customs is so definite or fixed as not to allow of extensive changes and adaptations; but nevertheless such fatal rigidity may be there. The vast scale upon which such things exist and the wide dispersion of their activities in place and time, make it difficult to comprehend them in one view and to understand their necessary connexions. But, besides that, the real ground of their stability and influence is necessarily hidden from us, namely, the character of the men who maintain and work them. This character consists of the inherited instincts and capacities of citizens, and their traditionary habits of thinking and feeling and acting, as determined by family training, by social, political and economic requirements, and by the tone and persistency of society in enforcing such requirements. Plainly, all institutions, lawcourts, parliaments, churches, depend for their efficacy entirely upon the character of those who carry them on or live under them: that determines whether they shall be living powers or empty masks. But how difficult a task it is to judge of national character, or to estimate its inherent resources, its latent capacities for change and adaptation, should a change of circumstances give opportunity for the manifestation of nobler or less noble dispositions !

That some nations fall and others rise is plain enough: the fact is not exceptional, but to be seen on every hand throughout the world, and in every age of recorded history : to discover the causes of it must be a matter of the utmost scientific interest, even if it should appear that the causes are too vast or too numerous for practical control. And it would be of importance to our present subject; for it is generally held, and 
seems to be quite plain, that the retrogradation of national life carries with it a widespread moral decline amongst the citizens; not perhaps in all of them but in the great majority. We have seen that the State is necessary to human development, but that the chief trait of human development is morality, or the individual's power of self-guidance to remote, comprehensive and noble ends. We have also seen that custom, polity, industry, religion and art, whilst in many ways favourable to human life, in other ways tend to moral corruption; and the accumulation of pernicious tendencies as institutions grow old may be one reason why nations culminate and decline, and why their citizens fall with them.

Any attempt to judge whether in a particular nation moral decline is, or has been in progress, or is about to set in, must be very hazardous. It nearly always happens within the nation itself that some section or class is losing ground whilst others are improving, and a witness of such changes may easily mistake a part for the whole. And we must in every case be on guard against the temptation to estimate the nature of changes going on before us according to our own prejudices or practices; since every moral advance implies some departure from standards hitherto accepted-in fact, a kind of social experimentation. For example, the increasing number of divorces in several countries at present is, prima facie, a sign of moral corruption; but we are so incapable at present of predicting the course of events that, possibly, greater facilities of divorce may be a condition of re-establishing sexual relationships in greater justice and harmony, and may therefore in reality be favourable to the consolidation and perpetuation of family life. Or, again, the movement for shortening the hours of labour and multiplying holidays, which to some bystanders seems due to laziness or shirking, may prove to be rational economy by increasing the efficiency of labour and raising the level of culture.

$\S 2$. To explain why some nations rise and others fall would require a large volume; and I shall only refer to the problem here to illustrate its bearing upon morality. To begin with, we must distinguish between the fall and the 
relative decline or obscuration of a people. The Dutch, for example, have been relatively obscured by the development of neighbouring powers with more extensive territory and population; but they have not fallen; their power is, no doubt, greater than in their glorious seventeenth century; and their colonial empire is still, in wealth and population, the second in the world. Such a relative change involves no moral degeneracy; though it reduces a people's incentives and opportunities of expansion, and is likely to make their virtues less conspicuous and to diminish the lustre of their great men. Similarly with the Scandinavian powers.

Ever since the conditions of national prosperity have excited reflection, some of them have been noticed and frequently enlarged upon without being clearly understood. The influence of climate, for example, so impressed Herodotus that he closed his history with a report how the Persians adhered to the advice of Cyrus to remain in their mountain fastnesses and preserve their manhood and liberty rather than descend into the conquered plain of the Euphrates and there become the slaves of others. And Aristotle says that climate made the northern barbarians too fierce, and the southern too soft for civilisation, whilst the Greeks enjoyed the happy mean. It now appears, however, that civilisation is possible even north of the Danube. And physiologists have explained that in southern regions it is not heat so much as the combination of heat with moisture that is enervating: a combination that does not exist in Syria or Egypt. The effect of such regions as the plain of the Euphrates has been well derived by Buckle (History of Civilisation, c. ii.) from the low physical standard of living there and the ease with which the minimum of subsistence can be obtained. This leaves a huge population in abject poverty and, therefore, in dependence upon the lords of the soil and moneylenders. The defence of the country then depends entirely upon the army; the people have no interest in it. The army conquered, the dynasty and aristocracy are changed; but such events may occur again and again for ages without either a rise or fall in the political or moral condition of the bulk of the people. 
Other effects of climate have been pointed out by the late C. H. Pearson in his National Life and Character. He shows that the European races are incapable of colonising the tropics. The Chinese, Hindoos and Negroes do not give way before white invaders, as the Australians and the Indians of North America have done. In his Principles of Heredity G. Archdall Reid explains this fact by the adaptation of all races of the Old World to the prevalent diseases of that World; which rapidly exterminate the inhabitants of those regions to which they are new. Accordingly, Chinese, Hindoos and Negroes may, with the help of the science and capital of Europe, densely people the tropics and establish great empires there. This by itself would bring about a relative decline of European power and, possibly, military danger; but, further, the industrial competition of such powers, employing scientific machinery and having command of the cheapest raw material and of labourers with a standard of living much lower than our own, must lower general prices in international trade and, therefore, the rates of wages which at present are the chief condition of maintaining our physical superiority with all the rest that depends upon it. Pearson indicates other consequences of such an exploitation of the tropics that are even more alarming.

Luxury, again, as a cause of national ruin, has been a favourite theme of moralists. But "luxury" is a very indefinite word: the luxury of one age may be only the necessary sustentation of another. The rise of every great nation is marked by a characteristic material civilisation, which is luxury in contrast with its earlier life-the life of the "city of pigs." Commodious dwellings, improved cookery, raiment and equipage, the cultivation of manners and the enjoyment of the Arts in private life-so much is development, not decadence. Even this has drawn censure from the more severe moralists. But that other kind of luxury which reasonably excites anxiety is merely a symptom of decadence; it is for the most part an effect not the cause of corruption. Extravagant ostentation and outrageous sensual indulgence are only possible to a parasitic wealthy class (with their 
retainers and favourites), a court, an oligarchy, a priesthood, or heirs of financial 'magnates,' whom some cause has separated from the normal active life of war, administration, or other employment. The cause may be contempt of all restraint, or incapacity for business, or extrusion from office: as happened to the French noblesse in the seventeenth century, when they were superseded in their feudal duties by intendants and bureaucrats. In any case such a class may gratify its vanity, or love of predominance, or dread of ennui by violent excitement, indulgence, distraction; which is not the less grateful if it offends the unhappy moralist. They impoverish themselves and their dependents, and, debase the Arts that they patronise; for there is no other class with taste and wealth onough to sustain a classical tradition. But the worst of them is their example, for they are necessarily admired by great crowds who in a cheap yet self-destructive way imitate them as well as they can. A strong middle class may, indeed, resist their influence; for the chief affinity of social scum is with social dregs. The outrageous sort of luxury is never at its worst, except in a Slave-state; where contempt for human life and dignity, and the extremes of cruelty are possible. It seems naturally to tend to its own extirpation by destroying the class that practises it; for such a class, besides being impoverished, becomes infertile from various causes, such as nervous exhaustion and marriage with heiresses who are survivors of infertile families. I cannot, however, remember any case in which a luxurious class died a natural death; but either it was overwhelmed by a revolution or by a war, along with the nation whose vitals were its prey.

Whatever the other causes of the baser luxury it always implies a relaxation of tribal or civic discipline. Every barbarous tribe, every City-state, every conquering aristocracy in country States, has always had its discipline under inviolable customs. This is everywhere the necessary substitute for personal morality so far as morality is still ineffective. By one means or another there must be social cohesion and national service; and the only means are self-control and discipline. When Pericles boasted of the superiority of the 
Athenians over others who were more strictly disciplined, his praise implied the superiority of their character as individuals (Thucydides, Book II.). Upon modern nations discipline has for a long time been losing its hold; and some think that the spread of socialist ideas is the sign of a general feeling that a new discipline is necessary. Germany submits to a completer discipline than any other country, and believes that to discipline is due, in no small measure, her honourable distinction in the arts of peace and war. What shall we say of ourselves? For centuries military discipline has ceased to be obligatory upon any class; in industry the rules of apprenticeship have long gone out of use; the discipline of family life has been remarkably relaxed. It is, I believe, the purpose of the National Service League, not only to obtain an army of citizens but also to stiffen our fibre by wholesome discipline; and it seems to me that the League's great difficulty lies in persuading us that moral strength would result from a military education to which we have never been accustomed. But if we will not, or cannot, adopt any form of national disciplineholding that our character, however imperfect, is better than it otherwise could have been, even because of the narrow place that restraint has had in our life-it is surely the more important to maintain in all directions, in industry, in commerce, education, municipal and political affairs and in private life, the free conditions under which our character has hitherto been formed.

To trust much to discipline is dangerous, seeing that it may so easily break down; at last it always has broken down, as we see in the histories even of Rome and Sparta. Discipline cannot flourish merely by its own power : the spirit that gave it life must keep it alive; and this spirit depends on other things. Moreover, it is a substitute for morality only so far as it applies to our life, and its prevalence in certain departments of life is compatible with gross licentiousness in others. Whereas the régime of freedom and self-control needs no artificial support but only to be let alone. We do not ask the fussy meddler and the busybody to help us, but merely to keep their hands off our throats. 
$\S 3$. Whether a nation shall advance or recede depends a good deal upon its neighbours-the geo-political environment. This is a matter partly of direct contiguity, partly of the conditions of communication. Adam Smith shows how important was the Eastern Mediterranean, with its peninsulas, islands, and approaching shores, to the civilisation that sprang up around it and which we now know to have existed there much earlier than he could have supposed. To be on the high road of commerce is stimulating; to lie remote from it is to be in danger of stagnation. Superior neighbours stimulate and civilise ; inferior corrupt and barbarise a nation. It is, therefore, a check upon any nation to find itself superior to all others within reach. That, at the present time, several nations compete for the highest place and that none has a decisive superiority is the most wholesome counteraction of the desire to rest, to be safe, to avoid the struggle for existence. The nation that confesses itself tired of competition, and attempts to rest, is like a man who in a snowstorm gives way to sleep and wakes no more. War or the preparation for war, commerce and the communication of arts and sciences and inventions, make a continual demand upon the intelligence, energy and character of every one; and those who cannot respond with the necessary adaptation to such ever-changing conditions perish, and it is good that they should perish.

Modern facilities of travel have made all nations of the world a sort of neighbours, and there is an increasing flow of population from the poorer countries to the richer. Still, great distance and the cost of it remain effective obstacles to large migrations. It is fortunate that India is so much farther from England than Syria was from Rome, or else the Ganges would soon wash out the whole valley of the Thames.

The influx of strangers is one of the means by which a dominant race may be submerged and lost; and I believe that the exhaustion or submerging of a dominant race is a most general cause, if not the only cause, of the degeneracy, as distinguished from the relative obscuration of a people. I admit that the idea of race is a treacherous one, and that the 
influence of race is difficult to prove amidst the numerous causes that determine the course of history, and, therefore, I resort to it as rarely as possible. But to treat the problems of history and society without reference to it is too crude a repudiation of common sense. The possible formation of races has an easy biological explanation; we have only to suppose that a certain group of men are, during a certain period, relatively isolated from others, and exposed to special conditions of selection. If the period of isolation were long enough and the conditions of selection severe enough, a new species would be formed; but, as it happens, only a variety is produced, distinguishable but perhaps very fragile as to its idiosyncrasies; so that it is very liable to reversion and very liable to be dissipated by intermarriage with other varieties. Dominant races, being the more recent varieties, are likely to be the most perishable, according to a widely accepted hypothesis; and they may be represented by small numbers compared with a subject people. But a slender strain of good blood may, whilst it lasts, give distinction to a nation, because it provides leaders; for the average men may not greatly differ from one nation to another, and who they are may not matter if only they can and will follow.

Assuming then not merely that races so different as Negroes, Turanians, and Teutons, but even that varieties so much alike as Teutons, Latins, Greeks, are really distinct enough in cast of intelligence, energy and character to behave differently in similar circumstances; so that their existence is a real cause essential to the producing of certain types of national power and culture; it seems to me reasonable to say that the Greeks declined in power and influence, because the Greek race was submerged or dispersed; that the spirit of the Roman Government changed and weakened, because the Romans were dispersed, or overwhelmed by slaves and immigrants; that the power of Spain declined, because the Visigoths who had raised it, after the expulsion of the Moors, were in a few generations lost by celibacy, or emigration, or intermarriage with the Iberian populace; and similarly in other less conspicuous cases. As for Greece, we know that 
from the first the 'Aryan' invaders were superimposed upon a more ancient stock, so that their peculiar strains of blood were always in danger of being submerged; how at a later date foreigners swarmed in Athens; and how at Sparta in Aristotle's time (Pol. II. ix.) there were only 1000 Spartans left (say 330 B.c.); whilst Plutarch, in his Life of Agis, says that at that king's accession (244 B.c.) there were only 700 families, of whom only a hundred were landowners. The destruction of the Roman stock is notorious. Writing of Cæsar's time, Mommsen says that the good stock of the Latin nation had long since wholly disappeared from Rome (History of Rome, Book V. c. xi.). Traditionary policy, good laws, and the organisation of the army and administration preserved the State and Empire long after the people who created it were dead or dispersed; for, as Mommsen shows in an earlier chapter, Rome had always depended on her traditionary policy rather than on distinguished individuals. In Spain after the Visigothic refugees, issuing from the Asturias, had recovered the peninsula from the Moors, their power rose rapidly in the sixteenth century to a domineering ascendancy both in Europe and in the New World, and then in the seventeenth century as rapidly sank, not merely obscured by the competition of France, but by a positive declension that continues to this day. Galton has indicated two probable causes of this conspicuous portent (Hereditary Genius, c. xxi.): first, the celibacy of monks and nuns which cut off the heredity of gentle natures, fitting them " to deeds of charity, to meditation, to literature or to art"; and, secondly, the infernal persecution which, for centuries, at the rate of one thousand annually, brought "the foremost thinkers and men of political aptitudes to the scaffold, or imprisoned them during a large part of their manhood, or drove them as emigrants into other lands." If to these causes of degeneracy we add the emigration of ardent and enterprising spirits to Mexico, Peru and other colonies, and also intermarriage with inferior stocks, they give a sufficient explanation of how the blue blood was drained utterly away and the nation left destitute of genius. But as pride and superstition never learn, the worst of these causes 
are equally active at this very hour in destroying the genius of Russia; whilst the whole time-serving world looks on with shameful assentation.

A minor race, however, such as Greek or Teuton, having been differentiated during no very long series of generations, is probably (as I have said) so unstable as to lose easily its more specific complexion of qualities. If noble, then, the more it deserves our care. For, in fact, I suppose it can only be effectually maintained for any length of time if it stands (1) relatively isolated, (2) exposed to circumstances similar to those that produced it, and (3) purged by active natural selection or by careful breeding and elimination. No European race or aristocracy has fulfilled these conditions. Changed circumstances, failure of selective forces, careless breeding and intermarriage have been continually merging the conquering tribes of the Dark Ages into the general population of the Roman Empire. The computation is well known which shows that if any one can trace an ancestor in the fifteenth century (not to go too far back), then, supposing thirteen generations to have passed, the blood that he inherits from that ancestor (apart from the occasional intermarrying of cousins) is only the 8,192nd part of all that flows in his veins; whilst it is certain that multitudes inherit the same share of that blood without having been at the pains to remember it, together with a similar share from many of the rascals who were living at that time.

On the other hand, some modern nations have a tendency to form new varieties. Our own, for example, including much blood that is neither Teutonic nor Keltic, has for more than a thousand years been relatively isolated (for the non-Norman companions of William I. were not numerous, nor were the later Huguenots); the conditions of life underwent no great change until the end of the eighteenth century; until that date active selection prevailed (the population taking two hundred years to double itself); the conformable to law and custom were favoured and the non-conformable discouraged; and these things, together with imitation, to which Walter Bagehot attached so much importance, have produced a type generally recognisable by friends and enemies. But any one 
who looks through the country must see that the men are too heterogeneous to constitute a race: indeed, a mixture of anatomical types affords the simplest explanation of our general ugliness.

A conquering race in changing its habitat usually also intermarries with the conquered. Then subsequent selection is likely to favour those offspring who are of the mother's constitution, already adapted to climate, disease, etc., by long residence in the country. In any case at each intermarriage the blood, whatever its value, is halved; and if the conquerors are comparatively few the strain must soon be lost. There is some evidence that, even within the human race, a mixture of different anatomical types produces infertile as well as ugly hybrids; and also that, when fertile, such crossing causes reversion to a primitive type more savage than either parent (Avebury's Origin of Civilisation, p. 543, and Darwin's Variation of Plants and Animals, c. xiii.).

The character and stamina of a nation have sometimes been lowered and enfeebled by long wars; as happened to France during the Napoleonic Wars, and to Greece, but especially Athens, during the Peloponnesian War, closing with the calamitous Sicilian Expedition.

It has been argued, again, that the recent change of life in Europe, and in a less degree in North America, from conditions chiefly agricultural to the confinement of cities, must give an advantage to some strains of the population over others, and that in time this must alter the constitution and character of nations. Possibly the regularity and closeness of urban life may directly impair fertility, just as confinement does in the case of many species of animal.

$\$ 4$. The essential condition of civilisation, as we have often said, is the growth of the co-operative character, the character that induces men to take their share in industry or in professional service of whatever useful kind, without grudging and without compulsion, and to fit themselves to do their best, and to act even in the meanest office with a sense of the public good that requires it and that, therefore, ennobles 
it. Such a character and the intelligent activities favourable to social life that flow from it, are the reality of civilisation; the prosperity that follows and the increase and diffusion of wealth and leisure are but their necessary manifestations. Such a character is nearly the same thing as the moral disposition; and, accordingly, the most serious mark of moral declension, and also a powerful cause of it, is failure to co-operate, or social incohesion.

Social incohesion exists wherever there are people or classes of people who render no useful services in return for the expenses of their sustentation: social parasites, who cannot or will not get their own living, but suck the blood of those who can and do. One mode of this nuisance is the swarming of idle gentry, such as the French noblesse of the eighteenth century, or the Spanish hidalgoes;-but in fact it occurs in some degree wherever absurd laws encourage the inheriting of wealth without commensurate duties. To the idle gentry add all their servants, who must be as useless as their employers are, and who, if there were general enlightenment as to the nature of idleness, might be expected to know that their life was not a worthy one. As no such enlightenment exists, the servants are justly free from disapprobation; and so, in fact, for the most part, are the idle gentry themselves. Law, opinion, religion never warns them, and many of them would be surprised to hear that they were not models of "self-realisation" to mankind. Nay, in the general mind there is so little appreciation of the high interest of the World in leisure as the condition of culture, and so little appreciation of the difference between leisure and idleness, that idleness must be tolerated for fear leisure should be encroached upon; even although it be true that as long as wealthy idlers are respected, industry cannot be duly honoured.

Similar nuisances are redundant soldiers hired for parade or tyranny; redundant priests, the monks and friars that swarmed in mediæval Europe and may be said still to possess

Those happy regions Italy and Spain,

to say nothing of India and Thibet; thieves, too, and cour- 
tesans, and beggars and other parasites, whose injuriousness varies from the annoyance of lice to the mortal grip of cancer: perpetually discouraging the practice of industry, piety, chastity, self-respect, and degrading the institutions of nobility, religion and family life.

Incohesion and its correlative moral failure also exist wherever persons or classes, though self-maintaining and on the whole socially useful, nevertheless avoid some of their social responsibilities. The foremost of all responsibilities is the rearing of families; and it is too well known how this has fallen off not only amongst ourselves but throughout the civilised world and, strange to say, not least in America and Australasia, where we might have supposed there was room for expansion. The reason of this is that the illusion of love has partly been found out. Husband and wife see plainly that the growth of a family must condemn them to incessant labour and care. They say to themselves that the fewer children there are the more they can do for them; that for the unborn it is no injury not to be born; and the long vista of future generations, which is the secret purpose of natural passion, is too much for their imagination to grasp. But what they say to themselves is not the whole truth. If they are on the footing of the better paid artisans, the love of comfort often overcomes them : excusable enough! If on the footing of the professional classes, they find themselves with narrow means and the education and tastes of the wealthy: whose way of life becomes their model and suffocates their offspring. Looking over the history and present conditions of the Teutonic tribes, it seems to me that admiration of riches and love of comfort are the most constant traits of their character, and have done them more good and more harm than anything else.

Military service, again, has been expected of every freeman, and for the most part cheerfully given by him, in every country or tribe known to history, except where a condition of unusual safety has made it needless. At present the English are the only civilised nations that generally neglect it: in Britain, America, Australia they, in effect, inhabit 
islands, and feel secure against attack. But is there not more in military service than the safety of the country? To be sure, there can be nothing greater than that. But is it not a school of manners, an occasion of comradeship, a means of culture through the acquisition of skill and participation in a great tradition? Must it not mitigate the clownishness of those engaged in heavy labour, and the danger of effeminacy to those employed in softer tasks? Does it not make every one think of his place in the nation's life and history? It is true, perhaps, that long and severe discipline would lessen the independence and spontaneous self-control of our people, and might decrease their originality, inventiveness, adaptiveness ; but, surely, this must depend upon the length and severity of the discipline. However, if adopted in this country, universal military service must not become a means of increasing the influence of the wealthy in the quality of officers; and the demand for it must come from the people themselves, it cannot be imposed upon them.

A general interest in political affairs, and municipal affairs, and public spirit to undertake the numerous offices and duties that cannot or ought not to be paid for, are also necessary to national cohesion; and happily there is very little sign of their failing amongst ourselves. Let it always be remembered that whoever discharges an office for honour prevents the appointment of an official, and that an overgrown bureaucracy is the worst of parasites. Whatever their faults, the great Unpaid are not the greatest of evils. But there is another direction in which our countrymen are very negligent, unaware perhaps that any sort of public duty is involved in it: I mean self-culture, which I have been constrained to praise as the Chief Good. Nothing is more necessary at present than a very great increase in the number of those who are capable of forming independent judgments, enlightened by a familiarity (as Matthew Arnold used to say) with " the best that has been thought and said"; well-informed and independent judgments upon literature, morals, religion, politics. One reason of this necessity is the prodigious increase of late years in the numbers of those who, without anything worth 
calling education, have learnt to read, and do read, for the most part, trashy stories, football and racing news and partisan papers. To balance the ever-growing rubbish-heap of opinion worse than ignorance there has been no expansion of culture at the other end of society. The great difference between men of the more instructed classes is, that one man when he leaves the University thinks that he has " finished his education," as Mr. Larynx says in Peacock's Nightmare Abbey; whereas another thinks that the valuable part of his education-self-education-is now to begin. In the latter sort of man, the only sort whose culture is worth anything at all, there has been practically no increase; because the fashion is for every one who has leisure (after sleeping, dressing and eating too much) to spend it in violent excitement or violent exercise. It is not impossible for self-culture to become fashionable or customary in the wealthy classes; and unless it does become customary there is nothing to counteract and put to shame the ignorance and opinionativeness of a crowd fed on printed nonsense. At present the opinions of all classes seem to be on the same footing; else there would be some difference in their organs of opinion; but the penny papers are no better than the halfpenny ones. Vain to leave the matter to schoolmasters, tutors and men of letters: a professional opinion upon the great affairs of the world, literature, morals, religion, politics, is never a sane one: the only sane judgment is that of cultivated men who are experienced in the world.

The extreme of incohesion is reached where factions form in a State, and proceed to break it up by civil war or to deliver it over to a foreign conqueror. Short of this there may be all degrees of opposition between parties or classes, from good-humoured electioneering to the verge of faction. The commonest of all opposition of parties is between the rich and poor: though amongst ourselves the generosity and public spirit of many wealthy men has never allowed parties to divide merely upon wealth. If we consider our history from (say) 1400 to 1850 , it will appear that the contrast between classes greatly decreased: first, because the abolition 
of status and serfdom got rid of a greater difference than could be made by wealth alone; and, secondly, because the unprecedented growth of the middle class masked the contrast between the extremes of riches and poverty, and at the same time provided a sort of ladder by which an able man might climb from the lowest to near the highest station. But recently there has been a portentous growth of large fortunes; at the same time poverty has become, if not worse than ever before (which may be impossible), at any rate more conspicuous by accumulating in special districts of large towns; and an extension throughout the poorest classes of the ability to read has made them more keenly aware than ever before of the contrast between the luxury or comfort of others and their own misery. The moral unwholesomeness of this situation every one can see. Yet if the conspicuousness of the fact brings home to us the greatness of the evil, more good than harm may follow. Extreme poverty involves incohesion: the very poor, not having the stamina to earn a living wage, are necessarily parasitic. Herded together in cities, they establish their own customs, more difficult to break than the personal habits of scattered poverty; customs of filth, slovenly living, irregular and feeble work (to say no more), which, because customary, cease to seem offensive or even undesirable, and become a tradition from generation to generation.

To most observers a new sort of party-strife seems to be presented by the feminist insurrection. But others hold, not without the support of observations upon savages, that women everywhere constitute a party in fact, and that recent outbreaks are due merely to unwonted opportunity and to the confidence of women in their safety without special protection in civilised society. "All the laws of the Church and State," it has been said, "are framed only by men for men in the interests of men. Women are not consulted in the matter; therefore no respect and no obedience is due by women to those laws." Few would express their belief so crudely who could do it so concisely; but is not the opinion very prevalent that the laws and institutions of the country are artificial inventions in somebody's interest, that they 
do not represent natural conditions of co-operation, and that there is no ground of obligation except one's own contract? Thus necessary relations amongst mankind are denied, social tradition is despised, family and tribal instincts are repudiated, and nothing remains to determine the cohesion or incohesion of society except the treacherous cement of self-will. It is true, no doubt, that laws are often unjust, sometimes because they have been enacted in the interests of a ruling class; but then the ground for opposing such laws is their injustice, and the ground for respecting good laws is their reasonableness, not our own consent to them. Merely political activity amongst women is, however, less serious than their industrial activity, which is already well established. The effects of displacing men in some employments, and in others of discouraging marriage or maternity, are complicated with those described in the last section to produce a falling marriage-rate, a falling birth-rate and increasing celibacy: incohesion indeed! and the most disquieting sign of our times. All wholesome people ought to be married before the age of twenty-five: with us it is now impossible; and from that impossibility there must follow evils that cannot be numbered, that cannot be named.

$\S 5$. Whatever may anywhere be the causes of national and moral degeneracy, whether climate or the influence of neighbours, or racial exhaustion, the central condition is always failure of character. The manifestation and, in the long run, the existence of national character depends upon the same conditions as personal character. Character is a certain organic complex of instincts, purposes, dispositions that determine our actions, in such a way that we behave with some consistency during a long period. And, leaving out a few men of exceptional independence, the manifestation of any type of character requires that there shall be opportunities and provocatives for its leading instincts and purposes to be acted out, and that circumstances tending to repress such instincts and purposes shall be absent or not too strong to be overcome. Thus a strict social system that prevents men from rising in the world discourages enterprise, a soft climate 
or too easy means of livelihood also discourages enterprise; if men are excluded from every occupation but money-lending, greed is stimulated; cruelty is stimulated in men who have irresponsible power over others; war or persecution may destroy in immense numbers men of genius and virtue, and with them the inheritance of their qualities. Generally, the utmost possible personal freedom and the greatest variety of occupations are favourable to the richest differentiation of character.

Social incohesion is caused partly by the want of natural occupations. Idlers are people of leisure who cannot think of anything useful to do. Formerly, incessant wars absorbed them in large measure: now they might discharge a most essential function (since many of them have great mental ability) by forming that highly enlightened body of taste and impartial opinion which is so much needed. And possibly they would do so, if the fashion were decisively set by those whom (on account of their station) they are accustomed to imitate; but few of them have enough strength of mind to make a life for themselves. For want of culture they take part in all sorts of foolish plans and blind rushes, and are no longer able to recognise their true leaders; so that a man of great distinction at the head of a party may have difficulty in keeping his place against a gang of eager rufflers whom his followers really admire. It was through want of culture that the English gentry lost their control of public affairs. A few conspicuous exceptions could not save them: the bucolic crowd determined their general policy. Without culture people cannot understand that rank and proprietorship are not merely personal advantages (by tradition they never were) but offices of public trust: civilised co-operative life requires that they shall be held on that condition; on no other terms can they be held without constant intrigue and social strife. But the gentry of the last age, giving way to arrogance and greed, enacted unjust laws relating to land, commerce, public meeting and the expression of opinion, and resisted with violence every enlightened project of reform. So that power had to be taken from them and given to the middle class, and 
then to the working class, in order that the bulk of the people might defend themselves against intolerable aggression: not that they are fit to govern. Far from it.

Thieves and courtesans, again, exist partly because of the failure of suitable occupations; in the latter case especially, by the longer and longer deferring of marriage in all classes of society: but to account for idleness, theft and other vices, there is something else, namely, the survival amongst us of barbarous dispositions to violence, cunning, promiscuity, vanity, hatred of regular work. In the long run we may expect that these evil dispositions will be eliminated from every civilised nation; but, by the measure of anthropology, industry at once free and regular is quite new in the world, and therefore the population is not adapted to it. Go back a thousand years in our own history, and you find that most labourers are serfs and most gentlemen are pirates.

No doubt the instincts and inherited or traditionary dispositions that constitute character are liable to be weakened or perverted or disorganised by the loss or impairment of those illusions that hitherto have stimulated and directed our life. The illusions of riches and ambition are still strong enough; but perhaps loyalty is enfeebled, romantic love has lost something of its glamour, religion much of its confidence. Without them what shall we do? Bacon says too harshly that a "love of the lie" is characteristic of us; for our illusions have been sincere. But they are necessarily modified by philosophical ideas, and ideas always come with civilisation. The cast of thought is indeed pale, and blanches the native hue of resolution. 'Is it true?' or 'Is it worth while?' are questions fatal to an active career. The World, nevertheless, going on its way, after every partial 'enlightenment' a reaction takes place, either under the old or under new illusions : as happened to the classical civilisation. Civilisation then disappeared from Western Europe, and its uncomfortable ideas went with it. But they have returned; and so the World must wag until a race arises that can endure ideas, having imagination enough to comprehend the fact which illusions disguise, whose symbolic presentation constitutes their utility; so that men may feel as 
warmly toward the truth as ever they did toward the illusions, perhaps more warmly, more unwaveringly, and therefore act with more than the old confidence and devotion. There needs a great expansion of imagination to realise all that is meant by love and religion. Love ensures the old family life with its friendships the most lasting and the most restful, where we are born and die amongst friends, and it prepares the future of mankind in whom we are still to live, though ourselves oblivious and forgotten. Religion is in some sort to the nation or to the race what love is to the family, embracing our forefathers, ourselves and our children's children in an eternal family or patriarchal kingdom, where all the good or evil of our actions is realised or expiated. It presides over our birth, adolescence, marriage and death with consecrating ceremonies, that signify the spiritual life of the eternal family in which we are redeemed from the brutality of our origins. Now understanding resolves all such symbolism into the relations of men and women who act and suffer; and unflinchingly to set this bare reality before the mind's eye, to love it and live for it, is what I mean by the capacity to endure ideas. Considering how unamiable many of us are to one another, it may be doubted whether the direct 'service of humanity' is possible until the race has been purified; but here, again, we have before us the symbol of one who saw the race as it is and yet did not turn away.

$\$ 6$. Whether a change has taken place in any nation's character may be very difficult to judge. We can derive little information from statistics of physique, crime, earning-ability, and so forth, because statistics scientifically collected and analysed are all recent. And even if we had statistics of several bygone generations, and found in our own 'a superior physique, less crime, higher earnings, we could not infer any improvement in the race; since the changes might be due to better nutrition, less temptation, more education - causes affecting only individuals and not transmissible. The proportion of juvenile delinquents is everywhere increasing: see the evidence adduced by Stanley Hall in Adolescence (Vol. I. pp. 325-46). But if this is due to congenital inability to adapt 
themselves to civilised life, and if they are strictly eliminated, the population on the whole may be the better for it. Can anything be learnt about the changes of national character from institutions, literature, popular practices? Is it a safe inference that wherever the criminal law has been ameliorated the national character is more humane? Even if institutions remain outwardly the same, a change of character ought to show itself in the spirit of administration; but how shall it be traced? To take our own country, there is, I believe, a diminishing love of freedom - that is, disinterested love of freedom which respects and is ready to defend the freedom of others; and an increasing belief in regulation by central or municipal government through officials, in order to obtain some supposed immediate good. Opposition to this policy is called Individualism, a term of reproach that means nothing else than the custom of the English people. Unfortunately the support of Individualism against Socialism, to which the increase of interference by government necessarily leads, is always conducted in such a way as to appear to be not a national policy, but a defence of the privileges of some class. That plan is quite useless.

Another sign of a nation's change of character might be found in its popular amusements and literature; and we are frequently told that our own amusements have become very shallow or frivolous, as in watching football matches and indifferent theatrical performances. But, looking backward, it appears that we always loved to watch wrestling and fighting, and whether our forefathers participated in violent exercises more or less than we do by mere sympathy, is hard to say. And, as for the theatre, except that from time to time its history has been illuminated by men of genius, I fear it was always unsatisfactory: because there has never been enough love of culture amongst us to maintain the theatre steadily at a high level. The idlers have a good deal to do with the encouragement of theatrical and musical and 'knockabout' performances; and when that great reform has taken place amongst them that is so devoutly to be wished you will see the benefit of it. As for literature its history is always 
a record of ebb and flood, and at present we are at ebb; but the tide may flow again. There is not, I believe, a single poet of the first rank anywhere in the civilised world: I should be tempted to say "or even of the second rank," if it were not for the shining merit of one or two poets who, like Gray and Collins in the eighteenth century, have sung so little as to prove the hostility of our age to poetic genius.

Perhaps the ideals of a nation may sometimes. be seen to change-I mean, of course, not the personal ideals, but the generally accepted notions of a desirable life; there is, however, little sign of change amongst ourselves. Independence may be less and comfort more prized than formerly; but this may be due to the fact that now large numbers, for the first time, see comfort within their reach; and one cannot regret that. Admiration of fighting and admiration of benevolence are as strong as ever they were; and we are as willing as ever either to kill or to cure.

Perhaps superstition is increasing amongst us; by which I mean any reliance upon actions or observances that are not real causes of welfare: occult rites, prophecy, omens, luck and so forth; modern revivals of animism and magic. Gambling is very common, chiefly with the scum and the dregs. Queer religions spring up under leaders so destitute of personal distinction as to discredit historical reputations. Palmistry and astrology are advertised in the streets at such expense as to argue a very profitable trade. The lower the average level of the population in intelligence and character, the greater the tendency to superstition; and I have mentioned that the threefold multiplication of our numbers during the last century implies a lowering of average ability. An "age of enlightenment" is nothing to minds that, like Leibniz's monads, have no windows. Still, whether there is really an increase of superstition may be doubted. Some of our forefathers gambled worse than we dare do; they bought prophetic almanacs freely, and debased their religion by a pragmatical belief in witches and devils. On the other hand, some eminent men (on other grounds justly respected) now hope to support the traditionary faith in God by consulting obscure phenomena 
that not long ago would have been confidently ascribed to the Devil: rightly enough, since they degrade our ideas of a spiritual world. The good life must rest upon those truths that are best ascertained. Insight into the conditions of social and personal welfare is the ground of all free cooperation; the more intelligent and scientific such insight is, the further co-operation can be carried, and the nearer we may hope to approach the good life; and, therefore, I have ventured upon this brief inquiry into the natural and social foundations of morals.

$\S 7$. Well: on the supposition that any nation is declining what can be done to restore, or (if not declining) to raise it? For there has never been good ground for contentment with any nation that ever existed. Setting aside schemes of improvement that are notoriously absurd or hypocritical, the remainder (or most of them) come, I believe, under the head of education, or of benevolent social reform, or of purification or conservation of the breed.

Education is the beginning of all culture and of the higher human life, and, fortunately, it is now so necessary to the sustentation and defence of each generation that more and more care will certainly be given to it: so that it can do no harm to mention that, in the opinion of most biologists, it does nothing to improve the breed; that, if this be true, it does some harm by enabling many to live who would otherwise have been eliminated, and by increasing the amount of formally-trained ability with which original genius must contend before it can obtain recognition; and that the higher education of women especially, tasking their organisms to the utmost in order to prepare them to get their own living, or for any purpose except marriage, is likely to unfit them for marriage and for maternity.

Proposals for social reform are plentiful enough, and range from the providing of sustentation for all mothers; food, clothing and baths for all school-children; a living wage for all labourers and pensions for everybody, down to a modest law against spitting on the pavement. This last reform, a short while ago, was demanded by every journalist and at every 
dinner-table: in the panic it seemed to be the only thing that really mattered. Such plans always have one purpose, to raise the nation by attending merely to the health and comfort of the living. But it is certain that benevolent schemes often fail, and that the amiable is not always the useful. If one feels a disposition toward good works, to encourage the co-operative movement may be the most useful service: remembering that if any cause needs encouragement it is not very likely to thrive.

Bagehot has observed (Physics and Politics, c. v.) that "the most melancholy of human reflections is that, on the whole, it is a question whether the benevolence of mankind does most good or harm. Great good, no doubt, philanthropy does, but then it also does great evil. It augments so much vice, it multiplies so much suffering, it brings to life such great populations to suffer and to be vicious, that it is open to argument whether it be or be not an evil in the world; and this is entirely because excellent people fancy that they can do much by rapid action-that they will most benefit the world when they most relieve their own feelings; that as soon as an evil is seen 'something' ought to be done to stay and prevent it. One may incline to hope that the balance of good over evil is in favour of benevolence; one can hardly bear to think it is not so; but anyhow it is certain that there is a most heavy debit of evil, and that this burden might almost all have been spared to us if philanthropists as well as others had not inherited from their barbarous forefathers a wild passion for instant action." The desire for instant action is, no doubt, one cause of the miscarrying of benevolence; but there is another, the aptness of benevolence to respond only to immediate evils, and to be insensitive to remote consequences. The consequences may accumulate for a generation or a century before the mischief becomes so glaring that none can deny it any longer; when those who did the mischief have long since been buried with flattering epitaphs. "'Tis highly necessary to observe," says Hutcheson (on Moral Good and Evil, § 3), "that under this name [benevolence] are included very different dispositions of the soul"; and he distinguishes 
"calm good-will" from the "turbulent passions" of pity, sympathy and congratulation. These turbulent passions of pity for every cry of distress, and congratulation for every smile of happiness, do nearly all that mischief that Bagehot speaks of; mischief that would not be done if we were chiefly moved by calm good-will toward all creatures and, therefore, considered the welfare of future generations as much as our own. Immediate sympathy has its place in a full imagination to supplement, interpret and qualify laws and duties by considerateness, equity and mercy; but it cannot itself be the ground of laws and institutions, nor can there be any other ground of them than justice-the surest way of being truly benevolent.

On the supposition that the inheritance of qualities in a nation is continuous from age to age, failure of character must be due either to the destruction of some superior strain of blood in the national stock, or to a failure of the conditions which make the expression of character effective. A strain of blood once lost can never be restored; but an injurious change of conditions may not be irremediable. Changes of a temporary kind, like the Puritanic movement that repressed for a generation or more the gaiety of our people, may be compensated by others more favourable: ages of emancipation occur now and again, if not periodically, as from 1580 to 1620 and 1790 to 1830 , and enable a nation to reveal depths and directions of its character that the humdrum life of ordinary years represses. It is not the temporary but the chronic change of conditions for which, if injurious, a remedy must be sought.

One remedy for a deteriorating breed has already been discussed in the fifth chapter: namely, the dissemination of reasonable beliefs with regard to marriage, and the prevention of marriage between those who are unfit to be the parents of future generations. If any one supposes that any plan for the segregation of failures is contrary to the principle of liberty which I have often commended, he should consider that civil liberty has never been held incompatible with the prevention of crime; and that the marriage of unfit people 
-a gross wrong to others who are helpless-only differs from legal crime in this, that the law has not yet condemned it. There would be less sentimental opposition to eugenic proposals, if the public were aware of the extent to which inheritable diseases and insane perversions of instinct infect even the most civilised nations. But the magnitude and the detail of this corruption is known only to doctors and a few other students of human nature.

Liberty itself, in fact, the ancient boast of our country, the utmost that can be endured with civil order is, I believe, the only other remedy that need be considered: opportunities in every sort of avocation equally open to all, and let every one choose, and take the risk, and take the consequences : toleration of seeming error and eccentricity, which may in fact be truth and good sense. This plan ensures the continual adaptation of national life to new circumstances by the efforts of individuals; it is favourable to intelligence, and to giving the chief responsibility to the most efficient; and it is favourable to enterprise, endurance, and courage: of all our national qualities the most precious and the most in danger of being weakened by a premature mechanical organisation. Liberty is also most favourable to co-operation and to effective sympathy : it is generally admitted that the English nations are still the greatest and also, I believe, that they are the most effectually sympathetic; but there will be an end of that if every one in trouble is provided for by some impersonal agency. Sympathy and affection flourish most where they are most needed, where a man's relations and friends are his chief reliance. Liberty has served us well, and still would serve us well; but our faith in liberty is failing us; and except by faith liberty cannot live: nor yet without patience on our part to endure many excesses, many foolish actions, many selfish claims, many disappointments, still trusting that our lot is better than any that ingenuity could substitute for liberty. For what understanding is able to unravel all the means by which she strengthens them that trust her? What imagination can conceive the remote good with which she blesses them that endure her 
present severity? But faith is sick, and understanding and imagination are still in their nonage.

The great mass of men will have its own way and will listen to none who does not utter its own desires. Passionate desire engenders fixed ideas and stifles all contradiction. In the obsession of eager hope, argument cannot be heard, evidence cannot be seen. Like a maniac or a criminal in the dark, intent on theft or murder, a crowd pursues its blind purpose. In a crowd you cannot think, because you are in the crowd; and you will not listen to the bystander, because he is not in the crowd: but you will all try to do 'something.' To deal with any obstacle by trying one movement, then another, and still another, without any comprehension of the obstacle, is the method of the simplest living things; in social affairs, it remains the method of mankind. We know only a few general principles of human nature and of social change; and to try to live by them asks courage. Most of us cannot understand general principles, much less can we put our trust in them. If the condition in which we live is civilisation, it has come too soon: the reign of Man has been extended over Nature before he is able to govern himself. Where lies the Good he faintly divines, but cannot yet seek it; for he does not yet desire it with all his heart; and, if he did, he does not know the way thither, but is like Christian struggling in the Slough of Despond with no Evangelist to reach him a hand or to instruct him concerning his long journey. If instruction be needed in more than the bare principles of life, - some definite plan for constructing the future or retrieving the past-it is nowhere to be had. The actual courses of the world are beyond our knowledge, much more beyond our control. The wisest of men cannot yet predict even the near future, or give us any certain guidance there; and, if they could, the rest of us are not wise enough to follow them. 



\section{INDEX}

\section{Addison, 253}

Adolescence, 302

Adonis, Attis, Osiris, 86, 110

Aschylus, 267

Agis, Life of, 291

Alciphron, 57, 237

Alexander the Great, 84

Altruism, 35, 75

Analogy, Butler's, 3, 14

Analysis of Natural Religion, 237

Ancient Law, 233

Apathy, 24, 27

Appeal from New to Old Whigs, $29 n$.

Areopagitica, 241

Ariosto, 267

Aristophanes, 267

Aristotle on reason and desire, 7 ; on self-love, 37 ; the philosophic life, $42 f$; moral choice, 56 ; on law, 192 ; on honours, 206 ; on slavery, 238 ; on $\kappa \dot{\alpha} \theta a \rho \sigma \iota s, 255$; Art and Virtue, 257 ; other references, $6,11-14,26,28,45$, $50,58 n_{.}, 63,66,80-81,88-89,94$, $107,116,123,127,173,285,291$

Arnold, M., 195, 247, 277, 296

Augustus, 271

Austin, 56

Avebury, 293

Babylon, 261

Bacon on Atheism, 243, 245 ; on Truth, 301

Bagehot, W., 292, 306

Bain, A., on Conscience, 54

Bateson, W., xxii $f$.

Beauchamp, Phillip, 237

Beccaria, 202

Bentham on motives, 11 ; moral causation, 17 ; of duties, 47 ; on reward, 206 ; other references, $51,66,122$, 200, 202, 255

Beowulf, 86

Berkeley on disinterested Virtue, 57; use of language, 57 ; divine attributes, 237-44
Biographia Literaria, 254

Blackstone, 194

Brahmanism, 241

Buckle, 285

Buddha, 85

Buddhism, 225, 238-41

Buonaparte, 102, 183

Burke on the original Contract, $29 n$. ; on democracy, 138 ; on Party, 187 ; on eternal justice, 237 ; other references, 197, 276

Butler o.l meaning of "natural," 3, 28 ; on the Chief Good, 14-15; on desire, 23 ; on Self-love, $35-36$; on Conscience, 54 ; other references, 11, 13, 57-58

Cairnes, J. E., 101

Calvin, 227

Capitalism, $\mathrm{xx}, 211 f$.

Carlyle, 97

Causes of the Discontents, 187

Chaucer, 87-88

Cicero, 25

Clarke, S., 6, 13, 14-15, 96

Cleopatra, 102

Clifford, W. K., 4

Coleridge, S. T., on Poetry, 254

Collins, 304

Commentaries on the Laws of England, 194

Common Sense, 9, 28, 47, 60, 96, 137

Comte, A., 59, 195, 262

Co-operation, xxi, $211 f$.

Corn Laws, 181

Cudworth on the Good, 14

Culture and Anarchy, 195

Cumberland on moral laws, 17, 105

Cynics, 64

Cyrenaics, 64

Cyrus, 285

Dahomey, 261

Dante, 246

Darwin, 71, 106, 293 


\section{2}

\section{NATURAL AND SOCIAL MORALS}

Dawn of Civilisation, 222

Deism, 243

Deontology, 17

Descartes, 117, 244

Discourse on Satire, 253

Dissertation on Virtue, 58

Divinity and Naturalism, xix, 9, $243 f$.

Doctrine and Discipline of Divorce, 162

Dualism, moral, 35

Duration of Life, 31

Dryden on Art, 253 ; quoted, 274, 294

Ecclesiastical Polity, 168

Egotism, 25, 35

Eikonoklastes, 191, 237

Elements of Moral Philosophy, 16, 46

Emerson, 244

Epicurus, 25, 45, 64

Ethica, Spinoza's, 93, 108, 122

Ethics of Naturalism, 5

Euclid's Elements, 254

Eugenics, xxi, xxv, 69, $112 f ., 307$

Euripides, 84, 267

Examination of Hamilton's Philosophy, 237

Expedition to Torres Straits, 83, 85

Faëry Queene, 267

Faraday, 251

Fetishism, 221

Filmer, 168

Fouillée, 54

Fowler, T., 100

Frazer, J. G., 16, 86, 110, 226

Frogs, The, 267

Galileo, 246

Galton, F., on the average man, 33, 177 ; on marriage laws, 114 ; law of regression, 158 ; celibacy, 183, 291

Generic Consciousness, xvii

Genesis, 234

George Eliot, 84

Gillen, Spencer and, 50, 134, 225

Goethe, 84

Golden Bough, 16

Golden Rule, 96

Gray, Thomas, 304

Green, T. H., on man and nature, 6, 47 ; on moral philosophy, 128 ; on punishment, 203

Gresham, Sir Th., 88

Groos, Karl, 269

Grotius, 242

Haddon, A. C., 83, 85

Hall, Stanley, 302:

Hannibal, 183
Hartmann, Von, 27

Hedonism, 24, 122

Hegel on the actuality of morals, 66 128, 193 ; on punishment, 204

Hegelian Cosmology, 204

Hereditary Genius, 183, 291

Heredity, Principles of, 286

Herodotus, 285

Hirn, Yrgö, 258

History of Civilisation, 285

Hobbes on moral obligation, 6, 50, 66 , 192 ; on pleasure and life, 117 ; on the Contract, 168, 195 ; on Rights, 197

Hobhouse, L. T., 38, 104

Hooker on the Contract, 168-69; on the Law of Nature, 195

Human Faculty, 33

Human Knowledge, Principles of, 57

Human Marriage, 129, 144, 147, 150

Hume on is and ought, 5-6, 95; on Reason in morals, 7 ; ntility of Virtue, 11 ; on the Contract, $29 n$.; utility of Government, 172, 196 ; Religion and drama, 224 ; other references, 57, 66,219

Hutcheson on Rights, 196 ; on Art, 258 ; on Benevolence, 306

Idealism in morals, 65 ; in Art, 274

Imlac, 48

Individualism, 213, 303

Islamism, 240

James, William, 226-27

Jesuits, 59

Jus Naturale, 13-14, 17

Kant, self-love and obligation, 35 ; authoritative tone of morals, 54-56, 64 ; pleasure and life, 117 ; in rela. tion to Religion, 244 ; on æsthetic judgment, 258 ; other references, 11, 20,96, 107-108, 117

King Lear, 254

Knox (John), 227

Kwoiam, 84

Iangland quoted, 246

Ia Place, 106

Laws, The (Plato), 82

Laws of Nature, 17, 105

Lazarus on national character, 85

Le Bon, Gustave, on Socialism, 212

Lectures on the History of Moral Philosophy, 13

Lectures on Political Obligation, 203

Lectures on Spencer's Ethics, 118

Leibniz, 304 
Lettres Provinciales, 100

Leviathan, 50, 193

Lex talionis, 198

Livingstone, 223

Locke, 6, 168-69, 195, 244

Louis XIV., 271

Lucretius, 229

Luther, 110, 227

Lycurgus, 85

Machiavelli, 237

Mafeking, 266

Maine, Henry, 233

Malebranche, 244

Malthus, 157

Malthusian Law, 156

Manu, Code of, 50, 159

Maspero, 222

Materialism, 5-6, 243

Maurice, F. D., xx, 244

M'Dougall, W., xi, 118

M'Taggart, J. E., 204

Mechanism, 6

Mendel's Principles of Heredity, xxii

Merck, J. H., 258

Metaphysics of Nature, xii $f ., 17,38,98$, 123, 147, 213, 248, 256

Methods of Ethics, 37, 60, 96, 100, 138

Middlemarch, 84

Mill, J. S., on Motives, 12 ; quality of pleasure, 41; character of women, 165 ; divine attributes, 237 ; on Theism, 249 ; on Poetry, 269 ; other references, 66-67, 101, 120,157, 174

Milton on divorce, 162 ; religion and tyranny, 191, 237; Nature and the State, 195 ; God's Englishmen, 241 ; other references, xi, $45,84,168,246$, 254

Mommsen, 291

Moral Good and Evil, 306

Morals in Evolution, 38, 104

More, Sir Thomas, 4, 155

National Life and Character, 286

National Service League, 288

Natural Inheritance, 158

Naturalism, 5-6

New Testament, 239

Nicomachean Ethics, 7, 27-28, 37, 50, $56,58 n ., 63,89,116$

Nightmare Abbey, 297

Obligation of Natural Religion, 6 n., 14 Elipus, 46

Old Testament, 239

Origin and Development of Moral Ideas,
$103,129,132-33,147,200,220-22$, 238,252

Origin and Growth of the Moral Instinct, $103,129,144,149,164$

Origin of Civilisation, 293

Original of our Ideas of Beauty and Virtue, 258

Pantheism, 219, $244 f$., 248f.

Pascal, 100

Peacock, 297

Pearson, C. H., 286

Pearson, Karl, xxi

Perfection, 24-25

Pericles, 287

Pessimism, 27, 116, 240

Pessimism (Sully), 117

Philosophy of Law, 204

Physics and Politics, 306

Physiological Psychology, 118

Plato on social relations, 63,82 ; purpose of government, 108 ; moral education, 123 ; Communism, 155 ; on Art, 253 ; other references, 20-21, 26, $41,54,59,167,228,264$

Play of Animals, 269

Play of Man, 269

Plutarch, 291

Poetics (Aristotle), 256, 291

Political Economy, like Morals, 17, 101 ; also 240

Politics (Aristotle), 255

Poor Laws, 153-55, 210

Population in England, 158

Positivism, General View of, 262

Practical Ethics, 100

Practical Eugenics, Problem of, xxi

Primitive Culture, 16, 219

Principe, Il, 237

Principles of Biology, 121

Principles of Ethics, 20, 46, 54, 95, 103 $105,116,119$

Principles of Morals, 100

Principles of Psychology, 54, 60, 82, 117

Principles of Sociology, 81, 132, 149, 165,219

Prolegomena to Ethics, 128

Psychologie des Sentiments, 73

Ptolemy, 271

Quakers, 62

Raleigh (Sir W.), 267

Rashdall, H., 100

Rationale of Reward, 206, 225

Rationalism, 7

Realism, crude, 65 ; true, 274

Reflections on French Revolution, 237 


\section{NATURAL AND SOCIAL MORALS}

Reformation, 59, 227

Regression, Law of, 158

Reid, Archdall, 131, 286

Religion, Psychology of, 92

Religion of Nature, $6 n$.

Renaissance, 59, 271

Republic, 21, 41, 54, 82, 108

Ribot, Th., 73

Rivers, W. H. R., 222

Romanes, 218

Rome, History of, 291

Rousseal, 110

Sagas, 134, 275

Salmasius, 168

Salvation Army, 266

Savage mind, 136

Schopenhauer on suicide, 9 ; on Pessimism, 27, 116; on illusion, 31 ; morality and sympathy, 160

Sensus Communis, 29 n.

Sermons (Butler), 23, 35-36, 54

Shaftesbury, 26, 29 n., 189, 258

Shakespeare, 183

Shelley, P. B., 49, 196, 267

Sidgwick, H., on self-love, 37 ; on Common Sense, 60, 100, 137 ; on moral axioms, 96 ; pleasure and evolution, 118

Sidney (Sir Ph.), 85

Smith, Adam, 270, 289

Socialism, $\mathrm{xx}, 211 \mathrm{f}$.

Sociological Papers, 114

Socrates, 59

Sophists, 59

Sorley, W. R., 5

Spectator, 253

Spencer, H., Ideal State, 20, 38, 101; power of emotion, 78 ; data of Ethics, 95 ; morality and evolution, 105-107; pleasure and life, $116-19$; on population, 120, 156; non-human gods, 220 ; other references, $46,60,66-67$, $81,103,106,108,132,149,165$, 219

Spencer and Gillen, 50, 134, 225

Spenser (Edmund), 267

Spinoza on the Good, 26, 43 ; purpose of government, 108 ; desire and good, 122 ; on pity, 200 ; other references, $6,93,94,107,117,195$

Starbuck, E. D., 92

Statute of Labourers, 181
Stoicism, 14, 17, 26, 56, 63-64, 128, 195 238

Subjection of Woman, 165

Sully, J., 117

Sutherland, A., 103, 129, 144, 149, 164

Tasso, 267

Thebes, 261

Theism, $244 f$., $248 f$.

Theism (Mill on), 249

Theory of Good and Evil, 100

Thucydides, 288

Todas, The, 222

Totems, 85

Travels in South Africa, 223

Treatise on Human Nature, 5, 224

Tribes of Central A ustralia, 134, 225

Twining, 256

Tyler, E. B., 16, 219

Unitarianism, 244

Utilitarianism, 9, 25, 96, 116, 240

Utilitarianism, 12, 41

Utopia, 4, 155

Uzzah, 46

Variation of Plants and Animals, 71, 293

Varieties of Religious Experience, 226227

Vincy, Rosamund, 84

Visigoths, 290

Wallace, A. R., 31

Wallas Graham, xi

Weismann, A., 31

Wesley, S., 110

Westermarck, E., on the ground of moral judgments, 129-32 ; primitive marriage, $145-48$; on punishment, $200 \mathrm{f}$.; on Animism, 220; other references, $103,133,144,238,252$

Whewell on Dependent and Independent Systems, 13 ; on the imperative form of morals, 16 ; on indifferent actions, 46

Whittington, 88

Wilson, J. M., 100

Wollaston, $6 n$.

Zeno, 20

Printed by R. \& R. Clark, Limited, Edinburgh. 


\section{THE METAPHYSICS OF NATURE}

Second Edition. Demy octavo. Cloth.

Post free, $7 / 10$ PRICE $7 / 6$ NET Post free, 7/10

\section{SOME PRESS OPINIONS}

"It is a pleasure to record this early appearance of a second edition of Prof. Read's ably and often finely written work."-Mind.

"A book which must be ranked among the most important of recent years."-Nature.

"A singularly important contribution it is to the critical and philosophic theory of our time."-Pall Mall Gazette.

"We hail with delight a work so masterly and so moderate, and written with such lucidity and often with brilliance."-The Examiner.

"The book gives evidence of much ability, and of a thorough mastery of the subject, especially in its historical aspects, and is written in a style which for the most part is fresh and forcible as well as clear."-Glasgow Herald.

"Interwoven with the severest processes of reasoning we cannot fail to discover an open-eyed imagination, grace of style, and a characteristic vein of humour." -Manchester Courier.

"His reflections are suggestive and stimulating even in their modesty. His book is the result of deep thought. It puts new aspects on old truths."-Dundee Advertiser.

"Intelligible in expression, the author deals forcibly with each aspect of his subject, and moderation marks the summing up of his views."-Nottingham Guardian.

"A book written throughout, we may say, with both force and moderation."-Westminster Gazette.

\section{Published By}

ADAM AND CHARLES BLACK, SOHO SQUARE, LONDON, W. 


\section{RUDOLF EUCKEN'S PHILOSOPHY OF LIFE}

By W. R. BOYCE GIBSON, M.A.

Second Edition. With Frontispiece Portrait of Rudolf Edcken

Crown 8vo, Cloth PRICE $3 / 6$ NET Post free, 3/9

"No reader should fail to find pleasure in a book so full of fresh and stimulatin thought, expressed with great felicity of language."-The Scottish Review.

"It is done with just the proper combination of sympathy and criticism." $-T \prime$ British Weekly.

\section{THE MEANING AND VALUE OF LITI}

\section{BX RUDOLF EUCKEN}

Translated By W. R. BOYCE GIBSON, M.A., and LUCY JUDGE GIBSC
Crown 8vo, Cloth
PRICE $3 / 6$ NET
Post free, 3/9

In this, the latest work of Professor Eucken, we find packed into brief compass and presented in simple and striking form the central convictions of his philosophy. The author's aim has been to bring the problem of human life home to the reader's thought and conscience, and to offer a solution which, by securing spiritual stability to life, must meet the deepest need of our human nature.

The work is particularly well adapted to serve as an introduction, not only to the author's own philosophy, but to any and every constructive scheme of human life. It stands for the attempt to build a life-philosophy upon a basis sufficiently broad to meet all the just demands both of Religion and of Modern Thought.

\section{GOD WITH US}

\section{A STUDY IN RELIGIOUS IDEALISM}

BY W. R. BOYCE GIBSON, M.A.

Crown 8vo, Cloth

PRICE $3 / 6$ NET

Post free, $3 / 9$

"No mere summary of contents can give a true account of the worth of this volume. Mr. Gibson is a seeker on the quest, and his work has the freshness and stimulating power which only one on the trail can give. It is a book sure to be widely read." -The Aberdeen Journal.

\section{THE PROBLEM OF LOGIC}

\section{Br W. R. BOYCE GIBSON, M.A.}

\section{Demy 8vo, Cloth PRICE 12/6 NET \\ Post free, 13/-}

"An invaluable work which at once supersedes older books on logic, and is likely to take its place, in this country at least, as the standard text-book on the subject."-The Scottish Review.

PÜlished BY

ADAM AND CHARLES BLACK, SOHO SQUARE, LONDON, W. 
182 Distinquished Znew 


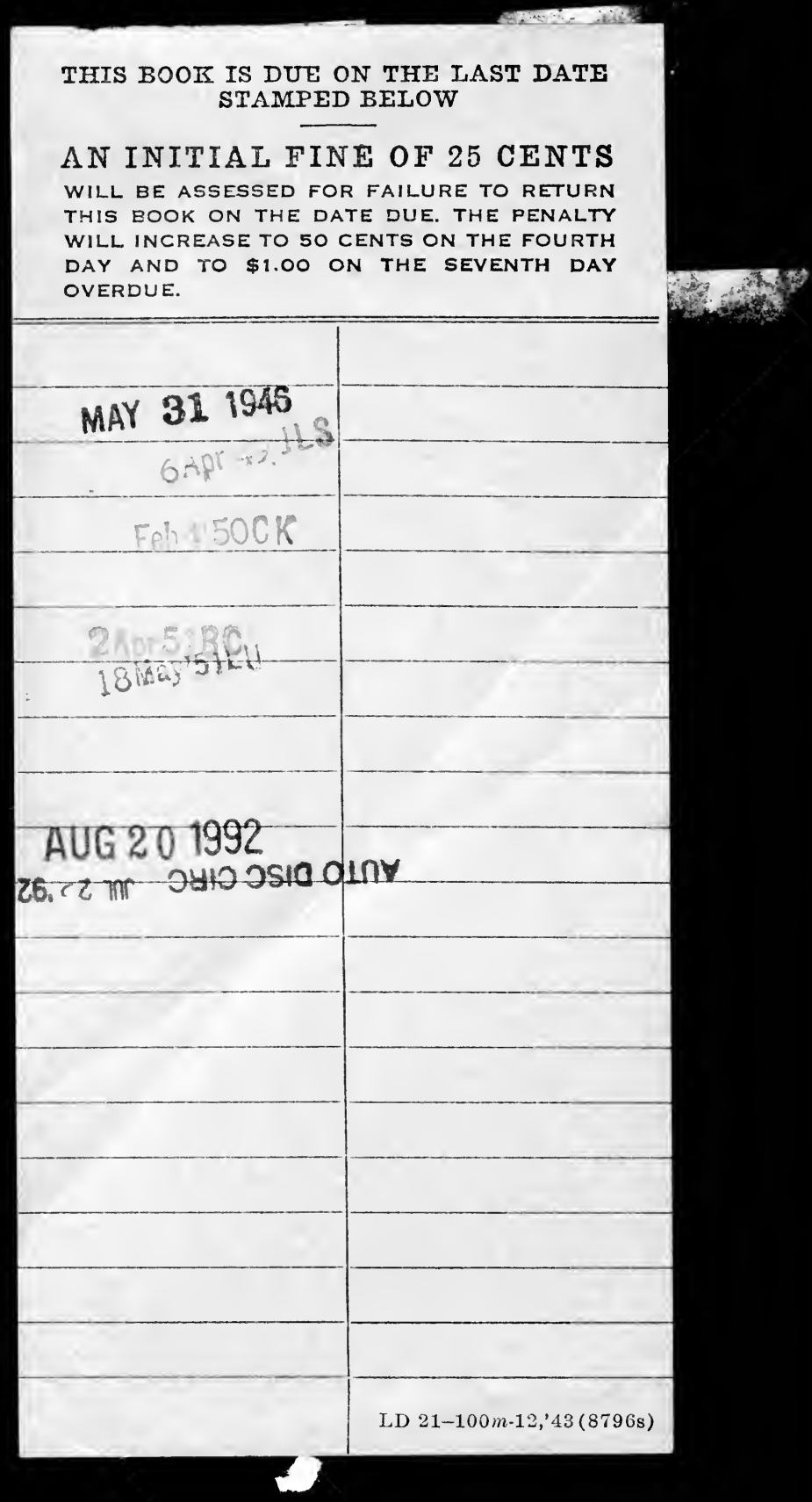




\section{YC 30330}

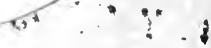

\section{6}


